
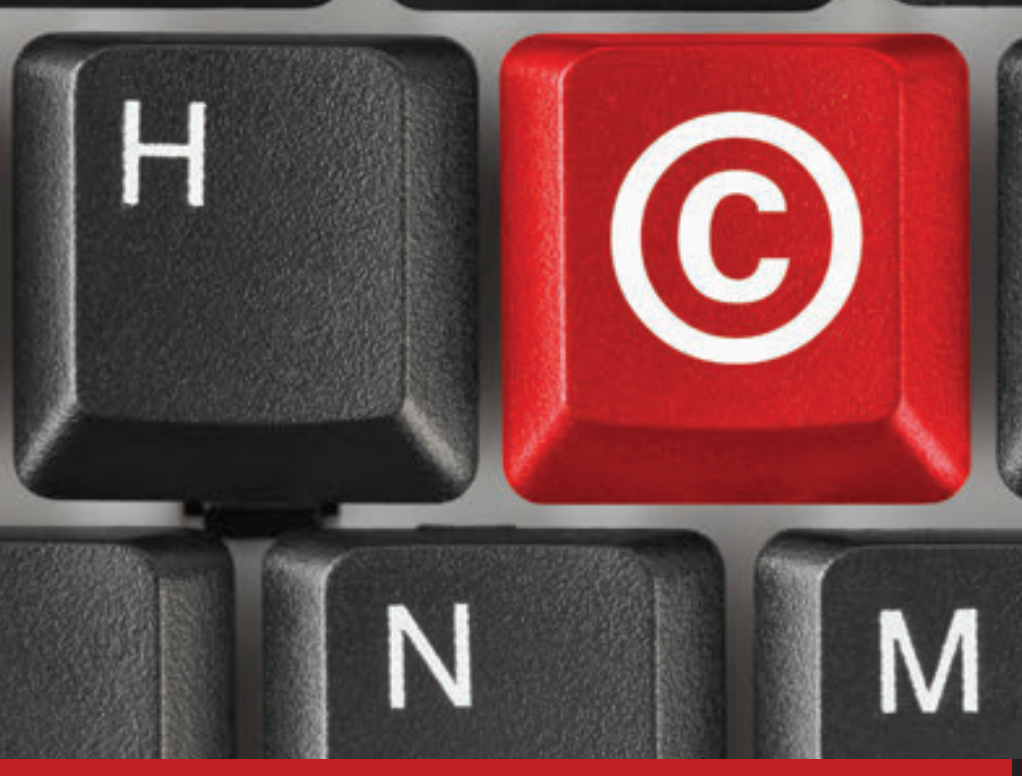

\title{
K
}

Serie Investigación

DERECHOS DE AUTOR,

TECNOLOGÍA Y EDUCACIÓN

PARA EL SIGLO XXI:

EL TRATADO DE LIBRE COMERCIO

entre Colombia y Estados Unidos

Marcela Palacio Puerta 


\section{DERECHOS DE AUTOR, TECNOLOGÍA Y EDUCACIÓN PARA EL SIGLO XXI: El tratado de libre comercio entre Colombia y Estados Unidos}

Marcela Palacio Puerta

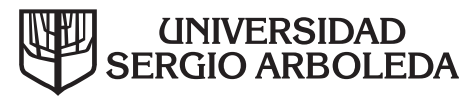

Bogotá. Colombia 2016 
Palacio Puerta, Marcela

Derechos de autor, tecnología y educación para el siglo XXI : el tratado de libre comercio entre Colombia y Estados Unidos / Marcela Palacio Puerta - Bogotá: Universidad Sergio Arboleda, 2016.

$278 \mathrm{p}$.

ISBN: 978-958-59490-4-1

1.DERECHOS DE AUTOR - INNOVACIONES TEGNOLÓGICAS - COLOMBIA 2. EDUCACIÓN INNOVACIONES TECNOLÓGICAS - COLOMBIA 3. COLOMBIA-TRATADOS COMERCIALES - PROTECGIÓN DE LOS DERECHOS DE AUTOR - ESTADOS UNIDOS

346.048 ed. 21

\section{DERECHOS DE AUTOR, TECNOLOGÍA Y EDUCACIÓN PARA EL SIGLO XXI: El tratado de libre comercio entre Colombia y Estados Unidos \\ (C) Marcela Palacio Puerta}

ISBN: 978-958-59490-4-1 Rustica

ISBN: 978-958-59490-5-8 Digital

Edición: junio de 2016

Este material editorial puede ser distribuido, copiado y exhibido por terceros sólo si su (s) autor(es) se muestra(n) en los créditos. No se puede obtener ningún beneficio comercial o cualquier acto que implique algún beneficio pecuniario con éste. No se pueden realizar obras derivadas, entendidas éstas como variaciones totales o parciales del mismo. Es decir, se permite copiar, distribuir, mostrar y ejecutar sólo copias literales del mismo.

Edición: Yadira Caballero Quintero - Carlos Andrés Caho Rodríguez

Calle 74 No. 14-14

Teléfono: (571) 3257500 ext. 2131/2260

www.usergioarboleda.edu.co

Bogotá, D.C.

Directora Publicaciones Científicas: Yadira Caballero Quintero yadira.caballero@usa.edu.co

Director del Fondo de Publicaciones:

Jaime Arturo Barahona Caicedo

jaime.barahona@usa.edu.co

Diseño carátula y diagramación: Maruja Esther Flórez Jiménez

Impresión: Digiprint

Bogotá, D.C. 
A mis padres, Patricia y fuan Ángel, con cariño, por su apoyo incondicionaly generosidad. A mis hermanos, Juan Luis y Carlos Eduardo, por su comprensión en tiempos de crisis. A mi hermana, Maria Adelaida, gracias a quien hoy este libro se hace realidad. 



\section{GONTENIDO}

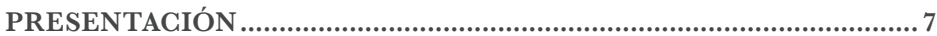

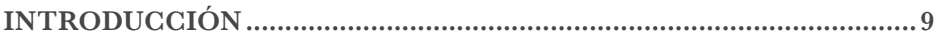

Capítulo 1

LA UTILIZAGIÓN DE LAS TEGNOLOGÍAS DE LA INFORMAGIÓN

Y LA GOMUNICAGIÓN (TIC) EN EDUGAGIÓN: MIRANDO HAGIA

UNA EDUGAGIÓN PARA EL SIGLO XXI .......................................... 11

La incorporación de las TIC en la educación .........................................................12

Estado actual de la transformación del proceso educativo a nivel mundial. 21

La incorporación de las TIC en la educación para países en desarrollo ................22

La situación actual de la educación en Colombia.........................................24

La política colombiana de las TIC en la educación. ......................................28

La política de las TIC en la educación y su relación con los derechos de autor . 36

Conclusión

Capítulo 2

EL DESARROLLO DEL DEREGHO INTERNAGIONAL DE LOS

DERECHOS DE AUTOR EN EL ESGENARIO MULTILATERAL ........ 39

Revisión sobre la relación entre derechos de autor y educación ......................... 40

Aspectos básicos sobre el derecho de autor. ................................................... 40

Derechos de autor, educación y TIC .............................................................4 43

La multeralización del derecho de autor............................................................. 49

El Convenio de Berna. .................................................................................. 49

El Convenio de Berna: el rol del conflicto norte-sur. ................................. 54

El acuerdo ADPIC: una estrategia de los países desarrollados.....................63

El tratado de la OMPI sobre derecho de autor. .............................................. 70

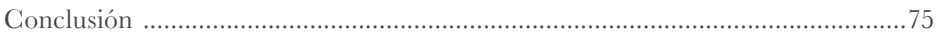

Capítulo 3

LA IMPLEMENTAGIÓN NORTEAMERICANA DE LAS

OBLIGACIONES INGLUIDAS EN EL TRATADO DE OMPI SOBRE

DEREGHOS DE AUTOR Y SU IMPLICAGIÓN PARA UN MODELO

DE EDUGAGIÓN PARA EL SIGLO XXI ....................................... 77

El modelo estadounidense de limitaciones a la responsabilidad de Proveedores

de Servicios de Internet y protección a las Medidas Tecnológicas de Protección ..... 78

El modelo estadounidense de limitaciones a la responsabilidad de

Proveedores de Servicios de Internet. ..........................................................78

El modelo estadounidense de Medidas Tecnológicas de Protección. .............91

La DMCA y la educación para el siglo XXI .................................................... 98

Afectación a la utilización de Internet como núcleo del nuevo sistema de aprendizaje.

Afectación al desarrollo de nuevas metodologías necesarias en un proceso de aprendizaje transformado.

Iniciativas de aprendizaje permanente y de colaboración. ....................105

Modelo de "Siempre Aprendiendo"..................................................... 121

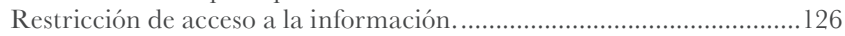

Afectación a la adopción de una educación más inclusiva.................... 131 


\section{Capítulo 4}

\section{LA EXPORTAGIÓN DE LOS ESTADOS UNIDOS DE SU MODELO DE LIMITAGIONES A LA RESPONSABILIDAD DEL PROVEEDOR DE SERVIGIOS DE INTERNET Y DE PROTEGGIÓN A LAS MEDIDAS TEGNOLÓGIGAS DE PROTEGGIÓN}

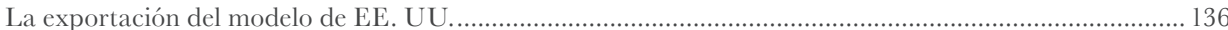

El Tratado de Libre Comercio Estados Unidos-Colombia (USCO) ................................................... 141

Las disposiciones de derechos de autor incorporadas en el USCO. ............................................. 145

Conclusión.....

Capítulo 5

ESTUDIO DE LOS INTENTOS DE IMPLEMENTAGIÓN DE GOLOMBIA DEL TRATADO DE LIBRE GOMERGIO DE ESTADOS UNIDOS-COLOMBIA Y SUS POTENGIALES EFEGTOS EN LA EDUGAGIÓN

La ley actual de derechos de autor de Colombia ................................................................................... 150

La responsabilidad del ISP sobre infracciones de derechos de autor bajo la ley colombiana actual.........157

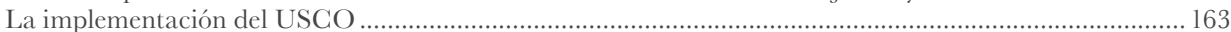

Historia de la implementación del USCO: Ley Lleras (Proyecto de Ley 241) y Ley Lleras 2.0 (Ley 1520)...... 163

El contenido de los intentos de implementación del USCO. ........................................................... 166

Las consecuencias de un estilo de implementación copy-paste del USCO para la promoción de la

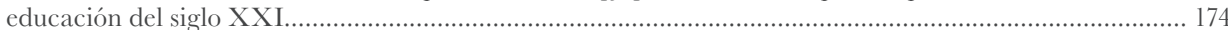

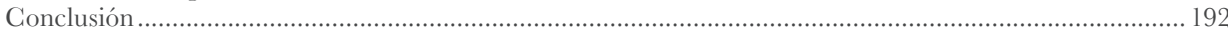

Capítulo 6

CHILE Y AUSTRALIA GOMO EJEMPLOS DE IMPLEMENTAGIÓN: HACIA UNA

PROPUESTA DE IMPLEMENTAGIÓN PARA GOLOMBIA .............................................. 195

Chile ................ 196

El Tratado de Libre Comercio entre Estados Unidos-Chile (USCHILE) .......................................... 196

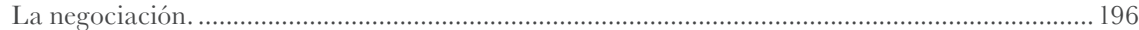

Las obligaciones de derechos de autor incluidas en USCHILE.............................................. 197

La implementación chilena del modelo de limitación a la responsabilidad de ISP. ............................ 201

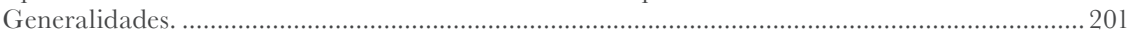

La implementación del modelo de limitación sobre responsabilidad ISP del USCHILE:

el toque chileno.

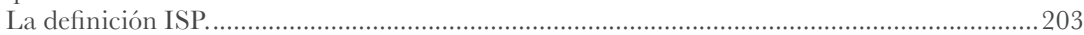

El requisito de terminación de cuentas a los infractores reincidentes judicialmente calificados. ....... 205

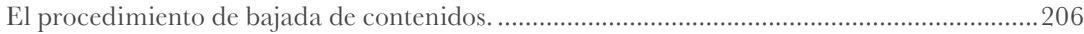

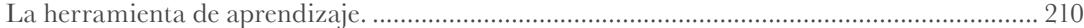

El procedimiento de identificación de presuntos infractores. .............................................. 210

Las reacciones internacionales a la implementación del USCHILE en Chile.................................. 211

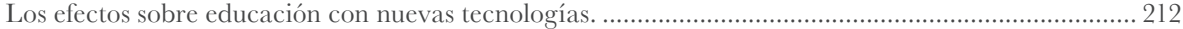

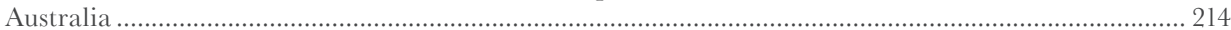

El Tratado de Libre Comercio Estados Unidos-Australia (AUSFTA). .............................................. 214

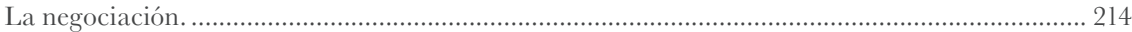

Las disposiciones de derechos de autor del AUSFTA. ........................................................... 216

La implementación de las disposiciones sobre medidas tecnológicas de protección. ..........................2220

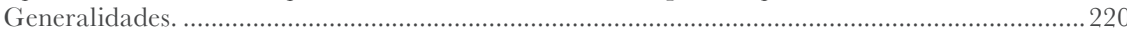

La implementación de las disposiciones de TPM: el toque australiano. ............................................2222

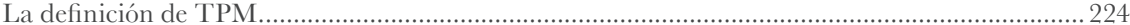

El alcance de los términos "fabricación" e "importación”...........................................................222

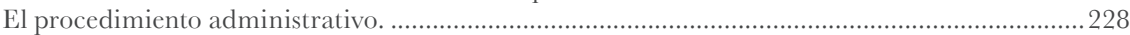

Acción contra una amenaza infundada de procedimiento de TPM. ..........................................2230

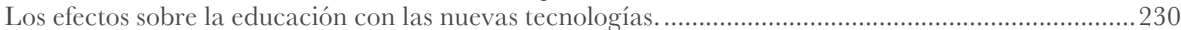

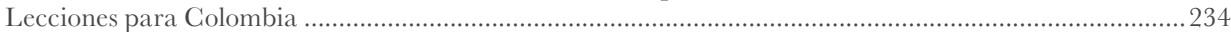

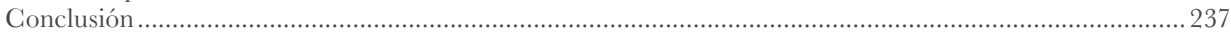

GONGLUSIÓN

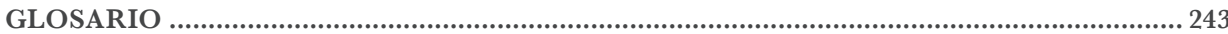




\section{PRESENTAGIÓN}

Toy en día la tecnología se ha convertido en una

1 herramienta esencial para la educación. Por esta razón, muchos países alrededor del mundo han comenzado a incorporarla en sus procesos educativos teniendo como resultado el inicio de una transformación de dicho proceso con el objetivo de brindarle a los estudiantes del siglo XXI las nuevas habilidades que estos requieren. Los países en vías de desarrollo han visto en la incorporación de la tecnología en la educación no solo la oportunidad de educar adecuadamente a los nuevos estudiantes, sino también la oportunidad de resolver serias falencias de sus sistemas educativos. No obstante, muchos países durante este proceso han obviado que es la regulación de derechos de autor la que, hasta cierto punto, determina cómo la tecnología va a poder ser utilizada dentro de su sistema educativo, y por lo tanto, han adoptado regímenes autorales que no favorecen dicho tipo de políticas educativas impulsados por el cumplimiento de obligaciones internacionales en la materia.

Aunque la conexión entre derechos de autor y educación ha sido un tema altamente debatido desde los inicios de dicho derecho, la literatura existente en el tema no ha abarcado la conexión entre la incorporación de las tecnologías de la información y la comunicación (TIC) en educación y la regulación de los derechos de autor. Adicionalmente, hay una brecha en la literatura existente acerca de los efectos que las disposiciones sobre derechos de autor incorporadas en el Tratado de Libre Comercio (TLC) entre Colombia y Estados Unidos pueden tener sobre la educación en Colombia. De esta 
manera, por primera vez en la literatura sobre derechos de autor, este libro abarca de forma conjunta tres temas altamente controversiales en la materia: educación, tecnología y tratados de libre comercio, enfocándose en el caso del TLC entre Colombia y los Estados Unidos.

Por consiguiente, este libro se convierte en una herramienta esencial no solo para la academia, estudiantes y expertos, sino que también es una importante guía para los responsables de políticas públicas en países en vías de desarrollo que están en proceso de implementar los compromisos en materia de derechos de autor adquiridos en tratados de libre comercio firmados con los Estados Unidos. 


\section{INTRODUGGIÓN}

T a regulación de derechos de autor y educación

Lcomparten una larga historia. Una serie de hechos, entre otros, nos evoca esta fuerte relación entre estas dos ramas: primero, los textos de clase son materiales protegidos por el derecho de autor, al igual que muchas otras fuentes educativas. Segundo, la industria editorial ha sido uno de los fuertes promotores de la regulación y protección de los derechos de autor. Tercero, los profesores no están en capacidad de producir o escribir cada uno de los materiales necesarios para sus actividades educativas, y al mismo tiempo, los creadores de las diferentes obras utilizadas en educación requieren cierto nivel de protección sobre sus obras. Es de esta manera, como la regulación a los derechos de autor y educación han estado unidos desde el comienzo de la primera. No obstante, dicha relación es complicada, ya que debe existir un balance entre la protección otorgada a los creadores y el acceso a dichas obras, el cual representa un punto clave en educación.

Adicionalmente, la tecnología ha entrado a desempeñar un papel muy importante en la educación, que permitiría borrar barreras en el mercado global donde existen importadores y exportadores de obras protegidas por el derecho de autor, incluidos los materiales educativos, e incursionar en un nuevo modelo educativo dirigido a dar las habilidades que los aprendices del siglo XXI requieren, y en países en vías de desarrollo, a resolver falencias educativas. No obstante, existe un vacío que se hace cada vez más grande entre lo que la tecnología permite en términos de acceder a dichos materiales y promover un nuevo modelo educativo y lo que la ley permite. Este vacío 
es especialmente grande y contraproducente en países en vía de desarrollo. De esta forma, se debe buscar un adecuado balance en la regulación de derechos de autor de dichos países entre protección y acceso de tal forma que tenga en cuenta los beneficios del mundo digital en la educación permitiendo la transformación del panorama educativo mediante la incorporación de las TIC. Sin embargo, el debate sobre los efectos de la regulación de derechos de autor en el ambiente digital y su relación con educación es frecuentemente limitado a la prohibición que dicha regulación puede imponer al acceso de materiales educativos. Así pues, este libro entra a explorar la relación existente entre derechos de autor y el empoderamiento de la educación a través del uso de las nuevas tecnologías en Colombia.

No obstante, lograr dicho balance entre protección y acceso en un país como Colombia no depende únicamente del desarrollo de una política nacional en la materia. Debido a desarrollos históricos en la regulación de derechos de autor que han llevado a relacionar este derecho con el comercio internacional, el campo de acción para el desarrollo de una política nacional en materia de derechos de autor ha quedado cada vez más reducido. Por ejemplo, en el caso de Colombia su soberanía para desarrollar políticas públicas en materia de derechos de autor ha quedado restringida por sus relaciones comerciales con países desarrollados como sucede en el caso del TLC firmado con los Estados Unidos. No obstante, y por otro lado, dichas restricciones impuestas por el acuerdo comercial han sido sobrevaloradas en Colombia, situación que podría llevar a crear consecuencias nefastas en educación, cuando en realidad todavía existe un campo de acción mayor a aquel que el Congreso colombiano ha determinado, como se estudiará en este libro. 


\section{Capítulo 1}

\section{LA UTILIZAGIÓN DE LAS TEGNOLOGÍAS DE LA INFORMACIÓN Y LA GOMUNICACIÓN (TIG) EN EDUGAGIÓN: MIRANDO HAGIA UNA EDUGAGIÓN PARA EL SIGLO XXI}

T a tecnología, especialmente Internet, ha influen-

Lciado cada aspecto de la vida humana incluida la educación. En dicha materia, las TIC tienen la capacidad y están en el proceso de transformar el proceso educativo con el objetivo de brindar a los nuevos estudiantes las habilidades requeridas en la sociedad del siglo XXI, y al mismo tiempo, educar a los nuevos productores de contenido quienes se convierten en una pieza esencial en una economía del conocimiento como la que impera actualmente. No obstante, la transformación del proceso educativo a través del uso de la tecnología es una realidad mundial que se encuentra en continuo desarrollo, lo cual significa que ningún país en el mundo ha logrado una transformación total de su proceso educativo. Por otro lado, la incorporación de las TIC en la educación ha significado para los países en vías de desarrollo la oportunidad de sanear serias falencias de sus sistemas educativos. Un ejemplo de los países donde se apuesta al uso de las TIC con dicho propósito es Colombia.

La sección primera de este capítulo explica el nuevo paradigma educativo para el siglo XXI describiendo las nuevas metodologías necesarias para dicho sistema, los beneficios de incorporar las TIC en la educación y 
presenta un recuento del estado actual de la transformación del proceso educativo a través del uso de la tecnología a nivel mundial. La sección segunda, describe la importancia de esta transformación para países en vías de desarrollo utilizando Colombia como caso de estudio.

\section{La incorporación de las TIC en la educación}

Actualmente las TIC están siendo incorporadas en el proceso educativo por al menos dos razones importantes: 1) los aprendices actuales son diferentes y 2) la economía actual ha cambiado. Respecto del primer punto, tenemos que los aprendices o estudiantes de hoy en día difieren de los aprendices del pasado (Trilling \& Fadel, 2009, p. 27)', estamos frente a una generación que ha nacido en un mundo digital, y por tal, no conocen un mundo sin Internet, portátiles, tabletas, entre otras tecnologías (Kalaš et al., 2012, p. 16) ${ }^{2}$. Por lo tanto, los niños de hoy en día requieren desarrollar y adquirir habilidades que simplemente los niños del pasado no necesitaban. Estamos hablando de adquirir habilidades que abarcan el alfabetismo TIC, el cual, es un concepto que va mucho más allá de la simple idea de saber leer y escribir (Anderson, 2010, pp. 20-26) , y se refiere a la capacidad de usar todas las extensiones electrónicas de leer y escribir, tales como navegar en la web, enviar correos electrónicos, saber interpretar nuevos tipos de códigos, gráficos y videos (Anderson, 2010, p. 26, citando a Nallaya, 2010)4 . Igualmente, las habilidades necesarias en el siglo XXI hacen referencia a otras capacidades tales como el manejo de la información, comunicación, habilidad para trabajar en equipo, espíritu emprendedor, conciencia social, compromiso civil y la habilidad para resolver problemas (Kozma \& Wagner, 2005, p. 27) 5 .

\footnotetext{
1 'Whether you call them 'digital natives', 'net geners', 'netizens', 'homo zappiens', or comething else, it is clear that the members of the first generation to grow up surrounded by digital media [...] are different from the 'digital immigrants' who learned to 'do technology' later in life" (p. 27).

2 "One of the most significant changes over the past decade is this: at primary school we nowadays deal with children of the digital or net generation, that is, with children that were born into a world where breath-taking technologies have become commonplace" (p. 16).

3 Describiendo los nativos digitales y las nuevas habilidades necesarias para un aprendiz en el siglo XXI.

4 Describiendo el nuevo concepto de alfabetismo.

5 Describiendo las habilidades necesarias para el siglo XXI.
} 
Respecto del segundo punto, la economía actual está basada en el conocimiento, por lo tanto, los ciudadanos actuales necesitan ser entrenados tanto para analizar como para producir dicho conocimiento (Kozma, 2011, p. 22) ${ }^{6}$, y en este proceso las TIC se convierten en una herramienta esencial (UNESCO, 2005, p. 19) ${ }^{7}$. Bajo esta línea de pensamiento, la incorporación de las TIC en la educación está diseñada para brindar a los nuevos aprendices las nuevas habilidades que ellos requieren para ser útiles en la economía actual.

La incorporación de las TIC en la educación trae consigo grandes beneficios, siendo inicialmente uno de estos la capacidad de ampliar el acceso a fuentes educativas y de la información más allá de los límites de las paredes de un salón de clase (Banco Mundial, s.f. $)^{8}$. Internet brinda la posibilidad, por ejemplo, de acceder a fuentes educativas y materiales de un país a otro (párr. 1, sección Content and Curriculum) ${ }^{9}$, de igual forma, permite la democratización del conocimiento local de una región a otra. Por mencionar algunos ejemplos podemos referirnos a la Biblioteca Nacional de España ${ }^{10}$, la cual pone a disposición del mundo entero el contenido local español, o el famoso museo Louvre en París, el cual dispone de tours virtuales de sus salas de exhibición ${ }^{11}$, permitiendo a cualquier persona en el mundo con conexión a Internet acceder a su colección sin tener que viajar a Francia. De esta manera, vemos cómo Internet le permite a cualquier persona poner a disposición del público a nivel mundial algún tipo de obra comercialmente disponible como reportes, artículos, libros, canciones, entre otros, aumentando la cantidad de fuentes aprovechables para las personas

6 Estableciendo que una educación transformada tiene impacto sobre la economía basada en el conocimiento y en la sociedad, puesto que todo el mundo se encuentra en la capacidad de producir y consumir conocimiento.

"The new technology revolution marks the entrance of information and knowledge in a cumulative logic, which Manuel Castells describes as 'the application of such knowledge to knowledge generation and information processing/communication devices, in a cumulative feedback look between innovation and the uses of innovation"” (p. 19).

8 "Accessing information is the main use of ICTs in education" (párr. 1. Sección Content and Curriculum).

9 "ICTs $[. .$.$] provide access to a world of educational resources" (párr. 1. Sección Content$ and Curriculum).

10 Ver Biblioteca Digital Hispánica: http://www.bne.es/es/Catalogos/Biblioteca DigitalHispanica/Inicio/

11 Ver Louvre, Online Tours: http://www.louvre.fr/en/visites-en-ligne 
al otro lado de la conexión sin importar su ubicación. Esta característica de Internet permite beneficiar la educación, especialmente, de aquellos lugares donde las obras no son desarrolladas o simplemente no están disponibles por diversos motivos. De esta forma, por citar un ejemplo, una vez que un libro haya sido publicado en el Reino Unido, y se ha puesto a disposición en Internet, los profesores, estudiantes e investigadores colombianos podrían beneficiarse de esta información que de otra manera no podrían conseguir en Colombia, especialmente, entre otras razones, porque la industria editorial colombiana en línea está todavía en sus inicios (Medina, 18 de noviembre de 2014) y las fuentes educativas en Colombia son materiales escasos ${ }^{12}$.

Adicionalmente, las TIC gracias a su componente informativo y de comunicación permite ampliar el acceso a la educación rompiendo barreras de tiempo y espacio. Tener acceso a Internet permite traer educación formal y no formal a lugares donde no estaba disponible anteriormente o a personas que no pueden acceder a un escenario educativo tradicional, a través de la educación a distancia (Kehoe, 2006) $)^{13}$. Aunque es cierto que antiguas tecnologías como la radio o la televisión ya habían incursionado en la educación a distancia, es Internet el que permite por primera vez encaminarse en actividades educativas asincrónicas donde es el estudiante quien decide en qué momento y dónde realizar sus actividades académicas (Craig, 2000) $)^{14}$.

No obstante, esta capacidad de las TIC de ampliar el acceso a fuentes educativas y el acceso a la educación, aunque importante, no es el único beneficio o el único uso de la tecnología en la educación. La incorporación de las TIC en educación significa hacer de estas parte integral del proceso educativo ${ }^{15}$, y consecuentemente, embarca en nuevas actividades,

12 Ver discusión abajo.

13 Ver Kehoe (2006), estableciendo que la educación a distancia permite beneficiar a las poblaciones más vulnerables como aquellas que encuentran barreras geográficas o a quienes no pueden acceder a un escenario educativo presencial.

14 Estableciendo que con la llegada de Internet se permitió realizar actividades asincrónicas y sincrónicas.

15 Ver UNESCO (2002): "In this new paradigm, ICTs are not a substitute for schooling. They constitute one integral element of this education model-supplementing and enriching traditional institutions, delivery systems, and instructional materials. In this sense, ICTs contribute to the whole system of knowledge dissemination and learning" (pp. 8-9); ver también Anderson (2010): “[ ...] when the transforming stage is reached, 
metodologías y contenidos a la educación (UNESCO, 2002a). Lo anterior significa que incorporar las TIC en la educación va mucho más allá de utilizar portátiles, PG o tabletas como herramientas de productividad e Internet como un remplazo del material impreso al interior del salón (UNESCO, 2002b, p. 66), estamos hablando de tomar ventaja de las capacidades informativas y de comunicaciones propias de estas nuevas tecnologías para promover y generar una nueva variedad de actividades y metodologías de enseñanza y aprendizaje que le permita a los aprendices del siglo XXI adquirir las habilidades necesarias para la realidad que los rodea (Kalaš et al., 2012, p. $22)^{16}$. De esta forma, cuando las TIC son incorporadas de manera apropiada al interior del proceso educativo dicho proceso es transformado: el profesor se convierte en un coaprendiz o facilitador (Anderson, 2010, p. 6) ${ }^{17}$, y el estudiante deja su rol pasivo y comienza a actuar como un aprendiz activo y un productor de conocimiento (UNESCO, 2002a, p. 14) ${ }^{18}$, convirtiendo el paradigma educativo en un proceso relativo a aprender pero también a crear (Kozma, 2011, p. 22) ${ }^{19}$.

Dentro de las nuevas metodologías necesarias para lograr el nuevo paradigma educativo encontramos la metodología colaborativa y la interactiva, dichas metodologías tienen el objetivo de tomar ventaja de herramientas Web 2.0 como lo son los wikis, blogs, plataformas para compartir videos, entre otras, los cuales permiten no solo compartir y transformar obras (Anderson, 2010, p. $72)^{20}$, sino también trabajar de manera conjunta entre diversos individuos para lograr la creación de nuevos contenidos, el intercambio de ideas, materiales y experiencias. Un ejemplo de estas actividades se encuentra en Nueva Zelanda

the whole ethos of the institutions is changed: teachers and other support staff regard ICT as a natural part of everyday life of their institutions, which have become centers of learning for their communities" (p. 33).

16 "More and more we are aware of the importance of new skills for the 21st century and new perceptions about literacy-digital and media literacy being its natural component" (p.22).

17 Tabla 1.1, describiendo el cambio en el rol del profesor.

18 "Perhaps the most profound shift is from systems of teaching and supervision of learning to systems of learning and facilitation of learning"; ver también Anderson (2010), describiendo el nuevo rol del estudiante al interior de un proceso educativo transformador (p. 6).

19 Estableciendo que el nuevo proceso educativo se vuelve relativo a aprender y a crear.

20 Estableciendo las características de las herramientas Web 2.0 y su utilización en educación. 
en la educación primaria, donde los profesores comparten las actividades del salón de clase en una página web que pueden ser consultadas por padres de familia, niños y profesores de otras escuelas y por el público en general (Kalaš et al., 2012, p. 42) ${ }^{21}$.

La metodología colaborativa dentro de un proceso educativo transformado puede ser de dos tipos: 1) colaboración al interior del salón, la cual busca promover la colaboración entre profesores y estudiantes, y estudiantes entre sí, para el desarrollo conjunto de proyectos con el objetivo de crear sus propios productos de conocimiento (Kozma \& Shafika, 2011, p. 22) ${ }^{22}$; y 2) la colaboración entre profesores y estudiantes con expertos alrededor del mundo ${ }^{23}$ a través de comunidades de aprendizaje (UNESCO 2002c; García-Valcárcel, Basilotta \& López, 2014) ${ }^{24}$. Estas comunidades permiten poner en contacto a profesores, investigadores y estudiantes con sus pares alrededor del mundo y compartir e intercambiar contenidos, experiencias y cualquier otro tipo de información útil (Kozma, 2011, p. 22; UNESCO 2002a, p. 65 $)^{25}$. Esta metodología colaborativa juega un rol importante en la sociedad actual donde los empleadores buscan personas capaces de crear y trabajar en equipos (p. 36) ${ }^{26}$.

Podemos mencionar varios ejemplos de herramientas Web 2.0 que actualmente son usadas dentro de los salones de clase para promover colaboración pero que también hacen sus veces de comunidades de

21 Describiendo el caso de Nueva Zelanda.

22 Estableciendo que las TIC permiten la colaboración entre profesores y estudiantes.

23 Ver UNESCO (2002c), usando TIC en educación: "[...] becomes quite natural to collaborate with other teachers in solving common problems and to share their teaching experiences with others" (p. 20).

24 "[...] it is the role of information and communication technologies (ICT) to offer new possibilities for social intervention, to create collaborative learning environments (communities) that allow students to carry out group activities, activities that are integrated into the real world and planned with real objectives" (p. 66).

25 "With ICTs, sharing knowledge resources is enhanced many times over. Putting information on the Web makes it available immediately to anyone in the world with suitable connection. Teachers can share lesson plans with their colleagues in their own jurisdictions and with those far removed from their jurisdictions. Students from all over the world can undertake joint projects, exchange findings, analyze data collectively, and draw reasoned conclusions" (UNESCO, 2002a, p. 65).

26 "Globalization, creativity, and collaboration are key words in the modern workplace, where employers and employees are expected to share knowledge and work together toward common goals" (UNESCO, 2002a, p. 36). 
aprendizaje. Este es el caso de Wikipedia ${ }^{27}$, una comunidad de aprendizaje que se convirtió en la enciclopedia más grande del mundo gracias a la colaboración y participación de varios expertos en diferentes temas e individuos dispuestos a compartir su conocimiento (Anderson, 2010, p. 64) ${ }^{28}$. Los blogs, como en el caso de Edublogs ${ }^{29}$, permiten a los investigadores y educadores compartir sus fuentes, experiencias e inclusive intercambiar tips entre la comunidad interesada. De esta manera, podría darse el escenario donde un investigador comparta artículos científicos que no son altamente disponibles en diferentes áreas del país, o podría compartir sus traducciones de dichos artículos especializados cuando no están disponibles en el idioma local haciéndolos disponibles a muchos más profesores, finalmente, y solo por mencionar algunas situaciones, un profesor podría compartir sus presentaciones de clases que incluyen videos, música y fotos para que otros profesores lo usen en sus clases.

Así mismo, actualmente se han desarrollado plataformas especializadas para compartir investigación y que representan un excelente ejemplo de comunidad de aprendizaje como los son el Social Science Research Network (SSRN) y Academia.edu. SSRN es una biblioteca electrónica que pone a disposición artículos de diferentes publicaciones e instituciones, y resúmenes de próximas investigaciones de alta calidad. Igualmente permite a los lectores ponerse en contacto con los autores para propiciar las discusiones científicas ${ }^{30}$. Academia.edu permite a los investigadores compartir sus trabajos y seguir el trabajo de sus colegas en diferentes áreas de interés ${ }^{31}$. Adicionalmente, se han desarrollado plataformas para que específicamente sirvan como comunidades de aprendizaje dirigidas al intercambio entre profesores de materiales educativos, currículos, y fuentes desarrolladas por los propios profesores como lo son UNESCO Asia-Pacific Education Community Portal $(\mathrm{EC})^{32}$ o Twinning ${ }^{33}$, la comunidad de aprendizaje de las escuelas europeas.

\footnotetext{
27 Ver Wikipedia: http://en.wikipedia.org/wiki/Main_Page

28 Estableciendo que Wikipedia se convirtió en la enciclopedia más grande gracias a la colaboración de diversos individuos.

29 Ver Edublogs: http://edublogs.org/why-edublogs/

30 Ver Social Science Research Network: http://www.ssrn.com/en/

31 Ver Academia.edu: http://www.academia.edu/about

32 Ver Education Community: http://ict.unescobkk.org

33 Ver Twinning: http://www.etwinning.net/en/pub/index.htm
} 
Otra metodología importante para un sistema educativo transformado es la implementación de un modelo de "siempre aprendiendo". Dicho modelo responde a una nueva realidad que viven nuestros nuevos aprendices quienes están constantemente accediendo a información en cualquier lugar y a cualquier hora, y por tanto, el sistema educativo debe adaptarse

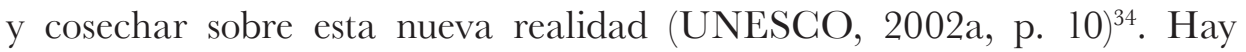
diversas alternativas para lograr dicho modelo usando las TIC, por ejemplo, implementando el uso en la educación de blogs que puedan ser accedidos por los estudiantes en cualquier momento, o implementando el uso de la "nube" en el aprendizaje. Esta última alternativa ha sido exaltada y reconocida por la UNESCO gracias a su habilidad de brindar en todo momento experiencias educativas a los estudiantes sin importar el hardware utilizado al momento de acceder al contenido (UNESCO, 2013, p. 20). Cuando el contenido se encuentra en la "nube", los estudiantes pueden tomar ventaja al momento de desarrollar sus actividades escolares de las diferentes características de los dispositivos. Por ejemplo, los estudiantes podrían utilizar su computador de escritorio para escribir ensayos o para hacer investigaciones extensas sobre un tema y, a su vez, podrían usar sus tabletas o celulares para llevar dicha información y tomar notas e ideas durante los trabajos de campo (p. 20). El objetivo de este modelo es que los estudiantes tengan disponibles cualquier fuente o cualquier trabajo que hayan elaborado en cualquier momento y en cualquier equipo que tengan a la mano, asegurando de esta forma la continuidad de la experiencia educativa (p. 20) . $^{35}$.

De igual forma, al interior de la educación las TIC promueven el uso de nuevos contenidos como, por ejemplo, de materiales multimedia, ya que dichas tecnologías permiten su fácil creación y utilización. El uso de materiales multimedia en educación trae diversos beneficios para los estudiantes, ya que al tomar provecho de diferentes aspectos de las tecnologías para ensamblar piezas que incluyen video, sonido, texto y animación se logra promover el uso de los diferentes sentidos al aprender y lograr un proceso de aprendizaje más natural, activo y dinámico (Ministerio de Educación Nacional de Colombia [MinEducación], 2004a). Por ende, el uso de materiales multimedia facilita

34 "Technology's capacity to reach learners in any place and at any time has the potential to promote revolutionary changes in the educational paradigm. Such capacity eliminates the premise that learning time equals classroom time" (p. 10).

35 Describiendo la importancia de usar la "nube" en la educación. 
la comprensión de los materiales educativos por parte de los estudiantes (Kozma, 2011, p. 21) $)^{36}$.

El uso de las TIC en educación también es importante porque promueve el aprendizaje permanente, al igual que permite incursionar en una educación más inclusiva. Respecto del primer punto, promover el aprendizaje permanente es necesario en nuestra sociedad actual (Leal, 2008, p.78) ${ }^{37}$, donde las personas necesitamos evolucionar en preparación y conocimiento para ser valiosas en el mercado global. Actualmente, los años de aprendizaje no pueden estar limitados a aquellos que dedicamos a un salón de clase (UNESCO, 2005, p. $77)^{38}$, realidad que ha sido reconocida por los educadores (Anderson, 2010, p. 10$)^{39}$. De esta manera, el uso de las TIC en la educación permite a las personas acudir a la educación informal para ganar conocimiento y nuevas habilidades (UNESCO, 2002a, p. 11) ${ }^{40}$, y a su vez, permite a los individuos e

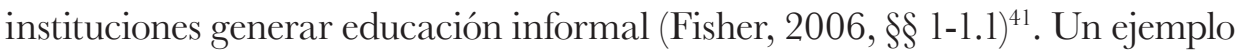
importante de instituciones promoviendo el aprendizaje permanente a través de las TIC es el Massachusetts Institute of Technology, el cual puso a disposición del público general los materiales enseñados en la institución ${ }^{42}$, brindando acceso a una educación de alta calidad a cualquier interesado alrededor del mundo (UNESCO, 2005, p. 85) $)^{43}$.

36 Estableciendo que la multimedia hace el contenido más entendible; ver también MinEducación (2004b).

37 Estableciendo que el aprendizaje permanente es un requisito para nuestra sociedad actual.

38 "Lifelong education can provide a response to the growing job volatility that most forecasters predict. Increasingly, people will be changing jobs several times in a lifetime, and education can no longer be limited to offering a single specialization, but must develop each person's ability to change course during his or her lifetime, and to cope with economic and social change" (p. 77).

39 Estableciendo que lo educadores reconocen que la educación no debe terminar al final de la educación formal.

40 "This may be the first time in history of the human race when lifelong learning is not only desirable and urgent, but feasible as well" (p. 11).

41 Estableciendo que la tecnología permite a instituciones educativas tradicionales abrir sus cursos al público en general, y también permite a individuos enseñar.

42 Ver Massachusetts Institute of Technology, Mitopencourseware: http://ocw.mit.edu/ index.htm

43 Estableciendo que la iniciativa de MIT concede acceso a conocimiento de alta calidad alrededor del mundo. 
El aprendizaje permanente se ha beneficiado de las herramientas Web 2.0. Un ejemplo de dichas herramientas que promueve el aprendizaje permanente, y también permite generar colaboración, comunidades de aprendizaje y la utilización de productos multimedia en la educación es YouTube y su categoría más específica YouTube.Edu. Dicha herramienta permite a los profesores o usuarios en general acceder a una gran variedad de cursos diseñados en diversos rincones del mundo, o videos elaborados por colegas educadores en diferentes áreas como matemáticas, física, ciencias naturales, entre otros. Igualmente, YouTube y YouTube.Edu permiten a los educadores, investigadores e individuos en general crear sus propios canales para compartir su conocimiento $^{44}$. Para hacerse a una mejor idea vamos a describir un ejemplo específico, en YouTube podemos encontrar, entre muchas cosas, lecciones sobre el sistema tegumentario ${ }^{45}$. En el video su autor desarrolla la lección tal como si estuviera al interior de un salón de clases y utiliza materiales multimedia, haciendo uso de fotos de humanos, uñas, plumas y dibujos de piel humana entre otros materiales para comunicar satisfactoriamente la lección. Este video, compartido por un individuo que le gusta enseñar se convierte en una fuente de conocimiento útil para otros profesores, ya sea para autopreparación, o como fuente educativa para usar dentro del salón de clase (Light \& Polin, 2010, p. 16 $)^{46}$. Actualmente, los profesores de escuelas americanas encuentran en los videos de YouTube una fuente importante de materiales educativos. Por ejemplo, un profesor americano de lenguaje describe cómo utiliza videos de Disney para explicar conceptos complicados a sus alumnos (p. 15). Por lo tanto, como lo ha descrito la UNESCO (s.f.), vemos cómo herramientas y redes que no iniciaron como recursos educativos, hoy en día se vuelven importantes para la educación (p. 7 $)^{47}$.

Finalmente, y como se mencionó anteriormente, otro beneficio de incorporar las tecnologías en la educación es promover una educación más incluyente, la cual tenga en consideración las necesidades de aprendices con

44 Ver YouTube.Edu: https://www.youtube.com/t/education, esta herramienta ha estado disponible en inglés desde el año 2012. En el 2014 se hizo disponible su versión en español iniciando con 23.000 videos en diversas materias.

45 Ver Bozeman Science (10 de marzo de 2014).

46 Enunciando ejemplos de cómo son usados por profesores americanos los contenidos disponibles gracias a herramientas Web 2.0

47 "Other networks with a basic educational function (e.g., YouTube) are also evolving outside of educational practice and authority" (p. 7). 
discapacidades y permita brindarles iguales oportunidades que sus pares (UNESCO, 2002a, p. 30) ${ }^{48}$. Para mencionar algunos ejemplos, hoy en día gracias a la tecnología aprendices con discapacidad visual pueden hacer uso de tecnologías read-aloud o engrandecedores de texto para acceder a la información; aprendices con dislexia pueden mejorar su comprensión lectora reformateando el texto para adaptarlo a un dispositivo de pantalla pequeña (UNESCO, 2013, p. 23) ${ }^{49}$; y por último, algunos software ayudan a mejorar la memoria de personas que han sufrido lesiones cerebrales (UNESCO, 2002a, p. 30 ${ }^{50}$. Por lo tanto, hacer de las TIC el centro del proceso educativo permite brindar una participación más activa a las personas con discapacidad.

En conclusión, las TIC implementadas apropiadamente dentro del sistema educativo permite brindar a los aprendices del siglo XXI las habilidades necesarias para la era de la tecnología, e igualmente, prepararlos para el mercado global basado en una economía del conocimiento.

\section{Estado actual de la transformación del proceso educativo a nivel mundial.}

La transformación del proceso de aprendizaje a través de la incorporación de la tecnología es un proceso en desarrollo continuo en todo el mundo, el cual está siendo impulsado por los gobiernos, las organizaciones internacionales y por iniciativas privadas. $\mathrm{Al}$ ser un proceso en desarrollo, todo el potencial de la incorporación de las TIC en la educación se encuentra todavía en proceso de ser desarrollado y sus resultados a la espera de ser medidos. Por desgracia, actualmente los datos disponibles para apoyar o refutar la utilidad de las TIC en la educación como herramienta empoderadora de los maestros y alumnos son limitados (Trucano, 2005) $)^{51}$. No obstante, a pesar de esta realidad, varios

48 "For persons with disabilities -who represent another significant and forgotten sector of the world population- technologies provide essential supports enabling them to participate in the educational system and the job market" (p. 30). Ver también UNESCO (2013), estableciendo que el uso de las tecnologías mejora el aprendizaje de personas con discapacidades (p. 23).

49 Explicando el proceso desarrollado para mejorar la comprensión lectora de personas con dislexia.

50 Estableciendo los beneficios de usar software para mejorar la memoria de personas que han sufrido lesiones cerebrales.

51 "It is generally believed that ICTs can empower teachers and learners, promote change and foster the development of 21 st century skills, but data to support these beliefs are 
países están comenzando a darse cuenta de la necesidad de incorporar las TIG en el proceso de aprendizaje y, en consecuencia, están desarrollando políticas educativas encaminadas a lograr esta transformación (párr. 2) ${ }^{52}$. Sin embargo, incluso en los países más avanzados no se ha logrado una transformación total de sus sistemas educativos (Banco Mundial, s.f. $)^{53}$.

No obstante, algunos países desarrollados ya han comenzado a poner en práctica metodologías de colaboración en su sistema educativo. Singapur, por ejemplo, reconoció el valor de las herramientas Web 2.0 para la educación y se convirtió en el primer país en ofrecer dichas herramientas para todos los maestros en el sistema escolar público (Anderson, 2010, p. 89). De la misma forma, las herramientas Web 2.0 están empezando a desempeñar un papel importante en las aulas estadounidenses, donde los profesores mejoran la creatividad y la colaboración de sus estudiantes mediante la creación de su propio contenido en línea (Discovery Education \& CDW-G, 2009, p. 3$)^{54}$. Por otra parte, los países en desarrollo también han empezado a diseñar políticas dirigidas a transformar sus sistemas educativos, empezando por superar los problemas de acceso al hardware, conectividad, entrenamiento de los profesores en el uso de las TIC, e incluso mejorar el suministro de electricidad confiable con el fin de beneficiarse de la incorporación de las TIC en la educación (Kozma, 2011, p. 18) ${ }^{55}$.

\section{La incorporación de las TIG en la educación para países en desarrollo}

Aunque la incorporación de las TIC en la educación es esencial tanto para países desarrollados como para países en desarrollo, para los últimos,

still limited" (párr. 1); ver Banco Mundial (s.f.), estableciendo que es necesaria hacer más investigación en el tema entre la relación educación y TIC.

52 "Many ICT in education initiatives in LDCs seek (at least in their rhetoric) to place ICT as central to teaching and learning" (párr. 2).

53 "Studies have shown that even in the most advanced schools in industrialized countries, ICTs are generally not considered central to the teaching and learning process" (párr. 1); ver Trucano (2005): "Even in the most advanced schools in OECD countries, ICTs are generally not considered central to the teaching and learning process" (párr. 2).

54 Hablando acerca de la utilización de herramientas Web 2.0 por parte de los maestros americanos.

55 Estableciendo que la falta de infraestructura en los países de bajos ingresos genera diversas adversidades al momento de integrar las TIC a la educación, especialmente por el alto costo de la infraestructura. 
el uso de las TIC en la educación también ha generado la convicción que su utilización puede ayudar a solucionar serios problemas de sus sistemas educativos (Rossini, 2010, p. 114) ${ }^{56}$. Esta habilidad de las TIC ha sido reconocida por gobiernos nacionales (Lugo \& Schurmann, 2012, p. 17) ${ }^{57}$ y organizaciones internacionales como la UNESCO, el Banco Mundial y el UN ICT Task Force y, por lo tanto, ha llevado a que los países en desarrollo decidan invertir en su utilización. Algunos ejemplos de la participación de organizaciones internacionales en la promoción de las TIC para solucionar problemas educativos en países en desarrollo son proyectos como: Mobile Learning Program de la UNESCO, el cual busca tomar ventaja de la gran disponibilidad de dispositivos móviles para alfabetizar las partes más vulnerables de la sociedad (West \& Chew, 2014); el programa del Banco Mundial denominado The World Links for Development Programme (WorLD), el cual busca por medio de las tecnologías conectar a estudiantes y profesores de secundaria de países en desarrollo con sus pares en países desarrollados con el propósito de realizar proyectos de investigación conjuntamente (World Bank, s.f. ${ }^{58}$; y por último tenemos el proyecto Global e-Schools and Communities Initiative (GESTI) de la UN ICT Task Force, el cual busca apoyar a países en desarrollo en el uso de las TIC para mejorar el acceso y la calidad de la educación ${ }^{59}$.

Por lo tanto, la incorporación de las TIC en la educación de los países en desarrollo no solo representa la capacidad de educar a los ciudadanos y generadores de contenido, sino también la capacidad de resolver problemas de su sistema educativo. Un ejemplo de este intento de utilizar la tecnología en la educación para resolver los problemas más destacados del sistema educativo lo encontramos en Colombia, como se discutirá más adelante.

56 "[...] developing nations in particular look to use the Internet to replace outdated and insufficient educational systems [...]" (p. 11); ver Kozma (2011), estableciendo que las políticas de uso de las TIC en educación son vistas en países en vías de desarrollo como la respuesta para solucionar diversos problemas que estos países enfrentan (p. 4).

57 Por ejemplo, algunos proyectos desarrollados por países de América Latina son: "Red Escolar" en México; "Programa de Informática Educativa" en Costa Rica; "Edu.ar" y "Conectar Igualdad" en Argentina; "Colombia Aprende" en Colombia; "Huascarán" en Perú y "Plan Ceibal" en Uruguay, entre otros.

58 Ver World Links for Development Programme (WorLD) (World Bank, s.f.).

59 Ver GESCI: http://www.gesci.org 


\section{La situación actual de la educación en Colombia.}

Colombia, como país en desarrollo de América Latina, no escapa del panorama general de la educación en la región donde existen problemas de acceso y calidad: actualmente, la educación en Colombia presenta grandes deficiencias como altas tasas de deserción escolar, falta de acceso a la educación, falta de educación de calidad, falta de maestros de calidad y analfabetismo adulto (UNDP, 2015, p. 243 tabla 10) ${ }^{60}$. Respecto de acceso, Colombia sufre una importante falta de acceso a la educación superior, como lo demuestra una tasa de escolarización de solo el $48 \%$, frente a un $93 \%$ en el nivel de secundaria y $115 \%$ en el nivel primario (p. 243, tabla 10). Aunque la tasa de acceso en los niveles primario y secundario no representa una preocupación saliente, el problema con respecto a estos niveles de la educación es la falta de calidad. De acuerdo con la última colección de datos por parte del Programa para la Evaluación Internacional de Alumnos (PISA 2012), que evalúa los sistemas educativos de todo el mundo, Colombia ocupó el puesto $62^{61}$ de 65 países participantes. De lo anterior se desprende que los estudiantes de Colombia tienen falencias en lectura, matemáticas y ciencias, en comparación con sus pares de otros países (OECD, 2013). Por ejemplo, el rendimiento promedio de los estudiantes colombianos en lectura fue de 403 puntos, siendo un resultado muy inferior al promedio de 496 puntos de los estudiantes de países de la OCDE (párr. 1). Las ciencias fue la materia donde las diferencias entre estudiantes colombianos y estudiantes de países OCDE fueron más pronunciadas; el promedio de los estudiantes colombianos fue de 399 puntos, mientras que el promedio de la OCDE fue de 501 puntos (párr. 3).

Dicha falta de calidad de la educación en Colombia obedece parcialmente a la falta de maestros de calidad. En Colombia, la carrera docente no es atractiva para los mejores estudiantes debido a la falta de reputación y los bajos salarios de la misma (Linares, 17 de diciembre de 2012). Además, el régimen de enseñanza que cubre la gran mayoría de los docentes en Colombia no permite la medición de la evaluación de los profesores, lo que hace que sea difícil determinar si los maestros son eficaces (Gossaín, 28 de febrero de 2014).

60 En Colombia el $6 \%$ al $7 \%$ de la población adulta es analfabeta: ver UNDP (2015, p. 243, tabla 10).

61 Los resultados de Colombia estuvieron por encima de Qatar, Indonesia y Perú. 
Aunque los problemas mencionados anteriormente son la regla general dentro del sistema educativo colombiano, estos se vuelven más profundos en la parte más vulnerable de la sociedad, ya que, como en otros países de la región, las desigualdades sociales son una de las principales fuentes de la crisis. Colombia es un país de ingresos moderados pero con grandes disparidades entre la población con respecto a los ingresos, el género y la ubicación geográfica. Por ejemplo, el coeficiente de Gini, que mide la desigualdad de la distribución del ingreso, para Colombia fue de 53,5 \% en el 2015. Para el 2014 el coeficiente de Gini se estableció en 55,9 \% demostrando que solo doce países tenían más desigualdad en el ingreso entre su población que Colombia (Economía y Negocios, 25 de julio de 2014; UNDP, 2014, p. 169, tabla 3; UNDP, 2015, p. 217, tabla 3). Por otra parte, Colombia ocupa el puesto 92 de los 188 países en desigualdad de género (UNDP, 2015, p. 225, tabla 5) y estas diferencias entre la población influyen en las oportunidades educativas de las personas.

Por ejemplo, las disparidades de ingresos y distribución geográfica afectan el acceso de los niños a la educación; aunque la mayoría de los niños de alto nivel socioeconómico logran acceder a la educación secundaria, solo la mitad de los niños de bajo nivel socioeconómico logran acceder a la escuela secundaria debido a la necesidad de dejar la escuela para obtener ingresos para la familia (UNESCO, 2012, p. 4) ${ }^{62}$. Igualmente, mientras los niños de nivel socioeconómico alto asisten a la escuela durante ocho horas por día, los niños de bajo nivel socioeconómico asisten cinco o menos horas por día (Congote \& Malaver, 19 de agosto de 2014). Por otro lado, de los estudiantes que logran llegar a la educación superior, la mitad no puede terminar sus estudios, en parte, por razones económicas. Para el año 2011, uno de cada dos colombianos que accedió a la educación superior no terminó sus estudios debido a razones económicas y a otras restricciones (MinEducación, abril de 2012, p. 7).

Igualmente, como se mencionó anteriormente, el acceso a la educación superior se encuentra también determinado por la ubicación geográfica de los niños. Los niños que viven en las zonas rurales y los niños indígenas se les dificulta acceder a la educación debido a la falta de cobertura de educación

$\overline{62}$ Estableciendo que las diferencias se incrementan a medida que pasa el tiempo debido a la necesidad de los niños de bajo nivel socioeconómico de conseguir soporte económico para sus familias. 
en las zonas rurales ("La educación se revoluciona en el campo", s.f) (33 $^{\text {. }}$ Además, estos niños también tienen mayores tasas de deserción escolar que los niños de alto nivel socioeconómico o los niños que viven en ciudades. Según la UNESCO, por cada adolescente de nivel socioeconómico alto que abandona la escuela secundaria, cuatro adolescentes de nivel socioeconómico bajo abandonan (Lugo \& Schurmann, 2012, p. 12), y dichas diferencias también se encuentran en las tasas de deserción escolar entre los adolescentes que habitan en las ciudades y adolescentes que habitan en zonas rurales, donde por cada adolescente de zona urbana que no asiste a la escuela, dos adolescentes de zona rural no asisten (p. 12).

De igual manera, la calidad de la educación también se ve afectada por las disparidades dentro de la sociedad, ya que la calidad de la educación que los niños de bajo nivel socioeconómico reciben es considerablemente más baja que la calidad de la educación que reciben los niños de alto nivel socioeconómico. Por ejemplo, del total de los niños de nivel socioeconómico bajo que asisten a la escuela, solamente alrededor del $10 \%$ de ellos logra alcanzar el nivel mínimo de conocimientos en matemáticas, mientras que el $55 \%$ de los niños de alto nivel socioeconómico lo logran adquirir (MinEducación, abril de 2012, p. 8) ${ }^{64}$. Adicionalmente, la educación de baja calidad que reciben los niños de bajo nivel socioeconómico y de aquellos que habitan en zonas rurales se agrava por la falta de maestros de calidad para esta parte de la población; las regiones más remotas, así como las regiones más afectadas por el conflicto armado, y las regiones más pobres tienen una mayor concentración de los maestros con menor experiencia y menor capacitación (García et al., 2014, p. 173).

Adicional a todos los problemas del sistema educativo mencionados anteriormente, se suma el hecho de que en Colombia las instituciones educativas tienen escasos recursos educativos, especialmente, aquellas instituciones ubicadas en zonas de bajo nivel socioeconómico. Sus bibliotecas no tienen suficientes materiales educativos, lo que crea una gran barrera

63 De acuerdo con los últimos datos disponibles en 2007 el porcentaje de cobertura de educación en las zonas rurales fue de $31.8 \%$.

64 Describiendo las diferencias en el resultado en educación entre los niños de bajo y alto nivel socioeconómico. Ver UNESCO (2012), establece que los niños de bajo nivel socioeconómico empiezan la escuela a una edad más avanzada (p. 4); ver UNESCO (2014a). 
para el acceso a la educación por estos estudiantes (Eduteka, septiembre de 2007). Por otra parte, aunque el acceso tanto a la educación pública primaria como secundaria ha sido gratis desde 2012, las familias todavía deben proporcionar los libros de texto ${ }^{65}$, lo que afecta el acceso a dichos materiales cuando los padres no pueden pagarlos.

Por otro lado, para un estudiante que desee obtener acceso a material educativo hay pocas alternativas distintas a las bibliotecas escolares, y eso si estas últimas existen, por distintas razones. Por ejemplo, muchas regiones carecen de material impreso. Ana Roda, directora de la Biblioteca Nacional de Colombia, afirma que, según los últimos datos de 2009, alrededor del 44 $\%$ de las librerías del país se encontraban en las tres ciudades principales de Colombia. Trece regiones tenían menos de cinco librerías, seis regiones tenían una librería en la capital y, por último, cuatro regiones no tenían librería alguna (Roda, 20 de marzo de 2013). Igualmente, los hogares colombianos carecen de libros, en una medición en el 2010 se encontró que el 22,1 \% de los hogares colombianos no tenían ni un solo libro (Plan Nacional de Lectura y Escritura, s.f), y que el 22,4 \% tenían entre uno y cinco libros (párr. 5). Finalmente, la cantidad de materiales disponibles en bibliotecas son pocos, dando una proporción de un libro por cada seis personas (párr. 7).

Aunque el Ministerio de Cultura empezó a desarrollar el "Plan Nacional de Lectura y Escritura" con el fin de construir bibliotecas físicas en cada municipio y subsanar la falta de materiales impresos, muchas veces dichas bibliotecas no están bien equipadas (Plan nacional de lectura y escritura, s. f.) o no son de fácil acceso para todas las personas en muchos lugares, especialmente en las zonas rurales. En un intento por remediar esta falta de materiales educativos en las zonas más remotas y marginadas, se desarrolló una campaña llamada "El Biblioburro"66, desarrollado por el profesor Luis Humberto Soriano Bohórquez, el cual busca llevar libros y lecturas a los niños víctimas de la violencia de las zonas rurales en el Magdalena (Nuestro proyecto social, 25 de febrero de 2013). Hoy en día, este proyecto se ha ampliado e incluye cerca de 8.000 libros de tecnología, incluyendo e-libros

\footnotetext{
65 Ver Decreto 4807 de 2011, que establece la gratuidad de la educación. Sin embargo, el decreto no incluye la gratuidad de los textos educativos.

66 Ver el blog "El Biblioburro" (Nuestro proyecto social, 25 de febrero de 2013).
} 
o películas para familiarizar a los niños con las tecnologías. No obstante, y desafortunadamente, no todas las regiones tienen "Biblioburros".

Adicionalmente, Colombia sufre una brecha digital en comparación con los países desarrollados y una brecha digital al interior de su población. En 2013, el 9,1 \% de la población de Colombia tenía acceso a Internet fijo, siendo esta cifra muy por debajo del $27,2 \%$ de personas que tienen acceso a Internet fijo en países desarrollados (Fedesarrollo, 2013, p. 21) ${ }^{67}$. Por otra parte, estas diferencias también son evidentes entre las regiones colombianas; 16,4 \% de los residentes de Bogotá, la capital, tiene acceso a Internet fijo, no obstante, regiones remotas como Chocó o Bolívar tienen tasas de acceso de solo el $2 \%$ y $6,1 \%$, respectivamente (p. 21) ${ }^{68}$. El acceso de Colombia a Internet móvil a partir de 2013 fue del $8 \%$, mientras que dicha tasa en los países desarrollados fue de $75 \%$ (p. 25) ${ }^{69}$. Además, en 2013, la velocidad de Internet en Colombia era solo la mitad de los demás países de la región como México y Chile (p. 14) ${ }^{70}$. Por último, para el 2012 solo 4.720 .000 conexiones tenían acceso de banda ancha (Colombia alcanzará meta de conexión a banda ancha en 2014, 07 de febrero de 2013).

Por lo tanto, aunque el sistema educativo colombiano presenta problemas sobresalientes en general, estos problemas son más profundos en la parte más vulnerable de la sociedad, generando fuertes preocupaciones teniendo en cuenta que para el 2013 el porcentaje de personas de bajo nivel socioeconómico en Colombia fue de 30,6 \% de la población nacional (Departamento Administrativo Nacional de Estadística [DANE], 21 de marzo de 2014) ${ }^{71}$.

\section{La política colombiana de las TIG en la educación.}

Como una solución a la crisis de la educación en Colombia, y como muchos otros gobiernos alrededor del mundo, el gobierno colombiano está desarrollando una serie de planes y programas dirigidos a incorporar las TIC en la educación. Al hacerlo, Colombia busca brindar apoyo a otras políticas educativas para la cobertura, calidad y eficiencia de la educación (Programa

\footnotetext{
Estableciendo el porcentaje de acceso a Internet fijo (fig. 12).

Estableciendo el porcentaje de acceso a Internet fijo por regiones.

Estableciendo el porcentaje de acceso a Internet móvil (fig. 23).

70 Estableciendo que la velocidad de Internet en Colombia obedece a la mitad de la velocidad de Internet en Chile y México.

71 Estableciendo el porcentaje de pobreza en el 2013.
} 
Nacional de Nuevas Tecnologías, s.f. $)^{72}$. De esta manera, y encaminado a lograr el objetivo, el Gobierno colombiano ha invertido una enorme cantidad de dinero, teniendo en cuenta los escasos recursos del país, para hacer de este objetivo una realidad ("Barreras que Impiden la Masificación de Internet", s.f. $)^{73}$. Y aunque Colombia se encuentra todavía en las primeras etapas de la incorporación de las TIC en el sistema educativo, los planes del Gobierno no reflejan simplemente un aprovechamiento superficial de las TIC en la educación, como sucede en muchas ocasiones en otros países ${ }^{74}$, sino que evidencian el objetivo de utilizar esa tecnología para lograr la transformación del proceso de aprendizaje bajo los parámetros descritos anteriormente.

Colombia no tiene una política específica centrada en la incorporación de las TIC en la educación, en cambio, el Gobierno colombiano ha abordado los objetivos en este ámbito, principalmente en dos planes: "Visión 2019 para la educación"75 y el "Plan Nacional de TIC", así como varios programas ${ }^{76}$. Estos planes se han dirigido a cubrir tres frentes importantes para lograr un proceso de aprendizaje totalmente transformado. El primer frente se refiere a la provisión de infraestructura, hardware y conectividad. El segundo frente se refiere a la creación de contenido local y a la difusión de dichos contenidos. Por último, el tercer frente se refiere a la formación de profesores en el uso de las TIC y a la inversión en investigación para desarrollar nuevas metodologías educativas con el uso de las tecnologías (Programa Nacional de Nuevas Tecnologías, s.f. $)^{77}$.

72 Estableciendo que las políticas de las TIC en educación buscan dar apoyo a otras políticas educativas de cobertura, calidad y eficiencia.

73 Estableciendo que debido a la realidad colombiana, el gobierno nacional tiene recursos escasos para invertir en infraestructura.

74 Ver Sy Tan (4 de marzo de 2008): "Many governments advocate the use of ICT in education or launch the Multimedia Super Corridor without actually seeing to it that it is meaningfully integrated and internalized" (párr. 1); ver también UNESCO (2014b): "Often the emphasis of national strategies relating to ICT in Education is on ICT infrastructure, with the primary goal to provide computers to school, but without the support measures needed to make ICT use effective in schools" (p. 6).

75 Ver MinEducación (2006).

76 Estos planes son desarrollados en conexión con otros planes como: El Plan Nacional de Desarrollo; Política Nacional de Competitividad; Plan de Ciencia y Tecnología; Programa Estratégico de Uso de Medios y Tecnologías de la Información y Comunicaciones (MTIC) en la Educación, entre otros. Ver Ministerio de Comunicaciones (2008) (en adelante Plan Nacional TIC).

77 Describiendo los tres frentes de acción. 
Como se mencionó anteriormente, el primer frente de acción se encarga de proporcionar hardware y conectividad a las escuelas y se desarrolla a través de iniciativas como "Computadores para Educar" y Compartel (Programa Nacional de Nuevas Tecnologías, s.f.), el cual democratiza el acceso a Internet. Dicho frente de acción juega un paso crucial hacia la incorporación de las TIC en la educación debido a la brecha digital en el país donde muchas personas y regiones específicas aún carecen de acceso a la tecnología.

De acuerdo con datos del plan de las TIC, para el año 2005, el $55 \%$ de las escuelas primarias y secundarias públicas tenía hardware y $28 \%$ tenían conectividad (MinEducación, 2006, p. 59). Para el año 2008, solo el $10 \%$ de las instituciones de educación superior proporcionaban aprendizaje virtual (Ministerio de Comunicaciones, 2008, p. 36). Adicionalmente, solo un pequeño porcentaje de las bibliotecas estaban en capacidad de proporcionar conectividad a sus clientes ${ }^{78}$ debido a problemas presupuestarios (Roda, 20 de marzo de 2013) ${ }^{79}$. En aras de mejorar este panorama, el Gobierno nacional bajo el desarrollo de sus políticas TIC en la educación se planteó el objetivo para el 2019 de tener el $100 \%$ de dichas instituciones con el hardware y el $95 \%$ con la conectividad (MinEducación, 2006, p. 59), al igual que traer la conectividad a todas las bibliotecas en un período de tres años (Roda, 20 de marzo de 2013; Biblioteca Nacional de Colombia, 2013, p. 11) ${ }^{80}$. En un intento por lograr estos objetivos, el Gobierno invirtió 611.048 millones de pesos entre 2010 a 2014 para equipar a 34.191 instituciones educativas públicas con PG y tabletas (Ministerio de Tecnologías de la Información y las Comunicaciones MinTIC, 2014, p. 40). Igualmente, las bibliotecas y casas de cultura se incluyeron en esta iniciativa, y el Gobierno alcanzó la proporción de 12 niños por computador (p. 40) ${ }^{81}$. El programa conocido

78 De 1406 bibliotecas solo 523 tienen conectividad. Para el 2013 se esperaba brindar conectividad a un número adicional de 400 bibliotecas. Ver Biblioteca Nacional de Colombia (2013, p. 11).

79 Solo hasta el 2010 se promulgó la Ley 1379 en favor de las bibliotecas, la cual establece un presupuesto dirigido a mejorar sus infraestructura, material y servicios disponibles. $\mathrm{El}$ art. 10 de esta ley establece que las bibliotecas deben promover el conocimiento en TIC dentro de la comunidad, lo cual evidencia el propósito del gobierno a cada comunidad.

80 Ver Roda (20 de marzo de 2013); ver también Biblioteca Nacional de Colombia (2013, p. 11).

81 Estableciendo el porcentaje de PG y tabletas entregadas a instituciones educativas logrando una proporción de 12 niños por computador. 
como "Computadores para Educar" tuvo tanto éxito que el Gobierno de Colombia ganó el premio en el 2012 en la Cumbre Mundial sobre la Sociedad de la Información (CMSI) en la categoría de acceso a la información y el conocimiento (p. 46) ${ }^{82}$.

Además, con el fin de democratizar el acceso a Internet, el Gobierno nacional ha establecido centros de aprendizaje comunitarios, como Kioskos Digitales (MinTic, 2014 p. 117) ${ }^{83}$, los cuales son centros de tecnología que traen hardware y conectividad a las zonas más remotas y marginadas de Colombia. El kiosco digital permite a la comunidad capacitarse en el uso de las TIC y también acceder a Internet con diferentes fines, desempeñando un papel esencial en la educación, ya que funcionan como apoyo educativo para los estudiantes al momento de realizar las tareas de sus escuelas o realizar investigaciones, o simplemente por permitir el acceso a la educación a distancia. Actualmente, existen 5.300 kioscos digitales establecidos en pueblos de más de 100 habitantes ("Kioscos vive digital", s.f.). Para el 2014 se empezó la creación de kioscos digitales al interior de las instituciones educativas, con el fin de utilizarlos en educación en las horas escolares y abrirlos a la comunidad en horario posterior ("Aprovechamiento de las TIC para mejorar la calidad educativa", s.f.). Finalmente, en el 2013 el Gobierno apoyó la creación de 80 programas virtuales, lo que elevó las oportunidades de opciones para acceder a la educación a distancia ("Colombia avanza a paso firme, 18 de junio de 2013).

El segundo frente de acción para la integración de las TIC en educación, busca producir y compartir contenidos educativos y promover la creación y utilización de herramientas para promover metodologías de colaboración en la educación en Colombia. Este frente se desarrolla a través de la plataforma "Colombia Aprende" (Programa Nacional de Nuevas Tecnologías, s.f), la cual presenta un doble objetivo. En primer lugar, busca promover la generación de contenidos (MinEducación, 2004a) ${ }^{84}$. Para el año 2006, 9000 piezas diferentes de contenido habían sido subidos a la plataforma ("El programa

\footnotetext{
82 Estableciendo que "Computadores para Educar" ganó el premio de la cumbre WSIS.

83 Estableciendo que existen diferentes programas dirigidos a democratizar el acceso a Internet como "Puntos Vive Digital, el proyecto Conectividad de Alta Velocidad para Amazonas, Orino y Choco, los Kioscos Vive Digital, El proyecto Nacional de Fibra óptica" entre otros.

84 Estableciendo que "Colombia Aprende" busca promover la generación de contenidos.
} 
nacional en cifras", 2006) $)^{85}$ incluyendo videos, libros y juegos, diseñados específicamente para ayudar a los estudiantes, profesores e investigadores en su trabajo ("“Colombia Aprende' presenta nuevos contenidos de Educación Superior", 20 de octubre de 2005), facilitando la disponibilidad de recursos educativos en diferentes escenarios educativos. En segundo lugar, "Colombia Aprende" es la primera comunidad de aprendizaje de este país. Y, como la primera comunidad de aprendizaje, busca conectar a los profesores, investigadores y estudiantes entre sí y con sus compañeros ${ }^{86}$, promoviendo la adopción de la metodología de colaboración en Colombia, originando la discusión entre pares y el intercambio de experiencias (MinEducación, 2004a). Además, la plataforma anima a los profesores e investigadores a transformar y adaptar materiales ya existentes en la plataforma para su uso en sus actividades educativas.

Por último, el tercer frente de acción busca capacitar a los profesores en el uso de las TIC para posteriormente promover el diseño de metodologías para su incorporación en la educación con el objetivo de fomentar un proceso de aprendizaje colaborativo y crear comunidades educativas. La iniciativa central bajo este frente de acción se denomina "A que te cojo Ratón", así como la anteriormente mencionada "Computadores para Educar" (Ministerio de Comunicaciones, 2008, pp. 35-36) 87. "A que te cojo Ratón" busca capacitar a los profesores en el uso de la tecnología en diferentes etapas, desde familiarizarlos con las TIC hasta promover el desarrollo de metodologías de enseñanza utilizando las TIC (MinTIC, 2014, p. 44) ${ }^{88}$.

De 2010 a 2014, el Gobierno nacional invirtió 70.235 millones de pesos (MinTic, 2014, p. 44) ${ }^{89}$ en esta iniciativa y entrenó 38.372 profesores pertenecientes a 13.787 instituciones educativas (p. 43) ${ }^{90}$. También en el 2013,

85 Ver documento disponible para descarga en http://www.colombiaaprende.edu.co/ html/home/1592/article-102549.html

86 Estableciendo que "Colombia Aprende" permite a los usuarios ponerse en contacto entre sí, para debatir y compartir fuentes etc.

87 Estableciendo que las capacitaciones de los educadores se lleva a cabo en dos iniciativas: "A que te cojo ratón" y "Computadores para educar".

88 Estableciendo que la capacitación de educadores se inició en varios niveles que van desde enseñanza sobre los básicos de TIC hasta promover la creación de metodologías de la educación con TIC.

89 Estableciendo el presupuesto disponible para esta iniciativa.

90 Estableciendo el número de profesores e investigadores beneficiados con esta iniciativa. 
el Gobierno creó cinco centros de investigación (Centros de Innovación Educativa Regional [CIER]) dedicados a la investigación en el uso de las TIC en la educación ("Colombia avanza a paso firme en innovación educativa y uso pedagógico de las TIC", 18 de junio de 2013). Además, bajo estas iniciativas se han creado comunidades nacionales de aprendizaje tales como RENATA (Red Académica Nacional de Alta Velocidad) que trata de facilitar la comunicación entre las diferentes instituciones educativas promoviendo la colaboración y la innovación entre los profesores, investigadores y estudiantes ${ }^{91}$. Así mismo, el Gobierno ha participado en la comunidad de aprendizaje regional Red CLARA (Cooperación Latino Americana de Redes Avanzadas) (Programa Nacional de Nuevas Tecnologías, s.f.), la cual permite la comunicación y colaboración entre los trece países latinoamericanos posibilitando a los investigadores y profesores trabajar en colaboración con sus pares de la región (Red Clara, s.f. ${ }^{92}$.

Los tres frentes de acción de incorporación de las TIC en la educación pueden beneficiar y mejorar la educación en Colombia, en particular a la población más vulnerable. Aunque, como se mencionó anteriormente, no existen datos estadísticos que apoyen el uso de la tecnología en la educación como fuente mejoradora de ésta, lo cierto es que existe un consenso de que su uso mantiene a los estudiantes motivados mientras aprenden (Rossini, 2010, p. 30 $)^{93}$, y Colombia está empezando a ver estos resultados. La incorporación de las TIC en las escuelas ha ayudado a mejorar la educación, en la medida que ayuda a motivar y retener a los niños de las zonas rurales en la escolaridad. Por ejemplo, una pequeña escuela en la localidad rural de Chiquinquirá beneficiaria de las tabletas otorgadas por el Gobierno ha encontrado que los niños están dispuestos a permanecer más tiempo en la escuela y quieren seguir asistiendo a la escuela (MinTIC, 14 de septiembre de 2014), por lo tanto, esta alternativa ayudar a mitigar el alto porcentaje de deserción escolar.

\footnotetext{
91 Ver Renata Colombia: https://www.renata.edu.co/index.php/component/content/ article/3-que-es-renata/6110-identidad-renata.html

92 Respondiendo a la pregunta "¿para qué sirve la conexión a Redclara?”, se dice que dicha Red sirve para promover iniciativas de colaboración en la región.

93 "[...] there is also a general consensus that both teachers and students feel ICT use greatly contributes to student motivation for learning" (p. 30).
} 
Por otra parte, dado que uno de los beneficios de brindar acceso a Internet es que se amplía el acceso a la información (Institute for Communication and Development IICD, 2007, p. 29 ${ }^{94}$, este plan ha permitido a los estudiantes y maestros colombianos acceder a información más allá de aquella disponible dentro de las paredes del aula brindándoles las mismas posibilidades de acceso a recursos educativos que aquellas que tienen otros estudiantes alrededor del mundo (MinTIC, 3 de junio de 2014) ${ }^{95}$. Igualmente, el uso de la tecnología en la educación también ha ayudado a proporcionar una educación más inclusiva para los alumnos con discapacidad, permitiéndoles mayor acceso y participación (MinTIC, 2014, p. 42) ${ }^{96}$. Por último, la utilización de las TIC en la educación puede ayudar a aumentar el tiempo de escolaridad de los niños de bajos recursos económicos que por lo general asisten a un menor número de horas de escuela, debido al sistema de doble turno (UNESCO, 2002a, p. 32) $)^{97}$.

De igual manera, la democratización del acceso a Internet también permite que los estudiantes ubicados en las zonas rurales tengan acceso a diversas alternativas de educación supliendo la falta de cobertura en estas zonas, como lo sería educación a distancia y diversas iniciativas de aprendizaje permanente, las cuales, permiten tanto a profesores y estudiantes, como al público en general, mejorar sus habilidades. Por ejemplo, Quibdó, una de las regiones más marginadas de Colombia, recibió acceso a Internet gracias a la instalación de un Kiosco Digital, y como resultado, la banda de Los Titanes fue capaz de utilizar YouTube para aprender una coreografía para sus espectáculos, y como ellos mismos afirman, esta nueva habilidad ha hecho sus espectáculos más agradables para el público, y todo gracias a tener acceso a Internet (Skynet Kvd, 29 de octubre de 2013) ${ }^{98}$.

\footnotetext{
94 "Most primary and secondary schools in Africa and Latin America lack adequately trained teachers and have poor quality, or limited access to, learning materials. ICT can assist in addressing these challenges" (p. 29).

95 Estableciendo que gracias a las tabletas y PG entregadas por el Gobierno, los estudiantes colombianos tienen las mismas herramientas informativas que otros estudiantes alrededor del mundo.

96 Estableciendo que la iniciativa "Computadores para Educar" ha ayudado a estudiantes con alguna discapacidad.

97 "Students may attend school for half a day and spend the other half involved in educational activities at home, in a library, at work, or in another unconventional setting" (p. 32).

98 Describiendo lo que significó el uso de YouTube para sus shows.
} 
Adicionalmente, la inversión que ha realizado el Gobierno de Colombia en la creación de contenido local y la difusión de ese contenido en una plataforma de libre acceso va más allá del beneficio de acceso masivo a información que Internet proporciona, ya que, herramientas como "Colombia Aprende" permite a los profesores utilizar y transformar contenido existente y adaptarlo a necesidades locales. De esta manera, "Colombia Aprende" brinda la seguridad a profesores y estudiantes que utilizan la plataforma de estar empleando materiales adecuados para la preparación de las clases o la preparación de las tareas, en lugar de enfrentarse a una corriente masiva de información sin categorización alguna, la cual, no ayuda a los países en desarrollo (Banco Mundial, s.f. ${ }^{99}$.

Así mismo, "Colombia Aprende" ayuda a mejorar la calidad de la educación (UNESCO, 2002a, p. 32) ${ }^{100}$, ya que al ser la primera comunidad de aprendizaje, permite a los profesores e investigadores de los lugares más remotos ponerse en contacto con colegas expertos ubicados en otros lugares del país o del mundo para intercambiar recursos, consejos, ideas, e incluso desarrollar proyectos conjuntamente. Por ejemplo, el intercambio de productos multimedia entre varias escuelas puede ayudar a mejorar la educación en aquellas escuelas donde los maestros no han adquirido las habilidades para desarrollar el material por su cuenta (p. 10) ${ }^{101}$. Además, "Colombia Aprende" marca el principio de la apropiación de las TIC en la educación. Mientras que los profesores, investigadores y estudiantes utilizan la plataforma de colaboración, dicho escenario les sirve como práctica para iniciar a aplicar las metodologías interactivas, colaborativas y multimedia a sus propias clases usando otras herramientas como blogs y wikis. Por último, el hecho de que el Gobierno colombiano está invirtiendo en programas de formación y en los programas de investigación para el desarrollo de nuevas

99 "While ICTs, and the Internet in particular, provide access to a world of educational resources, those resources are rarely in a format that makes them easily accessible and relevant to most teachers and learners in developing countries" (párr 1, sección Content and Curriculum).

100 "ICTs have the potential to bring the products of the best teachers to classrooms anywhere in the world" (p. 32).

101 "Multimedia modules, the product of few instructional designers and master teachers, may be shared with many schools. Since expertise in instructional design and multimedia materials development is scarce, technological networking allows for economies of expertise". 
metodologías educativas en la educación nos demuestra que hay mucho más progreso por venir en esta área.

Por lo tanto, estos tres frentes de acción evidencian el objetivo claro del Gobierno colombiano y su compromiso hacia la incorporación de las TIC en el proceso de aprendizaje. Por otra parte, pone de manifiesto la intención del Gobierno de utilizar las TIC como herramienta para aliviar los problemas sobresalientes del sistema educativo.

\section{La política de las TIG en la educación y su relación con los derechos de autor}

La utilidad de las TIC en la educación está estrechamente ligada a la capacidad que tiene este tipo de tecnologías de acceder, difundir y transformar el contenido. Sin la capacidad de manipular, compartir y difundir el contenido, la infraestructura y la conectividad no es suficiente para mejorar la educación bajo los términos descritos anteriormente (UNESCO, 2002a, p. 15) ${ }^{102}$. De esta manera, la ley de derechos de autor puede afectar drásticamente la incorporación de la tecnología en la educación y su capacidad para resolver los problemas de la educación, debido a que es esta ley la que controla el uso de gran parte del contenido utilizado como material educativo, como se explicará en el siguiente capítulo.

Dicha realidad ha sido reconocida por el Gobierno colombiano, el cual ha manifestado que la ley actual de derechos de autor puede ser un obstáculo legal para el desarrollo de la política de las TIC en la educación y ha resaltado la importancia de la revisión de la legislación de derechos de autor para permitir usos educativos de contenido en el entorno digital (Ministerio de Comunicaciones, 2008, pp. 66, 110). Sin embargo, esta actualización de la normativa autoral no depende únicamente de la voluntad del legislador, ya que la autonomía de Colombia en esta materia puede estar restringida por una serie de obligaciones internacionales adquiridas, como se examinará en el próximo capítulo.

102 "Introducing TVs, radios, computers, and connectivity into schools without sufficient curriculum-related contentware is like building roads but without making cars available[...]" (p. 15). 


\section{Conclusión}

Un proceso de aprendizaje transformado por la incorporación de las TIC es acerca de compartir, intercambiar y crear contenido. De igual manera, se trata de lograr un nuevo sistema apto para la formación de los nuevos generadores de conocimiento necesarios para la economía actual y para proporcionar las habilidades necesarias para el siglo XXI, donde los materiales multimedia y los modelos de colaboración, de siempre en el aprendizaje, y aprendizaje permanente y educación inclusiva desempeñan un papel central.

Aunque la transformación del proceso de aprendizaje es un proceso en desarrollo alrededor del mundo, la incorporación de la tecnología en la educación representa para los países en desarrollo la oportunidad de resolver una serie de problemas relevantes en su sistema educativo. Por ello, muchos países en desarrollo han comenzado a generar políticas sobre el uso de las TIC en la educación. Un ejemplo de esta situación es Colombia, donde el Gobierno ha apoyado firmemente la incorporación de la tecnología en la educación mirando hacia la transformación del proceso de aprendizaje. El objetivo de la política es utilizar la tecnología para ayudar a resolver los problemas de acceso, calidad y falta de materiales educativos. Actualmente, dicha política ha ayudado a promover la educación de Colombia, y más beneficios están aún por evidenciarse, sin embargo, esta política debe complementarse con una política de derechos de autor la cual permita el uso de contenido para actividades educativas en el entorno digital. 

Capítulo 2

\section{EL DESARROLLO DEL DEREGHO INTERNACIONAL DE LOS DEREGHOS DE AUTOR EN EL ESGENARIO MULTILATERAL}

Hl derecho de autor y la educación han tenido $\Delta$ durante mucho tiempo una estrecha relación. La protección de los derechos de autor se ejerce sobre casi todas las piezas de material educativo y dicta cómo dichos derechos se pueden utilizar, y es por esa razón, que la protección de los derechos de autor determina cómo la gente puede aprender. A través del desarrollo de la legislación, las diversas leyes nacionales han tratado de establecer un equilibrio entre la protección del derecho de autor y el acceso con el fin de favorecer la educación. No obstante, actualmente, este equilibrio debe evolucionar para adaptarse a la utilización de la tecnología en la educación permitiendo el desarrollo de las nuevas políticas y metas nacionales en la materia.

Sin embargo, dicho equilibrio entre derechos de autor y educación se determina no solo por las necesidades y políticas de los países, sino también por los estándares internacionales de protección en la materia. Desde la promulgación del Convenio de Berna en 1886, los países miembros han cedido poco a poco su autonomía para determinar su propio nivel de protección en materia de derechos de autor a los acuerdos internacionales. No obstante, muchas veces, el nivel de protección establecido en aquellos tratados no corresponde con los intereses 
o necesidades de todos los países miembros, especialmente los países en desarrollo, ya que, en lugar de proteger los intereses de estos últimos, dichos tratados internacionales limitan su capacidad para adaptar la regulación de derechos de autor de manera que logre satisfacer necesidades educativas domésticas. Esta situación ha generado un conflicto norte-sur en el sistema internacional de protección de los derechos de autor.

La sección primera de este capítulo explica los fundamentos de derecho de autor para describir con más detalle la relación entre la educación y el derecho de autor, y cómo las leyes nacionales deben prestar atención a dicha relación y su evolución actual para proporcionar una protección adecuada y equilibrada. La sección segunda describe la multilateralización de la ley internacional de derechos de autor y cómo los países han cedido su autonomía a los tratados internacionales, limitando la capacidad de dar forma a su ley de derechos de autor de tal manera que satisfaga sus necesidades locales. Finalmente, esta sección evidencia el marcado conflicto norte-sur que ha caracterizado esta evolución demostrando que las normas internacionales no se ajustan a las necesidades de todos los miembros.

\section{Revisión sobre la relación entre derechos de autor y educación}

\section{Aspectos básicos sobre el derecho de autor.}

El derecho de autor concede al titular de los derechos un monopolio para la explotación de la creación, en este sentido, es el titular del derecho quien obtiene un conjunto de derechos exclusivos para la explotación de la obra o para autorizar a un tercero a realizar dicha explotación generalmente después del pago de una tasa. Dicho conjunto de derechos otorgados al titular del derecho de autor ha evolucionado con el tiempo, como se explicará más adelante; en términos generales y siguiendo las normas internacionales actuales en la materia, estos derechos consisten básicamente en la facultad de reproducir',

Ver Convenio de Berna de 1886 para la protección de las obras literarias y artísticas, revisado en París en julio de 1971, 25 U.S.T. 1341, 828 U.N.T.S. 221 [de aquí en adelante Convenio de Berna de 1971]. Art. 9, estableciendo el derecho de reproducción. 
distribuir ${ }^{2}$, transformar ${ }^{3}$ y comunicar ${ }^{4}$ cualquier material protegido por el derecho de autor. Igualmente, dicho derecho también otorga una serie de derechos morales al autor incluyendo el derecho de paternidad e integridad de la obra ${ }^{5}$, los cuales están dirigidas a proteger el vínculo autor-obra y la fiabilidad de la obra (Sundara, 2011, p. 7) .

Una de las principales características del derecho de autor es que este aplica a la obra desde su creación sin necesidad de ninguna formalidad (Convenio de Berna de 1971, art. 5 (2) $)^{7}$, y hasta la expiración del plazo de protección, el cual se extiende, generalmente, a 50 años después de la muerte del autor $(\operatorname{art} .7)^{8}$. Aunque los requisitos necesarios para obtener la protección de los derechos de autor varían de un país a otro, la regla general es que el umbral para obtener dicha protección es bajo. Según las normas internacionales actuales, la materia protegida por el derecho de autor incluye cualquier obra literaria, científica o artística: "cualquiera que sea el modo o forma de expresión" (art. 2) ${ }^{9}$. En consecuencia, el alcance de la protección del derecho de autor es muy amplio y solo requiere que una obra sea "original" (Ricketson \& Ginsburg, 2006, pp. 404-406) ${ }^{10}$ para ser protegido, recayendo sobre una gran diversidad de obras como pinturas, bases de datos, obras coreográficas, libros, folletos, canciones, fotografías, entre otros ${ }^{11}$. De igual manera, la obra puede ser protegida independientemente de la expresión de la obra (ya sea fijada u oral) y sin importar el medio de expresión (ya sea

2 Tratado de la OMPI sobre derecho de autor (WCT), 1996, 36 I.L.M. 65 (1997). Art. 6 , estableciendo un derecho de distribución en general.

3 Ver Convenio de Berna de 1971. Art. 8, 12, estableciendo el derecho de adaptación y de traducción.

4 Ver Tratado de la OMPI sobre Derecho de Autor (20 de diciembre de 1996, art. 8), estableciendo un derecho de comunicación en general.

5 Ver Convenio de Berna de 1971. Art. 6bis, estableciendo los derechos morales de paternidad e integridad.

$6 \quad$ "The purpose of moral rights is to protect the author from suffering the consequences of moral, intellectual, or spiritual harm inflicted on him through the mistreatment of his work" (p. 7).

7 Ver Convenio de Berna de 1971. Art. 5 (2), estableciendo que el derecho de autor recae en la obra sin la necesidad de ninguna formalidad.

$8 \quad$ Estableciendo la regla general de duración de la protección.

925 U.S.T 1341, 828 U.N.T.S. 221.

10 Estableciendo que no existe un nivel internacional de originalidad, por el contrario, este se establece a nivel nacional. No obstante, no debe ser muy alto.

11 Art. 2 del Convenio de Berna (1971) establece una lista ilustrativa. 
digital o análoga) (Convenio de Berna de 1971, art. 2). Por último, el derecho de autor protege la expresión de la idea, pero no la idea en sí (Tratado de la OMPI, 20 de diciembre de 1996, art. 2) ${ }^{12}$.

Los fundamentos para la existencia de los derechos de autor se pueden separar, grosso modo, en dos teorías: (1) la teoría de la ley natural; y (2) la teoría utilitarista. En primer lugar, la teoría de la ley natural, que prevalece en los países de los sistemas de derecho civil (Senftleben, 2004, p. 6) ${ }^{13}$, justifica la protección de derechos de autor sobre la base de la conexión especial que nace entre el autor con su creación y de la calidad de la obra como producto del trabajo del autor en su condición de ser humano ${ }^{14}$ representando al autor mismo $^{15}$. Bajo la lógica de esta teoría, el autor recibe los derechos de propiedad sobre su creación por ser el resultado de su trabajo (Davies, 2002) ${ }^{16}$. En segundo lugar, la teoría utilitarista, que prevalece en los sistemas de derecho anglosajón (Senftleben, 2004, p. 6), ${ }^{17}$ justifica la protección de los derechos de autor sobre la base de los beneficios que este tipo de creaciones podrían traer a la sociedad ${ }^{18}$. En este sentido, la ley de derechos de autor promete recompensas económicas con el fin de fomentar la creación que beneficiará a la sociedad mediante la difusión del conocimiento y la información ${ }^{19}$.

12 Estableciendo la dicotomía entre expresión/ idea.

13 Estableciendo que la teoría de la ley natural prevalece en los sistemas de ley civil.

14 Ver Dutfield \& Suthersanen (2008): "During the eighteenth and nineteenth centuries, inventors and authors began to conceive of themselves as private personae, whereby works emanated from them rather than from a divine being" ( p. 55).

15 Ver Efroni (2011): "in the case of copyright, personality theories inspired by Hegel's treatement view human creative expressions as the embodiment of the creator's self" (p. 113).

16 "Starting from the premise that people has a natural right of property in their bodies, [Locke] argued that people also owned the labour of their bodies and the result of that labour" ( 2-005).

17 Estableciendo que la teoría utilitarista prevalece en países de derecho anglosajón.

18 Ver Wong (2011): "The overreaching idea is that the 'public interest' would be advanced through the accumulation of inventions and other creative endeavors thus incentivized" (p. 16); ver también Senftleben (2004, p. 6), estableciendo que la teoría utilitarista busca brindar beneficios a la sociedad.

19 Ver Efroni (2001): "[...] utilitarian approaches to copyright aim to encourage the production of creative works in the future"(p. 120); ver también Senftleben (2004): "A marketable right is conferred to ensure a sufficient supply of disseminated knowledge and information" (p. 7). 
El derecho de autor también proporciona un sistema de equilibrio con el objetivo de permitir el uso de materiales protegidos en beneficio de la educación, la cultura y la información ${ }^{20}$. Desde el principio de la protección de derechos de autor a nivel nacional (Dutfield \& Suthersanen, 2008, p. 289) ${ }^{21}$ e internacional, se entendía que era necesario establecer, en favor del interés público, algunos límites al monopolio brindado por los derechos de autor (Ricketson \& Ginsburg, 2006, p. 756) ${ }^{22}$. Por ello, la ley de derechos de autor estableció un sistema de limitaciones y excepciones a la protección otorgada al titular de los derechos a fin de permitir usos que favorezcan la educación sin la autorización o el pago de una tasa, por ejemplo, la excepción de cita, la cual permite reproducir partes del trabajo de otra persona con fines de crítica e información, sin el pago de una licencia (Convenio de Berna de 1971, art. 10(1) $)^{23}$.

Por lo tanto, una ley nacional de derecho de autor debe brindar protección a los creadores, pero al mismo tiempo debe permitir el acceso a las obras protegidas con el fin de favorecer a la educación, entre otros intereses públicos. No obstante, el equilibrio necesario varía para cada país.

\section{Derechos de autor, educación y TIC.}

La protección de derechos de autor se relaciona de varias maneras con la educación. Dicha normativa puede promover la creación y distribución de los recursos educativos (Armstrong, De Beer, Kawooya, Prabhala \& Schonwetter, 2010, p. 3) $)^{24}$, o determinar cómo se pueden utilizar los

20 Ver Masouyé (1978), estableciendo que las limitaciones impuestas para usar las obras protegidas "meet the public's thirst for information" (p. 58); ver también Okediji (2006): "The role of copyright in disseminating information and promoting welfare can only be effectively realized when copyright law reflects a balance between the competing interests of protection and access" (p. 2).

21 "National copyright law has always sought to strike a balance between the rights of the owners and the rights of the users by allowing-within certain limits- unauthorized reproduction or communication of protected works" (p. 289).

22 Estableciendo que desde el comienzo de la protección nacional de derechos de autor y el nacimiento de la Convención de Berna se reconoció la necesidad de establecer ciertos límites a la protección brindada en favor del interés público.

23 Estableciendo la excepción de cita.

24 "[...] It could be argued that copyright itself facilitates the production and distribution of learning materials" (p. 3). 
materiales educativos (p. 3$)^{25}$, y de esta manera, establecer la forma de aprender (Krikorian \& Kapczynski, 2010, p. 24) ${ }^{26}$. Una razón de esto se debe a que el derecho de autor protege la mayor parte de los recursos que se utilizan como materiales educativos (Wahid, 2011, p. 87) ${ }^{27}$, incluyendo libros de ciencia, enciclopedias, mapas, poemas, productos de investigación científica, canciones, composiciones musicales, y así sucesivamente (Convenio de Berna de 19712) ${ }^{28}$. No obstante, los profesores no pueden encargarse de crear todos los materiales educativos necesarios para su actividad docente, por lo que deben acudir a las obras elaboradas por terceros.

Adicionalmente, la mayoría de los usos que se realizan en entornos educativos pertenecen al titular de los derechos, el cual tiene la capacidad de controlarlos. Por ejemplo, la reproducción de un artículo por parte de un profesor para compartir con sus estudiantes representa la explotación del derecho de reproducción que pertenece al titular de los derechos de

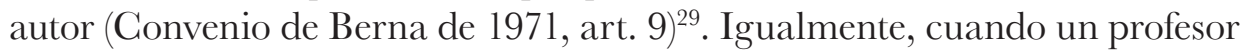
de artes visuales, por ejemplo, pone una película para sus estudiantes al interior del salón de clases representa la explotación del derecho de comunicación pública que pertenece al propietario de derecho de autor (Tratado de la OMPI, 20 de diciembre de 1996, art. 11) ${ }^{30}$. La traducción de una investigación exitosa e importante sobre el VIH por parte de un investigador representa la explotación del derecho de transformación que pertenece al titular del derecho de autor (Convenio de Berna de 1971, art. $8,12)^{31}$. Y por último, el préstamo por parte de una biblioteca de libros a sus visitantes puede representar la explotación del derecho de distribución, que como los anteriores pertenece al derecho de autor (Tratado de la OMPI, 20 de diciembre de 1996, art. 6$)^{32}$.

\footnotetext{
25 " $[\ldots]$ copyright - owners have the right to control how learning materials are produced, disseminated and used" (p. 3).

26 "Copyright also endemically shapes how we learn and think, for example, it affects the price of textbooks and the viability of online archives" (p. 24).

27 "Notably, much of the materials used in educational programmes are protected under copyright law" (pp. 86-87).

28 Estableciendo el material protegido por los derechos de autor y brindando ejemplos (art. 2).

29 Estableciendo el derecho de reproducción.

30 Estableciendo el derecho de comunicación pública.

31 Estableciendo el derecho de traducción y adaptación respectivamente.

32 Estableciendo el derecho de distribución.
} 
De esta manera, los maestros, las bibliotecas y los investigadores tienen que pedir la autorización del titular del derecho de autor o pagar el precio de una licencia para dedicarse a sus actividades docentes y de investigación (Armatas, 2008, p. 235) ${ }^{33}$. No obstante, esto puede resultar muy costoso y demorado ${ }^{34}$. Por consiguiente, es en este momento cuando las leyes nacionales de derechos de autor deben entrar a proporcionar un delicado equilibrio entre la protección y el acceso para permitir la realización de algunos de los usos mencionados sin autorización o pago.

Sin embargo, con la llegada de la tecnología, en particular Internet, el escenario donde el derecho de autor y la educación se cruza ha cambiado, creando una fricción adicional en la relación. La enseñanza a distancia digital, como una herramienta para el estudio auto-espaciado, sin límites geográficos ${ }^{35}$ (que a veces también se utiliza en conexión con la educación tradicional) (Armatas, 2008, p. 2) ${ }^{36}$ donde las actividades educativas se llevan a cabo de manera similar a como acontecen en un escenario tradicional de enseñanza (p. 5) ${ }^{37}$, genera algunas dificultades adicionales entre el derecho de autor y la educación, como se describirá más adelante, que debe ser abordado por las leyes nacionales. De hecho, algunas leyes nacionales han tratado de regular este tema ${ }^{38}$.

33 Describiendo las opciones para un educador que quiere usar el trabajo de un tercero.

34 Ver Gasaway (2001): "Even if licenses are granted, they are often continue to be prohibitively expensive with little recognition or credit given for the fact that the institution has lawfully obtained a copy [...]" (pp. 195-197); ver también Xalabarder (2003): "[Educational insittutions may face] difficulty in locating the copyright owner, inability to obtain a timely response, and unreasonable prices or other terms" (pp. 101-106).

35 Ver Wahid (2011), describiendo la relación entre derechos de autor y TIC en el caso de educación a distancia; ver también Papadopoulou (2010), describiendo las incertidumbres que se generan en la aplicación de la regulación de derechos de autor a la educación en línea; ver Latourette (2006), describiendo las controversias que hay dentro de la regulación de derechos de autor en casos de educación a distancia y educación mixta.

36 "Distance learning is not necessarily separate and distinct from on campus education, however. An individual course may contain both classroom and distance components" (p. 2).

37 "The advent of digital technologies has enabled more teacher-to-student and studentto-student interaction.... As a result of these advances, distance programs may now offer experiences more closely paralleling face-to-face teaching" (p. 5).

38 No todas las leyes nacionales han realizado los cambios necesarios a la regulación autoral para adaptarse a la educación a distancia. Algunos ejemplos de los países 
Las fricciones entre educación, derechos de autor y tecnología en un escenario de educación a distancia digital son diversos. En primer lugar, el uso de materiales protegidos por el derecho de autor por medio de las tecnologías crea una superposición de derechos que no se produce en el mundo analógico (Lemley, 1997) ${ }^{39}$. Por ejemplo, si el mismo profesor que reproduce el artículo para sus alumnos decidió subirlo a un Entorno Virtual de Aprendizaje (EVA) para ser accedido posteriormente por sus alumnos, dicho acto representaría, por lo menos, un acto de reproducción ${ }^{40}$ y un acto de comunicación pública ${ }^{41}$, mientras que en un entorno análogo solo representaría una reproducción. En segundo lugar, el uso de la tecnología en educación genera preocupación en los titulares del derecho, debido a la capacidad de las tecnologías de reproducir, difundir y comunicar sus obras de manera masiva y económica ${ }^{42}$. En tercer lugar, la incursión de las tecnologías en educación ha generado controversias acerca de la aplicación extensiva de las excepciones y limitaciones creadas a favor de la educación para un entorno educativo tradicional a un entorno digital ${ }^{43}$. Por último,

que lo han logrado son: Estados Unidos en el Technology, Education, and Copyright Harmonization Act (2002); La Unión Europea con la Directiva Europea (2001/29), artículo 5, que aplica a la educación a distancia.

39 Explicando la superposición de derechos que ocurre en el ambiente digital.

40 A raíz de la declaración concertada de art. 1.4 del Tratado de la OMPI (20 de diciembre de 1996), una copia creada en el servidor de la universidad y las demás copias RAM realizadas en las computadoras de los estudiantes se consideran reproducciones en virtud del derecho de autor.

41 De acuerdo con el art. 8 del Tratado de la OMPI (20 de diciembre de 1996).

42 Ver Crews (2000): "The ease of committing potential infringement escalates as distance education grows in volume and complexity" (p. 15); ver Jamar (2010): "[w]orks are more easily copied and distributed, and derivative works of all types (audio-visual, audio, graphic, etc.) and quality are easier to make than before" (p. 843); ver también Latourette (2006): "The vehicle of online education permits educators to place all forms of intellectual property on the Internet and coupled with distance education's potentially vast audience, enormously enhances the possibility of significant market harm to the creator/owner of the copyright if the works are widely disseminated" (p. 622).

43 Por ejemplo, la OMPI ha comisionado diversos estudios acerca de la aplicación de las limitaciones y excepciones de leyes nacionales a la educación digital: ver Sirinelli (diciembre de 1999); Ricketson (junio de 2003); Seng (diciembre de 2009); Xalabarder (diciembre de 2009); Monroy, (diciembre de 2009). Ver también Papadopoulou (2010): "[...] it is questionable whether the existing limitations or exceptions do cover all the uses of the copyrighted works during - or for- the e-education activities" (p.1); y finalmente Wahid (2011): "Exceptions to copyright rules which university tutors 
la educación a distancia también plantea preocupaciones acerca de la naturaleza transfronteriza de este tipo de educación y el cumplimiento de las distintas leyes nacionales de derechos de autor (Xalabarder, 2003, p. 107) ${ }^{44}$.

No obstante, a medida que el uso de la tecnología en la educación sigue evolucionando, se van presentando mayores retos para la ley de derechos de autor $^{45}$, especialmente en países como Colombia, que requiere aprovechar de los beneficios de la tecnología en la educación. En un proceso de aprendizaje transformado, como lo mencionábamos en el capítulo primero, que va más allá del uso de Internet en el concepto típico ${ }^{46}$ de la educación a distancia como una forma de educación en la que los estudiantes son separados de sus instructores por tiempo y/o espacio, se empiezan a ver mayores fricciones con la regulación autoral, especialmente porque este nuevo sistema transformado representa la realización de nuevas metodologías y actividades educativas ${ }^{47}$.

En primer lugar, en un proceso de aprendizaje transformado, tanto los estudiantes como los maestros trabajan en colaboración para la creación de nuevos contenidos, y por ende, tanto los estudiantes como los profesores se involucran en actos de reproducción, distribución y comunicación pública de la obra, los cuales, en la educación tradicional y en un programa de educación a distancia digital, solo correspondían a los profesores (Xalabarder, 2003, p. 107$)^{48}$. Igualmente, cuando la tecnología se vuelve parte importante del proceso educativo, los trabajos académicos de los estudiantes salen de la esfera de los actos privados (como lo consideran ciertas normas autorales) y

and lectures enjoy whilst teaching face-to-face in a lecture theatre or seminar room currently do not apply when they are teaching online" (p. 92).

44 "On the internet, where territorial borders have no significance, these differences [over national exceptions and limitations] may either become a serious impediment to the development of $\mathrm{D}$ [igital] $\mathrm{D}$ [istance] $\mathrm{E}$ [ducation], [...] or they may simply be ignored, with DDE functioning beyond compliance with any copyright laws" (p. 107). Ver discusión sobre el tema en los apartes superiores del texto.

46 No obstante, por lo menos una autora establece que no hay un concepto típico de educación a distancia. Ver Xalabarder (2003): "There is no 'typical' digital distance education course" (p. 104).

47 Ver información sobre un sistema educativo transformado en el capítulo 1 de este libro.

48 "[...] a regular teaching activity in our V [irtual] U[niversity] may be dissected into the following three basic acts: (1) upload-a digital copy of the work is uploaded to the VU server (usually by the teacher), so it can be accessed (usually, by students)" (p. 107). 
son comunicados públicamente teniendo impacto sobre la ley de derechos de autor (Monroy, diciembre de 2009, pp. 151-152) ${ }^{49}$

En segundo lugar, en un proceso de aprendizaje transformado, los actos de transformación realizados por los estudiantes y los profesores se vuelven fundamentales para la educación, los cuales no cumplían un rol esencial anteriormente. Aquello se debe a que en el escenario educativo transformado las obras autogeneradas se vuelven importantes para la educación creando fricciones, especialmente con el derecho exclusivo de transformación ${ }^{50}$. En tercer lugar, en un proceso de aprendizaje transformado se intenta promover actividades de aprendizaje permanente, donde los individuos, fuera del mundo académico, comienzan a tener una participación importante en la enseñanza e incursionan en usos educativos de materiales protegidos, los cuales, anteriormente, solo eran realizados por profesores en procesos educativos tradicionales (Xalabarder, 2003, p. 111) ${ }^{51}$; e igualmente, el público, para estas actividades educativas, deja de estar confinado a los estudiantes de un curso, como podría estarlo en un estudio de educación a distancia virtual (Armatas, 2008, p. 216) ${ }^{52}$ generando preocupación a los titulares de los derechos.

En conclusión, la ley nacional de derecho de autor debe reflejar un delicado equilibrio entre la protección de la creación y permitir el acceso para su uso educativo. Dicho equilibrio debe evolucionar y adaptarse para

$49 \quad$ Estableciendo que los actos académicos de los estudiantes pueden ser vistos como actos privados por la ley autoral colombiana, y por lo tanto no afectan el derecho de autor.

50 Ver Jamar (2010), describiendo la importancia de permitir los trabajos generados por los usuarios sin motivos comerciales y los problemas que estas obras puedan tener con respecto a la ley de derechos de autor. Aunque el autor no se refiere a la utilización del trabajo generado por los usuarios en entornos educativos, el artículo explica las dificultades de este tipo de obras con respeto a la ley de derechos de autor (p. 843); ver Glickman y Fingerhut (2012), estableciendo los problemas generados por los contenidos creados por los usuarios (p. 51); ver "Fair Use Principles for User" (s.f.), estableciendo unos principios donde el contenido producido por los usuarios puede estar bajo el fair use.

51 Estableciendo que en ciertos países las excepciones en favor de la enseñanza pueden beneficiar solo a ciertas instituciones y a ciertos individuos.

52 Hablando sobre la educación a distancia: " $[\mathrm{t}]$ hese venues of teaching often constitute instruction on a closed system limited to students who are pursuing educational opportunities as part of a systematic teaching activity or curriculum and are officially enrolled in the course" (p. 216). 
responder a las nuevas realidades de la educación en el entorno digital (Okediji, 2006, p. 25) ${ }^{53}$ y las políticas educativas nacionales de países como Colombia que tratan de beneficiarse del uso de la tecnología en la educación (p. 2$)^{54}$.

\section{La multeralización del derecho de autor}

Aunque las leyes de derechos de autor deben tener en cuenta las realidades nacionales, dichas normativas no son impulsadas o determinadas únicamente por estas. Con el tiempo, el ámbito nacional de decisión sobre la política en la materia ha cedido cada vez más a las normas internacionales ${ }^{55}$, las cuales han pasado a determinar diversos aspectos de la regulación autoral buscando el establecimiento de un modelo único (Gana, 1995) ${ }^{56}$. No obstante, el modelo internacional de protección de derechos de autor no representa las necesidades de cada país, haciendo especialmente difícil para los países en desarrollo ${ }^{57}$ hacer frente a las necesidades nacionales en materia de educación. La ampliación de las normas internacionales de protección de derechos de autor responde a una realidad del sistema de derechos de autor internacional guiado un conflicto norte-sur, como se discutirá más adelante.

\section{E1 Convenio de Berna.}

La protección de derechos de autor comenzó como una cuestión de derecho nacional y posteriormente se trasladó hacia la internacionalización.

53 "But it is not just preserving existing limitations and exceptions that is necessary, but also devising limitations and exceptions that are consistent with greater expectations of access and diffusion given new technological developments" (p. 25).

54 "Specifically, with regard to education and basic scientific knowledge, limitations and exceptions are an important component in creating an environment in which domestic economic initiatives and development policies can take root" (p. 2).

55 Para información acerca de qué lugar le queda a la ley nacional de derechos de autor ver Ginsburg (2000).

56 "What the internationalization of intellectual property implies, ultimately, is that there is only one way to participate in the international economy and that by playing in accordance with prescribed rules, regardless of its impact on a group of peoples" (p. 142).

57 Ver por ejemplo el comentario de Xu Yi-chong (2008): "The first international trade agreement on IPRs protection, the Agreement on Trade-Related Intellectual Property Rights (TRIPS Agreement) is skewed in favor of the interests of intellectual property right-holders and the countries where they reside at the expense of right-users and developing countries" (p. 46). 
A principios de la regulación autoral, cada país tenía la libertad de establecer normas de protección de los derechos de autor que concordaran con sus necesidades domésticas (Ringer, 1968, p. 1051) ${ }^{58}$. Durante el siglo XIX, la legislación de derechos de autor de los países europeos, que hasta ahora estaba emergiendo, se centró principalmente en regular la situación de los autores nacionales y la industria editorial nacional (Goldstein \& Hugenholtz, 2010, p. $31)^{59}$. Debido a esto, los autores extranjeros fueron generalmente excluidos de la protección o sujetos a formalidades más estrictas para adquirir protección (p. 31) ${ }^{60}$. No obstante, esta falta de protección hizo a los autores extranjeros y a la editorial local susceptibles a la piratería, especialmente en los países que compartían idiomas o fronteras (Ricketson \& Ginsburg, 2006, p. 19) ${ }^{61}$. Por ejemplo, los editores belgas pirateaban las obras de autores franceses, y los editores estadounidenses pirateaban a los autores ingleses (p. 20 ${ }^{62}$. En los países donde no se comparten idiomas, obras extranjeras eran generalmente traducidas (p.19) ${ }^{63}$.

La piratería de obras extranjeras afectaba a autores y editores extranjeros que no obtenían ingresos por su trabajo publicado en otros países, así como a los autores y editores del país donde se importaban las obras extranjeras, ya que simplemente no podían competir con las versiones extranjeras más baratas (Goldstein \& Hugenholtz, 2010, p. 31). Además, las copias piratas por lo general se exportan al país de origen a menores precios (Ricketson \& Ginsburg, 2006, p. 20) ${ }^{64}$. Y fue este problema de la piratería internacional el que esencialmente inició la internacionalización de la ley de derechos de autor (p. 20) $)^{65}$.

58 "At first international copyright protection was the exception rather than the rule" (p. 1051).

59 Estableciendo que durante el siglo XIX las normas de derechos de autor se centraban en los autores nacionales y la industria editorial local.

60 Describiendo la situación de los autores extranjeros.

61 Estableciendo que la piratería apareció entre esos países con gran creación artística y aquellos que compartían fronteras con estos.

62 Estableciendo que uno de los casos de mayor piratería fue el de los belgas a los trabajos franceses.

63 Estableciendo que las creaciones artísticas no tenían barreras y eran apreciadas así fuera necesaria la traducción.

64 Estableciendo que las copias más baratas usualmente eran exportadas al país de origen.

65 Estableciendo que la prevención de la piratería fue el mayor motivante para la internacionalización del derecho de autor. 
Bajo este escenario, los países europeos comenzaron a celebrar una serie de acuerdos bilaterales que tenían como objetivo asegurar la protección de los derechos de autor de autores nacionales en el extranjero sobre la base de principios de reciprocidad formal o material (Goldstein \& Hugenholtz, 2010 , pp. 31-32 ${ }^{66}$. Varios estados europeos se involucraron en la negociación bilateral (Ricketson \& Ginsburg, 2006, p. 29) ${ }^{67}$, no obstante, Estados Unidos, uno de los mayores piratas de los trabajos ingleses, se negó a entrar en acuerdos bilaterales durante el siglo XIX argumentando que necesitaba acceso al conocimiento (p. 21) ${ }^{68}$.

Los acuerdos bilaterales celebrados entre los diferentes países variaban con respecto a las personas protegidas, las obras protegidas y el alcance de los derechos concedidos (Ricketson \& Ginsburg, 2006, pp. 32-37) ${ }^{69}$, lo que hacía difícil determinar el nivel de protección de los autores en el extranjero $(\text { p. 38 })^{70}$. Esta dificultad se veía agravada por la duración incierta de los acuerdos y su inclusión de una cláusula de la nación más favorecida (p. 38 $)^{71}$. A nivel doméstico, los acuerdos bilaterales no redujeron la capacidad del país contratante de determinar su propio nivel de protección de los derechos de autor, ya que, la mayoría de las veces, los acuerdos otorgaban a los autores extranjeros el mismo nivel de protección que dicho país ofrecía a sus autores nacionales (p. 34) ${ }^{72}$. No obstante, estas circunstancias generaron una falta de uniformidad en la protección internacional.

Dado el contexto mencionado anteriormente, durante el siglo XIX, se desarrolló un movimiento para la adopción de una ley universal de los derechos de autor, la cual no estuviera sujeta al problema de la diversidad y la incertidumbre. Como resultado, en 1886, el Convenio de Berna para la Protección de las Obras Literarias y Artísticas ${ }^{73}$ fue firmado. El Convenio

\footnotetext{
Estableciendo que los acuerdos se basaban en el principio de reciprocidad.

Estableciendo que varios acuerdos eran celebrados entre países europeos.

Estableciendo que Estados Unidos se mantuvo por fuera de los acuerdos argumentando su necesidad de conocimiento.

69 Estableciendo las diferencias entre los acuerdos bilaterales.

70 Estableciendo las diferencias entre los acuerdos bilaterales: "[M]ade the task of ascerting an author's entitlement to protection in a country other than his own a difficult and laborious one" (p. 38)

71 Describiendo las dificultades causadas por los acuerdos.

72 Estableciendo que los acuerdos mandaban el principio de trato nacional.

73 Ver Convenio de Berna de 1971.
} 
de Berna creó la Unión de Berna ${ }^{74}$, significando que el acuerdo no podía ser afectado por la salida o incorporación de nuevos Estados contratantes (Ricketson \& Ginsburg, 2006, p. 221) 75 $^{7}$, como había ocurrido en los acuerdos bilaterales. De igual manera, significaba que la membresía estaba abierta para cualquier estado que quisiera unirse (p. 221). Por otra parte, a diferencia de los acuerdos bilaterales anteriores el Convenio de Berna promovió una ley universal de derechos de autor mediante el establecimiento de unas normas mínimas específicas que cada miembro de la Unión estaba obligado

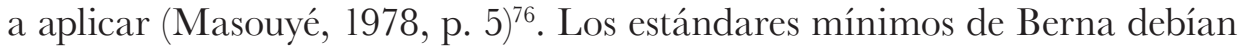
ser concedidos a (1) los nacionales de un país miembro; (2) cualquier trabajo publicado por primera vez en un país miembro; o (3) a un trabajo publicado de forma simultánea en un país fuera de la Unión y en un país parte de la Unión. En este sentido, se resolvió el problema de falta de uniformidad ${ }^{77}$. No obstante, esto también hizo que el derecho de autor se marchara de la esfera puramente nacional y se convirtiera en parte de los acuerdos multilaterales. En este momento, el derecho internacional de derechos de autor comenzó a limitar la capacidad de los países miembros para decidir su propio nivel de protección.

El Convenio de Berna de 1886 se basó en el principio de trato nacional, al igual que los acuerdos bilaterales anteriores (Goldstein \& Hugenholtz, 2010, pp. 31-34) $)^{78}$, y requirió a los países miembros otorgar los derechos de comunicación pública y de traducción (pp. 31-35) ${ }^{79}$, estableciendo para este último un plazo mínimo de protección de diez años ${ }^{80}$. El texto inicial de Berna fue solo el comienzo de todo el movimiento hacia el multilateralismo y la internacionalización de los derechos de autor.

\footnotetext{
74 Como artículo 1 de los Estados del Convenio de Berna.

75 Describiendo el significado de la palabra "Unión".

76 Estableciendo que los derechos mandados por la convención son de obligatorio cumplimiento.

77 Ver Convenio de Berna de 1971, art. 3(1) (b); ver también Goldstein y Hugenholtz (2010), describiendo quién podría beneficiarse de la protección de la convención (pp. $31,35,36)$.

78 Estableciendo que la convención no se apartó de los principios usados en los anteriores acuerdos internacionales.

79 Describiendo el contenido de la convención de 1886.

80 Describiendo la duración del derecho de traducción.
} 
El artículo 17 incluido en el Convenio de Berna mandaba a realizar revisiones periódicas de la convención con el fin de mejorar el sistema internacional de derechos de autor (Masouyé, 1978, p. 5) ${ }^{81}$. En la práctica, las revisiones se llevaron a cabo en períodos de veinte años. Durante cada una de las revisiones de Berna, la regulación internacional de protección de derechos de autor comenzó a expandirse. Por ejemplo, la revisión de París de 1896 agregó a las obras protegidas la fotografía ${ }^{82}$ y la arquitectura ${ }^{83}$. La revisión de Berlín de 1908 eliminó el requisito de las formalidades para obtener la protección del derecho de autor, brindó protección a las obras cinematográficas como obras derivadas, y estableció un plazo de protección de mínimo 50 años después de la muerte del autor (Goldstein, \& Hugenholtz, 2010, p. 36). ${ }^{84}$ La revisión de Roma de 1928 incluyó los derechos morales de integridad y paternidad y el derecho sobre la emisión de obras protegidas (pp. 31-36) ${ }^{85}$. Por último, la revisión de Bruselas de 1948 se encargó de clarificar la protección concedida en las revisiones anteriores (Ricketson \& Ginsburg, 2006, p. 119) ${ }^{86}$. Por ejemplo, la versión de Bruselas de 1948 protegió el derecho a autorizar adaptaciones de la obra en lugar de realizar una lista de reproducciones indirectas consideradas ilícitas (p. 118) ${ }^{87}$.

Este multilateralismo de la ley de derechos de autor tuvo un impacto en las políticas nacionales de los países. Desde el punto de vista de la política nacional de derechos de autor, cada vez que el estándar de Berna se incrementaba, la autonomía de los países para decidir la política de derechos de autor por las leyes nacionales disminuía. Por ejemplo, después de las revisiones de Bruselas de 1948, los países miembros ya no podían decidir si conceder o no a los autores el derecho de traducción. Esta pérdida de autonomía nacional marcó la primera controversia dentro del sistema internacional de derecho

81 Estableciendo que la convención ha sido revisada numerosas veces en orden a mejorar el sistema internacional de propiedad intelectual.

82 Ver Goldstein y Hugenholtz (2010), estableciendo que la protección a obra fotográfica fue establecido en 1896 (pp. 31-36).

83 Ver Ricketson y Ginsburg (2006), estableciendo que los trabajos arquitectónicos fueron añadidos (p. 89).

84 Estableciendo los cambios incluidos en la revisión de 1908.

85 Estableciendo los cambios hechos a la revisión de Roma.

86 "While it is true that the Brussels Conference made many changes to the Rome text, these did not embody fundamental extensions to author's rights. The reality is that the Conference was very much a 'holding operation"' (p. 119).

87 Estableciendo que la revisión de Bruselas clarificó el derecho de adaptación. 
de autor como se describirá adelante. Por lo tanto, Berna marcó el fin de la ley de derechos de autor como una cuestión de política nacional y comenzó la internacionalización de la ley de derechos de autor.

\section{El Convenio de Berna: el rol del conflicto norte-sur.}

La internacionalización de los derechos de autor y sus posteriores desarrollos se han alineado con un marcado conflicto norte-sur que ha persistido hasta la actualidad, y es dicho conflicto, el que ha influido en el establecimiento de las normas internacionales de protección de derechos de autor y la selección del foro para este tipo de normas.

Para la década de 1960, el sistema internacional de derechos de autor se regía principalmente por el Convenio de Berna. En un principio, el Convenio de Berna se desarrolló en su mayoría por los países europeos y sus colonias: Bélgica, Francia, Alemania, Italia, España, Suiza y el Reino Unido, así como Túnez y Haití (Ricketson \& Ginsburg, 2006, p. 82) ${ }^{88}$. No obstante, para la década de los 60, los miembros de Berna cambiaron, y muchos se convirtieron en nuevos territorios, lo que hoy serían considerados países en desarrollo (p. 121)

El cambio en la composición de Berna se debió al movimiento de descolonización que surgió después de la Segunda Guerra Mundial (Goldstein \& Hugenholtz, 2010, p. 22) ${ }^{90}$, donde varias excolonias, particularmente territorios asiáticos y africanos que habían sido adheridos a la convención por su colonizador, se convirtieron en las nuevas naciones independientes (Ricketson \& Ginsburg, 2006, p. 885) ${ }^{91}$. La gran mayoría de estas naciones, en particular los antiguos territorios africanos de Francia y Bélgica, decidieron seguir vinculados a Berna - a veces debido a la presión de las antiguas potencias colonizadoras- (Tocups, 1982, p. 407)92. Otros, como Indonesia,

88 Estableciendo los primeros signatarios de Berna.

89 Estableciendo que con el tiempo una tercera parte de los miembros de Berna eran países en vía de desarrollo.

90 Estableciendo que el movimiento independista comenzó en 1950.

91 Estableciendo que el proceso de descolonización trajo un gran número de naciones independientes.

92 Estableciendo que los antiguos colonizadores presionaron a sus antiguas colonias para mantener vinculados a la convención. 
se retiraron de la convención ${ }^{93}$. En consecuencia, en 1967, aproximadamente la mitad de los Estados miembros de Berna eran países en desarrollo (Von Lewinski, 2008, p. 73; Ricketson \& Ginsburg, 2006, p. 885) ${ }^{94}$. No obstante, estos países en desarrollo no habían tenido un papel activo en la elaboración de las disposiciones sustanciales de Berna por no haber sido territorios independientes, sobre todo en el caso de África y Asia (Tocups, 1982, p. 407) ${ }^{95}$. Por lo tanto, la Unión representaba el interés de los países desarrollados, pero también obligaba a aquellos países en desarrollo. Así, en 1960 los países en desarrollo sintieron que las disposiciones de Berna no tenían en cuenta sus necesidades especiales (Ricketson \& Ginsburg, 2006, p. 885) ${ }^{96}$.

La razón de la insatisfacción de los países en desarrollo con las disposiciones de Berna era que ellos tenían necesidades especiales de conocimiento y, como miembros de la convención internacional de derechos de autor, no podían diseñar sus leyes nacionales de derechos de autor de forma que fueran oportunas para satisfacer dichas necesidades.

Los países en desarrollo no contaban con una amplia producción nacional de obras protegidas por el derecho de autor, en cambio, se trataba de países importadores de tales obras (Johnson, 1971, p. 91) ${ }^{97}$. No obstante, el alto precio de estas obras disponibles en países desarrollados impedía su utilización para educar en los nuevos territorios (Olian, 1974, p. 90).98 Igualmente, tampoco podían importar en condiciones favorables o hacer reproducciones locales (p. 89, pie de página 38) ${ }^{99}$ de las obras debido a las

93 Ver Von Lewinski (2008, p. 73); ver también Ricketson y Ginsburg (2006), estableciendo que Indonesia se retiró de la convención (p. 885).

94 Estableciendo que para el tiempo de la revisión de Estocolmo, 24 de 57 miembros eran países en vías de desarrollo bajo los términos de las resoluciones de la ONU.

95 Estableciendo que los países en vías de desarrollo tuvieron poca participación en Berna debido a que como colonias no eran responsables de sus políticas públicas.

96 Estableciendo que los países en vías de desarrollo no estaban contentos con los estándares de Berna.

97 Estableciendo que los países en desarrollo no eran productores de obras protegidas por el derecho de autor pero eran consumidores de estas obras.

98 "Prices for books produced in the advanced nations generally reflect the higher costs of labor, materials, and distribution which prevail in such countries, and are exorbitant from the point of view of the inhabitants of developing countries" (p. 90). 
normas de derecho de autor (Johnson, 1970, p. 93) ${ }^{100}$. Berna había requerido a los países en desarrollo conceder protección a los autores extranjeros, independientemente del hecho de que los países carecían de los recursos financieros para pagar altos cánones por derechos de autor (Tocups, 1982, p. 408 $)^{101}$. Bajo este escenario, los países en desarrollo se dieron cuenta de que se habían adherido a Berna antes de tener la oportunidad de establecer su propio equilibrio de derechos de autor de acuerdo con sus intereses y necesidades (p. 408) ${ }^{102}$.

Sin embargo, no todos los países de reciente independencia eran miembros de la Unión de Berna. Con la excepción de Brasil ${ }^{103}$, la mayoría de los estados americanos no habían ratificado el Convenio de Berna en la década de 1960. Al igual que los países asiáticos y africanos recién independizados, los Estados americanos creían que Berna no encajaba para ellos debido a su estado actual de desarrollo (Ricketson \& Ginsburg, 2006, p. 1171) ${ }^{104}$. No obstante, debido a la influencia de Berna, los estados de América del Sur decidieron crear su propia Convención -la Convención de Montevideo--, así como otras convenciones adicionales de derechos de autor (p. 1171) ${ }^{105}$.

Los miembros de Berna buscaban lograr una unificación mundial de los derechos de autor y, por tanto, querían llegar a un acuerdo con los Estados americanos (Ricketson \& Ginsburg, 2006, pp. 110-112) ${ }^{106}$. Como resultado de los intentos de fusionar el Convenio de Berna y los Convenios de Buenos Aires / La Habana, la Convención Universal patrocinada por la

100 Estableciendo que países en desarrollo no podían importar en materiales en términos razonables.

101 Estableciendo que países en desarrollo no tenían las fuentes económicas para pagar altos precios por licencias de derechos de autor.

102 Estableciendo que los países en desarrollo se volvieron miembros de Berna sin tener la posibilidad de haber establecido su sistema de protección doméstica de derechos de autor.

103 Accedió la convención el 6 de febrero de 1922, para entonces Haití ya había denunciado la convención. Ver WIPO-Administered Treaties (s.f.).

104 Estableciendo que los países suramericanos no encontraron que Berna se ajustara a sus necesidades.

105 Estableciendo que los países suramericanos crearon sus propias convenciones.

106 Afirmando que una de las resoluciones al final de la revisión de Roma de 1928 fue buscar una reconciliación con los miembros de los convenios de Buenos Aires / La Habana. La falta de acuerdo entre Berna y los Estados americanos fue una de las razones que retrasaron la revisión de Bruselas. 
UNESCO $(\mathrm{UCC})^{107}$ fue ratificada en 1952. La UCG dirigida animosamente por Estados Unidos (WIPO, 2003, p. 7) ${ }^{108}$, ofreció niveles más bajos de protección de derechos de autor (Dutfield \& Suthersanen, 2008, p. 286; Ringer, 1968, p. 1064) ${ }^{109}$ en comparación con los de Berna con el fin de dar cabida a los países que no podían permitirse la concesión de las normas del Convenio de Berna. No obstante, la UCG posteriormente se convertiría en un fuerte opositor de Berna. Así, en 1967, dos convenciones principales de derechos de autor estaban en el panorama internacional: Berna y UCG. Sin embargo, aunque no todos los países ratificaron Berna, la mayoría de ellos lo habían hecho: tenemos que de 121 países en desarrollo, cincuenta y seis se habían adherido alguna de las dos convenciones o a ambas; veintidós países pertenecían a Berna, diecinueve a la UCG, y quince a ambos (Ringer, 1968, pp. 1064-1065) ${ }^{110}$. Es importante tener en cuenta que Estados Unidos no ratificó Berna pero sí ratificó la UCG en $1955^{111}$.

Los niveles de protección de la UCG diferían de aquellos del Convenio de Berna, dándole a los países miembros más margen de maniobra para elaborar leyes nacionales de manera que correspondieran a sus necesidades. Por ejemplo, la regla general de duración de la protección bajo la UCC era de la vida del autor más veinticinco años (UCC, 1952, art. IV), mientras que Berna requería una duración de la vida del autor más cincuenta años ${ }^{112}$. Por otra parte, las normas mínimas de la UCG no eran tan explícitas como en Berna. La UCG establecía que "cada Estado contratante se compromete a proporcionar la adecuada y efectiva protección de los derechos de los autores y otros titulares de derechos de autor en las obras literarias, científicas y artísticas" (UCG, 1952, art. I), mientras que Berna establecía diversos estándares mínimos de derechos como los derechos morales de paternidad y la integridad (Convención de Berna de 1948, art. 6bis), el derecho de adaptación (art. 12), el derecho de traducción (art. 8), el derecho de comunicación pública (art. 11bis), entre otros, dependiendo de la clase de obras. La UCG también concedió el derecho de traducción, pero sometido

\footnotetext{
107 Ver Universal Copyright Convention (1952), en adelante UCG.

108 Estableciendo que EE. UU. tuvo la iniciativa sobre la UCG.

109 "The UCC was popular with developing countries as it had fewer mandatory requirements and lower tresholds of protection" (p. 286).

110 Estableciendo el número de países en desarrollo miembros de Berna o de UCC.

111 Ver la lista de miembros y fecha de ratificación de la UGG en Universal Copyright Convention (s.f.).

112 Ver Convención de Berna de 1948 (art. 7).
} 
a un sistema de licencias obligatorias no exclusivas en caso de que una obra no fuera traducida después de siete años (UCG, 1952, art. V). Por otra parte, la UCG no eliminó por completo los procedimientos para obtener la protección del derecho de autor (art. III), como lo hizo Berna. No obstante, aunque la UCG requería un nivel más bajo de protección que la convención de Berna de 1948 (art. 4), dicha convención aún limitada la autonomía de los países para legislar cuestiones de derechos de autor. Como resultado, algunos países en desarrollo también manifestaron su malestar con la UCG (Ringer, 1968, pp. 1064-1065).

Así, a finales de los años 60, los países en desarrollo se vieron amarrados por un sistema internacional de derechos de autor que no fue diseñado por ellos o para ellos y que no correspondía con sus necesidades. Al darse cuenta de esto, los países en desarrollo comenzaron a buscar y promover el establecimiento de normas que les permitieran tener acceso a los materiales protegidos a un precio razonable con el objetivo de satisfacer sus necesidades educativas. No obstante, los países en desarrollo también querían obtener algún tipo de protección de derechos de autor para sus autores, por lo tanto, abandonar el sistema internacional de protección de derechos de autor no parecía una opción para ellos. Por ejemplo, los países africanos estaban preocupados por la protección de su propio folclore (Johnson, 1970, p. 108) ${ }^{113}$.

La UCG, a solicitud de Estados Unidos, fue la primera en considerar las peticiones de los países en desarrollo de conseguir normas que correspondieran a sus necesidades. La propuesta presentada bajo la UCG consistía en proporcionar apoyo en la redacción de las leyes de derechos de autor a los países recién independizados, especialmente los países africanos que no eran miembros de la UCG o Berna. Dicha propuesta fue aprobada durante la Conferencia General de 1960 de la UNESGO (Ricketson \& Ginsburg, 2006, p. 887; Johnson, 1970, pp. 94-103) ${ }^{114}$, donde la India fue un defensor activo de los países en desarrollo en materia de derechos de autor y expresó su preocupación por las normas actuales frente al tema (Ricketson \& Ginsburg, 2006, p. 887; Johnson, 1970, pp. 94-103). Más tarde, en agosto

113 Estableciendo que una de las recomendaciones del comité de expertos fue incluir disposiciones que "safeguarding the interests of the African countries in respect to their own folklore, on the one hand, and permitting, on the other, the free use of protected works for educational and school purposes" (p. 108).

114 Estableciendo la primera propuesta en favor de los países en vías de desarrollo. 
de 1963, se celebraron las conferencias de Brazzaville y de Nueva Delhi, las cuales fueron las primeras reuniones en las que las necesidades especiales de los países en desarrollo se abordaron en el contexto de Berna ${ }^{115}$.

La reunión de Brazzaville fue organizada por las Oficinas Internacionales Reunidas para la Protección de la Propiedad Intelectual (BIRPI) y la UNESCO, y tenía el objetivo de ayudar a las recién independientes naciones africanas a redactar su legislación de derechos de autor. Esta reunión desempeñó un papel importante en el sistema internacional de derechos de autor, ya que, por primera vez, se exhortó a Berna y a la UCG a trabajar a favor de avanzar en las necesidades de los países en desarrollo (Johnson, 1970, p.108). De esta manera, el Comité Brazzaville recomendó que se discutiera el tema en la Comisión de Expertos para la revisión del Convenio de Berna de 1967 (p. 109) ${ }^{116}$ que estaba a punto de reunirse, y se considerara la inclusión de disposiciones especiales dirigidas a permitir a los países africanos el uso libre de obras protegidas para la educación ${ }^{117}$.

En Nueva Delhi, en diciembre de 1963, el Comité Permanente de Berna y el Comité de Derechos de Autor Intergubernamental del UCC celebraron una reunión conjunta. Y por primera vez los dos comités consideraron la cuestión de los países en desarrollo. En la reunión, la India sugirió realizar un estudio sobre la posibilidad de incorporar dentro de la convención licencias obligatorias para material publicado e incorporar en Berna disposiciones similares a las contenidas en la UGC referente a traducciones (Johnson, 1970, pp. 116-118; Ricketson \& Ginsburg, 2006, p. 897).

Ambas conferencias cultivaron el camino para abordar las discusiones con respecto a las preocupaciones de los países en desarrollo en la revisión de Estocolmo de 1967. En esta revisión, los miembros de Berna abordaron de nuevo las necesidades especiales de los países en desarrollo y efectivamente concedieron medidas específicas a su favor, incluidas en un protocolo separado relacionado al documento principal. Las concesiones incorporadas permitían el uso de material con derechos de autor para fines educativos,

115 Para información general sobre las conferencias de Brazzaville y New Delhi ver Kaminstein (1964).

116 Estableciendo que el comité africano pidió que se consideraran las necesidades de los países en vías de desarrollo en la próxima revisión de Berna.

117 Ver Tocups (1982), describiendo la conferencia de New Delhi (pp. 441-412); ver también Johnson (1970, pp. 107-108). 
plazos más cortos de la protección y mandaba licencias obligatorias para reproducciones y traducciones, que eran las mayores preocupaciones de los países en desarrollo ${ }^{118}$. Sin embargo, el Protocolo de Estocolmo fue muy controvertido y nunca fue ratificado (Ricketson \& Ginsburg, 2006, p. 911). Esta situación fue posible gracias al artículo 28 (1) (b) (1) del documento principal de la Revisión de Estocolmo, el cual permitía a los Estados miembros ratificar o adherirse a la revisión de Estocolmo en partes. Así, los países tuvieron la oportunidad de ratificar los artículos del uno al veinte, que incorporaban disposiciones sustantivas, y el Protocolo, o las disposiciones administrativas, o ratificar ambos (p. 911).

La no ratificación del Protocolo de Estocolmo casi marcó el fin de la Unión de Berna (Burger, 1988, p. 39) ${ }^{119}$. Los países en desarrollo estaban enojados por la falta de ratificación del Protocolo y amenazaron con dejar Berna y unirse a la UCG (p. 39, pie de página 272) ${ }^{120}$. Esta solución no era útil tanto para países en desarrollo como desarrollados ya que la Cláusula de Seguridad de la UCG $(1951)^{121}$ retiraba cualquier tipo de protección de derechos de autor a los países que abandonaran el Convenio de Berna, haciendo difícil unirse a la UCG. Los países en desarrollo no podían permitirse la falta absoluta de protección de derechos de autor, ya que buscaban el reconocimiento de la protección de derechos de autor para el folclore y las tradiciones culturales (Tocups, 1982, p. 408) ${ }^{122}$. Por otro lado, a los países desarrollados les preocupaba que la Unión de Berna perdiera su universalidad $^{123}$. El conflicto norte-sur había comenzado.

118 Para mayor información sobre el Protocolo de Estocolmo ver Schrader (1970); Ricketson y Ginsburg (2006, pp. 899-912).

119 Estableciendo que el conflicto sobre la no ratificación del Protocolo casi marca el final de Berna.

120 Estableciendo que los países en desarrollo estaban amenazando con dejar Berna y unirse a la UCG.

121 Ver declaración apéndice, artículo XVII.

122 Estableciendo que los países en vías de desarrollo no podían arriesgarse a perder todo tipo de protección de derechos de autor porque ellos querían buscar la protección de su folclor y tradiciones culturales.

123 Ver Ndiaye (1986), estableciendo que si los países se iban, la convención perdería su universalidad (pp. 47-48); ver también Hadl (1970), estableciendo que la denuncia de las dos convenciones por países en vías de desarrollo no era atractivo para los países desarrollados (p. 196). 
De esta forma, los países desarrollados se dieron cuenta de que se debían hacer algunas concesiones especiales en favor de los países en desarrollo para preservar Berna. En 1969, el grupo de estudio conjunto preparó el marco para unas revisiones simultáneas de ambos convenios en favor de los países en desarrollo, establecimiento los términos y condiciones de dichas revisiones ${ }^{124}$. Estas recomendaciones condujeron a la revisión de París en 197125.

La revisión de París aprobó el anexo al Convenio de Berna ${ }^{126}$ y añadió algunas cláusulas a la UCG. Dicho anexo, incorporó cierta flexibilidad en favor de los países en desarrollo, consistiendo en un sistema de licencias obligatorias para traducciones y reproducciones (Ricketson \& Ginsburg, 2006, pp. 924-960) ${ }^{127}$. La revisión simultánea de ambos convenios hizo que la UCG no siguiera siendo más atractiva para los países en desarrollo que Berna, dado que ambas convenciones otorgaban las mismas ventajas a los países en desarrollo. Por lo tanto, aunque se retiró la "cláusula de salvaguardia de Berna", los países en desarrollo no tenían ninguna razón para dejarla (p. 956) ${ }^{128}$, quedándose en Berna por su prestigio.

Por lo tanto, aunque la revisión de París de 1971 no brindó las concesiones que los países en desarrollo esperaban (Ricketson \& Ginsburg, 2006, p. 956) ${ }^{129}$, estas fueron las suficientes para preservar la Unión de Berna. Las concesiones de la revisión de París no eran tan amplias como las que se habían incorporado en el Protocolo de Estocolmo y eran difíciles de ejecutar en la práctica debido a normas de procedimiento complicadas y las muchas condiciones establecidas (Burger, 1988, p. 40) ${ }^{130}$. Como resultado, los países en desarrollo quedaron sujetos aún a un sistema internacional de derechos

124 Para más información sobre las revisiones de Washington ver Ulmer (1971).

125 Para antecedentes históricos que llevaron a la revisión de París ver Hadl (1970).

126 Como anexo, se volvió automáticamente parte integral del acto de París.

127 Para mayor información sobre la revisión de París en Berna ver Ricketson y Ginsburg (2006, pp. 924-960).

128 "The advantages to developing countries under both conventions were now essentially the same, and there was not reason for them to move from one convention to another" (p. 956).

129 Hablando sobre la revisión de París "from [the point of view] of the developing countries, it represented a reluctant admission that this was the most they were likely to be able to obtain" (p. 956).

130 Hablando sobre la revisión de París " $[\mathrm{t}]$ he formula adopted is complicated and difficult to administer, but it is important in that it provided the compromise solution which ultimately preserved the Convention's membership [...]” (p. 40). 
de autor que no era útil para ellos, a pesar de que habían ganado posición dentro de la OMPI. La revisión de 1971 fue la última revisión del Convenio de Berna, luego de esta, la OMPI dudó en convocar a una nueva revisión (Von Lewinski, 2008, p. 76). La versión de Berna de 1971 fue ratificada por Estados Unidos en 1989 (WIPO-Administered Treaties, s.f.) ${ }^{131}$. La adopción de Berna por parte de EE. UU. es importante para el desarrollo de la nueva política del país en materia de derechos de autor de presionar por un aumento sobre los niveles de protección, como se describirá más adelante (Yu, 2004 p. 12) ${ }^{132}$.

Los artículos 1-21 y el apéndice de la actual versión del Convenio de Berna (1971), contienen disposiciones sustantivas de derechos de autor. Los artículos administrativos aparecen en los artículos 21-38 (Ricketson \& Ginsburg, 2006, p. 182 $)^{133}$. Las disposiciones del Convenio de Berna son difíciles de resumir debido al hecho que esta extiende algunos derechos en función de ciertos tipos de obras; por ejemplo, en Berna, el derecho de distribución aplica solo a las obras cinematográficas (Convenio de Berna de 1971, art. 14). En términos generales, Berna se basa en el principio de trato nacional (art.5) y abarca las obras literarias y artísticas "cualquiera que sea el modo o forma de expresión" (art. 2), concediendo protección a autores nacionales o domiciliados en un país miembro o cuando el trabajo ha sido publicado por primera vez o simultáneamente en un país miembro (art. 3). Berna reconoce los derechos morales y patrimoniales durante 50 años después de la muerte del autor (art. 7). En cuanto a los derechos morales, reconoce los derechos de paternidad e integridad (art. 6 bis). Dentro de los derechos patrimoniales, reconoce un derecho de traducción (art. 8), derecho de reproducción (art. 9), derecho de comunicación pública (art. 11 bis) y un derecho de la adaptación (art. 12).

Dentro de Berna, hay una posibilidad limitada de establecer algunas restricciones a los derechos exclusivos de los autores en forma de excepciones y limitaciones, licencias obligatorias, o materia excluida. Aparte de la excepción de cita (art. 10), el establecimiento de excepciones y limitaciones

131 Estableciendo la fecha de adhesión de EE. UU. a la convención de Berna.

132 "This adherence to the Berne Convention is particularly important to the United States' role in sahping the current international intellectual property regime $[\ldots]$ ".

133 Estableciendo la estructura de Berna. 
no es obligatorio; se dice que es limitada debido a que los países miembros deben ejercer dicha posibilidad de establecer excepciones y limitaciones siguiendo la regla de los tres pasos (art. 9(2)), la cual, Berna permite su aplicación al derecho de reproducción.

Así, el Convenio de Berna establece un conjunto de normas mínimas que todos los países miembros tienen que cumplir. Dichas normas aumentaron con el tiempo a pesar del hecho de que no beneficiaban a todos los países miembros, en particular a los países en desarrollo ya que estas normas reducen el ámbito para elaborar una política nacional en la materia que permita el desarrollo. Sin embargo, a pesar de que con el tiempo los países en desarrollo ganaron terreno en el sistema internacional de derechos de autor, no lograron obtener las concesiones que requerían.

\section{El acuerdo ADPIC: una estrategia de los países desarrollados.}

Para los países desarrollados, los estándares incorporados en Berna no eran suficientes para asegurar los ingresos por el uso de sus obras protegidas en países extranjeros (Leaffer, 1991, pp. 275-276) ${ }^{134}$. Las industrias de contenidos estadounidenses, especialmente las industrias de software y de entretenimiento, habían comenzado a exportar sus productos a todo el mundo, y por lo tanto, la propiedad intelectual se había convertido en un importante componente para el comercio y el empleo ${ }^{135}$; la piratería y el aprovechamiento del esfuerzo ajeno por parte de los países en desarrollo preocupaba a los países desarrollados ${ }^{136}$. Ante este escenario, Estados Unidos,

134 "U.S. companies traditionally have looked to basic international treaties as a remedy against the piracy of their intellectual property. To an owner of intellectual property, however, these treaties fall short of providing effective protection because they lack the power to enforce rights or to settle disputes" (pp. 275-276).

135 Ver Hansen (1996), expresando que las obras protegidas por el derecho de autor se habían convertido en un bien de exportación y un importante componente para el comercio y el mercado laboral (pp. 580-581); ver también Smith (1996): "In 1993 [...] the core copyright industries accounted for approximately $3.7 \%$ of the United States Gross Domestic Product (GDP), employed close to three million people $(2.5 \%$ of the U.S. workforce), and accounted for close to four times the rate of job growth in the economy as a whole" (p. 561).

136 Ver Adede (2003): "The Uruguay Round of multilateral trade negotiations [...] took place against the background of claims by US industries in such sectors as computer softwares and microelectronics, entertainment, chemicals, pharmaceutical, and biotechnology that they were loosening heavy losses from the absence of adequate 
que no había participado de manera activa en el sistema internacional de protección de derechos de autor cuando era un país en desarrollo (Ringer, 1968, p. 1051) $)^{137}$, cambia su política y se vuelve un activo promotor de un alto nivel de protección de derechos de autor y toma un papel activo en el aumento de los estándares internacionales.

En este sentido, los países desarrollados comenzaron un intento por aumentar los estándares internacionales de derechos de autor, especialmente aquellos relacionados con la observancia de la norma en los países extranjeros (Stewart, 1993, p. 467) ${ }^{138}$. No obstante, los países desarrollados, en especial Estados Unidos, no pensaban que la OMPI o que Berna fueran el escenario adecuado para lograr sus objetivos, por diversas razones: 1) La OMPI no pudo resolver el conflicto norte-sur, y como se mencionó anteriormente, los países en desarrollo habían ganado terreno en la OMPI (Sell, 2011, p. $450)^{139}$. 2) Berna no contempló un mecanismo de ejecución de sus mandatos aparte de la posibilidad de acudir a la Corte Internacional de Justicia ${ }^{140}$. 3) Ni Berna ni la OMPI podían ser directamente influenciados, ya que cada miembro tenía un voto (p. 450) ${ }^{141}$. 4) Berna requería la unanimidad de sus signatarios a fin de convocar a una nueva revisión (Convenio de Berna de

protection of their IPRs in foreign markets" (p. 24); ver también Deere (2009), expresando que las industrias del entretenimiento se encontraban preocupadas por el efecto de la piratería en sus ingresos. Igualmente, las industrias estaban preocupadas que el "free riding" de sus competidores en mercados extranjeros que les permitiera equiparar a la industria norteamericana (pp. 45-47).

137 "Until the Second World War the United States had little reason to take pride in its international copyright relations; in fact, it had a great deal to be ashamed of. With few exceptions its role in international copyright law was marked by intellectual shortsightedness, political isolationism, and narrow economic self-interest" (p. 1051).

138 Estableciendo el deseo de los países desarrollados en aumentar la protección de los DPI.

139 Expresando que EE. UU. se encontraba frustrada con la OMPI y su atención a los países en desarrollo.

140 Ver Leaffer (1991): "The Conventions have proven to be ineffective when countries simply do not enforce their laws. The agreements do not contain effective mechanisrmas for challenging countries that ignore their obligations" (p. 294); ver también Sell (2011), estableciendo que EE. UU. estaba frustrado por la falta de un mecanismo de ejecución en la OMPI (p. 450).

141 Estableciendo que EE. UU. estaba frustrada con la OMPI porque necesitaba un mecanismo directamente influenciable. 
1971, art. 27(3)) lo cual parecía difícil debido al conflicto de intereses entre países en desarrollo y desarrollados (Deere, 2009, p. 47) $)^{142}$.

De esta manera, Estados Unidos, en su nuevo papel de promotor de los derechos de autor, intentó un cambio de foro encontrando en el Acuerdo General sobre Aranceles Aduaneros y Comercio (GATT) el escenario perfecto para la consecución de sus objetivos de aumento de la protección de derechos de autor. No obstante, el vínculo entre el comercio y derechos de propiedad intelectual no era todavía adoptado internacionalmente (Deere, 2009, p. 52). Por lo tanto, los Estados Unidos, junto con la Unión Europea y Japón, empezaron a presionar para incluir dentro de la agenda de la ronda de Uruguay en Punta del Este, en septiembre de 1986, el tema de la lucha contra la falsificación (Goldstein, 2001, pp. 53-54) ${ }^{143}$, y a pesar de la oposición de los países en desarrollo a dicha proposición, argumentando que la OMPI tenía la jurisdicción exclusiva sobre asuntos de falsificación (Bradley, 1987, pp. 67, 81, pie de página 72) ${ }^{144}$, se logró la incorporación dentro de la agenda del tema relativo a "aspectos de los derechos de propiedad intelectual relacionados con el comercio, incluyendo el comercio de mercancías falsificadas" (Gervais, 1998, p. 10)

Una vez que la lucha contra la falsificación se incluyó dentro de la agenda del GATT, la discusión entre los países desarrollados y en desarrollo se dirigió a determinar en qué medida los derechos de propiedad intelectual debían ser incorporados en dicho acuerdo. Basado en el texto incluido en la Declaración Ministerial de Punta del Este, el cual se encontraba escrito de una manera limitada ${ }^{146}$, los países desarrollados querían una incorporación

142 Estableciendo las diferentes posiciones entre países desarrollados y países en desarrollo.

143 Estableciendo que la ronda de Uruguay fue solicitada por Estados Unidos y la Unión Europea en orden de incluir la discusión sobre derechos de propiedad intelectual en el GATT. Para mayor información sobre la historia de la ronda de Uruguay ver Bradley (1987).

144 Describiendo la oposición de países en desarrollo.

145 "The Swiss-Colombian majority text served as the basis for the Ministerial Conference. In the list of 'subjects for negotiation', Ministers included the item 'trade-related aspects of intellectual property rights, including trade in counterfeit goods"” (p. 10).

146 El mandato de la declaración ministerial de la ronda de Uruguay establecía: "In order to reduce the distortions and impediments to international trade, and taking into account the need to promote effective and adequate protection of intellectual property rights, and to ensure that measures and procedures to enforce intellectual property rights do not themselves become barriers to legitimate trade, the negotiations 
integral de derechos de propiedad intelectual dentro del GATT ${ }^{147}$, mientras que los países en desarrollo querían restringir la incorporación de derechos de propiedad intelectual a aquellos que distorsionan el comercio (Goldstein, 2001, p. 54), tratando de evitar cualquier intento de establecer nuevos estándares de protección de los derechos de autor o de aumentar los estándares existentes (Primo, 1989, p. 250) ${ }^{148}$.

No obstante, a pesar de la oposición de los países en desarrollo, Estados Unidos logró la incorporación de los derechos de propiedad intelectual en el GATT, por medio del uso de recompensas de mercado y castigos bilaterales (Drahos, 2003, p. 102) ${ }^{149}$, como el Sistema General de Preferencias (SGP) y la Sección 301 del Trade Act y Special 301, los cuales eran usados para recompensar a los países que mejoraran sus sistemas de protección de propiedad intelectual o para castigar a aquellos que se oponían a su propósito como India y Brasil (p. 102) ${ }^{150}$, líderes de la oposición.

Al final, el foro internacional de derechos de autor se desplazó de la OMPI a la Organización Mundial del Comercio $(\mathrm{OMC})^{151}$. El acuerdo de la OMG incorporó en el anexo $1 \mathrm{C}$ un texto integral sobre derechos de propiedad intelectual (DPI) llamado el Acuerdo sobre los Aspectos de los

shall aim to clarify GATT provisions and elaborate as appropriate new rules and disciplines.

Negotiations shall aim to develop a multilateral framework of principles, rules and disciplines dealing with international trade in counterfeit goods, taking into account work already undertaken in the GAIT.

These negotiations shall be without prejudice to other complementary initiatives that may be taken in the World Intellectual Property Organization and elsewhere to deal with these matters" (Gervais, 1998, p. 11), incluyendo el mandato establecido en la orden ministerial.

147 Para una breve exposición de las propuestas de los países desarrollados como en desarrollo ver Stewart (1993, pp. 478-487).

148 Estableciendo que los países en desarrollo se oponían a cualquier aumento de los estándares de protección de DPI.

149 Expresando que los EE. UU. se valió del bilateralismo para derribar resistencias. Para mayor información sobre los bilateralismos usados contra Brasil, Argentina, Tailandia, India, China, Taiwán, Arabia Saudita, Sur Corea, la Unión Europea, Australia, Hungría, Polonia, Filipinas, Turquía, Egipto, México y Canadá (NAFTA) y los países andinos ver Stewart (1993, pp. 497-509).

150 Expresando que durante las negociaciones del ADPIC, E.E. U.U. eliminó a Brasil e India a través de bilateralismos.

151 La Organización Mundial del Comercio fue creada en la ronda de Uruguay y fue el sucesor del GATT. 
Derechos de Propiedad Intelectual relacionados con el Comercio (ADPIC), firmado en Marrakech el 15 de abril de $1994^{152}$. Esta fue la primera vez que un capítulo de los DPI fue incluido en un acuerdo principalmente comercial (Correa, 2007, p. 10), permitiendo a los países desarrollados compensar con acceso a los mercados el costo social del establecimiento de una mayor protección de los DPI en los países en desarrollo ${ }^{153}$. El hecho de que los DPI se negociaron en un paquete permitió que los países en desarrollo accedieran a la incorporación de los ADPIC, al intercambiar protección de DPI por acceso a los mercados de los países desarrollados en otras áreas como la agricultura, textiles, prendas de vestir y productos tropicales, entre otros (Adede, 2003, pp. 30-31) 154 $^{15}$ Al mismo tiempo, esta compensación permitió a los países desarrollados aumentar el nivel de protección de DPI como estaban buscando (pp. 30-31) ${ }^{155}$.

Como resultado de la incorporación de las cuestiones de derechos de autor en la OMC, la situación de los países en desarrollo en materia de derecho internacional de los derechos de autor se hizo peor que como estaba en Berna. El vínculo entre los DPI y otros compromisos de la OMC habían hecho más difícil para los países en desarrollo reducir sus obligaciones internacionales en materia de DPI ${ }^{156}$. Las obligaciones de DPI se adjuntaron al Entendimiento sobre Solución de Diferencias (ESD) de la OMC, lo que permitiría a las naciones buscar el cumplimiento de la obligación de derechos

152 Ver Acuerdo sobre los Aspectos de los Derechos de Propiedad Intelectual relacionados con el Comercio [TRIPs] (1994), anexo 1C.

153 Ver Watal (2001):"Subjects of interest to developing countries, such as the eventual integration of textiles and agriculture into GATT disciplines, were meant to compensate developing countries for concessions made, particularly in the new areas of services, investment and intellectual property"(p. 19); ver también Correa y Yusuf (2008).

154 Explicando los beneficios de vincular DPI con comercio en orden de alcanzar los objetivos.

155 Explicando que los países desarrollados vieron en GATT la oportunidad de aumentar los DPI.

156 Ver Primo (2004): “[...] by bringing the minimum standards of protection under the Berne Convention (with the exception of moral rights) to the fold of the WTO, the TRIPS agreement will strengthen the monitoring and enforcement of copyright protection worldwide" (p. 8); ver también Deere (2009): "Further, the links between TRIPS and the suite of other WTO agreements concluded as part of the Uruguay Round make it more difficult than ever before for developing countries to shy from their international IP commitments" (p. 12). 
de propiedad intelectual a través de sanciones comerciales ${ }^{157}$. En Berna, la falta de un mecanismo eficaz para el cumplimiento de las obligaciones significaba que no había manera práctica de sancionar a los países que no lograran cumplir con las normas mínimas (Dinwoodie, 2007, p. 756) . $^{158}$. Además, los dos principios fundamentales de GATT - tales como el trato nacional y de nación más favorecida- también se aplican a los ADPIC (Roffe et al., 2010, p. 267) ${ }^{159}$. Todas estas circunstancias hicieron que las disposiciones ADPIC fueran más fuertes que las obligaciones pre-ADPIC y, en consecuencia, redujeron aún más el alcance de la política nacional de los países en materia de derechos de autor (Otieno, 2014, p. 241) 160 $^{16}$.

En materia de derechos de autor, los ADPIC incorporaron por referencia las disposiciones sustantivas del Convenio de Berna, con excepción del artículo 6 (bis) (TRIPs, 1994, art, 9(1)). No obstante, aumentó la protección en la materia al incluir los programas de computador (art. 10 (1)) y las bases de datos (art. 10 (2)) como obras protegidas, incorporó nuevos derechos como el derecho de alquiler (art. 11); restringió las limitaciones y excepciones existentes (art. 13), e incorporó medidas de observancia (arts. 41-61) $)^{161}$ que no estaban presentes en Berna, la cual había dejado el tema de observancia de la ley a la legislación nacional (Ricketson \& Ginsburg, 2006, p. 138) ${ }^{162}$. Así, por primera vez, un tratado internacional en el campo del derecho de autor estableció no solo las normas mínimas para la protección de los

157 Ver Gana (1996), estableciendo que como parte del GATT, la violación del ADPIC puede llevar a sanciones comerciales (p. 759, pie de pagina 92); ver también Roffe, Spennemann y Von Braun (2010): "the full incorporation of IP into the international trading system leads to the application of the WTO's Dispute Settlement Understanding (DSU) of the TRIPS Agreement" (p. 267).

158 Estableciendo que en Berna no había mecanismo para sancionar a aquellos miembros que "sailed too close to the wind" (p. 756).

159 "Stating that with the inclusion of IP to the international trading system the main pillars of it such as national treatment and most fauvored nation treatment 'apply to IP relations between WTO members"” (p. 267).

160 "Prior to the coming into effect of TRIPS, national governments had policy space and various flexibilities relating to the scope and coverage of IP within their national jurisdictions" (p. 241).

161 Medidas de frontera.

162 Estableciendo que Berna había dejado como asunto de política nacional el establecimiento de medidas de ejecución de los estándares de protección. 
derechos de autor, sino también normas mínimas de medidas de ejecución para garantizar la aplicación de dichos mínimos (Roffe, 2006, p. 2) ${ }^{163}$.

Entonces, una vez más, como en Berna, las normas internacionales de protección de derechos de autor habían aumentado en los ADPIC y los países en desarrollo no habían recibido concesiones especiales distintos a períodos de transición (TRIPs, 1994, art. 65-66). No obstante, debido a que los países en desarrollo tuvieron una participación más activa en la redacción de los ADPIC lograron incorporar cierta flexibilidad en el texto del acuerdo. La insistencia de los países en desarrollo sobre unir los DPI con el bienestar social y económico les permitió incorporar dentro del preámbulo del ADPIC algunas menciones a objetivos de política pública y a la necesidad de brindar flexibilidad a los países menos adelantados al momento de implementar las obligaciones (preámbulo).

Además, en los artículos 7 y 8, los ADPIC establecen los principios y objetivos del acuerdo, afirmando que la protección de derechos de propiedad intelectual debe ser a favor de la transferencia de tecnología y el "beneficio recíproco de los productores y de los usuarios" (art. 7) ${ }^{164}$, y debe promover el interés público y la prevención de los abusos de los derechos de propiedad intelectual (TRIPs, 1994, art. 8) ${ }^{165}$. Así mismo, los ADPIC, en orden de favorecer a los países menos desarrollados, mandan a los países desarrollados a promover la transferencia de tecnología a dichos países (art. 66.2) y a proporcionar asistencia técnica y financiera a petición (art. 67). Igualmente, el texto del Acuerdo incluyó algunos términos amplios, indefinidos y ciertas ambigüedades para permitir la flexibilidad en la aplicación nacional.

Estas flexibilidades, aunque útil para los países en desarrollo, no contrarrestaban las altas normas sustantivas y de ejecución que ADPIC estableció (Yu, 2011, p. 318). Adicionalmente, no todos los países en desarrollo hicieron uso de dichas salvaguardias en el momento de implementar el

163 Ver Roffe (2006): "[TRIPs] included for the first time ever in international agreeemnts a systematic set of minimum standards on enforcement of IPRs” (p. 2).

164 Para mayor información sobre el art. 7 ver Correa y Yusuf (2008, pp. 11-12).

165 Para mayor información sobre los objetivos de interés público y prevención de abusos ver Correa y Yusuf (2008, pp. 12-14). Para mayor información sobre la historia e interpretación de los artículos 7 y 8 del acuerdo TRIPs (1994) ver Yu (2010). 
ADPIC en la legislación nacional (Land, 2014, p.145) (166 $^{2}$ muchas veces debido a presiones ejercidas por los países desarrollados, las multinacionales y las organizaciones internacionales quienes buscaban evitar que se hiciera uso de las flexibilidades, generando que dichos países terminaran adoptando estándares de protección más altos que los requeridos por ADPIC (Deere, 2009, p. 1) $)^{167}$.

Al final de la negociación de los ADPIC, el panorama internacional se parecía al que había quedado luego de Berna, en el sentido de que ni los países en desarrollo ni los países desarrollados habían quedado contentos

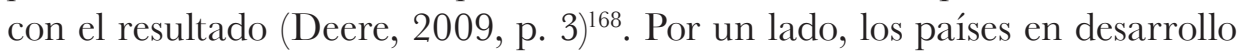
consideraban que los ADPIC agravaron sus problemas (Gana, 1996, pp. 739740) y no tomaron en cuenta su nivel de desarrollo, por ejemplo, las normas de derecho de autor incorporadas en ADPIC no les permiten satisfacer sus necesidades educativas (Land, 2014, p. 247) ${ }^{169}$. Por otro lado, los países desarrollados encontraban las normas ADPIC "primitive, constrained, inadequate, and ineffective" (Yu, 2011, p. 326). Por lo tanto, ambas partes buscaron acuerdos post-ADPIC, que se discutirán más adelante en el capítulo 4 .

\section{El tratado de la OMPI sobre derecho de autor.}

Después de la revisión de 1971 de París del Convenio de Berna, otra revisión al Convenio parecía poco probable debido principalmente al conflicto norte-sur (Ricketson \& Ginsburg, 2006, p. 140) ${ }^{170}$. En cualquier caso, el Convenio tenía preocupaciones con respecto a las nuevas formas de explotación de las obras protegidas como resultado de los avances

166 "Many countries, however, including many of the least-developed states, have explicitly foregone flexibilities... or have adopted national laws beyond what is required by TRIPS [...]" (p. 145).

167 Estableciendo las presiones recibidas por los países en desarrollo.

168 "The final TRIPS deal left both proponents and detractors dissatisfied, provoking post agreements efforts from both sides to revise the contested text [...]" (p. 3).

169 "Efforts to modify the Berne Convention to take into account educational and development needs of developing countries have failed to succeed. Despite this, the scope of copyright protection has increased to include software protection, use of Internet and domain name protection" (p. 247).

170 Estableciendo que una nueva revisión a Berna parecía poco probable luego del colapso del sistema en 1967 y 1971. 
tecnológicos (p. 140) $)^{171}$. Así, en 1991, la OMPI inició una discusión sobre la posibilidad de realizar un nuevo protocolo al Convenio de Berna (p. 143) No obstante, después de firmar los ADPIC, se aceleró la discusión entre las partes y se pasó de la idea de hacer un protocolo a Berna a realizar un "acuerdo especial" en los términos del artículo 20 con respecto a temas relacionados con el nuevo desarrollo tecnológico: Internet (p. 147) ${ }^{173}$.

La discusión acelerada acerca de la realización de un posible tratado se debió en parte al hecho de que las negociaciones del ADPIC habían terminado antes de la expansión de Internet. Cómo manejar Internet era una cuestión no resuelta en el plano internacional (WIPO, 2003, p. 11) De esta forma, los países desarrollados, en especial Estados Unidos, estaban interesados en el establecimiento de normas internacionales para regular la aplicación de los derechos de autor en Internet. Así es como se firma el acuerdo especial (Tratado de la OMPI, 20 de diciembre de 1996, art. 1) ${ }^{175}$ denominado Tratado de la OMPI sobre Derecho de Autor (WCT por sus siglas en inglés) (Tratado de la OMPI, 20 de diciembre de 1996) en Ginebra en diciembre de 1996, junto con su tratado hermano, el Tratado de la OMPI sobre Interpretación o Ejecución y Fonogramas (WPPT por sus siglas en inglés $)^{176}$. Estados Unidos ratificó el WCT y el WPPT el 14 de septiembre de 1999. Colombia hizo lo mismo el 29 de noviembre de $2000^{177}$. En 2002, el WCT entró en vigor ${ }^{178}$.

Estados Unidos volvió a desempeñar un papel central en el desarrollo del WCT (Scheinblatt, 1998, p. 535) ${ }^{179}$. En 1995, la administración Clinton

171 Estableciendo que la convención tenía problemas debido a las nuevas formas de explotación.

172 Estableciendo que en 1991 empezó la discusión acerca de un nuevo protocolo a Berna.

173 Estableciendo que hubo un cambio entre hacer un protocolo y un acuerdo especial que se encargara de asuntos relativos a la agenda digital.

174 Estableciendo que la expansión de Internet comenzó luego de la terminación de ADPIC, por lo tanto, se utilizó la OMPI para actualizar las normas de derecho de autor.

175 Estableciendo que se trata de un acuerdo especial dentro de los términos del artículo 20 de Berna.

176 Ver WIPO Performances and Phonograms Treaty (1997), en adelante WPPT.

177 Ver WIPO-Administered Treaties. (s.f.), estableciendo los miembros del WCT.

178 Ver WCT Notification No. 32 (2001).

179 Describiendo el papel central que desempeñó EE. UU. en el desarrollo del WCT. 
desarrolló la "Information Infrastructure Task Force White Paper", que cubría las recomendaciones para promover la infraestructura de información emergente que tendría un impacto positivo en el comercio, la educación y otras áreas (Samuelson, 1997, p. 379) ${ }^{180}$, promoviendo cambios en la ley de derechos de autor y su aplicación en el entorno digital (pp. 373-374) ${ }^{181}$. No obstante, el White Paper no recibió una buena acogida en el Congreso Norteamericano (Yu, 2004, p. 29) ${ }^{182}$. Por lo tanto, Estados Unidos comenzó a presionar en el ámbito mundial, incluyendo en Ginebra, para incluir a nivel internacional las medidas que deseaba conseguir en casa. Dicha táctica fue un éxito, y la mayoría de las propuestas del White Paper se incluyeron en Ginebra (pp. 29-30; Samuelson, 1997, pp. 373-374). Sin embargo, la oposición de los países en desarrollo y las ONG no permitió a Estados Unidos incluir todas sus propuestas en el texto final del tratado (Yu, 2004, pp. 29-30) ${ }^{183}$. En cualquier caso, Estados Unidos logró incluir en un tratado internacional uno de los temas que más preocupaban a las industrias americanas (p. 30) ${ }^{184}$ : la aplicación de la ley de derechos de autor en el entorno digital.

El WCT se encargó de aclarar el alcance de algunos de los derechos al igual que la aplicación del Convenio de Berna al entorno digital, y finalmente el WCT añadió algunos nuevos derechos (Ginsburg, 2000, p. 272)185. Respecto del primer punto, el WCT aclaró que los programas de ordenador son obras literarias en virtud del artículo 2 del Convenio de Berna (Tratado de la OMPI, 20 de diciembre de 1996, art. 4) y que las compilaciones son obras protegidas (art. 5); amplió la duración de la protección de las obras fotográficas (art. 8) y adoptó expresamente el principio de protección

180 Describiendo los objetivos del Information Infrastructure Task Force.

181 Estableciendo que la aplicación de las normas de derecho de autor en Internet fue incluido en el White Paper de 1995.

182 Estableciendo que el White Paper fue muy controversial en EE. UU.; ver Samuelson (1997, p. 373).

183 Estableciendo que los países menos desarrollados y ONG se opusieron a las propuestas de EE. UU.

184 "The Unite States managed to update the international intellectual property regime in areas that are of major interest to the American copyright industries" (p. 30).

185 "The 1996 WCT, now open for ratification, not only continues the trend of increased specification of the minimum international content of copyright subject matter and rights, but creates new obligations to protect against the circumvention of technological protection measures, and against the removal or tampering with copyright management information" (p. 272). 
de la expresión más no de la idea (art. 2). Respecto del segundo punto, el WCT clarifica que el derecho de reproducción aplica al entorno digital y que el "almacenamiento en forma digital en un soporte electrónico de una obra protegida, constituye una reproducción en el sentido del artículo 9 del Convenio de Berna" (declaración concertada respecto al art. 1 (4)). Igualmente, amplió la aplicación de la regla de los tres pasos, establecida en Berna para el derecho de reproducción (Convenio de Berna de 1971, art. 9 (2)), a todos los derechos exclusivos del autor (Tratado de la OMPI, 20 de diciembre de 1996, art. 10) como ya lo había hecho ADPIC (TRIPs, 1994, art. 13), y finalmente confirmó la aplicación de las limitaciones y excepciones existentes al entorno digital (Tratado de la OMPI, 20 de diciembre de 1996) ${ }^{186}$. Por otra parte, el WCT amplió el derecho de comunicación pública para cubrir la "puesta a disposición del público de sus obras, de tal forma que los miembros del público puedan acceder a estas obras desde el lugar y en el momento que cada uno de ellos elija" (art. 8), abarcando la protección de las obras en Internet. No obstante, en la declaración concertada del derecho de comunicación pública, el WCT aclaró que "el simple suministro de instalaciones físicas para facilitar o realizar una comunicación, en sí mismo, no representa una comunicación en el sentido del presente Tratado o del Convenio de Berna" (art. 8) ${ }^{187}$. Se abordará la importancia de esta declaración infra, capítulo 4, en la discusión de la responsabilidad de los proveedores de servicios de Internet.

Respecto del tercer punto, el WCT establece el derecho de distribución de objetos tangibles (art. 8) ${ }^{188}$, el cual puede ser objeto de agotamiento (art. 6) y que Berna reconoce solo para las obras cinematográficas (Convenio de Berna de 1971, art. 14), también estableció el derecho de arrendamiento a favor, por lo menos, de los programas de ordenador, obras cinematográficas y obras incorporadas en fonogramas (Tratado de la OMPI, 20 de diciembre de 1996, art. 7). Por otra parte, por primera vez, un tratado de derechos de autor ofrece protección a los asuntos tangenciales a derechos de autor

\footnotetext{
186 En declaración concertada al artículo 10.

187 En declaración concertada al artículo 8.

188 En declaración concertada a los artículos 6 y 7 refiriéndose a que el término copias "refer exclusively to fixed copies that can be put into circulation as tangible objects".
} 
(Reinbothe \& Von Lewinski, 2002, p. 139) ${ }^{189}$, tales como medidas tecnológicas de protección (Tratado de la OMPI, 20 de diciembre de 1996, art. 11) (TPM por sus siglas en ingles) y las medidas de información sobre la gestión de derechos (art. 12). Y, por último, el WCT exige establecer un mecanismo efectivo para cumplimiento de los derechos en virtud del tratado (art. 14 (2)).

Respecto de TPM, el WCT establece las normas mínimas de protección a dichas medidas impuestas por el autor que los países miembros deben conceder (art. 11). Aunque estas medidas no son objeto de protección por la legislación autora el WCT elimina la capacidad de los países miembros para decidir si se debe dar protección legal a tales medidas, la obligación incorporada en el WCT, en el artículo 11, se encuentra establecida en términos generales:

Las Partes Contratantes proporcionarán protección jurídica adecuada y recursos jurídicos efectivos contra la acción de eludir las medidas tecnológicas efectivas que sean utilizadas por los autores en relación con el ejercicio de sus derechos en virtud del presente Tratado o del Convenio de Berna y que, respecto de sus obras, restrinjan actos que no estén autorizados por los autores concernidos o permitidos por la Ley (art. 11) (cursivas de la autora).

De esta manera, el tratado permite al país miembro determinar la protección jurídica ofrecida a TPM, así como los recursos disponibles (Ficsor, 2010, p. 259) ${ }^{190}$. El WCT tampoco define términos clave como "medida tecnológica efectiva" y "elusión". Este tipo de ambigüedad era necesario para regular un tema de tal novedad que muchos países no habían abordado antes. La regulación de medidas tecnológicas de protección del WCT se abordará más adelante en el capítulo 3.

Por lo tanto, el WCT al igual que los tratados previos, incrementó las normas de protección de derechos de autor establecidas en Berna, en particular con respecto a la aplicación de la ley de derechos de autor al ambiente digital. No obstante, dicha situación es propia de la naturaleza del WCT como un

189 "Article 11 WCT constitutes the first time that technological measures, which are used to protect authors' rights, have enjoyed protection through a separate provisions in a multilateral treaty" (p. 139).

190 "The Treaties do not determine the details how Contracting Parties may and should provide adequate legal protection. What they do determine, however, is the obligation to provide legal machinery that is able to produce, as a result, such protection' (p. 259). 
acuerdo especial de Berna (Convenio de Berna de1971, art. 20) ${ }^{191}$. Como afirma Mihály Ficsor (2010), "el nivel de protección exigido por los tratados [de internet de la OMPI] puede caracterizarse como de Berna / Roma plus y ADPIC plus" (p. 12), ya que superan el nivel de protección establecido en dichos tratados. Igualmente, el WCT también limita la autonomía de los países miembros a legislar cuestiones de derechos de autor en Internet. Por ejemplo, el WCT permite a los países ampliar o crear nuevas excepciones aplicables al entorno digital pero solo cuando están justificadas y cumplen con la regla de los tres pasos (Tratado de la OMPI, 20 de diciembre de 1996, art. 10 y declaraciones concertadas sobre este artículo). Por consiguiente, el WCT es la continuación de una internacionalización de la ley de derechos de autor que se inició con Berna y no ha parado desde entonces. A pesar de los esfuerzos de los países en desarrollo por obtener normas más favorables, no ha sido posible debido a la contraofensiva de los países desarrollados. En la actualidad, la capacidad de los miembros para definir la política de derechos de autor en el ámbito nacional se encuentra más disminuida que cuando se adhirieron al sistema, y las normas de los tratados no son favorables aún para todos los miembros. Por último, el WCT proporciona la base para la futura evolución del derecho internacional de los derechos de autor: los bilateralismos, que se abordarán más adelante en el capítulo 4 .

\section{Conclusión}

El derecho de autor y la educación se han relacionado a través de la historia. Las leyes nacionales de derechos de autor deben forjar un delicado equilibrio entre la protección y el acceso para permitir el desarrollo de las metas educativas. A pesar de esta posición sensata, la ley de derechos de autor doméstica de los países miembros se ve muchas veces determinada y definida por las normas internacionales de protección de derechos de autor.

Durante el desarrollo del derecho internacional de derechos de autor, las normas mínimas de protección se han vuelto más fuertes debido a la posición de los países desarrollados. Esta situación no favorece a todos los miembros de

191 "The countries of the Union reserve the right to enter into special agreements among themselves, in so far as such agreements grant to authors more extensive rights than those granted by the Convention, or contain other provisions not contrary to this Convention" (p. 20). 
los tratados internacionales; los países en desarrollo tienen otras necesidades que no se ajustan a las normas internacionales, especialmente las necesidades educativas. Los países en desarrollo se debaten entre la presión interna (nacional) para obtener algunas flexibilidades que les permitan cumplir con sus necesidades de educación y la presión externa (internacional) que les impone incrementar la protección de los derechos de autor. Este conflicto se ha denominado como el conflicto norte-sur. 
Capítulo 3

\section{LA IMPLEMENTAGIÓN NORTEAMERIGANA DE LAS OBLIGACIONES INCLUIDAS EN EL TRATADO DE OMPI SOBRE DERECHOS DE AUTOR Y SU IMPLICACIÓN PARA UN MODELO DE EDUGAGIÓN PARA EL SIGLO XXI}

7 stados Unidos en 1998, como miembro del trata-

Udo WCT, promulgó una ley para cumplir con las obligaciones adquiridas en dicho tratado. Esta legislación fue la Digital Millennium Copyright Act (DMCA) (1998) la cual incluía disposiciones relacionadas con la limitación de la responsabilidad de Proveedores de Servicio de Internet (ISP) y la protección de Medidas Tecnológicas de Protección (TPM). Dicha legislación ha sido descrita por expertos en la materia como un acercamiento maximalista de las obligaciones del WCT, teniendo como resultado un modelo único de protección que se diferencia de otros sistemas alrededor del mundo. Igualmente, la DMCA ha sido caracterizada en el ámbito nacional como excesivamente protectora.

Estados Unidos, al igual que los demás países alrededor del mundo, está trabajando para promover un nuevo sistema educativo apropiado para el siglo XXI. Como se describió en el capítulo 1, este sistema trata de aprovechar la tecnología para incursionar en diferentes métodos y actividades dirigidas a dar a los nuevos estudiantes las habi- 
lidades necesarias para participar en una sociedad basada en el conocimiento. Dado que Estados Unidos se encuentra en un nivel avanzado de proporcionamiento de hardware y conectividad, ha comenzado a participar en el desarrollo de nuevos métodos de educación con uso de las tecnologías. No obstante, la imposición de un enfoque maximalista de protección de derechos de autor puede disuadir y frenar la adopción de este nuevo paradigma educativo -aun cuando no exista infracción a la normativa autoral-.

La sección primera de este capítulo describe la implementación norteamericana de las obligaciones del WCT, la DMCA, haciendo hincapié en el enfoque maximalista y los aspectos que diferencian su sistema de limitación a la responsabilidad de los ISP y la protección de TPM de otros sistemas en todo el mundo. La sección segunda argumenta que este enfoque maximalista no permite el desarrollo del nuevo paradigma educativo, aun cuando la protección al derecho de autor no está en juego.

\section{El modelo estadounidense de limitaciones a la responsabilidad de Proveedores de Servicios de Internet y protección a las Medidas Tecnológicas de Protección}

\section{El modelo estadounidense de limitaciones a la responsabili- dad de Proveedores de Servicios de Internet.}

Durante la década de los 90, los ISP comenzaron a presionar al Congreso de los Estados Unidos para obtener alguna certeza sobre la legalidad de sus actividades. La razón de tal presión era que los ISP se encontraban preocupados por el riesgo de ser considerados responsables de la conducta de su cliente (The Copyright Infringement, 1997) ${ }^{1}$ bajo las teorías de la infracción secundaria, como la responsabilidad contributiva [contributory liability] y la responsabilidad vicaria [vicarious liability]. Bajo la ley de derechos de autor de Estados Unidos, un tercero puede ser considerado responsable de la infracción de los derechos de autor bajo la teoría de contributory liability cuando "induce, causa o contribuye materialmente a la conducta infractora de otro, con el conocimiento de la actividad infractora" (Nimmer, M \&

Estableciendo que los ISP se encontraban preocupados por la potencial responsabilidad debido a la conducta de sus clientes. 
Nimmer, D, 1998, vol. 3, § 12A.01)2. De igual manera, un tercero también puede ser considerado responsable en virtud de la teoría de vicarious liability cuando la persona "posee el derecho y la capacidad de supervisar la conducta de infracción y tiene un interés financiero directo en ella"3. La preocupación de los ISP sobre la posibilidad de ser hallados responsables ante este tipo de circunstancias no era nueva ya que anteriormente había sido aclamada por las compañías telefónicas cuando se utilizaron sus instalaciones para la retransmisión de señales de cable, y dichas compañías presionaron al Congreso para recibir protección contra este tipo de responsabilidad obteniendo "the passive carrier exemption" . Por ende, los ISP estaban preocupados por el riesgo de responsabilidad que esas teorías representaban en cara de la expansión de Internet (Nimmer , M \& Nimmer, D, 1998, vol. 4, § 12B.01). De hecho, antes de la promulgación de la DMCA, los ISP ya habían participado en algunos casos donde los tribunales los habían hallado responsables con base en la responsabilidad directa, contributiva y vicaria ${ }^{5}$.

En el plano internacional, algunos países miembros intentaron incluir la responsabilidad de los ISP en el WCT ${ }^{6}$, no obstante, el WCT no abordó el tema. Sin embargo, durante la implementación doméstica del WCT, el Congreso de Estados Unidos se mostró comprensivo con el deseo y las necesidades de los ISP y promulgó una serie de "puertos seguros" para protegerlos de responsabilidad (S. Rep. 105-190, 1998, p. 19)7.

De esta manera, el Congreso de los Estados Unidos promulgó la sección 512, título II de la DMCA, denominada "the Online Copyright Infringement Liability Limitation Act” (OCILLA) (17 U.S.C. § 512). La OCILLA establece

$2 \quad$ Ver Yen (2000, pp. 1872-1880) (traducción no oficial).

3 Ver Nimmer, M y Nimmer, D, (1998, vol. 3, § 12A.01); ver también Yen (2000, pp. 1843-1872) (traducción no oficial).

4 Ver Nimmer, M y Nimmer, D, (1998, vol. 4, § 12B.01), explicando la situación de las compañías telefónicas.

5 Algunos de los casos fueron Religious Technology Center vs. Netcom On-Line Services (1995); Playboy Enterprises vs. Frena (1993); y Marobie-FL vs. Nat. Assn. of Fire Equipment Distributors (1997).

6 Ver Nimmer, M y Nimmer, D, (1998, vol. 4, § 12B.01), estableciendo que la discusión sobre las limitaciones a la responsabilidad de los ISP también se dio en el contexto del WCT.

7 Estableciendo que aunque las limitaciones a la responsabilidad de los ISP no estaban cubiertas por el tratado, el comité se simpatiza con las preocupaciones de los ISP y les da unos puertos seguros. 
un procedimiento voluntario que otorga protecciones contra indemnizaciones y limita las medida cautelares (17 U.S.C $\$ 512$ (j) $)^{8}$ que se pueden imponer contra los ISP que cumplen con los requisitos de cada puerto seguro. Debido a que es un procedimiento voluntario, los ISP no están obligados a cumplirlo

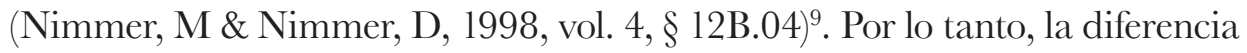
entre un ISP que cumpla con OCILLA y aquel que decida no cumplir es la defensa disponible al momento de ser demandados, ya que, los ISP que no cumplan con el procedimiento no podrán acudir a la defensa del OCILLA, aunque pueden plantear otras defensas incluyendo fair use (17 U.S.C § $512(\mathrm{l}))^{10}$.

Una de las características de la protección del OCILLA a los ISP es que solo aplica a los casos de infracción de derechos de autor. Este aspecto diferencia la legislación estadounidense del régimen europeo de responsabilidad de los ISP, establecido en la Directiva Europea de 2000 (Directiva sobre comercio electrónico), la cual establece las reglas de responsabilidad de los ISP en la Unión Europea con el fin de promover el comercio electrónico en Europa (Kur, 2013, p. 541)11. A diferencia de OCILLA, la Directiva establece un sistema horizontal de responsabilidad de los ISP, lo que significa que aplica a otros ámbitos del derecho que impliquen ISP y no solo a aspectos relacionados con las leyes de derechos de autor (Tian, 2009, p. 191).

Para recibir las protecciones de OCILLA bajo la DMCA, los ISP deben cumplir diversos requisitos. En primer lugar, los proveedores de Internet deben ser considerados un ISP bajo la definición de la OCILLA. La DMCA establece dos definiciones diferentes para los ISP: una en sentido estricto y otra en sentido amplio (17 U.S.C § $512(\mathrm{k}))$. La definición en sentido estricto se refiere a los ISP como proveedor de red de acceso. En palabras de la DMCA, un proveedor de Internet es "una entidad que ofrece la transmisión, enrutamiento o suministro de conexiones para comunicaciones digitales en línea, entre los puntos especificados por el usuario, de material seleccionado por el usuario, sin necesidad de modificar el contenido del material como

\footnotetext{
Enumerando las medidas cautelares disponibles.

$9 \quad$ Estableciendo que el ISP es libre de cumplir con el sistema de notificación de bajada de contenido.

10 Ver 17 U.S.C § 512 (l); ver también Nimmer, M y Nimmer, D, (1998, vol. 4, § 12B.04), estableciendo que el ISP no es responsable si no cumple el DMCA, simplemente no puede utilizarlo como defensa.

11 Estableciendo que la Directiva buscó promover el comercio electrónico en Europa.
} 
enviado o recibido". Esta definición se aplica solamente al puerto seguro de comunicaciones transitorias, (Nimmer, M \& Nimmer, D, 1998, vol. 4, § 12B.02) ${ }^{12}$ el cual se describirá a continuación. Su propósito es aclarar que solo las funciones de conducción se encuentran cubiertas por la protección. La definición más amplia abarca un mayor número de proveedores de Internet, ya que se refiere al ISP como "un proveedor de servicios en línea o acceso a la red, o el operador de las instalaciones para ello". Esta definición es tan amplia que abarca no solo los proveedores de Internet en los términos de la definición en sentido estricto, sino que básicamente incluye casi cualquier intermediario en línea $(\S 12 \mathrm{~B} .03)^{13}$.

En segundo lugar, para que un ISP bajo la definición de la OCILLA obtenga la protección, debe cumplir además de los requisitos específicos para cada puerto seguro, que se describirán a continuación, con dos requisitos generales. Primero, el ISP debe adoptar una política de cancelación de cuentas para infractores reincidentes en determinadas circunstancias (17 U.S.G § 512 (i) (A)). La ley no establece los parámetros para el cumplimiento de esta obligación (Nimmer, M \& Nimmer, D, 1998, vol. 4, § 12B.10)¹4. Según Nimmer, este requisito trata de controlar los futuros actos de infracción de una persona basado en su pasado infractor en lugar de castigar las infracciones pasadas $(\S 12 \mathrm{~B} .10)^{15}$. Y en segundo lugar, el ISP no debe interferir con medidas tecnológicas estándar (17 U.S.C § 512 (i) (B)). Aunque la DMCA define lo que debe entenderse por "medida tecnológica estándar" (§ 512 (i) (B) (2)), el cumplimiento de sus requisitos, tales como un "amplio consenso de los propietarios de derechos de autor y proveedores de servicios" (§ 512 (i) (B) (2) (A)) ha causado dificultades e inconsistencias en el cumplimiento de este requerimiento (Nimmer, M \& Nimmer, D, 1998, vol. 4, § 12B.02) ${ }^{16}$.

Un aspecto importante recordar es que la OCILLA, al igual que la mayoría de los regímenes de ISP de todo el mundo, no establece un régimen de

12 Estableciendo que la definición está basada en the Communications Act of 1934: "in recognition of the fact that the functions covered here 'are essentially conduit-only functions"".

13 Estableciendo que la definición amplia "has almost no limit".

14 Estableciendo que el estatuto no establece los estándares para cumplir con esa obligación.

15 Estableciendo que el uso de esa política busca prevenir futuros actos de infracción.

16 Estableciendo que no es claro que esos estándares existan. 
responsabilidad aplicable a los proveedores de Internet, sino que establece un régimen de exenciones a dicha responsabilidad. La clave para obtener dicha exención de responsabilidad está en que el funcionamiento del ISP recaiga en actividades denominadas "puertos seguros". La OCILLA establece cuatro puertos seguros: el puerto seguro de comunicaciones transitorias (17 U.S.C $\S 512$ (a)), el puerto seguro de almacenamiento en caché (§ 512 (b)), el puerto seguro de almacenamiento de información (§ 512 (c)), y el puerto seguro de herramientas de búsqueda de información $(\S 512$ (d)).

Los dos primeros puertos seguros protegen esencialmente el ISP de responsabilidad dependiendo por cómo funciona Internet (Ballon, 2013, 4.12 [1]). El puerto seguro de comunicaciones transitorias protege el ISP de responsabilidad cuando el ISP actúa como un mero transmisor de información. Es decir, ese puerto seguro protege a un ISP que está transmitiendo la información de un punto a otro a petición de alguien (que no sea el ISP). Con el fin de beneficiarse de la exención, el ISP debe cumplir con cinco requisitos que se dirigen a asegurar que el ISP no participó activamente en la selección del material transmitido (17 U.S.C § 512 (a) (1)), la selección de los destinatarios (§ 512 (a) (3)), o modificando el contenido ( $\$ 512$ (a) (5)). Así, este puerto seguro protege a un ISP cuando su actividad se trate solo de una mera transmisión de dicha información a través de un proceso automático (§ 512 (a) (2)). Adicionalmente, las copias realizadas a través del proceso de transmisión no deben mantenerse durante un período más largo de lo que es razonablemente necesario para la transmisión (§ 512 (a) (4)).

Respecto del puerto seguro de almacenamiento en caché, como su nombre lo indica, protege un ISP de cuando éste hace una copia como resultado de un sistema de almacenamiento en caché. Este sistema de almacenamiento permite que Internet funcione más rápido; el ISP crea una copia caché en su sistema, de modo que la información que se ha solicitado a nivel local pueda ser servida a nivel local, lo que permite al ISP reducir tiempo y costos de la descarga de información desde el servidor original (S. Rep. No. 105-190, p. 42, 1998). Por otra parte, acelera el tráfico y "descongestiona" sitios web populares (p. 42). El puerto seguro de almacenamiento en caché protege el ISP cuando se cumple con algunos requisitos dirigidos a demostrar que el ISP no inició de forma activa la transmisión (17 U.S.C § 512 (b) (1) (B)) o puso a disposición el contenido (§512 (b) (1) (A)), y que el sistema de almacenamiento 
en caché fue parte de un proceso automático (§ 512 (b) (1) (G)) que cumple con los estándares de la industria acerca de la recarga y actualización (§ 512 (b) (2) (B)). Además, el ISP no puede interferir con la "capacidad de la tecnología asociada con el material para volver al [proveedor de contenido]" $(\S 512$ (b) (2) (G)); debe permitir el acceso al material solo a las personas que cumplieron con los requisitos para tener acceso al material (§ 512 (b) (2) (D)); y, por último, debe cumplir con el procedimiento de bajada de contenidos (§ 512 (b) (2) (E)), que se discutirá en detalle más adelante.

Los dos últimos puertos seguros - los puertos seguros de almacenamiento de información y de herramientas de búsqueda de información- protegen a un ISP de responsabilidad subsidiaria por el comportamiento del usuario. El puerto seguro de almacenamiento de información, conocido como la limitación de almacenamiento de usuario (Ballon, 2013, 4.12 [1] ${ }^{17}$, protege a los ISP de material alojado en sus sitios o red cuando este material se ha publicado, almacenado o transmitido por el usuario infractor (4.12 [1]). La limitación de almacenamiento de usuario es atractivo para los ISP debido a la gran cantidad de servicios interactivos en Internet, como blogs, wikis, redes sociales y almacenamiento en la nube, entre otros (4.12 [1]). Sin embargo, este puerto seguro blinda a un ISP de responsabilidad solo cuando el ISP no tiene conocimiento efectivo de la infracción (17 U.S.G § 512 (c) (1) (A) (i)) o no era consiente de algunos hechos o circunstancias por los que la infracción era evidente (§ 512 (c) (1) (A) (ii)). De igual manera, el ISP también debe actuar con prontitud para retirar o desactivar el acceso al contenido una vez es notificado de la presunta infracción (§ 512 (c) (1) (C)). No obstante, incluso en ausencia de conocimiento, un ISP se hace responsable si recibe un beneficio financiero directo atribuible a la actividad infractora cuando se tiene el derecho y capacidad de controlar tal actividad (§ 512 (c) (1) (B)).

Por último, el puerto seguro de herramientas de búsqueda de información protege a los ISP de enlaces, índices, hipervínculos, entre otros, a contenido infractor cuando esos vínculos se proporcionan ya sea por el proveedor de Internet, como en el caso de los motores de búsqueda, o por el usuario dentro de la red del ISP o en el sitio web (Ballon, 2013, 4.12 [1]). Aunque un enlace no constituye una infracción de derechos de autor por sí solo, los ISP han sido sancionados cuando los enlaces inducen o contribuyen a la actividad

17 Explicando la excepción de almacenamiento de usuario. 
infractora (4.12 [1]). Este puerto seguro se incluyó para promover la creación de herramientas de búsqueda de información, las cuales desempeñan un papel muy importante en la búsqueda en Internet (S. Rep. No. 105-109, 1998 p. 49) ${ }^{18}$. Los requisitos para obtener protección en virtud de las herramientas de búsqueda de información de puerto seguro son los mismos que los establecidos para la limitación de almacenamiento del usuario.

Como se mencionó anteriormente, otros regímenes al rededor del mundo han establecido limitaciones sobre la responsabilidad del ISP basado en puertos seguros. No obstante, el establecimiento de un puerto seguro de herramientas de búsqueda de información diferencia el procedimiento de la OCILLA de otros regímenes, ya que, aunque la mayoría de los otros regímenes reconocen los tres primeros puertos seguros, el cuarto no es ampliamente adoptado. Por ejemplo, la Directiva europea sobre comercio electrónico, cuya implementación varía en los países europeos, no incluyó la obligación de establecer un puerto seguro de herramientas de búsqueda de información (Directiva 2001/31) ${ }^{19}$, y países como el Reino Unido siguieron la Directiva y rechazaron el cuarto puerto seguro (Electronic Commerce, 2002, I.S §§ 17-19). En este caso, el gobierno británico consideró que la provisión de un hipervínculo a material infractor no necesariamente significaba que el enlace sería utilizado y los derechos de autor infringidos (Bayer, 2007, p. 71).

Dentro de los requisitos para obtener la protección de la responsabilidad en caso de los puertos seguros de almacenamiento en caché ${ }^{20}$, almacenamiento de usuario y en el uso de herramientas de búsqueda de información [linking] ${ }^{21}$ existen dos requisitos a cumplir, los cuales son importantes para ejecutar los derechos de autor con prontitud en el entorno digital: (1) los procedimientos de bajada de contenido (S. Rep. No. 105-190, 1998, p. 45)²2; y (2) la obligación de los ISP a responder a ordenes [subpoenas] obtenidos por los titulares de

18 Estableciendo que este puerto seguro busca promover la creación de motores de búsqueda, índices, entre otros.

19 Cubre en el art. 12 mera transmisión, art. 13 caching, y art. 14 almacenamiento.

20 No obstante, en el caso de almacenamiento caché, el ISP solo es requerido a bajar el contenido, si dicho contenido ha sido bajado de la página original. Ver Casey (2000, p. 108).

21 Ver 17 U.S.C $§ 512$ (c) (1) (C); ver también 17 U.S.C $§ 512$ (d) (1) (3).

22 "This 'notice and takedown' procedure is a formalization and refinement of a cooperative process that has been employed to deal efficiently with network-based copyright infringement" (p. 45). 
derechos de autor para identificar al infractor (17 U.S.C § 512 (h)). Estos dos mecanismos, en especial el procedimiento de bajada de contenidos, son dos de las características que diferencian a OCCILLA de otros regímenes de derechos de autor.

El procedimiento de subpoenas permite a los titulares de derechos de autor identificar al presunto infractor para lograr aplicar la ley. Por lo general, cuando se produce una infracción en Internet, esta se presenta de forma anónima; el titular de los derechos de autor puede obtener la dirección IP del presunto infractor, pero necesita la cooperación de la ISP para identificarlo. De esta forma, la sección 512 (h) de la OCILLA establece el derecho del titular de los derechos de autor o su agente de servir una subpoena al proveedor de servicios para obtener la identificación del presunto infractor $(\S 512(\mathrm{~h})(1))$. La característica especial de este mecanismo es que los requisitos para ser otorgado son muy bajos, por ende, los titulares de derechos de autor pueden obtener fácilmente de los proveedores de Internet la información personal del presunto infractor, incluso antes de que el caso haya iniciado (Serwin, 2010, § 2:21).

La OCILLA establece tres requisitos que el titular de los derechos de autor debe cumplir para obtener la subpoena: (1) un notificación de bajada de contenido; (2) una propuesta de subpoena; y (3) una declaración jurada de que el propósito de la subpoena es el de obtener la información del presunto infractor y usarlo solo para la protección de los derechos de autor (17 U.S.C $\S 512$ (h) (2)). Una vez que se cumplan estos requisitos de procedimiento, el funcionario de la corte deberá emitir la subpoena $a^{23}$. El ISP, al recibir la subpoena deberá revelar la información del presunto infractor (S. Rep. No. 105-190, p. 51) ${ }^{24}$. Es importante tener en cuenta que el ISP debe cumplir con

23 Sin embargo, los tribunales han señalado que la subpoena no debe ser emitida en el caso que los proveedores de servicios actúen como un mero transitor. La subpoena deberá emitirse solo cuando los proveedores de servicios están actuando como caché, almacenamiento o herramientas de vinculación de información. Ver Recording Indus. Ass'n de Am. vs. Verizon Internet Servs., Inc (2003/2004).

24 "The Committee intends that an order for disclosure be interpreted as requiring disclosure of information in the possession of the service provider, rather than obliging the service provider to conduct searches for information that is available from other systems or networks" (p. 51). 
la subpoena, incluso si el ISP ha decidido no cumplir con la notificación de bajada de contenido (Nimmer, M. \& Nimmer, D., 1998, § 12B.09) ${ }^{25}$.

Este proceso de subpoena proporciona una manera, en Estados Unidos, para obtener la identidad del presunto infractor a través de un procedimiento administrativo. No obstante, este tipo de procedimiento diferencia los distintos modelos de responsabilidad de ISP alrededor del mundo. Australia, por ejemplo, no tiene un procedimiento para identificar un presunto infractor ${ }^{26}$, mientras que otros países, como Chile, han optado por establecer un procedimiento judicial para obtener la identificación del presunto infractor ${ }^{27}$.

Respecto del proceso de bajada de contenidos [takedown process] de OCILLA, encontramos que es un mecanismo de aplicación privada y expedita. El procedimiento es consistente con la idea de que un ISP no se hace responsable si no sabía o tenía razones para saber que el material es infractor (Bayer, 2007, p. 38). Por tanto, el procedimiento está destinado a brindar al ISP ese conocimiento. En este sentido, el procedimiento de bajada de contenidos es un intercambio de protección para un ISP que elimina expeditamente el material identificado como presuntamente infractor (Carroll, 2014, pp. 432-433) ${ }^{28}$.

El proceso de bajada de contenidos inicia con el titular de los derechos de autor mediante el envío de una notificación, que cumpla sustancialmente los requisitos establecidos para esta en la DMCA, al agente designado por un ISP (17 U.S.C § 512 (c) (2)). Dentro de estos requisitos encontramos que la notificación debe ser una comunicación por escrito ${ }^{29}$, que incluya la firma del titular de los derechos de autor o de la persona autorizada para actuar en su nombre (\$512 (c) (3) (A) (i)), debe identificar la obra cuyos derechos de autor se ha infringido (§512 (c) (3) (A) (ii)), el contenido presuntamente

25 Estableciendo que el ISP debe cumplir con la subpoena sin importar su decisión acerca de cumplir con la notificación de bajada de contenidos.

26 Ver Copyright Act. 1968, división 2AA.

27 Ver capítulo 6 sobre la regulación chilena.

28 Indicando que el artículo 512 protege al ISP de responsabilidad monetaria a cambio de la eliminación rápida de material presuntamente infractor a favor de los titulares de derechos de autor.

29 Ver 17 U.S.G $\$ 512$ (c) (3) (A), este requisito se puede cumplir con el envío de un correo electrónico. Ver también Ballon, 2013, 4.12 [9] [B]. 
infractor (§ 512 (c) (3) (A) (iii)), la información de contacto de la parte reclamante (§512 (c) (3) (A) (iv)), contener una declaración estableciendo que la parte reclamante cree de buena fe que dicha presunta utilización infractora no está autorizada (§ 512 (c) (3) (A) (v)) y una declaración bajo pena de perjurio, que la parte reclamante está autorizada para actuar en nombre del propietario del derecho de autor (§ 512 (c) (3) (A) (vi)). El propósito de estos requisitos es reducir los casos de presentación de notificaciones falsas y/o abusivas de derechos de autor (Schwabach, 2006, p. 159). No obstante, como se mencionó, la notificación de bajada de contenido no tiene que cumplir estrictamente con todos estos requisitos, sino que debe estar conforme a estos sustancialmente (Ballon, 2013, 4.12 [9] [B] ${ }^{30}$. Determinar si una notificación cumple sustancialmente los requisitos de la DMCA es importante para determinar si el ISP tiene conocimiento efectivo de la infracción (17 U.S.C § 512 (c) (3) (B) (i)). No obstante, si la notificación enviada al agente designado no cumple sustancialmente con los requisitos, pero proporciona información de identificación de la parte reclamante, el ISP deberá intentar ponerse en contacto con la persona para ayudar en el cumplimiento sustancial de los requisitos ${ }^{31}$.

Luego que un ISP recibe una notificación de bajada de contenido que cumpla sustancialmente con los requisitos, el ISP mecánica y expeditamente deberá desactivar o eliminar el contenido presuntamente infractor ${ }^{32}$. La reacción del ISP dependerá de la actividad que esté realizando, así cuando el contenido presuntamente infractor se ha almacenado en caché, el ISP deberá eliminar o desactivar el acceso al material presuntamente infractor que se ha eliminado o desactivado en la página principal (17 U.S.C § 512 (b) (2) (E)). En el caso de linking, el ISP deberá desactivar o eliminar el enlace al material infractor (§ 512 (d) (3)). Por último, en el caso de almacenamiento

30 Explicando que el Congreso no estableció lo que debe considerarse como un cumplimiento sustancial de los requisitos de la notificación. No obstante, parece que el cumplimiento del numeral (ii), (iii) y (vi) no hace que dicho aviso cumpla de manera sustancial como se desprende de la sección 512 (c) (B) (ii).

31 Ver 17 U.S.C § 512 (c) (3) (B) (ii); ver también Nimmer, M. B. y Nimmer, D. (1998), estableciendo la oportunidad de curar la notificación (vol. 4, § 12B.04).

32 Esto significa que el ISP solo tiene que analizar si la notificación de bajada de contenido cumple sustancialmente con los elementos de la DMCA, pero no los méritos de tal aviso en materia de derechos de autor; si la notificación es conforme, el ISP puede proceder a eliminar o desactivar el acceso al material infractor alegado. Ver 1 Ballon, 2013, 4.12 [9] [D]. 
de material de un suscriptor, el ISP deberá eliminar o desactivar el acceso al contenido presuntamente infractor (§ 512 (c) (1) (C)). Si el ISP cumple con este proceso, a continuación, se encuentra protegido de la responsabilidad por infracción de derechos de autor de un tercero. No obstante, en el caso de almacenamiento de material de un suscriptor, el ISP también deberá cumplir con el proceso de contranotificación, a fin de estar protegidos de la responsabilidad por la eliminación o inhabilitación del acceso al material del usuario $(\S 512(\mathrm{~g})(3))$.

La OCILLA también establece los procedimientos de contranotificación. Una vez el ISP desactive o elimine el material presuntamente infractor deberá notificar con prontitud al usuario acerca de dicha eliminación o desactivación de material, quien podrá optar por enviar una contranotificación escrita al ISP pidiendo restaurar el material. La contranotificación, como la notificación, debe cumplir sustancialmente con los requisitos establecidos para esta $(\S 512(\mathrm{~g})(3))$, uno de los cuales es la firma por parte del usuario de una declaración de consentimiento a la jurisdicción estadounidense $(\S 512$ (g) (3) (D)). Este elemento es importante porque permitirá al titular de los derechos llevar la infracción a juicio. Una vez que un proveedor de Internet ha recibido la contranotificación, deberá notificar de inmediato a la parte reclamante acerca de la contranotificación e informarles que restaurará el contenido eliminado dentro de los diez días hábiles siguientes (§ 512 (g) (2) (B)). Es importante tener en cuenta que si el ISP restaura materiales basado en un contranotificación cuando no está autorizado por la DMCA, puede ser considerado responsable de la infracción a derechos de autor ${ }^{33}$. Si la parte reclamante no quiere que el contenido sea restaurado, entonces deberá presentar al agente designado del ISP un aviso de que ha presentado una acción judicial para impedir que el presunto infractor continúe realizando dicha actividad infractora dentro de catorce días hábiles siguientes (17 U.S.G $\S 512(\mathrm{~g})(2)(\mathrm{C}))$.

33 No hay necesidad de cumplir con el proceso de contranotificación a fin de quedar exentos de la responsabilidad del usuario en cualquier otro puerto seguro, como en el caso de almacenamiento en caché o de herramientas de búsqueda de información. Ver Ballon (2013, 4,12 [9] [C]). 
Debido a que el procedimiento de bajada de contenido es susceptible de ser abusado (Schwabach, 2006, p. 159) ${ }^{34}$, la OCILLA también establece una acción de falsa representación en contra de cualquier persona que a sabiendas señala falsamente un material como infractor o cuando el material fue removido o deshabilitado por error o mala identificación (17 U.S.C § 512 (f)). Esta persona será responsable por daños y perjuicios, incluyendo honorarios de abogados que el perjudicado tuvo que incurrir durante el proceso ( $§ 512$ (f)). Sin embargo, esta acción de falsa representación solo procede cuando el ISP ha actuado de acuerdo con la declaración falsa (Ballon, 2013, 4.12 [9] [D]); si la tergiversación fue incluido en una notificación o contranotificación, pero el ISP no ha ejecutado el procedimiento de bajada de contenido o de restauración de contenido, la acción no procede. Por otra parte, la OCILLA protege a los ISP que ha colaborado con el titular de los derechos de autor y que ha bajado el material de buena fe (17 U.S.C § 512 (g) (1)). De este modo, el ISP está protegido de responsabilidad cuando cumpla con notificaciones falsas.

$\mathrm{Al}$ igual que el proceso de subpoena, el procedimiento de bajada de contenido se ha abordado de manera diferente alrededor del mundo. Por ejemplo, la Directiva sobre comercio electrónico, a diferencia de la DMCA, no establece claramente un procedimiento de bajada de contenido. Cualquier persona puede, de cualquier manera, enviar un aviso al ISP relacionado con sus derechos de autor, incluso aunque no sea el titular de los derechos o una persona autorizada para enviar la notificación a un ISP, o puede notificar verbalmente a los ISP (Bayer, 2007, p. 74). No obstante, según la Directiva, los países pueden, si lo desean, establecer un procedimiento de bajada de contenido (Directiva 2000/31, art. 14 (3)). El Reino Unido, por ejemplo, establece algunos de los requisitos que una notificación de derechos de autor debe cumplir, como proporcionar alguna información de identificación del remitente, la ubicación del contenido supuestamente infractor y los derechos de autor de infracción (Electronic Commerce, 2002, regulación 22). Sin embargo, la Directiva europea no exige a los países establecer un proceso para restaurar el material removido; incluso si el ISP decide reemplazar el material retirado después de la recepción de una contranotificación por el

34 Estableciendo que el procedimiento de bajada de contenido es susceptible al abuso y por lo tanto se establece una acción de falsa representación. 
proveedor de contenido, no va a estar protegido de responsabilidad (Bayer, 2007, p. 74).

El sistema de Canadá es otro ejemplo de modelo que difiere de la OCILLA. En Canadá, el establecimiento del procedimiento de notificación-notificación [notice-and-notice] comenzó como una cuestión de autorregulación entre la Asociación Canadiense de Proveedores de Servicios de Internet (CAIP), la Asociación Canadiense de Televisión por Cable (ACTG) y la Asociación de la Industria Discográfica Canadiense (CRIA) (p. 58). Bajo el sistema de notificación-notificación, un titular de derechos de autor debe enviar una notificación al ISP, el cual la envía al cliente. El ISP puede cobrar un cargo por este servicio. Después, el ISP informa al titular de los derechos que el usuario ha sido notificado y que deja en manos del usuario la determinación de bajar el material presuntamente infractor. Si el usuario no baja el contenido, a continuación, el titular puede demandar al usuario en la corte (p. 58). Por esta razón, los ISP están obligados a conservar la información del presunto infractor durante seis meses (p. 59). El incumplimiento de dicho procedimiento puede significar el pago de daños estatutarios al reclamante por parte del ISP. Este procedimiento fue codificado en 2012 en la Copyright Modernization Act ${ }^{35}$. Por último, otros países como Chile establecen un mecanismo judicial para bajar contenido infractor, como se analizará en el capítulo 6 .

Aunque la OCILLA promueve la cooperación entre el ISP con los titulares de los derechos de autor, es responsabilidad de los titulares de derechos de autor controlar y monitorear su trabajo. El OCILLA exime expresamente el ISP de una obligación de supervisión (17 U.S.C § 512 (m)) al igual que lo hace la Directiva sobre comercio electrónico (Directiva 2000/31, art. 15). Una característica única de la OCILLA es que, a pesar de que no diferencia entre los ISP comerciales y proveedores de Internet no comerciales, otorga cierta protección a las instituciones educativas sin fines de lucro que actúan como proveedores de Internet, si cumplen con unos requisitos estrictos. Bajo esta protección, las instituciones educativas no son responsables de la infracción cometida durante actividades de investigación o de enseñanza por un profesor o un estudiante de posgrado que trabaja en la institución, siempre que dichas instituciones cumplan con algunos requisitos adicionales (17 U.S.C $§ 512$ (e)). En primer lugar, la actividad

35 Ver secciones 41.25- 41.26. 
infractora no debe implicar "la provisión de acceso en línea a los materiales de instrucción que son o fueron requeridos o recomendados, dentro del plazo de tres años anteriores, para un curso impartido en la institución de dicha facultad, miembro o estudiante de posgrado" (§ 512 (e) (1) (A) $)^{36}$. Esta excepción se concedió debido a las preocupaciones especiales que las instituciones educativas tenían de perder la protección de OCILLA, basado en la forma en que la academia funciona (S. Rep. No.105-190, 1998, pp. 20-21). En segundo lugar, las instituciones no pueden haber recibido dentro de los tres años precedentes más de dos notificaciones de derechos de autor sobre la actividad infractora del profesor o estudiante de posgrado (17 U.S.C $\S 512$ (e) (1) (B)). En tercer lugar, la institución educativa debe proporcionar a los usuarios del sistema información sobre las leyes de derecho de autor y promover su cumplimiento (§ $512(\mathrm{e})(1)(\mathrm{C}))$.

Por lo tanto, el régimen de los ISP establecido en la OCILLA tiene algunas características únicas que lo hacen diferente de otros regímenes de ISP de todo el mundo. Las diferencias son más pronunciadas en características tales como el puerto seguro de herramienta de localización de información, el proceso para identificar a los presuntos infractores, el procedimiento de bajada de contenido y la excepción en favor de las instituciones educativas.

\section{El modelo estadounidense de Medidas Tecnológicas de Protección.}

El título I de la DMCA establece la protección contra la elusión de medidas tecnológicas de protección. Su objetivo era promover el desarrollo del comercio electrónico, la comunicación, la investigación, el desarrollo y la educación en la era digital (S. Rep. No. 105-190, 1998, pp. 1, 2) mediante la protección a los titulares de derecho de autor para que hicieran sus obras disponibles en Internet. Estas disposiciones fueron promulgadas como implementación de los estándares internacionales en la materia.

La implementación de Estados Unidos de estos estándares internacionales se ha caracterizado por un enfoque maximalista de las obligaciones del WCT y WPPT, ya que va más allá de los mandatos de estos dos tratados ${ }^{37}$. No obstante, aunque no era necesario este tipo de implementación, el WCT no lo prohibía. Al igual que con el régimen de responsabilidad de los ISP,

\footnotetext{
36 Traducción no oficial realizada por la autora.

37 Para más información sobre enfoque maximalista de la DMCA ver Samuelson (1999).
} 
la protección de las TPM establecida en la DMCA proporciona un modelo único de aplicación que se diferencia de otros modelos de todo el mundo ${ }^{38}$.

La sección 1201 de la DMCA prohíbe tres actividades relativas a la elusión de medidas tecnológicas. En primer lugar, la ley prohíbe el acto de elusión de una medida tecnológica efectiva que protege el acceso al contenido ${ }^{39}$. La DMCA no define el término "medida tecnológica", pero define cuándo una medida tecnológica "controla efectivamente el acceso a la obra" (17 U.S.C $\S 1201$ (a) (3) (B) $)^{40}$ y lo que "eludir una medida tecnológica" (§ 1201 (a) (3) (A) $)^{41}$ significa. En un intento de preservar el fair use de las obras, la DMCA diferencia el tratamiento de una medida de control de acceso y una medida de control de copia (Lejeune, 2003, pp. 369-370). A diferencia del caso de una medida de control de acceso, el acto de eludir una medida de control de copia no es ilegal bajo la DMCA, al no prohibir la elusión de una medida de control de copia se busca que el usuario pueda hacer uso del fair use de obras protegidas (Nimmer, M. \& Nimmer, D., 1998, vol.3 § 12A.03) ${ }^{42}$. La razón de ser, bajo la diferenciación de las protecciones para las medidas de control de acceso frente a medidas de control de copia, es que el usuario necesita obtener acceso legal a la obra antes de intentar realizar fair uses (Yi-Jun, 2005, p. 770) ${ }^{43}$.

No obstante, la protección de la DMCA de medidas de control de acceso no es ampliamente utilizada en todo el mundo. Por ejemplo, algunos países solo protegen contra los actos de eludir una medida de control de copia; este es el caso en Colombia (Ley 599 de 2000, art. 272) ${ }^{44}$. Además, las diferencias

\footnotetext{
38 Para más información sobre los diferentes modelos de protección de TPM ver Gasser (2006, p. 19).

39 Ver 17 U.S.C § 1201 (a) (1) (A), ver definición en § 1201(a) (3) (B).

40 "A technological measure 'effectively controls access to a work' if the measure, in the ordinary course of its operation, requires the application of information, or a process or a treatment, with the authority of the copyright owner, to gain access to the work" $(\S 1201$ (a) (3) (B)).

41 'To 'circumvent a technological measure' means to descramble a scrambled work, to decrypt an encrypted work, or otherwise to avoid, bypass, remove, deactivate, or impair a technological measure, without the authority of the copyright owner $[\ldots]$ " $(\S$ 1201 (a) (3) (A)).

42 Estableciendo que una vez se ha obtenido acceso legal el usuario puede eludir para realizar usos justos.

43 El Congreso decidió que para hacer un uso justo es necesario tener primero acceso legal al trabajo.

44338 En adelante Código Penal.
} 
marcadas de la DMCA entre la protección otorgada a una medida de control de acceso frente a una medida de control de copia lo diferencia de otros sistemas. La Unión Europea en la Directiva de la Sociedad de la Información (Directiva Europea, 2001/29), que tiene como objetivo armonizar el régimen europeo de derechos de autor y aplicar los tratados de Internet de la OMPI, declara ilegal el acto de eludir a sabiendas una medida tecnológica de protección (art. 6.1). La Directiva, sin embargo, no distingue entre las medidas de control de acceso y control de copia en la definición de "medida tecnológica de protección". Países como Alemania y el Reino Unido prohíben el acto de elusión de ambas medidas tecnológicas de protección (Gasser, 2006, p. 22). Otra diferencia entre el modelo de Estados Unidos y el modelo europeo es el requisito del conocimiento en el momento de eludir una TPM. Para los Estados Unidos una persona no requiere "conocimiento" para ser responsable, mientras que el modelo europeo requiere expresamente que la persona, a sabiendas, eluda una TPM.

La protección legal de la DMCA para las TPM que controlan el acceso a una obra con derechos de autor va más allá de los requisitos del WCT, el cual ordena solamente que los países protejan TPM utilizadas "por los autores en relación con el ejercicio de sus derechos en virtud de este tratado" (Tratado de la OMPI, 20 de diciembre de 1996, art. 11), es decir, la protección de TPM que protegen los derechos exclusivos del autor, los cuales no incluyen el acceso a una obra. Por lo tanto, el WCT no requiere que los países protejan contra el acceso a una obra (Ginsburg, 1999, p. 142) ${ }^{45}$.

Las dos actividades restantes prohibidas por la DMCA son: (1) el tráfico en los servicios y dispositivos principalmente diseñado para eludir una medida de control de acceso (17 U.S.C § 1201 (a) (2)), y (2) el tráfico en los servicios y dispositivos diseñado principalmente para eludir una medida de control de copia (§ 1201 (b) (1)). Estas prohibiciones contra el tráfico en los dispositivos y servicios abarcan cualquier herramienta "diseñada o producida principalmente para eludir"46; "comercializado por esa persona para su uso

\footnotetext{
45 "The WCT does not compel signatory countries to protect technological measures that control the breath of 'access' covered by $\$ 1201(a)$ " (p. 142).

46 Ver 17 U.S.C $\$ 1201$ (a) (2) (A), respecto de una medida de control de acceso; ver 17 U.S.G § 1201 (b) (1) (A), respecto de una medida de control de copia (traducción no oficial realizada por la autora).
} 
en la elusión"47; o "sólo tiene un limitado propósito comercial [...] diferente al de eludir" ${ }^{\prime 4}$, independientemente de que las herramientas sean utilizadas para eludir con fines no infractores (Gasser, 2006, p. 19). La Directiva de Sociedad de la Información también sigue esta posición, prohibiendo el tráfico de productos, dispositivos o servicios dirigidos o promovidos para eludir una medida de protección tecnológica (Directiva Europea, 2001/29, art. 6.2).

La prohibición tanto del acto de elusión como de actos preparatorios de la DMCA es un enfoque maximalista de los tratados de la OMPI. El mandato del WCT establece que los países deben proporcionar "protección jurídica adecuada" a las medidas tecnológicas (Tratado de la OMPI, 20 de diciembre de 1996, art. 11).

La sección 1201 de la DMCA establece algunas limitaciones confinadas en siete excepciones. Mientras que las siete excepciones son aplicables al acto de eludir una medida de control de acceso, solo algunas de ellas se aplican al tráfico de servicios y dispositivos. Las siete excepciones son: (1) excepción para bibliotecas de archivo e instituciones educativas sin fines de lucro (17 U.S.C $\S$ 1201 (d)); (2) la excepción de ingeniería inversa (§ 1201 (f)); (3) la excepción de investigación de cifrado $(\S 1201(\mathrm{~g})) ;$; 4 ) la excepción de protección de menores (§ 1201 (h)); (5) la excepción de privacidad ( § 1201 (i)); (6) la excepción de pruebas de seguridad $(\S 1201(\mathrm{j})) ;$ y $(7)$ la de actividades gubernamentales. De estas siete excepciones, solo la excepción de la investigación de cifrado $(§ 1201$ (g) (4) $)^{49}$ y la excepción de pruebas de seguridad (§ 1201 (j) (4)) aplican al tráfico en los servicios y dispositivos para eludir una medida de control de acceso. La excepción de ingeniería inversa (§ 1201 (f) (2)) es la única excepción que se aplicará a todas las actividades prohibidas.

Aunque la DMCA protegió fuertemente las TPM, también reconoció que dicha protección puede afectar el futuro acceso de materiales para fines

47 Ver 17 U.S.C $\$ 1201$ (a) (2) (C), respecto de una medida de control de acceso; ver 17 U.S.C § 1201 (b) (1) (C), respecto de una medida de control de copia (traducción no oficial realizada por la autora).

48 Ver 17 U.S.C $§ 1201$ (a) (2) (B), respecto de una medida de control de acceso; ver 17 U.S.C § 1201 (b) (1) (B), respecto de una medida de control de copia (traducción no oficial realizada por la autora).

49 Solo se refiere al tráfico en los dispositivos y servicios de eludir una medida de control de acceso. 
lícitos (Casa de Representantes, 1998, p. 36) ${ }^{50}$. En consecuencia, la DMCA estableció un mecanismo adicional para crear nuevas excepciones a la elusión de medidas tecnológicas de control de acceso que se llama: el procedimiento de elaboración de normas administrativas [the administrative rule-making procedure] (17 U.S.C § 1201 (a) (1) (C)). El procedimiento de elaboración de normas administrativas busca crear excepciones en favor de las "personas que son usuarios de una obra con derechos de autor que pertenece a una clase particular de obra [... que están] afectados negativamente por virtud de esa prohibición en su capacidad para hacer usos no infractores” (§ 1201 (a) (1) (B)) (traducción no oficial realizada por la autora). Las entidades encargadas de realizar este procedimiento son la Biblioteca del Congreso y el Registro de Derechos de Autor $(\S 1201$ (a) (1) (C)). La primera toma la decisión acerca de cuáles excepciones deben ser promulgadas con base en las recomendaciones del segundo (Exemption to prohibition, octubre de 2012, p. 65261). Su papel es el de determinar si las medidas de control de acceso disminuyen la capacidad de hacer usos legítimos de obras protegidas (p. 65261) ${ }^{51}$.

Las excepciones como resultado del procedimiento de elaboración de normas administrativas tienen una duración de tres años (17 U.S.C § 1201 (a) (1) (C)) sin derecho de renovación automática (Exemption to prohibition, octubre de 2012, p. 65621) ${ }^{52}$. No obstante, los usuarios afectados pueden obtener la excepción un número ilimitado de veces mediante la demostración de la necesidad de la excepción durante cada procedimiento (p. 65621) ${ }^{53}$. En dicho procedimiento, el usuario debe mostrar evidencia de que existe un impacto negativo real o que es probable que exista en un plazo de tres años (p. 65621) ${ }^{54}$. Sin embargo, ninguna excepción producto del procedimiento de elaboración de normas aplica a la prohibición de tráfico de servicios o dispositivos para eludir medidas de control de acceso o copia (17 U.S.C § 1201 (a) (1) (B)).

50 "Given the threat of a diminution of otherwise lawful access to works and information, the Committee on Commerce Believes that a 'fail-safe' mechanism is required" (p. 36).

51 Describiendo las obligaciones del bibliotecario del Congreso y del registrador.

52 Indicando que cada procedimiento de reglamentación revisa el "proposed classes de novo".

53 Describiendo el procedimiento.

54 Describiendo lo que el usuario debe demostrar durante el procedimiento. 
No obstante, la DMCA no establece una excepción general en favor del fair use, que a su vez lo diferencia del sistema europeo. La Directiva de la Sociedad de la Información, en un intento de evitar afectar actos lícitos, estableció en el artículo 6.4 la obligación de los Estados miembros a tomar "[...] las medidas pertinentes para que los titulares de los derechos faciliten al beneficiario de una excepción o limitación establecida por el Derecho nacional [...], los medios adecuados para disfrutar de dicha excepción o limitación" (Directiva Europea, 2001/29, art. 6.4). Estas medidas están destinadas a aplicarse cuando los titulares de derechos de autor no han tomado medidas voluntarias para permitir usos legales de sus obras (art. 6.4). Sin embargo, estas excepciones no se aplican si el contenido protegido se hizo disponible en línea (art. 6.4)

Otro ejemplo de la legislación de derechos de autor que permite eludir medidas tecnológicas de protección para realizar usos permitidos es la Ley de Derechos de Autor de Nueva Zelanda. La Ley de Derecho de Autor de 1994, modificada por la enmienda de 2008 de Derecho de Autor (Nuevas Tecnologías), no solo permite la elusión de medidas tecnológicas de protección para llevar a cabo un acto permitido, sino que también permite "la fabricación, importación, venta, o dejar para el alquiler de un dispositivo de elusión TPM para permitir a una persona calificada ejercer un acto permitido" (Copyright Act 1994, art. 226D-226E) (traducción no oficial realizada por la autora). Esta última es una distinción importante de la DMCA que, como se mencionó anteriormente, no establece ninguna excepción general a la disposición contra el tráfico de dispositivos o servicios elusivos de TPM.

Otra de las características de la protección de la DMCA sobre las medidas tecnológicas es que es una disposición independiente. Lo anterior quiere decir que independientemente de si existe infracción a los derechos de autor, la elusión de medidas tecnológicas de protección se sanciona por vía civil y penal (17 U.S.C $\S 1203 ; \S 1204)^{56}$. El hecho que sea una disposición independiente distingue el sistema DMCA de otros, tales como el sistema suizo. La Ley Federal de Derecho de Autor y la Ley de Derechos Conexos suiza (Federal Act on Copyright and Related Rights, 1992) otorgan protección

$55 \quad$ Ver Kur (2013): "however, if the protected content is made available online, technical protection measures always prevail" (p. 272).

56 Ver también Lejeune (2003, p. 369). 
tanto contra el acto de elusión de una medida tecnológica (art. 39a (1)) - ya sea de control de acceso o control de copia (art. 39a (1) $)^{57}$, , como el tráfico de dispositivos y servicios de elusión (art. 39a (1) $)^{58}$. Sin embargo, la ley suiza contra la elusión solo se aplica en la medida en que el acto de elusión no esté relacionado con el ejercicio de un uso legalmente permitido (art. 39a (1) $)^{59}$. Por lo tanto, la protección de medidas tecnológicas de protección bajo la ley suiza es una medida complementaria al ejercicio de la protección de la ley de derecho de autor y no una medida de protección en sí (Van Eechoud, Hugenholtz, Van Gompel, Guibault \& Helberger, 2009) ${ }^{60}$.

La protección de la DMCA de TPM como una disposición independiente a una infracción de derechos de autor también es una muestra que la implementación va más allá del WCT. El acuerdo requiere que los signatarios otorguen protección a las medidas tecnológicas efectivas que "restrinjan actos [...] que no estén autorizados por los autores concernidos o permitidos por la ley" (Tratado de la OMPI, 20 de diciembre de 1996, art. 11). Esta disposición significa que no todos los actos de elusión deben prohibirse. Al referirse a los "actos permitidos por la ley", el tratado se refiere a las excepciones y limitaciones (Gasser, 2006, p. 10) ${ }^{61}$. Esto significa que las leyes nacionales pueden permitir la elusión de TPM cuando el usuario intenta ejercer una limitación y excepción a la protección de los derechos de autor conforme a la legislación nacional (p. 10). Por otra parte, proporcionando las sanciones civiles y penales a la elusión de medidas tecnológicas de protección es también un enfoque maximalista al WCT, el cual establece solo el requisito de brindar "recursos jurídicos efectivos" (Tratado de la OMPI, 20 de diciembre de 1996, art. 11), lo cual podría ser satisfecho estableciendo solo recursos civiles.

Por último, algunas disposiciones de la DMCA buscan limitar el alcance de la protección brindada a las medidas tecnológicas de protección. La sección 1201 (c) establece que "[n]ada en esta sección afectará a los derechos, recursos, limitaciones o defensas contra la infracción de derechos de autor, incluyendo el fair use" (17 U.S.G § 1201 (c) (1)) (traducción no oficial realizada

\footnotetext{
57 En conexión con art. 39a (2).

58 En conexión con art. 39a (3).

59 En conexión con art. 39a (4).

60 Estableciendo que la protección a una TPM se da como una medida complementaria a la protección de derechos de autor.

61 Estableciendo que "actos permitidos por la ley" se refiere a limitaciones y excepciones.
} 
por la autora); y "[n]ada en esta sección deberá aumentar o disminuir la responsabilidad civil subsidiaria o contributiva por infracción de derechos de autor en relación con cualquier tecnología, producto, servicio, dispositivo, componente, o parte de ella" (§ 1201(c) (2)) (traducción no oficial realizada por la autora). A pesar de las afirmaciones sobre fair use de la sección 1201 (c), la naturaleza independiente de la protección a las medidas contra la elusión no permite la aplicación de principios de fair use a la protección contra la elusión de una medida de control de acceso o de las disposiciones contra el tráfico de dispositivos. Esta disposición es relevante para las acciones de derechos de autor solo cuando se trata de la elusión de una medida de control de copia o de actos que se produjo después de obtener el acceso (Garlick, 2004,). Además, la DMCA reconoció que podrían surgir algunas preocupaciones sobre la Primera Enmienda (Yi-Jun, 2005, p. 227) y de esta forma afirma que "[n]ada en esta sección deberá aumentar o disminuir los derechos de libertad de expresión o de prensa para las actividades que utilizan el consumo de electrónicos, telecomunicaciones, o productos de computación" (17 U.S.G § 1201 (c) (4)) (traducción no oficial realizada por la autora).

Por último, las medidas contra la elusión de TPM instituidas en la DMCA establecen la "no mandate rule", lo que significa que fabricantes de electrónicos de consumo, telecomunicaciones o productos informáticos no están obligados a responder a una medida tecnológica en particular $(\S 1201(3)(2))^{62}$.

En conclusión, al igual que el régimen de ISP, la protección de la DMCA de medidas tecnológicas de protección contiene características únicas que la diferencian de otros modelos de alrededor del mundo, especialmente en la protección concedida a una medida de control de acceso y en un sistema de excepciones confinadas.

\section{La DMGA y la educación para el siglo XXI}

Como el propósito de este libro es explicar la relación entre las nuevas tecnologías, educación y derechos de autor, esta sección se encargará de explicar la relación entre las tres y, más específicamente, cómo la implementación de

62 No obstante la sección 1201 (k) manda a incluir la tecnología de protección the Macrovision copy protection a cualquier sistema de grabación de video análoga. Ver Lejeune (2003, p. 370). 
Estados Unidos de las obligaciones del WCT -la DMCA- puede afectar la adopción de una educación necesaria para los estudiantes del siglo XXI.

Estados Unidos no es ajeno a la tendencia mundial de la transformación de la educación a través del uso de las TIC. Estados Unidos, como país desarrollado, se encuentra en una etapa avanzada de incorporación de las TIC en todos los niveles de educación. El problema de proporcionar hardware y conectividad ya ha sido resuelto; $100 \%$ de las escuelas públicas del país norteamericano tienen conectividad. Para el año 2005, todas las escuelas públicas de primaria y secundaria se encontraban conectadas a Internet (Wells \& Lewis, 2006, p. 10.4) ${ }^{63}$. Por otra parte, la educación mixta [blended education] y la educación a distancia han sido ampliamente incorporadas en todos los niveles educativos. Para el año 2004 el 90 \% de las instituciones públicas de educación superior que ofrecían carreras de más de cuatro años de duración y la mitad de las instituciones privadas de educación superior ofrecían educación en línea (U.S. Department of Education, 2004). Para el año 2009 el $55 \%$ de las escuelas públicas K-12 reportaron tener cursos de educación a distancia (Queen \& Lewis, 2011, pp. 3-4).

Ante este panorama, Estados Unidos ha desarrollado una política para transformar el actual sistema educativo en un sistema educativo del siglo XXI. Por ende, han basado su política en la aplicación de las TIC al proceso de aprendizaje, estableciendo dichos parámetros en The Department of Education's National Education Technology Plan of 2010, Transforming American Education: Learning Powered by Technology. (U.S. Department of Education, 2010). Este plan busca involucrar a las TIC en la educación, aprovechar el acceso a los recursos interpuestos por la tecnología y desarrollar diferentes metodologías que necesitan los estudiantes del siglo XXI tales como la colaboración, la multimedia, el aprendizaje permanente y la educación siempre en el aprendizaje. Por otra parte, se trata de ofrecer una educación más inclusiva, ayudando a los alumnos con discapacidad. De igual manera, el plan busca posicionar la educación de Estados Unidos como uno de los mejores sistemas educativos y educar a los estudiantes estadounidenses de

63 La discusión ya no recaía en si la institución proporcionaba conectividad, sino qué tipo de conectividad proporcionada. Para el 2005 el $97 \%$ de las escuelas públicas tenían conexión de banda ancha para acceder a Internet. El número de estudiantes por computador era de 3,8 alumnos o menos y el 83 \% de estas escuelas habían proporcionado formación a sus maestros sobre la incorporación de las TIC en la educación. 
manera "activa, creativa, eficiente, y como participantes éticos en nuestra sociedad globalmente conectada" (p. 1). Estados Unidos, al igual que otros países en el mundo, busca la transformación de su sistema educativo a través de la incorporación de las TIC ${ }^{64}$.

Respecto de la DMCA, como se mencionó anteriormente, el Congreso estadounidense al aprobarla buscaba proteger a sus industrias de derechos de autor en el entorno digital, y a su vez, incrementar la investigación, el desarrollo, el comercio electrónico y la educación en la era digital. No obstante, a pesar de las buenas intenciones de la DMCA, esta se ha convertido en una legislación muy controvertida en Estados Unidos debido, principalmente, a la creación de consecuencias imprevistas que afectan importantes intereses públicos, como la libertad de expresión ${ }^{65}$, los derechos del consumidor y el libre mercado ${ }^{66}$. La educación ha cambiado significativamente desde la promulgación de la DMCA. La necesidad en cuanto a promover la educación en la era digital hace dieciséis años, cuando la DMCA fue promulgada, no es la misma de hoy en día (U.S. Department of Education, enero de 2004) ${ }^{67}$, ya que se busca desarrollar y participar en las nuevas metodologías para aprovechar las TIC y transformar el proceso de aprendizaje. No obstante, regímenes maximalistas de responsabilidad de ISP y protección a TPM, como los descritos anteriormente, pueden afectar el desarrollo pleno de este nuevo estilo de educación que la tecnología permite, como se explicará enseguida.

\section{Afectación a la utilización de Internet como núcleo del nuevo sistema de aprendizaje.}

Una educación transformada para los estudiantes del siglo XXI busca utilizar las capacidades de información y comunicación de Internet para educar a los nuevos alumnos ${ }^{68}$. Por lo tanto, Internet se convierte en el núcleo central del proceso educativo. No obstante, este uso central de Internet en

64 Ver capítulo 1, información sobre educación transformada.

65 Para información sobre la afectación de la DMCA a la libertad de expresión ver Seltzer (2010).

66 Para más información sobre los abusos ver Unintended Consequences (marzo de 2013). Para información detallada sobre los abusos al proceso de bajada de contenidos ver Cox (2012); ver también Urban y Quilter (2005, p. 638).

67 Estableciendo que para ese tiempo la necesidad era pensar en brindar acceso de banda ancha a las escuelas.

68 Ver capítulo 1. 
educación se puede ver perjudicado por las disposiciones de la OCILLA. La OCILLA exige a los ISP, como requisito general para obtener protección, establecer una "política que prevé la cancelación de cuenta de los suscriptores y titulares de cuentas del sistema del proveedor de servicios o de la red que son infractores reincidentes" (17 U.S.C § 512 (i) (1) (A)) (traducción no oficial realizada por la autora). Si el ISP no termina las cuentas de los infractores reincidentes no podrá obtener la protección de OCAILA (Cooley, 2011, p. 707$)^{69}$. En el caso de las instituciones educativas, los "suscriptores" son estudiantes (Casa de Representantes, 1998, p. 61, n. 3) ${ }^{70}$, lo que quiere decir que para cumplir con OCILLA, las instituciones educativas que actúan como proveedores de Internet deben establecer políticas para cancelar cuentas de los estudiantes cuando estos son infractores reincidentes.

No obstante, en un proceso de aprendizaje transformado, el uso de Internet no puede ser considerado como un "extra" y la terminación de conectividad puede afectar el desarrollo de los estudiantes. Como señala el Plan Nacional de Educación Tecnológica, "ya sea el dominio del idioma Inglés, artes, matemáticas, ciencias, estudios sociales, historia [...] las competencias del siglo 21 y la experiencia, como el pensamiento crítico, resolución de problemas complejos, la colaboración y la comunicación multimedia deben ser tejidas en todas las áreas de contenido" (U.S. Department of Education, 2010, p. 13), y es Internet el que permite a los estudiantes desarrollar estas competencias mediante la participación en tareas interactivas y colaborativas (pp. 52-55 $)^{71}$. De igual manera, la

69 Indicando que la jurisprudencia ha demostrado que si los ISP no terminan las cuentas de infractores no obtendrán la protección.

70 " $\backslash 3 \backslash$ In using the term 'subscribers', the Committee intends to include account holders that have a business relationship with the service provider that justifies treating them as subscribers, for the purposes of new Section 512, even if no formal subscription agreement exists. For example, 'subscribers' would include students who are granted access to a university's system or network for digital on-line communications; employees who have access to their employer's system or network; or household members with access to a consumer on-line service by virtue of a subscription agreement between the service provider and another member of that household" (p. 61).

71 Por ejemplo, el Plan Nacional de Educación Tecnológica reconoce la importancia de contar con Internet de buena calidad disponible en todas partes. De esta forma, el Plan promueve una infraestructura que incluye redes de banda ancha con cobertura inalámbrica para todos los estudiantes. También se promueve la disponibilidad de dispositivos de acceso a Internet para todos los estudiantes y el educador. 
UNESCO ha declarado que las TIC no son meras herramientas y que una persona excluida de acceso a Internet pierde formas de estar en el mundo, y el mundo a su vez pierde sus contribuciones (UNESCO, 2014c, p. 18). Este argumento ofrece una gran comprensión de la situación en la que se corta el acceso a Internet dentro de un proceso de aprendizaje transformado, ya que explica cómo los estudiantes que queden sin acceso a Internet pueden perder oportunidades de participar en actividades de colaboración, y a su vez, sus compañeros pierden esa colaboración también (Kozma, 2011, p. 22) ${ }^{72}$. Por lo tanto, las instituciones educativas no deberían estar obligadas a cancelar las cuentas de los estudiantes.

Empero, la verdad es que, bajo la ley de derechos de autor de Estados Unidos, un proceso de aprendizaje transformado genera un mayor riesgo de responsabilidad secundaria debido a la cantidad de contenido alojado y vinculado a las instituciones educativas. De esta forma, parece apropiado para este tipo de organizaciones buscar la protección que brinda el OCILLA (Carroll, 2014, p. 433) ${ }^{73}$. Así pues, para obtener protección pero también promover un sistema educativo transformado, las instituciones educativas, teniendo en cuenta la libertad que otorga la ley, podrían adaptar y limitar lo mejor posible su política de terminación de cuentas a infractores reincidentes.

Lo anterior es posible porque la DMCA dejó indefinida ${ }^{74}$ la política de terminación de cuentas, es decir, es el papel de la ISP dar sentido a esa política (Ballon, 2013, vol. 4, 49.05 [2] $)^{75}$. Por lo tanto, teniendo en cuenta

${ }^{72}$ Estableciendo que el uso de las TIC en la educación promueve un ambiente colaborativo y la generación de conocimiento.

73 La protección en materia de responsabilidad de las instituciones educativas puede favorecer el desarrollo de las actividades educativas que involucran metodologías basadas en alojamiento de contenidos y enlaces a materiales como lo ha hecho en beneficio del desarrollo de las plataformas en línea. Ver Carroll (2014): "The Decisión to limit service provider liability for monetary relief in $\S 512$ is good policy in the United States' context, and it has provided the necasary security to attract investements in developing online platforms, through which users share creative works with each other" (p. 433).

74 Ver Sirichit (2013): "[...] both the statutory language and legislative history are equally opaque as to what kind of subscriber would qualify as a 'repeat' or 'flagrant' infringer" (p. 119); ver también Bridy (2010): "Compared to the detailed notice and takedown framework from $\S 512$ (c), the requirements of $\S 512$ (i) are much loosely defined" (p. 91).

75 "The statute affords service providers significant flexibility in designing and implementing a repeat infringer policy" (49.05 [2]). 
las capacidades de acceso a la información de Internet y los usos de este dentro de la educación, las instituciones deben diseñar una política que tenga en cuenta los usos educativos que se han producido en el sistema y crear sanciones en función del tipo de infracción (vol. 1, 4.12 [3] [B] [iii] $)^{76}$. De esta forma, las instituciones educativas deben prestar especial atención a la hora de determinar quién es un infractor reincidente (4.12 [3] [B] [iii] $)^{77}$ y solo cuando sea adecuado suspender la cuenta del estudiante, ya que la OCILLA requiere solo una aplicación razonable (17 U.S.G § 512 (i) (1) (A)) de una política de este tipo, lo que significa que una aplicación estricta no es necesaria para obtener protección (Ballon, 2013, vol. 114.12 [3] [B] [iii]) ${ }^{78}$. De igual manera se debe recordar que es más difícil para los estudiantes como suscriptores cambiar de ISP cuando sus cuentas se han terminado, ya que los estudiantes dependen de sus universidades para el acceso (Bridy, 2010, p. 95) ${ }^{79}$.

Sin embargo, el escenario descrito anteriormente no es la regla general en los Estados Unidos. En la práctica, las instituciones educativas han adoptado políticas muy estrictas de terminación de cuentas, no solo para promover el cumplimiento de la ley de derechos de autor dentro de la comunidad estudiantil, sino también debido a las presiones de la industria del derecho de autor (Quilter \& Heins, 2007, p. 19) ${ }^{80}$. En este sentido, las disposiciones de la OCILLA permiten a la industria de derechos de autor interferir con la educación mediante la limitación de la libertad de las instituciones de educación superior para desarrollar una adecuada política de cancelación de cuentas. Y, aunque este exceso de cumplimiento puede enviar un mensaje

76 Estableciendo que el Congreso requirió aplicar la política solo en circunstancias apropiadas: "[...] the statute is intended to be flexible and allow service providers to implement policies that they deem appropriate for their services or based on the type of infringing activity involved" (4.12 [3] [B] [iii]).

77 Afirmando que para dar sentido a la política, el ISP debe determinar cómo se va a identificar a un usuario como un infractor reincidente.

78 "[... $]$ reasonably implemented [...] suggests both that the policy in fact must be implemented, but also that it may be reasoanle, rather than stricty implemented" (4.12 [3] [B] [iii]).

79 "From the provider's point of view, terminating any customer's access is a distasteful prospect because every user's continued access translates into revenue for the provider and users whose access is terminated can usually take their business to a competitor" (p. 95).

80 Indicando que la mayoría de las veces las instituciones educativas van más allá de su obligación legal. Esta reacción puede estar justificada por la intención de educar un buen ciudadano y también por las presiones de las industrias de derechos de autor. 
de estricto cumplimiento y respeto a la protección de derechos de autor, también puede afectar la transformación del proceso de aprendizaje, a veces sin obligación o necesidad.

En una encuesta realizada por Laura Quilter que incluyó entrevistas con los administradores de tecnología de la información y abogados de ocho instituciones educativas (Universidad de California, la Universidad de Cornell, la Universidad de Georgetown, del Instituto de Tecnología de Georgia, la Universidad de Indiana, Reed College, Stanford y la Universidad del sistema de Texas) se hizo evidente que estas universidades terminan la cuenta de los estudiantes después de haber recibido solo una notificación de presunta infracción y sin siquiera analizarla adecuadamente (Quilter \& Heins, 2007, pp. 20-21) ${ }^{81}$. Por ejemplo, la Universidad de Indiana termina cuentas de los estudiantes después de recibir la primera notificación y sin antes realizar una investigación al respecto, especialmente, tras recibir una notificación por el uso de sistemas peer-to-peer ${ }^{82}$. Igualmente, Stanford University otorga al supuesto infractor solo dos días hábiles después de recibir la notificación de derechos de autor para establecer que el contenido infractor se ha eliminado y pasar un cuestionario de cinco preguntas. Si el estudiante no cumple con estas obligaciones, a continuación, el tráfico de red se restringe de forma automática (Stanford, s.f.). Georgia Tech diferencia entre el acceso a Internet y de acceso a la red, y cancela el acceso a Internet pero permite el acceso a material educativo de la escuela (Quilter \& Heins, 2007, pp. 19-20) ${ }^{83}$. Sin embargo, castigar a los suscriptores sobre la base de una sola notificación va más allá de la intención del Congreso en el establecimiento de una política de infractor reincidente (Blom, 2009, p. 55$)^{84}$. Por otra parte, los tribunales han establecido que el conocimiento

\footnotetext{
81 Describiendo las políticas.

82 El Tutorial de los derechos de autor de la Universidad de Indiana dirigido a sus estudiantes explica que con el fin de evitar ser considerado responsable de las actividades de los usuarios de su red, se sigue la DMCA. Por lo tanto, cuando se recibe una notificación de derechos de autor se actúa rápido desactivando el acceso a la red de la computadora infractora. También el estudiante es sancionado con una multa de 50 dólares y obligado a tomar un seminario de intercambio de archivos. En caso de que el estudiante sea reincidente el castigo es más fuerte. Ver Indiana University (s.f.).

83 Describiendo la política de la Universidad.

84 "Congress intended for repeat infringers to suffer a realistic threat of losing [internet] access, 'yet ISP's censorship of users based solely on a notice sent by a copyright holder goes beyond the scope of Congressional intend" (p. 55).
} 
de reincidencia no puede imputarse solamente basado en la recepción de notificaciones de infracción ${ }^{85}$.

Por lo tanto, esta situación establece que mientras la OCILLA exige a las instituciones educativas terminar cuentas de los estudiantes infractores y decidir cuándo y cómo cumplir con esta obligación, pone a estas instituciones en una situación donde tienen que dar prioridad a las notificaciones de los titulares de derechos de autor sobre el acceso a Internet de los estudiantes con el fin de obtener protección. Esta decisión es problemática por varias razones. En primer lugar, con toda claridad, impedir el acceso a Internet de un estudiante luego de ser acusado de infracción a los derechos de autor limita severamente el acceso a la información de dicho estudiante. Tener un amplio acceso a material educativo es uno de los beneficios de implementar el uso de las TIC en la educación ${ }^{86}$. Por otra parte, cortar el acceso a Internet a los estudiantes es problemático en un sistema educativo que pretende adoptar nuevas metodologías educativas basadas en la utilización de las capacidades de información y comunicación de la tecnología. Si los estudiantes en un proceso de aprendizaje transformado se dejan fuera de Internet, a continuación, se les deja fuera del desarrollo e interacción en el mundo académico ${ }^{87}$. Por último, tener que cortar el acceso a Internet para obtener la protección de la responsabilidad puede disuadir a las instituciones educativas de adoptar un proceso de aprendizaje transformado sólido donde el Internet se encuentre en el centro del proceso.

\section{Afectación al desarrollo de nuevas metodologías necesarias en un proceso de aprendizaje transformado.}

\section{Iniciativas de aprendizaje permanente y de colaboración.}

Existen dos metodologías importantes para un nuevo proceso educativo: aprendizaje permanente y de colaboración ${ }^{88}$. Los mismos tipos de herramientas sirven tanto para desarrollar metodologías de colaboración como de aprendizaje

85 Ver Corbis Corporation vs. Amazon.com (2004). La posición fue también adoptada en UMG Recordings Inc. vs. Veoh Networks Inc (2009) (traducción no oficial realizada por la autora).

86 Ver capítulo 1.

87 Ver capítulo 1.

88 Ver capítulo 1. 
permanente como lo son: wikis, blogs y plataformas de contenido generado por los usuarios. Estas herramientas facilitan metodologías de colaboración en la medida en que promueven la comunicación y el intercambio entre alumnos y profesores (U.S. Department of Education, 2010, p. 18), y promueven el aprendizaje permanente ya que permiten a cualquier persona participar en la enseñanza y en el aprendizaje. Como se mencionó anteriormente, un ejemplo de herramienta útil para este tipo de metodologías es YouTube EDU ${ }^{89}$, así como el propio YouTube, cuya importancia fue reconocida por el Plan Tecnológico Nacional de Educación 2010 afirmando que: "contenido multimedia creado por profesores y alumnos, blogs a podcasts, los vídeos de YouTube o creaciones y representaciones en los mundos virtuales [...] enriquecen el aprendizaje " (U.S. Department of Education, 2010, p. 18). Por lo tanto, las herramientas como YouTube EDU y YouTube se han convertido en un importante instrumento para el desarrollo y la formación de la nueva sociedad, aunque no fueron desarrollados inicialmente para tal fin.

No obstante, el procedimiento de bajada de contenidos puede alterar o afectar el potencial de estas herramientas para la educación, inclusive si no existe infracción a los derechos de autor, ya que la inclusión de obras protegidas durante la utilización de este tipo de herramientas, como se haría en cualquier salón de clase, podría significar la bajada de la lección como parte de cumplimiento de dicho procedimiento.

En el procedimiento de bajada de contenidos la notificación enviada por el titular del derecho de autor es una herramienta de gran alcance ${ }^{90}$, en el sentido de que los ISP cumplen con ella de manera expedita con el objetivo de recibir la protección del OCILLA. Los problemas surgen, especialmente, cuando la notificación es falsa, o no existe infracción de derechos de autor, o el contenido infractor ha sido identificado erróneamente, pero de igual manera el ISP cumple con la notificación bajando el contenido. Esto sucede ya que el ISP, en general, prefiere errar a favor de los titulares de derechos de

$89 \quad$ Ver https://www.youtube.com/t/education

$90 \quad$ Ver Seltzer (2010): "The treat of secondary liability induces service providers to comply with the DMCA's notice-and-takedown provisions" (p. 177); ver también Reuveni (2013): "This reversal [counter-notification] combined with the safe harbor creates a set of incentives that facilitate over claiming by content owners and zealous takedowns by ISPs eager to keep their inmmunity" (p. 791). 
autor y cumplir con notificaciones dudosas en lugar de apoyar al usuario ${ }^{91}$. La razón de este tipo de actitud se debe a que, bajando el contenido, los ISP se protegerán de responsabilidad de derechos de autor. Sin embargo, si los ISP se equivocan al no cumplir con una notificación de bajada de contenidos basado en la creencia de que dicha notificación es falsa, o que no hay infracción de derechos de autor, o que el contenido infractor fue identificado erróneamente, los ISP perderían la protección de puerto seguro ${ }^{92}$.

Adicionalmente, la manera como el procedimiento de bajada de contenidos fue diseñado hace que sea fácil para el titular de los derechos de autor enviar una notificación, ya que sólo requiere creer de buena fe que el uso de la obra que está realizando el usuario es un uso infractor ${ }^{93}$. De esta forma, los titulares de derechos de autor a veces simplemente no analizan si el supuesto uso no autorizado está cubierto por el fair use (Garon, 2013, p.523) ${ }^{94}$ o hacen uso de un software que envía notificaciones de manera automática, los cuales también evitan este tipo de análisis (Carroll, 2014, p. 424$)^{95}$. Igualmente, a veces se envían notificaciones sin ninguna prueba

91 Ver Urban y Quilter (2005), explicando algunas de las críticas hechas al procedimiento de bajada de contenidos (p. 638); ver también Blom (2009): "[...] ISPs have no incentive to verify the authenticity of the notices they receive" (p. 54).

92 Ver Urban y Quilter (2005), explicando algunas de las críticas hechas al procedimiento de bajada de contenidos (p. 638); ver también Seltzer (2010): "The law offers service providers protection from copyright liability if they remove material "expeditiously" in response to unverified caomplains of infringement" (pp. 175-176).

93 Ver 17 U.S.C $\$ 512$ (c) (3) (A) (v); ver Seltzer (2010): “[ . . ] the promise of rapid takedown creates an incentive for copyright claimants to file dubios takedown claims" (p. 178); ver Reuveni (2013): "Essentially, The DMCA makes too easy for inapropiate claims of infringement to produce takedowns [...]" (p. 791); ver también Gilden (2013): "Copyright holders have stretched this 'good faith' requirement quite far, and some estimate that roughly one-third of DMCA takedown notices stand on shaky legal ground" (p. 1176). Los tribunales han analizado el requisito de buena fe. En el caso Rossi v. Motion Picture Ass'n of America Inc (2004), el tribunal sostuvo que la buena fe es un análisis subjetivo y no objetivo. Esta situación crea una alta carga de la prueba a favor del acusado si quiere hacer uso de la acción de falsa representación. Sin embargo, en Lenz vs. Universal Music Corp (2008), el tribunal sostuvo que con el fin de tener una creencia de buena fe el titular de los derechos de autor debe analizar primero si el uso es un uso justo. Ver también Miller (2010, pp. 1721-1722).

94 "Although copyright holders must have a good faith determination that the material uploaded by third parties violates their exclusive rights, this may not mean that the copyright holders make bona fide assessments of fair use" (p. 523).

95 "[...] some copyright owners have invested in automated enforcement by relaying on computer algorithms to identify the presence of a copyrighted work-usually recorded 
de infracción ("No Downtime for Free Speech", s.f.) o simplemente utilizan el mecanismo para bajar el contenido que no les gusta (Mulligan, 2013, p. 181$)^{96}$. De este modo, el ISP termina bajando casi cualquier material identificado como infractor en una notificación ${ }^{97}$, a pesar del hecho de que el uso de dichos materiales a veces se puede permitir bajo la doctrina de fair use (Seltzer, 2010a, p. 210) ${ }^{98}$ o simplemente no infringe o no está relacionado con los derechos de autor (Garon, 2013, p. 523) ${ }^{99}$.

Por otra parte, a veces los titulares de derechos de autor ni siquiera tienen la necesidad de emitir una notificación de derechos de autor en sentido estricto para bajar el contenido. Algunos ISP han desarrollado un software de identificación de contenido para combatir la infracción a los derechos de autor (Mehra \& Trimble, 2014, p. 691) ${ }^{100}$. De esta manera, cuando el software detecta una coincidencia entre el contenido subido por el usuario y el archivo del titular del derecho de autor, proporcionado anteriormente al ISP, el software baja automáticamente el contenido. Ejemplos de este tipo de software lo encontramos en el Content ID de YouTube y el hash filtering software de Veoh (pp. 691-692) ${ }^{101}$. No obstante, como se mencionó anteriormente, este tipo de software de identificación de contenido no puede determinar si el usuario hizo un fair use del contenido.

music or video- and to send an automated take-down notice to service providers without regard to whether the use of the work might be a fair use" (p. 424).

96 " $[\ldots]$ there is very little motivation for a person no to send a takedown notice for content they do not like" (p. 181).

97 Jamar (2010): “[...] Indeed, cases such as Lenz v. Universal Music Corp., where the court established that fair use must be considered before a Digital Millennium Copyright Act (DMCA) takedown notice [...] illustrate how copyright holders can chill even the most innocent of postings to YouTube" (p. 845); ver tambien Raymond (2013), estableciendo que bajo el procedimiento de bajada de contenidos del DMCA "[...] any claim of infringing activity results in the material being removed at least temporarily" (p. 473, ๆ33).

98 Hablando sobre la afectacion de procedimiento de bajada de contenidos a los usos permitidos: "[some scenarios] are too close to the edge between infringement and fair use to be decided accurately by the summary procedures of a service provider reviewing a § 512(c) notice" (p. 210).

99 Además, puede haber otras razones para bajadas erróneas tales como errores en la identidad de los proveedores de contenido o errores en cuanto a la fuente de la obra.

100 Indicando que algunos proveedores de Internet ofrecen herramientas de identificación de contenido a los titulares de derechos de autor.

101 Estableciendo los ejemplos de Veoh y YouTube. 
Trasladando esta realidad del procedimiento de bajada de contenidos al uso de plataformas como YouTube, entre otras, para incursionar en metodologías de colaboración y de aprendizaje permanente, nos muestra como dichas iniciativas han sido víctimas del proceso y tienen potencial de seguir siendo víctimas. Un ejemplo del procedimiento de bajada de contenidos utilizado para disuadir estas metodologías es el caso de la profesora de derecho Wendy Seltzer. La profesora Seltzer utilizó un canal de YouTube para publicar un video con fines educativos (Cobia, 2009, p. 369), el cual incorporaba un clip corto sobre la política de derechos de autor y de difusión de la Liga de Fútbol Nacional con la finalidad de hacer algún comentario o crítica de ello con propósitos educativos. No obstante, la Liga Nacional de Fútbol envió una notificación de derechos de autor con base en la DMCA para bajar el video, con lo cual YouTube obedeció (p. 369)102. Es importante recordar que el uso del material por parte de la profesora Seltzer muy probablemente representaba un fair use, no obstante, el video fue eliminado. Otro ejemplo similar al de la profesora Seltzer es el caso del profesor Larry Lessig, quien subió un video a YouTube explicando la doctrina del fair use (17 U.S.C § 107). En su video y como ejemplo para demostrar su punto, Lessig utilizó un fragmento de una canción de Warner Music, sin embargo, YouTube eliminó el video en cumplimiento con la $\mathrm{DMCA}^{103}$.

Estos dos ejemplos ilustran que a pesar de los intentos de los maestros para hacer uso de las tecnologías para promover el aprendizaje permanente y un ambiente de aprendizaje colaborativo el procedimiento de bajada de contenidos inhibió esta posibilidad. Esta situación puede desalentar el uso de la comunidad académica de esta tecnología para compartir sus conocimientos y participar más en las actividades educativas utilizando las herramientas Web 2.0 a disposición del público.

Del mismo modo, las políticas de bajada de contenidos excesivamente agresivas de las ISP pueden afectar el desarrollo de las actividades de colaboración en clase y de colaboración en comunidades de aprendizaje. Por ejemplo, un maestro puede asignar un proyecto de clase que requiera a sus estudiantes crear un informe utilizando herramientas como Google Docs, el cual permite a cada uno de los estudiantes transformar y contribuir a la

\footnotetext{
102 Describiendo el caso de la profesora Wendy Seltzer.

103 Lessig (2009); ver también (Masnick, 2010).
} 
obra. Esta actividad promueve la colaboración en su clase ${ }^{104}$. Sin embargo, si el proyecto se encuentra en una carpeta compartida -como debe ser con el fin de permitir la colaboración- un proveedor de Internet podría bajarla de la Web si un titular de derechos de autor decide enviar una notificación. Esta situación ocurrió cuando Warner Brothers envió una notificación de derechos de autor solicitando que un ISP bajara un archivo llamado "Reporte del libro Harry Potter", el cual se encontraba ubicado en una carpeta compartida. Al parecer, el titular de los derechos de autor había confundido el archivo con una copia ilegal de la película (Mark, 2003). Como se puede ver el titular de los derechos de autor no prestó mucha atención al archivo que contiene el nombre de "Harry Potter" antes de identificarlo como presuntamente infractor.

Por otra parte, en virtud del procedimiento de bajada de contenido el ISP es quien decide cómo cumplir con la notificación de derechos de autor. En otras palabras, el ISP decide cuánto del contenido identificado como presuntamente infractor debe ser eliminado o desactivado una vez que reciba la notificación. No obstante, esta situación ha generado algunas reacciones exageradas por parte de los ISP (Seltzer, 2010, p. 205) ${ }^{105}$, quienes como se mencionó anteriormente, prefieren errar hacia el lado de los titulares de derechos de autor. Dichas exageraciones también afectan actividades de colaboración, como en el caso de Edublogs. En el capítulo 1 se mencionó la importancia de Edublogs ${ }^{106}$ como un servicio que ofrece alojamiento de blogs para los profesores ("Why Educators use Blogs", s.f.) o para escuelas y universidades con fines educativos, que sirve para realizar actividades de colaboración $^{107}$. Un ejemplo del uso de Edublogs como una comunidad de aprendizaje es el blog de Larry Ferlazzo, el cual, ofrece consejos de enseñanza y estrategias de gestión del aula con base en sus experiencias, demostrando cómo una comunidad de aprendizaje funciona como una herramienta para mejorar el acceso a los recursos y experiencias entre personas con intereses comunes ${ }^{108}$.

104 Ver capítulo 1 sobre colaboración en clase.

105 Estableciendo que la forma como la DMCA está establecida puede generar respuestas exageradas por parte del ISP.

106 Ver Edublogs en http://edublogs.org/why-edublogs/

107 Ver capítulo 1 sobre actividades o metodologías de colaboración.

108 Por ejemplo, los profesores intercambian consejos entre ellos en sus blogs. Para ejemplo ver Ferlazzo (octubre de 2009). 
Sin embargo, a pesar del evidente valor de este recurso, en 2012, Edublogs y sus 1,45 millones de blogs fueron bajados como el resultado del envío de una sola notificación del DMCA. Sucedió cuando el servidor host de Edublogs, ServerBeach, recibió una notificación de DMCA por parte de Pearson sobre una única página que contenía un cuestionario con derechos de autor (Brodkin, 15 de octubre de 2012). Aunque Edublogs eliminó rápidamente el contenido después de recibir la notificación por parte de su ISP, ServerBeach decidió apagar temporalmente todos los 1,45 millones de blogs durante unos 60 minutos hasta que se confirmó que el cuestionario se había retirado (Brodkin, 15 de octubre de 2012).

Este caso es ligeramente diferente de los anteriores. En los casos anteriores, la política de protección de derechos de autor excesiva permitió a los titulares de derechos de autor abusar del procedimiento de bajada de contenidos. Esos titulares de derechos de autor impidieron la realización de fair uses de obras protegidas con derechos de autor o por error reclamaron derechos de autor sobre algunos materiales utilizados en actividades de aprendizaje permanente y comunidades de aprendizaje ${ }^{109}$. No obstante, en este caso, los hechos publicados no permiten determinar si en realidad el cuestionario estaba infringiendo los derechos de Pearson. Sin embargo, independientemente de este hecho, el ISP, en la eliminación de una pieza de contenido presuntamente infractor, ejerció daños colaterales en 1,45 millones de iniciativas no infractoras. De este modo, dicho caso ilustra que, con arreglo al procedimiento de bajada de contenidos, los ISP no dudarían en cumplir con una notificación, inclusive si van a afectar a millones de usos educativos.

No obstante, el caso de Edublogs no solo es producto de la cantidad de poder otorgado a los titulares de derechos de autor para eliminar el contenido, sino también de la insuficiencia del régimen ISP para regular los servicios de reventa. Esto sucede cuando un ISP revende servicio a otros ISP que a su vez aloja el contenido del usuario. Si el primer ISP quiere cumplir con el puerto seguro de almacenamiento del usuario, a continuación, tendrá que desactivar el acceso a todo un sistema ya que es técnicamente restringida la posibilidad de deshabilitar el acceso al contenido del segundo proveedor de

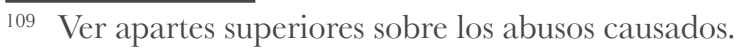


Internet (Ballon, 2009, p. 1241). En este caso, varios usuarios se ven afectados por la notificación de derechos de autor (p. 1242).

Como se explicó anteriormente, el procedimiento de bajada de contenido establece un procedimiento para el restablecimiento de dicho contenido, y que puede ser utilizado por los creadores de iniciativas colaborativas o de aprendizaje permanente para proteger su contenido. No obstante, en la práctica, no hay certeza que los materiales bajados por error serán reemplazados después de la retirada "temporal". Esto sucede porque una vez la contranotificación ${ }^{110}$ es notificada al usuario, el procedimiento de bajada de contenidos hace difícil para éste que su contenido sea restaurado ${ }^{111}$. La razón de esto es que el usuario tiene una carga más pesada al momento de enviar una contranotificación que aquella que tiene el titular de los derechos de autor al enviar una notificación. En primer lugar, el usuario debe aceptar la jurisdicción de los tribunales de Estados Unidos con el fin de presentar una contranotificación. Esta sola situación ya inhibe el uso de la herramienta (Loren, 2011, p. 759) ${ }^{112}$. Además, la contranotificación requiere hacer una declaración bajo pena de perjurio, que "el usuario tiene la creencia de buena fe que el material fue removido o inhabilitado como consecuencia de un error o identificación errónea" (17 U.S.C § 512 (g) (3) (G)) (traducción no oficial realizada por la autora). El titular del derecho de autor, por el contrario, solo necesita realizar bajo pena de perjurio una declaración que establezca que está autorizado para actuar en nombre del titular de los derechos (§512 (c) (3) (A) (vi)) y que tiene una creencia de buena fe que el uso no está autorizado por el titular del derecho de autor o por la ley (§ 512 (c) (3) (A) (v)). Como consecuencia de la carga más pesada, los usuarios raramente envían contranotificaciones ${ }^{113}$.

${ }^{110}$ Ver sección previa sobre la contranotificación.

111 Ver Urban y Quilter (2005), estableciendo que no hay certeza de que el contenido sea restablecido (p. 639); ver Seltzer (2010a): "Because the agent-service [ISP] does not share all the benefits of the principal-poster, the agent lacks a similarly strong incentive to take risks in defending posted material in the face of a complaint" ( $p$. 180); ver también Yen (2000): "As long as ISPs remove material upon the formal request of content providers and follow DMCA procedures, subscribes are barred from recovery" (p. 1888).

112 Estableciendo que los requisitos de identificación y aceptación de jurisdicción "[...] will cause many individuals to pause before sending one" (p. 759).

113 Ver Cobia (2009), estableciendo que las contranotificaciones son enviadas rara vez (pp. 391-393); ver Reuveni (2013), hablando sobre la contranotificación: "Facing 
Adicionalmente, los ISP pueden evitar el cumplimiento de contranotificaciones a través de cláusulas contractuales afirmando que se reservan el derecho de bajar cualquier contenido y cerrar cuentas ${ }^{114}$. Un ejemplo de los ISP utilizando obligaciones contractuales para eludir el cumplimiento de contranotificaciones es YouTube. En su política, YouTube determina que algunos acuerdos con propietarios de derechos de autor de música establecen que algunas obras musicales se bajarán y su restauración está prohibida, incluso después de que se reciba una contranotificación (YouTube Help, s.f.). Esta política significa que incluso si la contranotificación tiene un reclamo válido de fair use, YouTube no sustituirá el video. Por otra parte, los términos de servicio de YouTube establecen que puede restaurar el contenido eliminado después de la recepción de una contranotificación a su entera discreción (YouTube, 2010) ${ }^{115}$. Por lo tanto, YouTube está protegido de responsabilidad contra el usuario por la eliminación de contenido.

Esta política se ha aplicado en la práctica: un YouTuber publicó un video comentando sobre el récord de música de Eric B. \& Rakim de 1980. En este video de siete minutos el usuario comentó sobre los videos y presentó clips cortos de algunos segmentos de los récords. Universal Music Group (UMG) envió una notificación de DMCA, y YouTube bajó el contenido. El usuario, confiado en que sus usos de los cortos segmentos de pocos registros

the choice of litigating property of their post or accepting the takedown, only those with time and resources will choose the former, expensive path" (p. 791); ver también Loren (2011): "[...] users often are unaware of the ability to send a counter-notice and may even be unaware that material they posted has been removed" ( p. 759).

114 Ver Seltzer (2010): "In practice, most service providers have placed clauses in their terms of service to preemptively avoid liability to their subscribers, making their restoration of material in compliance with the counter-notifications wholly optional" (p. 203); ver Urban \& Quilter (2005): "However, while in theory an OSP might be subject to some sort of contractual liability for a wrongful takedown of content, in practice, OSPs limit their liability with their terms of service" (p. 629); ver también Loren (2011), hablando sobre el riesgo de un ISP de ser demandado por bajar contenido de un usuario: "[it] is often minimal due to limitations on liability that most service providers insist upon their contracts with users" (p. 758).

115 Términos y condiciones: "If a counter-notice is received by the Copyright Agent, YouTube may send a copy of the counter-notice to the original complaining party informing that person that it may replace the removed Content or cease disabling it in 10 business days. Unless the copyright owner files an action seeking a court order against the Content provider, member or user, the removed Content may be replaced, or access to it restored, in 10 to 14 business days or more after receipt of the counternotice, at YouTube's sole discretion.” (párr 6, literal B, numeral 8). 
constituían fair use, envió una contranotificación. Sin embargo, YouTube rechazó la petición sobre la base de sus obligaciones contractuales (McKay, 2013). Bajar este video, por tiempo indefinido, no solo inhibe la posibilidad de utilizar la obra como material de aprendizaje para alguien interesado en la historia del rap, sino que también pone de manifiesto que el procedimiento de bajada de contenidos puede afectar a algunas otras iniciativas educativas.

Es importante tener en cuenta que los recursos como YouTube son útiles no solo fuera de las aulas, sino también como un soporte multimedia para cursos al interior del aula. En otras palabras, estos recursos se utilizan como un recurso educativo en la educación formal. Este es el ejemplo que mencionábamos en el capítulo 1 acerca del uso en los salones americanos de videos de Disney para explicar conceptos complejos (Light \& Polin, 2010, p. 15). Esas herramientas multimedia son útiles para la educación ya que permiten la enseñanza de la información de una manera más natural a los estudiantes ${ }^{116}$. Por lo tanto, este tipo de herramientas no deben ser restringidos o limitados sin ningún motivo como se ha hecho por el procedimiento de bajada de contenidos.

No obstante, el procedimiento de bajada de contenidos no es el único mecanismo de protección de derechos de autor que afecta la incorporación de nuevas metodologías para la educación. La protección de medidas tecnológicas de protección, bajo los términos de la DMCA, también tiene la capacidad de afectar el desarrollo de las metodologías de colaboración. Como se explicó anteriormente, las metodologías colaborativas requieren la participación activa de cada participante en el proceso de aprendizaje - cada estudiante y maestro- con el fin de generar su propio conocimiento ${ }^{117}$. Esto también es cierto acerca de las comunidades de aprendizaje, las cuales requieren una participación activa de cada miembro de la comunidad con el fin de contribuir al intercambio de aprendizaje ${ }^{118}$. Aunque el intercambio y la experiencia de colaboración lograrían ser más fructíferas si obras enteras pudieran compartirse, no es posible debido a los titulares de los derechos ya que también deben beneficiarse de sus creaciones, por lo cual, se debe acudir, muchas veces, a los usos permitidos de las obras con derechos de autor

\footnotetext{
116 Ver capítulo 1.

117 Ver capítulo 1.

118 Ver capítulo 1.
} 
para promover estas actividades. Por ejemplo, un profesor puede iniciar un debate en clase en un blog compartiendo un extracto de un artículo sobre un tema, lo cual es un uso permitido de la obra protegida, y tomar ventaja del mundo digital "lleno de recursos y oportunidades de colaboración" (U.S. Department of Education, 2010, p. xii).

Sin embargo, la protección a TPM ha afectado, incluso, la capacidad de hacer usos permitidos de material con derechos de autor ${ }^{119}$. Las TPM bloquean la posibilidad de hacer fair use de copias digitales de obras. Por ejemplo, si el mismo profesor mencionado anteriormente quiere copiar y pegar un breve extracto de un libro electrónico en el blog del Entorno Virtual de Aprendizaje (EVA) o en herramientas como Edublogs para promover la discusión entre sus estudiantes, si dicho material está protegido por una TPM, esta actividad no sería posible (Seltzer, 2010b, p. 918) ${ }^{120}$. Igualmente, los estudiantes que quieren ofrecer otros recursos en la discusión del blog o apoyar su opinión con otras obras con derechos de autor se encontrarán en la misma situación. Por otra parte, el desarrollo de actividades de colaboración dentro de la comunidad de aprendizaje estaría afectado de la misma manera. Esta situación sin duda afecta el desarrollo de un proceso de aprendizaje colaborativo, donde todos los actores del proceso de aprendizaje deben ser capaces de utilizar, compartir, transmitir y transformar materiales, ya sea en virtud de una licencia o de un fair use aprovechando las bondades de las TIC.

La situación anteriormente descrita se origina a causa de las disposiciones contra el tráfico de servicios y dispositivos elusivos de la DMCA (Hinze, 2007, p. 799). Las TPM que controlan los usos de una obra con derechos de autor (o TPM de control de copia), como el descrito en el ejemplo anterior, buscan proteger los derechos exclusivos del titular de los derechos de autor; es decir, las medidas tecnológicas de protección buscan controlar la reproducción, distribución, transformación y comunicación. Sin embargo, como estos derechos son limitados, la DMCA permite la elusión de una

119 Ver Hinze (2007), afirmando que la DMCA permite a los titulares de derechos de autor controlar el uso de su obra, incluso cuando la legislación nacional del derecho de autor permite tales usos (p. 797); ver Benchell (2002): "the DMCA makes any use, fair or not, illegal" (p. 15).

120 Hablando sobre las críticas sobre las TPM por sus efectos sobre los usos permitidos: "[...] in a DRM-encumbered world, [...] a literacy critic is blocked from extracting e-book pages (or has the e-book deleted out from under her)" (p. 918). 
medida de control de copia con el fin de permitir tales usos (Lipton, 2005, p. 120$)^{121}$. Esto significa que en el ejemplo mencionado anteriormente, el profesor o los estudiantes podrían haber eludido esta medida de control de copia con el fin de utilizar el extracto del libro sin ser sancionados. No obstante, dicho profesor o estudiantes solo lo lograrían si fueran un usuario tecnológicamente bien informado ${ }^{122}$, debido a la prohibición del tráfico de servicios o dispositivos diseñados principalmente para la elusión ${ }^{123}$. En este sentido, solo los profesores y los estudiantes tecnológicamente sabiondos estarían habilitados para hacer fair uses de contenido protegido (Samuelson, 1999, p. 551) $)^{124}$, y así participar en el aprendizaje colaborativo. Por otra parte, las disposiciones contra el tráfico de dispositivos y servicios solo están sujetas a las excepciones de ingeniería inversa (17 U.S.C § 1201 (f) (2)), la cual tiene alcances muy limitados dejando por fuera el escenario (Kaplan, 2003, p. 7$)^{125}$ en el que se necesita hacer elusión para incurrir en usos autorizados.

Igualmente, los usuarios tecnológicamente bien informados solo podrán utilizar sus mentes y manos para eludir las medidas tecnológicas de protección. Esto se debe a que cada dispositivo para eludir está prohibido, al igual que la fabricación de un dispositivo ${ }^{126}$. De esta manera, inclusive

121 "There is, however, no specific restriction on circumventing a copy-control measure because of the Congressional intention to preserve this fair use of copyrighted works" (p. 120).

122 Yi-Jun (2005), indicando que el usuario necesita tener conocimiento de descifrado con el fin de ser capaz de hacer usos justos de un contenido protegido por un DRM de control de copia (p. 771-772); ver también Sharp (2002): "Unless the proverbial faculty member is a skilled hacker, statements about the sanctity and preservation of fair use under the DMCA provide little help in making fair use of technologically locked content" (p. 41).

123 Ver Yi-Jun (2005), indicando que para un usuario es difícil eludir una medida de control de copia debido a la prohibición de los dispositivos para ese propósito (pp. 771772); ver Hinze (2007), afirmando que en la práctica no hay herramientas disponibles para hacer los usos permitidos (p. 779); ver también Lipton (2005), estableciendo que muchos usuarios no tienen el conocimiento para eludir una medida tecnológica de control de copia (p. 125).

124 "It is unclear whether Congress intended for the technologically savvy who could 'do it themselves' to be the only ones who could engage in privileged acts of circumvention" (p. 551).

125 Hablando sobre las siete excepciones: "[...] it is fair to say that these exemptions are narrow and difficult to satisfy" (p. 7).

126 Ver 17 U.S.C § 1201 (b) (1); ver también Samuelson (1999): [...] even the technically sophisticated will often need to develop a tool to accomplish a privileged 
los usuarios tecnológicamente bien informados no podrían hacer fair uses, si para practicar dicha elusión requiriera de la ayuda de un dispositivo. Como resultado de las disposiciones de TPM, los profesores y los alumnos, especialmente aquellos que no sean tecnológicamente bien entendidos, no podrán hacer fair uses para realizar actividades de colaboración a pesar de que dichos usos están permitidos bajo la ley de derechos de autor ${ }^{127}$.

Podrían existir, por supuesto, algunos argumentos en contra de la posición de este libro, afirmando que la protección de medidas tecnológicas de protección no afecta el desarrollo de la educación en colaboración. Por ejemplo, en el caso del e-libro, se puede afirmar que el profesor podría transcribir el extracto logrando realizar los fair uses en el proceso de colaboración, al igual que sus alumnos. No obstante, no pasaría lo mismo en el caso de un profesor de música que tiene que hacer uso de un extracto de una grabación sonora, si es que la grabación está protegida por TPM; o el caso de un profesor de artes visuales que requiera utilizar algunos extractos de una película en el blog de una clase (Seltzer, 2010b, p. 918) ${ }^{128}$. En estos casos, siguiendo el proceso de pensamiento de algunos tribunales, se podría argumentar que el profesor puede utilizar una grabadora para grabar el extracto de la canción que necesita y luego descargarlo en su ordenador y finalmente subirlo al VLE ${ }^{129}$. Sin embargo, estos argumentos no son válidos dentro de un proceso de aprendizaje transformado, ya que, incluso si una obra se puede encontrar de otra manera, tener que acudir a este otro formato no permite a la comunidad de aprendizaje tomar ventaja de la tecnología y

circumvention; this would seem to put them at risk under a strict reading of section 1201(b) (1)" (p. 551).

127 Ver Yi-Jun (2005), afirmando que las disposiciones contra la elusión no posibilitan hacer usos justos permitidos bajo la ley de derechos de autor tradicional (pp. 779790); ver también Kaplan (2003): "[...] technological means of controlling access to copyrighted works, at least at this stage, cannot distinguish between fair and infringing uses. Unless circumvented, the foreclose both" (p. 7).

128 Hablando sobre las críticas de TPM por sus efectos en usos permitidos: "[...] in a DRM-encumbered world a media educator cannot cue movie clips for classroom commentary without special exemption" (p. 918).

129 Por ejemplo, en Universal City Studios, Inc. v. Corley 2001 se estableció: “[...] the DMCA does not impose even an arguable limitation on the opportunity to make a variety of traditional fair uses of DVD movies, such as commenting on their content, quoting excerpts from their screenplays, and even recording portions of the video images and sounds on film or tape by pointing a camera, a camcorder, or a microphone at a monitor as it displays the DVD movie" (p. 459). 
hacer uso de ésta para mejorar la educación. Además, la calidad del material no será el mismo, sin mencionar que se haría el proceso más complicado y costoso. Si nos apegamos a este modo de pensamiento sería más fácil para los profesores seguir utilizando un entorno educativo tradicional. De igual manera, se podría argumentar que el proceso colaborativo se podría realizar con recursos que permitieran su uso como recursos educativos abiertos o recursos bajo una licencia de Creative Commons. Sin embargo, no hay ninguna razón para impedir el uso de recursos de calidad con derechos de autor en el aula, simplemente porque están protegidos por un TPM.

Las consecuencias no son sustancialmente diferentes si la TPM impuesta al material educativo es una medida de control de acceso en lugar de una medida de control de copia. Las medidas de control de acceso pueden inhibir la capacidad de los profesores, investigadores y estudiantes de acceder inclusive a las obras de dominio público ${ }^{130}$. Afectar el acceso y usos de obras de dominio público puede socavar importantes usos educativos, como lo serían iniciativas de colaboración. Las obras de dominio público son libres de compartir, transformar y utilizar de alguna manera, lo que debería mejorar las oportunidades de colaboración sin preocupaciones legales.

Aunque el proceso de elaboración de normas administrativas fue creado para resolver circunstancias en las que los usos no infractores están siendo $\operatorname{afectados}^{131}$, este procedimiento no ha podido resolver el problema de la imposibilidad de hacer fair uses y tener acceso a material educativo (Kaplan, 2003, p. 7$)^{132}$. Uno de los problemas de este procedimiento es que la excepción resultante solo se aplica a la prohibición de elusión de una TPM de control de acceso, pero no a las disposiciones contra el tráfico de dispositivos y servicios ${ }^{133}$.

130 Ver sección posterior sobre los efectos causados por una medida de control de acceso.

131 Ver sección previa sobre el proceso de elaboración de normas administrativas.

132 Ver Kaplan (2003), hablando sobre el procedimiento administrativo: "[...] these legislative safety valves have not satisfied criTIC of the DMCA" (p. 7); ver también Lipton (2005): "The limited scope of the determinations is somewhat disappointing from the perspective of protecting legitimate interests in copyrighted works from restrictive DRM measures bolstered by the DMCA" (p. 121).

133 Ver 17 U.S.G $\$ 1201$ (a) (1) (B); ver McCardle (2004), indicando que estas excepciones solo se aplican al acto de eludir una medida de control de acceso (pp. 1023-1025); ver también Hinze (2007), indicando que uno de los mayores problemas del procedimiento de elaboración de normas administrativas es que sus excepciones no se aplican a la prohibición de dispositivos de elusión (p. 799). 
Por lo tanto, como en el caso de una TPM de control de copia donde el problema es la falta de herramientas o servicios para hacer la elusión permitida, los procedimientos no permiten a los usuarios hacer uso práctico de las nuevas excepciones o de las normas existentes de fair use (Lipton, 2005, p. 135) ${ }^{134}$.

No obstante, los tribunales estadounidenses han negado el argumento de que la prohibición de dispositivos y servicios erosionan el fair use. En el caso Elcom, el tribunal estableció que el fair use no otorga ningún derecho a hacer el uso tecnológicamente más conveniente. El tribunal entiende que las TPM hacen aún más difícil realizar fair uses, pero no imposible (Amicus Curiae Brief of Electronic Frontier Foundation, 2002) ${ }^{135}$. Sin embargo, si se requiere que los estudiantes y profesores adquieran otras tecnologías para lograr hacer un fair use de una obra protegida por TPM (como un tribunal sugirió en el contexto de grabar el extracto de una canción o partes de una película $)^{136}$, entonces el precio de educación aumentará, al igual que hará difícil promover el uso de metodologías de colaboración en clase o participar activamente en una comunidad de aprendizaje.

Otra manera en que las disposiciones de TPM pueden afectar la realización y consolidación de actividades de colaboración como la creación de comunidades de aprendizaje se presenta especialmente en el campo de la investigación de cifrado. Como se ha explicado anteriormente, las comunidades de aprendizaje tratan de traer a los estudiantes y profesores no solo el acceso a los recursos fuera de las aulas, sino también a profesores, expertos y mentores fuera del salón de clases ${ }^{137}$. La idea de las comunidades de aprendizaje es intercambiar experiencias y resolver problemas juntos(U.S. Department of Education, 2010, p. 16). No obstante, los investigadores en el

134 Hablando sobre la imposibilidad de crear excepciones a la regla de anti-tráfico: "the DMCA effectively destroys fair use when the user does not have the technological savvy to circumvent the technology nor the ability to acquire technology from others" (p. 135).

135 Ver Amicus Curiae Brief of Electronic Frontier Foundation (2002).

136 Universal City Studios, Inc. v. Corley 2001: “[...] the DMCA does not impose even an arguable limitation on the opportunity to make a variety of traditional fair uses of DVD movies, such as commenting on their content, quoting excerpts from their screenplays, and even recording portions of the video images and sounds on film or tape by pointing a camera, a camcorder, or a microphone at a monitor as it displays the DVD movie" (p. 459).

137 Ver capítulo 1. 
campo de la investigación cifrado tienen una base sólida para ser reacios a participar en comunidades de aprendizaje, como explicaremos enseguida.

La protección de medidas tecnológicas de protección se ha convertido en una herramienta para censurar la difusión de la investigación de cifrado, incluso como parte de una discusión académica. La situación comienza cuando durante su visita a los Estados Unidos para participar en una conferencia el programador ruso Dmitry Sklyarov fue encarcelado por distribuir un programa de Internet que eludía las medidas tecnológicas de protección de un e-book para convertirlo en un archivo PDF $^{138}$. Luego de dicho caso, los investigadores de cifrado han evitado la discusión y publicación de sus investigaciones debido al temor a infringir las disposiciones de la DMCA, incluso si tal discusión es con fines académicos. Por ejemplo, el criptógrafo holandés Niels Ferguson identificó algunas fallas en el sistema de cifrado de vídeo de Intel HDCP. En lugar de compartir esta información, Ferguson optó por autocensurarse y no subir sus hallazgos en su página web. Su razón para esta autocensura era su temor a ser procesado bajo las disposiciones contra la elusión de la DMCA en uno de sus viajes a Estados Unidos (Unintended Consequences, marzo de 2013). No obstante, Ferguson no fue el único investigador que, por miedo, eliminó los resultados de su investigación en Internet. Fred Cohen, profesor de análisis forense digital, y el investigador Doug Song también decidieron retirar de su página web información sobre el ámbito de la investigación de cifrado debido al temor a ser procesados bajo la DMCA (Unintended Consequences, marzo de 2013). Por último, el profesor Edward Felten de Princeton, quien identificó algunas fallas en tecnologías de encriptación de marca de agua para archivos de audio digital, fue censurado por la industria de los derechos de autor. Al final, Felten decidió que no quería presentar sus hallazgos en una conferencia debido a las amenazas que la Asociación de la Industria Discográfica de Estados Unidos había realizado en virtud de la DMCA ${ }^{139}$.

Aunque la DMCA establece una excepción en favor de la investigación de cifrado que se aplica al acto de eludir las medidas de control de acceso

138 Ver Unintended Consequences (marzo de 2013); ver también Benchell (2002), explicando el caso de Dmitry (p. 1).

139 Ver Imfeld (2003), describiendo el caso de Eduard Felten (pp. 136-138); ver también Benchell (2002), describiendo el caso de Eduard Felten (p. 2). 
y a la disposición contra el tráfico de dispositivos de elusión de control de acceso (17 U.S.C $\$ 1201(\mathrm{~g})$ ), su alcance es muy limitado (Liu, 2003, p. 509) ${ }^{140}$. Al proporcionar esta excepción, el Congreso trató de proteger el desarrollo y la libertad en el campo. No obstante, al hacerlo, se cuidaron de no crear una laguna en la protección jurídica de TPM (p. 508) ${ }^{141}$. De esta manera, la excepción solo permite la investigación de cifrado de buena fe y cuando la persona ha tratado de obtener el permiso del propietario de los derechos con antelación. De igual manera, la ley establece los factores para determinar la aplicabilidad de la excepción. Se pregunta si la persona está involucrada en un curso legítimo de estudio, si la persona esta empleada o está debidamente capacitada o con experiencia en el campo de la investigación de cifrado (17 U.S.C § 1201 (g) (3) (B)). Además, la excepción también analiza la naturaleza de la difusión de la información: ¿se difundió para avanzar en el estado del conocimiento?, o ¿fue difundido de manera que facilite la infracción? (§ 1201 (g) (3) (A) $)^{142}$. Por último, la excepción tiene en cuenta si la persona compartió los resultados con el titular de los derechos de autor $(\S 1201$ (g) (3) (C)). Así, aunque el objetivo de la excepción es promover la investigación de cifrado, el reducido ámbito de su redacción genera miedo significativo en el campo de la investigación de cifrado.

\section{Modelo de "Siempre Aprendiendo".}

Un proceso de aprendizaje transformado busca promover un modelo de siempre en el aprendizaje ${ }^{143}$. La realización de actividades educativas en clase y fuera de clase es importante para avanzar en este propósito. Como se mencionó anteriormente, una forma de lograr este objetivo es mediante el uso de los diferentes dispositivos disponibles en distintos contextos educativos,

\footnotetext{
140 "Since the passage of the DMCA, many legal and scientific commentators have criticized the exemption for being both too narrow and too vague, thereby chilling legitimate scientific encryption research" (p. 509).

141 "The exemption was essentially an attempt by Congress to preserve some freedom for encryption research while ensuring that the exemption would not create a loophole for illegitimate attempts to exploit vulnerabilities under the cover of encryption research" (p. 508).

142 En este factor se analiza si la información se difundió con el propósito de avanzar en el estado del conocimiento del área o si fue difundido de una manera que promueva la infracción.

143 Ver capítulo 1.
} 
independientemente de la ubicación del estudiante (U.S. Department of Education, 2010, p. 58) "144, beneficiándose de herramientas como la "nube".

En el capítulo 1 vimos cómo la importancia del uso de la nube ha sido declarada por la UNESCO (2013, p. 20) para ayudar a los estudiantes a aprovechar lo mejor de cada dispositivo dependiendo de la actividad que estén realizando (p. 20), y así lograr "garantizar continuidad [es] de la experiencia de aprendizaje” (p. 20). No obstante, en la práctica, esta posibilidad no se ve tan clara debido a las disposiciones de TPM de la DMCA. Aunque los estudiantes y los profesores pueden hacer uso de la nube en relación con el trabajo autogenerado (tales como fotografías tomadas por el estudiante durante el trabajo de campo), puede que no sea posible utilizar la nube en relación con los recursos con derechos de autor de terceros.

Las TPM pueden imponer restricción a la capacidad de adaptación y disponibilidad de los contenidos (Denicola, 2004, pp. 3-4) ${ }^{145}$. De esta forma, la sincronización de la información como artículos de investigación, imágenes o canciones con diferentes dispositivos puede ser restringida por medidas tecnológicas de protección, incluso si el acceso legal a la obra ha sido adquirida o la obra es de dominio público. Los titulares de derechos de autor han utilizado la protección de TPM no solo para evitar el acceso o el ejercicio de un derecho exclusivo, sino también para fijar el contenido a un dispositivo o software específico (Hinze, 2007, p. 800) ${ }^{146}$. Por ejemplo, los libros electrónicos adquiridos de Amazon se pueden descargar únicamente a dispositivos que tengan el software libre Kindle ${ }^{147}$. Si los dispositivos de los estudiantes no son compatibles con el software Kindle, en realidad, no podrían llevar la investigación donde quiera que vayan. Amazon reconoce que la aplicación

144 Describiendo que los estudiantes y los profesores pueden utilizar diferentes dispositivos para acceder a materiales educativos.

145 "A legal prohibition against circumventing the protective measures adopted by copyright owners leaves those owners with virtually absolute control over the terms of use. Technological restrictions backed by the force of law, coupled with contractual restraints imposed on users as a condition of granting access [...]” (pp. 3-4).

146 Afirmando que en la práctica las medidas tecnológicas de protección restringen los usos de los libros electrónicos como el dispositivo en el que el libro será leído, el número de copias y la capacidad para imprimir.

147 Ver Kindle (s.f.). 
Kindle no está disponible para todos los dispositivos ${ }^{148}$. La situación es similar con otro software tales como Adobe digital editions (s.f. ${ }^{149}$, donde el contenido se puede compartir entre dos dispositivos solo si se cumplen ciertas condiciones, como aquellos dispositivos que se activan con el mismo ID. Pero, si se pide prestado el contenido, entonces no hay posibilidad de utilizar el contenido en otro dispositivo debido a las restricciones sobre la copia (Adobe digital editions, s.f.) $)^{150}$. Adicionalmente, las TPM pueden controlar el número de reproducciones (descargas) del material con derechos de autor, y muchas veces no permiten ningún tipo adicional de distribución o reproducción, incluso a la cuenta del usuario o en otros dispositivos (Elkin-Koren, 2007, p. 1125) ${ }^{151}$. En este sentido, los titulares de derechos de autor no solo controlan el acceso a la obra, sino también cómo se debe utilizar el trabajo ${ }^{152}$.

Posteriormente, si el dispositivo de un estudiante no es compatible con el software para descargar el libro o si un estudiante simplemente prefiere utilizar otro software, entonces no hay manera que el estudiante pueda eludir la protección de medidas tecnológicas de protección con el fin de acceder al material. Aunque las medidas de control de acceso están sujetas a siete excepciones, estas excepciones son muy limitadas y dejan fuera de su alcance la posibilidad de eludir medidas tecnológicas de protección para este tipo de interoperabilidad. Por ejemplo, la excepción ingeniería inversa juega un

148 La página web de Amazon establece: "the kindle app is available for most major smartphones, tables and computer [...]" (párr. 1) (negritas añadidas por la autora). Este término establece que si el dispositivo no proviene de algunos de los mayores fabricantes de smartphones, tablets y computadores, la app no puede ser soportada.

149 " 6 . If the permission limits the books to be viewed on only one device, the copied books will not be able to be opened" (numeral 6, sección Content Portability).

150 "4. Books can be copied from one device to another device. If two devices are activated with the same ID, purchased books can be opened on the other device. If the other device is not activated or if it is activated with another ID, a pop up window will appear to ask for ID when opening the purchased books. Borrowed books cannot be opened on another computer regardless its activation status. It is because that the loan token is not copied" (numeral 4, sección Content Portability).

151 "[...] DRM might provide limited access to works for paying users only, limit some functions of digital files (e.g., the number of backup copies), or even prevent certain uses altogether (e.g., saving, printing, or annotating in a particular copy)" (p. 1125).

152 Ver Cohen (2003), los titulares de derecho de autor controlan no solo el acceso a la obra, sino cómo se accede la obra (pp. 980-981); ver también Elkin-Koren (2007): "The use of DRMs enables physical control over the use of cultural artifacts long after purchase by consuers" (p. 1124). 
papel central en los casos de elusión para la interoperabilidad (17 U.S.C $\S 1201$ (f)). Dicha excepción es también la única que se aplica a los tres actos prohibidos por la DMCA, lo que significa que también se aplica a la disposición contra el tráfico de dispositivos y servicios. Esta excepción se limita a la interoperabilidad de programa a programa y comunicar la información solo con el propósito y en la medida de lograr dicha interoperabilidad (17 U.S.G § 1201 (f)). De esta manera, la excepción de ingeniería inversa deja fuera de su cobertura la posibilidad de realizar ingeniería inversa para la interoperabilidad de programa a datos. En consecuencia, la capacidad de adaptación de los contenidos a diferentes dispositivos como es requerido por una educación siempre en el aprendizaje puede verse limitada por la protección de medidas tecnológicas de protección que no pueden ser eludidas sin hacer frente a la responsabilidad civil o penal. Por lo tanto, incluso si los estudiantes estadounidenses tienen libros electrónicos adquiridos de Amazon y los diferentes dispositivos para tomar ventaja de la nube en la educación, nada asegura que disfrutarán de los beneficios sin infringir la ley.

Aunque es importante proteger a los titulares de derechos de autor en la era digital y prohibir la elusión de medidas tecnológicas de protección es una manera de lograr ese objetivo, la situación de los e-libros demuestra que la DMCA sobreprotege las medidas tecnológicas de protección haciendo que sea difícil evolucionar a un nuevo tipo del sistema educativo. El uso de materiales en la "nube" puede ser la versión digital de la excepción de copia privada, que no es una infracción a los derechos de autor. Pero la ley no prevé ningún tipo de solución legal para permitir este tipo de usos aparte del procedimiento de elaboración de normas administrativas, el cual no resuelve el problema efectivamente debido a sus estrictas normas. Adicional a la inaplicabilidad de las excepciones creadas a través del proceso administrativo a las disposiciones contra el tráfico, explicada anteriormente, otro problema del procedimiento de reglamentación es que el bibliotecario del Congreso requiere un nivel alto de evidencia para apoyar la creación de una excepción.

La Oficina del Registro es estricta durante el procedimiento de elaboración de normas ya que afirma que solo se concede una excepción si se demuestra por una "preponderancia de evidencia que el perjuicio alegado es más probable que suceda a que no; un defensor no puede apoyarse en la especulación para sostener un caso de prima facie sobre los probables efectos 
adversos en usos no infractores" (Exemption to prohibition, noviembre de 2006, p. 68473) (traducción no oficial realizada por la autora). En este sentido, es muy posible que no se otorgue una excepción a las medidas de control de acceso por meros inconvenientes (p. 68473) ${ }^{153}$. Por otra parte, las excepciones promulgadas se conceden con base en clases de obras en lugar de concederse basándose en los usuarios ${ }^{154} \mathrm{o}$ a tipos de trabajo. Por lo tanto, no se promueve excepciones en favor de las instituciones educativas (Garlick, 2004, pp. 956-957) $)^{155}$. Además, los usuarios se sienten imposibilitados de participar en el proceso debido a que las normas técnicas y las cargas procesales hacen difícil actuar sin un abogado (Hinze, 2007, pp. 799-800) (156 $^{1}$. Esta situación hace difícil a los usuarios obtener excepciones adicionales a la elusión de una medida de control de acceso.

Por otra parte, el uso de la "nube" para promover una educación siempre en el aprendizaje también puede verse afectada por el procedimiento de bajada de contenidos. Una vez que el estudiante ha subido el material a la "nube", el proveedor de servicios puede ser obligado a bajar el contenido si recibe una notificación de la $\mathrm{DMCA}^{157}$. Aunque los servicios privados de la "nube" no reciben muchas notificaciones por su naturaleza privada (Leary, 2012, p. 1142) ${ }^{158}$, una notificación de derechos de autor que identifique el material generado por el estudiante como infractor requerirá que dicho

153 "De minimis problems, isolated harm or mere inconveniences are insufficient to provide the necessary showing" (p. 68473).

154 Garlick (2004), indicando que uno de los principales problemas de los procedimientos de elaboración de normas es que no concede excepciones sobre la base de usuarios o tipo de usos (pp. 956-957); ver también Sharp (2002), estableciendo que uno de los problemas que no permite al procedimiento administrativo al favorecer la educación es "because the provision applies to classes of works, and not to individuals or individual works, its aid to scholars and teachers is dubious" (pp. 43-44).

155 Indicando que el enfoque de la Biblioteca del Congreso no permite conceder excepciones sobre la base de usuarios, como estudiantes, técnicos, académicos o de investigación educativa, o de becas.

156 Afirmando que los consumidores encuentran difícil participar en el proceso sin comprometer los abogados en sus comunicaciones.

157 Ver Reuveni (2013), indicando que las notificaciones de DMCA pueden ser usadas para bajar contenido de la nube (p. 793); ver también Leary (2012), indicando que los servicios de nube privada califican para el puerto seguro de almacenamiento de información (p. 1142).

158 "Because of their private nature, private cloud service providers may rarely receive takedown letters" (p. 1142). 
contenido sea bajado. Como se mencionó anteriormente, el procedimiento de bajada de contenidos se puede utilizar para eliminar archivos erróneamente identificados como infractores por el titular de los derechos de autor ${ }^{159}$.

\section{Restricción de acceso a la información.}

Una de las ventajas y objetivos de la incorporación de las TIC en la educación es proporcionar acceso a un amplio catálogo de recursos de enseñanza y aprendizaje (U.S. Department of Education, 2010, p. xii). Las nuevas tecnologías permiten a los maestros y estudiantes tener acceso a materiales que de otro modo no están disponibles para ellos (p. x). No obstante, la protección a TPM ha afectado que las TIC puedan ser utilizadas para acceder inclusive aquel tipo de material que se encuentra por fuera de la protección de los derechos de autor, como las obras en el dominio público, las cuales, deben ser libres para traspasar fronteras de tiempo y espacio gracias a las tecnologías.

La protección de medidas tecnológicas de protección ha sido criticada por establecer un nuevo derecho a favor de los titulares de derechos de autor. Este derecho ha sido denominado como el "derecho de acceso" que aparece cuando la ley prohíbe la elusión de una TPM de control de acceso como una disposición independiente ${ }^{160}$. El derecho de acceso permite a los titulares de derechos de autor restringir el acceso a las obras, al limitar el acceso a la obra a solo aquellos que proporcionan una contraseña, adquirida, generalmente, después de pagar un precio. El derecho de acceso es nuevo porque la ley de derechos de autor no prohíbe el acceso a un material con derechos de autor - esta ley prohíbe reproducción, distribución, transformación o comunicación de la obra sin permiso-(17 U.S.C § 106). Un problema con el derecho de acceso, aparte del hecho de que no es un derecho exclusivo del autor, es que los titulares de derechos de autor lo han aplicado para encerrar la información que no se encuentra bajo la protección de derechos de autor, tales como hechos u obras que se localizan en el dominio público ${ }^{161}$. De esta

159 Ver discusión sobre el tema en la sección superior.

160 Ver Burk (2012, p. 16); ver también Sadd (2001), la protección de las medidas tecnológicas de protección introducen el derecho de acceso.

161 Ver Therien, (2001): "TPSs [...] can potentially protect any use on the Internet of copyrighted works, uncopyrightable works, or works that have fallen into the public domain" (p. 994); ver Yi-Jun (2005, pp. 772-777), estableciendo que las disposiciones 
forma, la protección a dichas TPM inhibe indebidamente el acceso, y por lo tanto, el uso de los recursos legalmente libres que podrían ser valiosos para el proceso de aprendizaje.

Técnicamente hablando, las TPM que impiden el acceso al material que no está bajo la protección de derechos de autor o de obras de dominio públicos no están protegidas bajo la Sección 1201 (Denicola, 2004, p. 5) ${ }^{162}$. Solo las medidas tecnológicas de protección que controlan efectivamente el acceso a una obra bajo derechos de autor están protegidas contra la elusión ${ }^{163}$. No obstante, en la práctica, estas medidas tecnológicas de protección se imponen sobre obras sin derechos de autor y obras de dominio público, por lo tanto, los usuarios, a menos que sean conocedores de la tecnología, no pueden eludir estas medidas debido a la prohibición de dispositivos y servicios de elusión (Amicus Curiae Brief of Electronic Frontier Foundation, 2002). Esta situación es similar a las medidas tecnológicas de control de copia descritas en la sección anterior. En este caso, aunque el acto de elusión no está fuera de la ley no hay medios legales para obtener herramientas o servicios directos a eludir para obtener acceso $^{164}$.

Además, el derecho de acceso también tiene la capacidad de ampliar la duración de la protección de los derechos de autor ${ }^{165}$. Esta situación se

de la DMCA respecto de TPM permite proteger trabajos que no caen dentro del ámbito de protección del derecho de autor; ver también Hinze (2007): “[...] overbroad TPM regimes and obsolescent DRM technologies pose a serious threat to the public's right of access to works that are no longer protected under copyright" (p. 801).

162 "The anti-circumvention and anti-trafficking provisions are applicable only to protective measures used on copyrighted works, but the ease with which copyrighted and public domain works can be bundled effectively ties up the latter works as well" (p. 5).

163 La Sección 1201 solo protege TPM de obras amparadas por el derecho de autor: "No person shall circumvent a technological measure that effectively controls access to a work protected under this title" (17 U.S.C § 1201(a) (1) (A)).

164 Ver sección previa sobre la falta de dispositivos o servicios en el caso de TPM de control de copia.

165 Cohen (2003), afirmando que las disposiciones contra la elusión permiten protección de los derechos de autor ilimitada exigible por ley (pp. 978-979). Este es el caso en el que la protección del derecho de autor ha expirado y el titular del derecho de autor usa un DRM para protegerlo; ver Blythe (2006), hablando sobre la habilidad de las TPM en aumentar la duración de la protección: "what was once a copyright of limited duration under the Copyright Act of 1976 now has taken on the form of a patent with unlimited duration under the DMCA" (p. 122); ver también Benchell (2002): 
presenta cuando las TPM de control de acceso se imponen en un trabajo que aún está bajo la protección del derecho de autor, pero permanece bloqueada una vez que cae en el dominio público. Al igual que en el caso de que se impongan medidas tecnológicas de protección en la materia sin protección, estas medidas tecnológicas de protección no están legalmente protegidas contra la elusión. Sin embargo, en realidad estas medidas tecnológicas de protección prohíben la libre utilización de ese trabajo porque no hay herramientas de elusión o servicios disponibles para permitir el acceso. Esta situación afecta a la capacidad de los profesores y los estudiantes que se beneficien de la expiración del derecho de autor (Sharp, 2002, p. 42) ${ }^{166}$.

Los tribunales estadounidenses han negado el argumento de que la prohibición de dispositivos de elusión impide el acceso a las obras de dominio público que están protegidos por TPM. El tribunal en el caso Elcom declaró que aunque una obra de dominio público esté protegida por medidas tecnológicas de protección, el público aún tiene acceso a ese trabajo en otro formato (United States v. Elcom Ltd., 2002, p. 19). El Tribunal dijo que:

Una obra de dominio público sigue siendo de dominio público y ninguna parte tiene ningún derecho de propiedad intelectual en la expresión de ese trabajo. Una falla en el argumento del demandado es que se presume que la única versión disponible de una obra de dominio público es una versión electrónica, tecnológicamente protegida (p. 19) (traducción no oficial realizada por la autora).

Sin embargo, el tribunal ignora el hecho de que la mayoría de los nuevos contenidos están siendo creados en un formato digital que desde su inicio está bloqueado con TPM, y nunca desbloqueado. Por otra parte, el tribunal, bajo este argumento, impuso cargas innecesarias a los usuarios como a los estudiantes y profesores que tendrán que gastar más tiempo en busca de versiones sin protección de la obra, de haber alguna disponible. Por último, esta corriente de pensamiento disminuye el beneficio que la tecnología puede ofrecer en la educación en los casos donde no hay infracción de derechos de autor.

\footnotetext{
"if a work is encrypted with a copyright protection measure, that work is effectively protected forever" (p. 14).

166 "For those conducting research and teaching on university campuses, two problems are on the horizon. First, public domain material may someday be locked up through technological barriers, requirement payments for access" (p. 42).
} 
Otra preocupación concerniente a las medidas de control de acceso es cuando dichas medidas se imponen sobre obras mixtas (que contienen material protegido y no protegido). Algunos proveedores de contenido utilizan medidas tecnológicas de protección para restringir el acceso a obras mixtas donde la mayor parte de la obra es de dominio público. Debido a que la tecnología no diferencia entre los componentes de una obra, la pieza entera queda bloqueada ${ }^{167}$. Esta situación difiere de la descrita anteriormente; en este caso el contenido bloqueado contiene una obra protegida por lo que el acto de elusión está prohibido legalmente. Por ejemplo, no sería raro encontrar una copia digital de la novela clásica de Jane Austen Orgullo y prejuicio - una obra de dominio público- que está bloqueada, ya que contiene un prólogo con derechos de autor ${ }^{168}$. En este caso, incluso un usuario conocedor de la tecnología y capaz de obtener acceso a la obra de dominio público violará la DMCA. Sin embargo, la ley no prevé una excepción para eludir medidas tecnológicas de control de acceso para obtener acceso a obras de dominio público.

Incluso cuando un usuario adquiere el acceso a una obra de dominio público protegido por una TPM de control de acceso, los editores suelen imponer también medidas de control de copia en la obra (Mazzone, 2011) ${ }^{169}$, la cual debe ser libre para ser utilizada en cualquier forma. Como en el caso de una medida de control de acceso, los usuarios tienen dificultades para tratar de eludir la medida de control de copia, aunque el acto no está prohibido por la ley debido a la prohibición de dispositivos y servicios de elusión ${ }^{170}$.

Adicionalmente, las TPM han disminuido la capacidad de las TIC para facilitar el acceso a los materiales en cualquier lugar y en cualquier momento

167 Ver Mazzone (2011, pp. 86-87); ver también Benchell (2002), afirmando que bajo la DMCA es posible tomar una obra del dominio público, combinarlos con el material protegido y aplicar la protección TPM para encerrar los contenidos de dominio público (p. 14).

168 Ejemplo adaptado de Mazzone (2011, p. 87).

169 Jason Mazzone trae un ejemplo en el que un libro de Adobe e-libro de las aventuras de Alicia en el país de las maravillas prohíbe la impresión, copiado y pegado del libro que está en el dominio público.

170 Ver secciones previas sobre el problema que crea la disposición anti-tráfico. 
(U.S. Department of Education, 2010, p. x $)^{171}$, como se desea en un proceso de aprendizaje transformado. Las bibliotecas desempeñan un papel central en la educación, y estas instituciones ofrecen a los estudiantes y maestros obras con derechos de autor necesarios para desarrollar el trabajo en clase y las tareas. Por lo tanto, las bibliotecas se han beneficiado de excepciones de derecho de autor a fin de facilitar dicho acceso desde el principio de la ley de derechos de autor ${ }^{172}$. A pesar de esta historia, las medidas tecnológicas de protección impiden realizar fair uses de los materiales protegidos en el caso de las bibliotecas. Por ejemplo, una biblioteca no puede prestar una obra digital legalmente adquirida o hacer una copia de archivo si la TPM no lo permite ${ }^{173}$. Más importante aún, a veces las medidas tecnológicas de protección no permiten a una biblioteca prestar un libro fuera de las instalaciones de la misma (Shashikant, 2005). Esta situación afecta especialmente a la capacidad de las TIC para potenciar el acceso a una amplia gama de recursos a los profesores y estudiantes que podría beneficiar incluso a aquellos que no tienen una biblioteca institucional o de una biblioteca pública cercana.

Aunque la DMCA establece una excepción a la elusión de una medida de control de acceso en favor de las bibliotecas, esta excepción también es muy limitada. La DMCA otorga a bibliotecas, archivos e instituciones educativas sin fines de lucro la "excepción de compra". Se ha denominado así ya que el alcance de la excepción permite la elusión de una TPM de control de acceso solo para determinar si hay que comprar el material y solo con respecto a las obras que no están razonablemente disponibles en otros formatos. Igualmente, la elusión únicamente se puede realizar durante el tiempo necesario para hacer tal determinación de compra (17 U.S.C § 1201 (d)). De este modo, una biblioteca solo puede eludir una TPM de control de acceso con el fin de decidir si adquirir el material o no. Sin embargo, la excepción deja expresamente fuera de su alcance cualquier otro tipo de elusión (17 U.S.C § 1201 (d) (1) (B)) para los propósitos mencionados anteriormente.

Por lo tanto, aunque un proceso de aprendizaje transformado busca aprovechar el acceso a una amplia gama de recursos, la protección a las

171 "Technology should be leveraged to provide access to more learning resources than are available in classrooms [...]" (p. x).

172 Excepción en favor de bibliotecas se basan en el artículo 10 (2) de Berna.

173 Ejemplos tomados de McCord (2005, p. 96). 
TPM restringe esta posibilidad mediante el bloqueo de acceso a los recursos no protegidos y a la restricción de la capacidad de las bibliotecas digitales para superar barreras de tiempo y espacio.

\section{Afectación a la adopción de una educación más inclusiva.}

Un proceso de aprendizaje centrado en la tecnología del siglo XXI busca llevar información para todos ${ }^{174}$. Este modelo se dirige directamente a las poblaciones marginadas que no tienen las mismas oportunidades que otras. En este sentido, el Plan Nacional de Tecnología reconoce que la tecnología puede proporcionar un ambiente de aprendizaje más eficaz para todos los alumnos (U.S. Department of Education, 2010, pp. 19-20). Aunque varios dispositivos electrónicos han sido desarrollados para ayudar a los alumnos con discapacidades como ampliadores de texto y lectores de pantalla (p. 20), muchos de estos dispositivos requieren recursos digitales para trabajar (pp. 20-21) ${ }^{175}$. La UNESCO (2013) ha puesto de relieve los beneficios de la tecnología para mejorar la educación para el alumno con discapacidad (p.23) ${ }^{176}$.

No obstante, estudiantes con discapacidad, especialmente con discapacidad visual, han tenido dificultades para beneficiarse de los avances de la tecnología debido a las barreras de acceso atribuibles a la protección de medidas tecnológicas de protección. Los titulares de derechos de autor imponen al contenido TPM de control de acceso que inhiben el cambio de formato, el número de copias, e imponen limitaciones sobre el software que se debe utilizar (Hinze, 2007, p. 800) ${ }^{177}$. Por lo tanto, los estudiantes con discapacidades visuales se les ha dificultado cambiar el formato de los datos para tomar ventajas de la herramientas tales como el ampliador de texto, transcripción de voz, y las tecnologías de conversión de texto a voz (p. 800) ${ }^{178}$. Una de las razones de esta imposibilidad es que una excepción en favor de las personas con discapacidad

174 Ver capítulo 1 sobre educación inclusiva.

175 Afirmando que tales dispositivos son difíciles y a veces imposibles de usar con materiales tradicionales de aprendizaje.

176 Afirmando que el uso de estas tecnologías mejora el aprendizaje de las personas con discapacidad.

177 Afirmando que en la práctica las medidas tecnológicas de protección restringen los usos de los libros electrónicos como el dispositivo en que el libro podrá ser leído, el número de copias y la opción de impresión, afectando a las personas con discapacidad.

178 Afirmando que TPM puede restringir la función de lectura en voz alta. 
visual no forma parte de las siete excepciones a la elusión (p. 800) ${ }^{179}$. Otra razón es que, como se mencionó anteriormente, la excepción de ingeniería inversa no cubre la interoperabilidad de datos a programa ${ }^{180}$. De esta forma, estudiantes con discapacidad se han visto limitados en su capacidad de utilizar la tecnología a su favor.

El Bibliotecario del Congreso, a través del procedimiento de elaboración de normas administrativas, entre 2003 y 2015, ha promulgado una excepción a las reglas que rodean la elusión de las medidas de control de acceso en "obras literarias, distribuidas electrónicamente, que están protegidas por las medidas tecnológicas que, o bien impiden la habilitación de la funcionalidad de lectura en voz alta o interfieren con los lectores de pantalla y otras aplicaciones o tecnologías de asistencia" (Exemption to prohibition, octubre de 2015, p. 65962) (traducción no oficial realizada por la autora) donde una copia fue legalmente adquirida por una persona con discapacidad visual total o con otro tipo de discapacidad, y cuando el trabajo es una obra literaria no dramática (p. 65962). Esta excepción permite a las personas con discapacidad visual total y personas con otra discapacidad visual eludir TPM a fin de poder utilizar los dispositivos de asistencia. Aunque es un hecho positivo, la comunidad con dificultades de visión se ve obligada a gastar recursos significativos cada tres años para asegurar que van a recibir esta excepción ${ }^{181}$. Por otra parte, la excepción no se aplica a la prohibición de tráfico de dispositivos haciendo que sea difícil para la población con discapacidad visual ejercer efectivamente esa excepción (Hinze, 2007, p. 800) $)^{182}$.

Por otra parte, la excepción para eludir medidas de control de acceso promulgadas a través del procedimiento de elaboración de normas

179 Indicando que uno de los problemas es que una excepción en favor de las personas con discapacidad no se establece como una excepción a las prohibiciones de la DMCA.

180 Ver discusión sobre la excepción de interoperabilidad en secciones previas.

181 Ver Reid (20 de marzo de 2013), indicando que las personas con discapacidad visual tienen que gastar recursos abogando por su excepción cada tres años; ver también Sharp (2002), indicando que uno de los problemas del procedimiento de elaboración de normas administrativas es la duración temporal: "users of exempted class of works must once again justify their need to breach the digital wall to gain access to what otherwise would be entitled to fair use" (p. 44).

182 Indicando que aunque la comunidad de personas con discapacidad visual ha obtenido una excepción a través del procedimiento de reglamentación, la excepción no legaliza las herramientas necesarias para la elusión. 
administrativas parece aplicarse solo para personas con discapacidad visual total o con algún tipo de discapacidad visual ${ }^{183}$. No obstante, las medidas de control de acceso también frustran estudiantes con otras discapacidades, como aquellos con problemas de aprendizaje. La UNESGO ha puesto de relieve la iniciativa del Harvard-Smithsonian Center for Astrophysics para ayudar a las personas con dislexia. El centro ha descubierto recientemente una manera de mejorar la velocidad y la comprensión de las personas con esta dificultad. Este método consiste en formatear el texto para que quepan en un dispositivo digital de pantalla pequeña (UNESCO, 2013, p. 23) ${ }^{184}$. Sin embargo, si el texto se encuentra protegido por una TPM puede suceder que reformatear no sea posible y, por lo tanto, el estudiante no pueda utilizar esa tecnología para leerlo. Por otra parte, en este caso, el estudiante con dislexia no necesariamente tiene una discapacidad visual y, por tanto, no podrán beneficiarse de la regulación aprobada por el Bibliotecario del Congreso.

Por lo tanto, la protección de las medidas de TPM disminuye la capacidad de la tecnología para promover y mejorar el aprendizaje de las personas con discapacidad como un proceso de aprendizaje transformado busca.

\section{Conclusión}

$\mathrm{El}$ sistema desarrollado en Estados Unidos para proteger a los titulares de derechos de autor en el entorno digital es único en todo el mundo. La DMCA implementó un modelo de régimen de limitaciones a la responsabilidad de ISP y de protección a TPM que no se encontraba establecido, pero tampoco prohibido en el WCT. Dicha implementación se ha caracterizado por su enfoque maximalista de las obligaciones del WCT, y la experiencia de Estados Unidos durante los dieciséis años de existencia de la DMCA ha establecido que sus mecanismos de limitación a la responsabilidad de ISP y protección a TPM pueden ser objeto de abuso.

183 Las regulaciones promulgadas establecen que se aplica a "blind or other person with disability", como tal, estas están definidas en 17 U.S.C 121. Dicha sección establece que: "blind or other person with disabilities' means individuals who are eligible or who may qualify in accordance with the Act entitled 'An Act to provide books for the adult blind' $[\ldots]$ to receive books and other publications produced in specialized format" .

184 Explicando el proceso desarrollado para ayudar a mejorar la comprensión de lectura de las personas con dislexia. 
Respecto a la educación, Estados Unidos está a la vanguardia de la tendencia mundial de la transformación del sistema educativo a través de la utilización de la tecnología. No obstante, los potenciales abusos de la protección TPM y del proceso de limitación a la responsabilidad de los ISP pueden afectar la transformación del proceso de aprendizaje. Estas disposiciones potencialmente hacen de Internet el elemento central de la educación en un proceso de aprendizaje transformado, prescindible. Por otra parte, estas medidas pueden disuadir a la adopción de metodologías como aprendizaje permanente y de colaboración, incluso cuando los derechos de autor no se están infringiendo. Por último, estas medidas no permiten en muchos casos que los estudiantes y profesores de todo el mundo aprovechen la tecnología para llevar un mayor acceso a los materiales educativos y proporcionar una educación más inclusiva. Por lo tanto, el modelo de la DMCA de protección con respecto a la limitación de la responsabilidad de ISP y la protección TPM ISP puede afectar el desarrollo de un proceso de aprendizaje transformado necesario para los estudiantes del siglo XXI. 
Capítulo 4

\section{LA EXPORTAGIÓN DE LOS ESTADOS UNIDOS DE SU MODELO DE LIMITACIONES A LA RESPONSABILIDAD DEL PROVEEDOR DE SERVIGIOS DE INTERNET Y DE PROTECGIÓN A LAS MEDIDAS TEGNOLÓGIGAS DE PROTEGGIÓN}

Hn el Tratado de la OMPI (el "WCT") la comuniEdad internacional estableció normas mínimas de protección de derechos de autor en la era digital. Estados Unidos, durante la implementación de las obligaciones internacionales en el WCT, como se mencionó en el capítulo 3, desarrolló un modelo único de limitaciones a la responsabilidad de los ISP y de protección a las TPM, el cual representa un enfoque maximalista de las obligaciones incorporadas en el acuerdo. Aunque el acuerdo no obliga a este tipo de aplicación maximalista, tampoco lo prohíbe.

Sin embargo, Estados Unidos ha adoptado una política internacional ofensiva ${ }^{1}$ que busca exportar su propio modelo de aplicación a los diversos países, en especial, a los países en desarrollo. Como medio para exportar dicho modelo, Estados Unidos ha acudido a la firma de diferentes acuerdos de libre comercio con los países en desarrollo, en los cuales, dicho país proporciona más privilegios que los establecidos en la OMC a cambio de una protección más

\footnotetext{
Por "ofensiva", me refiero a que Estados Unidos es proactivo en imponer su política a otros países.
} 
alta que aquellas establecidas en el ADPIC. Los países en desarrollo aceptan estos acuerdos con el fin de obtener los privilegios comerciales que Estados Unidos ofrece. Este es el caso del TLC firmado entre Colombia y Estados Unidos.

La sección primera de este capítulo describe la nueva política internacional de derechos de autor que Estados Unidos utiliza para exportar su propio nivel de protección de derechos de autor en la era digital y las razones que lo llevaron a adoptar esta política. La sección segunda de este capítulo describe la situación específica de la negociación del TLC entre los EE. UU.-Colombia. La sección tercera ofrece una descripción detallada de las obligaciones de derechos de autor incluidos en el acuerdo comercial entre EE. UU.-Colombia, evidenciando la cercanía entre el texto del tratado y ley de Estados Unidos.

\section{La exportación del modelo de EE. UU.}

La política internacional en materia de derechos de autor de Estados Unidos busca aumentar los niveles de protección de derechos de autor en la era digital, y por tanto, exporta las disposiciones de la DMCA, específicamente el modelo de limitaciones a la responsabilidad del ISP y la protección de TPM, a los países en desarrollo. Estas disposiciones constituyen normas ADPICplus, como se explicará más adelante. Dicha política internacional responde a una tendencia histórica en el campo del derecho de autor en los escenarios multilaterales hasta el $\mathrm{WCT}^{2}$, donde, al igual que con los tratados anteriores, los países desarrollados no se sentían cómodos con el nivel de protección incluido en los acuerdos internacionales en la materia. En esta etapa, algunos de los problemas del WCT, de acuerdo con los países desarrollados, era que no incluía normas sobre la responsabilidad de los intermediarios de Internet y la protección a las TPM se había establecido en normas muy generales ${ }^{3}$, lo que permitía diferentes niveles de implementación. De esta forma, países como Estados Unidos comenzaron a buscar aumentar los estándares de protección de derechos de autor, especialmente en los aspectos relacionados con el entorno digital, ya que les preocupaba la capacidad de las nuevas

\footnotetext{
Ver capítulo 2 sobre la historia del derecho internacional de los derechos de autor. Ver capítulo 2 acerca de las disposiciones del WCT.
} 
tecnologías para difundir ampliamente los materiales con derechos de autor y para realizar reproducciones perfectas de obras sin costo alguno.

En la búsqueda de nuevos estándares de protección, Estados Unidos cambió de nuevo el foro de negociación de los derechos de propiedad intelectual; y como sucedía anteriormente al Convenio de Berna, las negociaciones se tornaron bilaterales. La razón para el cambio de fórum se debió a que el escenario multilateral ya no representaba una forma eficiente o eficaz para aumentar las normas de derecho de autor. Los países en desarrollo, que se oponían al aumento de la protección de los derechos de autor, habían ganado territorio y rendido el enfoque multilateral menos eficaz (Yu, 2004, p. 2) ${ }^{4}$. Como se discutió en el capítulo 2, la OMPI y Berna no eran una opción para aumentar las normas de derecho de autor, llevando a los países desarrollados a buscar en la OMC un nuevo foro de negociación. Sin embargo, después de los ADPIC los países en desarrollo ganaron territorio en la OMG y ADPIC, por lo tanto, se tornó difícil para los países desarrollados usar este escenario para obtener un aumento en la protección de los derechos de autor.

De esta forma, Estados Unidos inició una política internacional en materia de derechos de autor ofensiva a finales de la década de 2000, la cual consistía en incluir estándares de derechos de propiedad intelectual que excedían las normas ADPIC dentro del texto de sus Tratados de Libre Comercio. Para el año 2014, EE. UU. celebró exitosamente varios TLC que incluían un capítulo dedicado a DPI con países como Australia ${ }^{5}$, Baréin ${ }^{6}$, Chile, Colombia $^{8}$, países de América Central (CAFTA) (Costa Rica ${ }^{9}$, El Salvador ${ }^{10}$,

4 "Less developed countries are reluctant to develop new international intellectual property norms despite repeated demands by developed countries" (p. 2).

5 Entrada en vigor el 1 de enero de 2005 (ver Free Trade Agreements Australia, s.f., 43 ILM 1248).

6 Entrada en vigor el 11 de enero de 2006 (ver Bahrain Free Trade Agreement. s.f., 44 ILM 544).

7 Entrada en vigor el 1 de julio de 2004 (ver Chile Free Trade Agreement, s.f., 42 ILM 1026).

8 Entrada en vigor el 15 de mayo de 2012 (ver Free Trade Agreement, U.S.- Colom [USCO]).

9 Entrada en vigor el 1 de enero de 2009 (ver CAFTA-DR [Dominican RepublicCentral America FTA], s.f.).

10 Entrada en vigor en 2006 (ver CAFTA-DR [Dominican Republic-Central America FTA], s.f.). 
Guatemala $^{11}$, Honduras ${ }^{12}$, Nicaragua ${ }^{13}$ y República Dominicana $\left.{ }^{14}\right)$, Corea ${ }^{15}$, Marruecos $^{16}$, Panamá ${ }^{17}$, Perú ${ }^{18}$ y Singapur ${ }^{19}$. Como se puede observar, la mayoría de los países que negociaron con EE. UU. son países en desarrollo.

Dicha política de Estados Unidos se caracteriza por dos cosas: (1) su proceso de negociación; y (2) el contenido de las obligaciones incorporadas en el tratado. Respecto del primer punto, tenemos que el proceso de negociación es oneroso y desequilibrado. El proceso inicia cuando Estados Unidos presenta el texto del capítulo a la otra parte negociadora en la forma de una plantilla (Drahos, 2001, p. 794) ${ }^{20}$, procediendo a la discusión sobre las obligaciones en la materia bajo la posición de "tómelo, o déjelo". Dicha plantilla, se fue volviendo cada vez más detallada, ya que, a medida que las negociaciones se fueron presentando, los resultados de negociación pasadas sentaban el precedente para negociaciones futuras (p. 794)

Adicionalmente, debido al carácter bilateral de las negociaciones y las características de las partes comerciales (la mayoría de ellos países en desarrollo), hacía que los socios comerciales se encontraran en una posición más débil y con poco poder de negociación para promover sus objetivos de propiedad intelectual (Yu, 2004, pp. 44-45)22 frente a los Estados Unidos. Esto se debía a que, al aislar a los países en desarrollo por medio de negociaciones

11 Entrada en vigor en 2006 (ver CAFTA-DR [Dominican Republic-Central America FTA], s.f.).

12 Entrada en vigor en 2006 (ver CAFTA-DR [Dominican Republic-Central America FTA], s.f.).

13 Entrada en vigor en 2006 (ver CAFTA-DR [Dominican Republic-Central America FTA], s.f.).

14 Entrada en vigor el 1 de marzo de 2007 (ver CAFTA-DR Dominican RepublicCentral America FTA], s.f.).

15 Entrada en vigor el 15 de marzo de 2012 (ver U.S. - Korea Free Trade Agreement, s.f.).

16 Entrada en vigor el 1 de enero de 2006 (ver Morocco Free Trade Agreement, s.f.).

17 Entrada en vigor el 31 de octubre de 2012 (ver U.S.-Panama Trade Agreement Now in Force, s.f.).

18 Entrada en vigor el 1 de febrero de 2009 (ver Peru Trade Promotion Agreement, s.f.).

19 Entrada en vigor el 1 de enero de 2004 (ver Singapore FTA, s.f.).

20 Explicando que con el fin de reducir los costos de la negociación, EE.UU. trae un texto ya preparado que sigue las normas de un tratado modelo ratificado por el Senado.

21 Afirmando que EE. UU. tiene incentivos para buscar la estandarización de acuerdos bilaterales. Usando el anterior TLC como modelo para futuras negociaciones.

22 Indicando que los países menos desarrollados no tienen poder de negociación para comerciar mejores acuerdos y terminan aceptando disposiciones de propiedad intelectual que podrían no beneficiarlos. 
bilaterales, Estados Unidos lograba evitar la oposición a sus estándares de derechos de propiedad intelectual y establecer los niveles de protección que la industria norteamericana exigía, los cuales, no se podrían lograr en un marco multilateral (Correa, 2004, p. 80) ${ }^{23}$. Igualmente, al existir un número reducido de socios comerciales, Estados Unidos podía ofrecer pagos colaterales dirigidos al interés específico de la parte comercial (Yu, 2004, p. 44), haciendo más atractivo el acuerdo para la otra parte negociadora a pesar de las disposiciones en materia de DPI. Aunque intercambiar derechos de propiedad intelectual por algunos beneficios comerciales no es adecuado para los países en desarrollo, como mostraba la historia, dichos países suelen aceptar el trato por diferentes razones. Por ejemplo, la República Dominicana lo vio como la opción menos costosa para la obtención de beneficios en otras áreas comerciales (Geist, 20 de octubre de 2003).

Respecto del segundo punto, las obligaciones integradas en el acuerdo se caracterizan por la incorporación de estándares "ADPIC-Plus" (VivasEugui, 2003, p. 3) y la alineación de la legislación del socio comercial a la ley de Estados Unidos ${ }^{24}$. Sobre la primera, las normas ADPIC-Plus son niveles de protección que, o bien exceden el nivel de protección incorporado en los acuerdos ADPIC o son normas que no se incluyeron en los ADPIC en lo absoluto ${ }^{25}$. De esta manera, Estados Unidos utilizó los acuerdos de libre comercio para incorporar obligaciones respecto a la limitación de responsabilidad de los ISP y la protección a las medidas tecnológicas de protección, siguiendo el modelo establecido en la DMCA (Christie, Waller \& Weatherall , 2007, p. 212), lo cual representa la inclusión de obligaciones ADPIC-plus.

A nivel internacional, no existe un estándar para establecer un sistema de limitaciones a la responsabilidad de un intermediario de internet por la infracción de derechos de autor. El acuerdo ADPIC no dice nada al

23 "Bilateral dealing permit the United States to obtain what it cannot easily get multilaterally [...]" (p. 80).

24 Ver Dinwoodie (2000): "Indeed, because of significant U.S. influence in the formation of Contemporary intellectual property treaties, U.S. law has undergone less change than most in order to comply with newly-assumed international obligations" (pp. 307307); ver también Kuanpoth (2007, p. 28).

25 Ver Drahos (2003), explicando el concepto ADPIC-Plus (pp. 792-793); ver también Vivas-Eugui (2003), afirmando que los ADPIC-Plus son las normas que van más allá de las normas mínimas de los ADPIC (p. 4). 
respecto, mientras que el WCT (Tratado de la OMPI, 20 de diciembre de 1996) hace alguna referencia a la responsabilidad del intermediario de una comunicación (Tratado de la OMPI, 20 de diciembre de 1996) ${ }^{26}$. Sin embargo, la referencia del WCT se limita a aclarar la ausencia de responsabilidad en las comunicaciones por la mera provisión de las instalaciones para facilitar o realizar dichas comunicaciones (Tratado de la OMPI, 20 de diciembre de 1996 ${ }^{27}$. En consecuencia, debido a la falta de normas internacionales, cada país es libre de decidir si incorporar un régimen de responsabilidad de los ISP dentro de su propio sistema legal. No obstante, el TLC manda a establecer dicho modelo utilizando la ley estadounidense como guía, y por lo tanto, estableciendo obligaciones ADPIC-Plus en la materia y limitando la autonomía a los países parte de los acuerdos comerciales.

La situación no es diferente en el caso de la protección a las medidas tecnológicas de protección. ADPIC no dice nada acerca de la protección a las medidas tecnológicas de protección (Gasser, 2006, p. 6) y tanto el WCT y el WPPT incluyen en el artículo 11 y 18, respectivamente, la obligación de los Estados miembros a promulgar la protección legal para cubrir las MTP. Sin embargo, dichas obligaciones se establecen en términos muy generales, lo que permite un amplio ámbito de implementación a los Estados miembros ${ }^{28}$. No obstante, los acuerdos de libre comercio de los Estados Unidos incorporan obligaciones detalladas -siguiendo su modelo establecido en la DMCA, superando la obligación de los Tratados Internet de la OMPIhaciendo de dicho modelo de protección el nuevo estándar internacional (Yu, 2006, p. 40) $)^{29}$.

Sobre la segunda, las disposiciones del régimen de limitaciones a la responsabilidad de ISP y la protección a las medidas tecnológicas de protección incorporadas en el texto del TLC de Estados Unidos siguen muy de cerca el modelo estadounidense de protección incorporado en la DMCA. La razón de este enfoque es que Estados Unidos quería no solo aumentar

\footnotetext{
Ver en declaración concertada al artículo 8.

Ver en declaración concertada al artículo 8.

Ver capítulo 2.

29 "The United States has actively pushed for bilateral and plurilateral treaties that seek to achieve 'a standard of protection similar to that found in United States law.' Thanks to these agreements, an anticircumvention regime that is modeled after the DMCA has now been exported to foreign countries" (p. 40).
} 
la protección de los derechos de autor, sino también poner la legislación de sus partes comerciales más cerca del modelo estadounidense de protección de los derechos de autor en la era digital. Esto a su vez haría de la ley de Estados Unidos el nuevo nivel de protección internacional del derecho de autor, evitando que dicho país se obligara a nuevos niveles de protección ${ }^{30}$.

Por lo tanto, la combinación entre la negociación bilateral y los socios comerciales que requieren aceptar el contenido del capítulo DPI para obtener el TLC, permite a Estados Unidos exportar su propio modelo de protección de los derechos de autor a otros países. Como algunos comentaristas han dicho, esta política ofensiva de derechos de autor restringe la capacidad de los socios comerciales de Estados Unidos de establecer sus propias políticas de derechos de autor en materia de protección de derechos de autor en la era digital $^{31}$. Hoy en día, alrededor de quince países han implementado o están en proceso de implementar un modelo basado en la DMCA dentro de su legislación de derechos de autor.

\section{E1 Tratado de Libre Comercio Estados Unidos-Colombia (USCO)}

La dinámica de la política internacional ofensiva de derechos de autor de Estados Unidos se ilustra en el caso del TLG que negoció con Colombia. La principal motivación de Colombia para negociar un TLC con Estados Unidos era económica; Colombia estaba dispuesta a firmar un TLC con Estados Unidos para poder tener acceso al mercado estadounidense ${ }^{32}$. De

30 Ver Chander (2006): "Free trade agreements are an oft-unnoticed forum for the export of American law. They rarely demand significant changes in United States law, but often require significant changes in the law of our trading partner" (p. 211); ver también Kaminski (2014, p. 1015).

31 Ver Okediji (2003-2004): "Undoubtedly, post-TRIPS trade agreements with intellectual property components have detrimental implications for sovereign discretion and pose attendant challenges for development concerns" (p. 130); ver también Drahos (2001): "Developing countries are being led into a highly complex multilateral/bilateral web of intellectual property standards that are progressively eroding not just their ability to set domestic standards, but also their ability to interpret their application through domestic administratively and judicial mechanisms" (p. 803).

32 Ver Rueda (2012), indicando que el mercado de Estados Unidos como el mayor mercado del mundo, y el mayor socio comercial de Colombia, hizo del TLC una gran oportunidad para el desarrollo del país suramericano (p. 270); ver también Díaz (2006), estableciendo que los países en desarrollo que entraron en negociaciones con EE. UU. tenían en sus metas poseer mayor acceso al mercado estadounidense y atraer mayor inversión directa (p. 23). 
hecho, fue por iniciativa colombiana que comenzaron las negociaciones del Tratado de Libre Comercio con el país norteamericano (USCO, 2006). En el 2003, el expresidente de Colombia Álvaro Uribe Vélez pidió a Estados Unidos entrar en negociaciones comerciales con Colombia (Silva, 2007, p. 123). Más tarde en ese año, el representante comercial de Estados Unidos, Robert Zoellick, anunció el deseo de Estados Unidos de negociar con Colombia, junto con otros dos países andinos: Perú y Ecuador (p. 124).

El proceso de negociación del USCO fue particularmente largo y polémico. Durante las negociaciones, los países andinos se separaron. De esta forma, lo que comenzó como un acuerdo comercial regional se convirtió en dos acuerdos comerciales bilaterales entre el Perú y los Estados Unidos, y Colombia y los Estados Unidos (Silva, 2007, p. 124) ${ }^{33}$. Luego de veintiún meses, quince rondas de negociación, y cien reuniones, el USCO fue firmado en el 2006 (Romero, 2006, p. 30) ${ }^{34}$. Sin embargo, tomó cinco años para que los Estados Unidos ratificaran el acuerdo. Solo en mayo de 2012 el acuerdo entró en vigor (Acuerdo de Promoción Comercial, s.f.), mientras que el tratado hermano entre Estados Unidos y Perú entró en vigor en 2009 (Peru Trade Promotion Agreement, s.f.).

Desde la firma del acuerdo, el Gobierno colombiano había identificado el USCO como el acuerdo económico más importante de la historia de Colombia (Ministerio de Comercio, Industria y Turismo [MinCIT], 2006a, p. 5) $)^{35}$, y este fuerte deseo de Colombia de tener un TLC influyó en su posición negociadora. De hecho, la orden presidencial de Colombia era actuar rápido y haciendo caso omiso de los obstáculos durante la negociación (López, 2007, p. 161) ${ }^{36}$, lo que llevó a Colombia a otorgar más concesiones de las que debía, dejando diversos intereses nacionales -tales como la propiedad intelectual- sin protección (p. 161). Además, el poder de negociación de Colombia sobre determinadas materias, incluida la

33 Describiendo las razones por las cuales los países andinos se separaron y el TLC Andino se convirtió en dos acuerdos bilaterales diferentes.

34 Estableciendo la duración del proceso de negociación.

35 Ministerio de Comercio afirmando que después de veintiún meses de negociación se concluyó el acuerdo comercial más importante de la historia de Colombia.

36 Afirmando que la política desempeñó un papel importante en la negociación del acuerdo de libre comercio. Por otra parte, las órdenes del presidente Alvaro Uribe Vélez fueron negociar "rapidito, rapidito así caigan rayos y centellas" (p. 161). 
propiedad intelectual, no era tan fuerte como la de Estados Unidos, sobre todo porque los negociadores estadounidenses no querían conformarse con menos protección que la que habían obtenido en los TLC anteriores con Chile y los países de Centroamérica (Madrid, mayo de 2006).

Estados Unidos, en el seguimiento de su política internacional DPI, estaba presionando para incorporar normas ADPIC-Plus dentro del acuerdo. Aunque los negociadores colombianos insistían que la incorporación de este tipo de normas, especialmente en la ley de patentes, no estaban a favor de Colombia, el Gobierno colombiano, a través de una decisión política, aceptó el capítulo de DPI haciendo caso omiso de las advertencias de los negociadores (Romero, 2006, pp. 62-63).

Los derechos de propiedad intelectual fueron un tema delicado durante la negociación del USCO. Sin embargo, el nivel de sensibilidad con que fueron tratadas las cuestiones varió dependiendo del tipo de protección de propiedad intelectual al que se refiriera. De esta forma, patentes y biodiversidad fueron temas de interés nacional (MinCIT, s.f., pp. 19-20) ) $^{37}$ y la comisión negociadora centró todos sus esfuerzos en la defensa nacional de acceso a los medicamentos y en detener la piratería biológica. A pesar de retirar a Carlos Correa de la comisión negociadora, a petición de los Estados Unidos (Correa, 30 de julio de 2004) (38 $^{38}$ la cual no fue refutada por Colombia- (López, 2007, pp. 156-157), los expertos colombianos estaban preocupados por aceptar las disposiciones de patentes incluidas en la propuesta del país norteamericano. Preocupaciones que compartían la academia y la sociedad colombiana (Madrid, mayo de 2006) ${ }^{39}$. Igualmente, el Ministerio de Comercio, Industria y Turismo, cabeza de las negociaciones del USCO, declaró que ningún acuerdo comercial era tan importante para inhibir el acceso de los ciudadanos colombianos a la medicina (MinCIT, 2006b, pp. 22-23) ${ }^{40}$. No obstante, la comisión de Estados Unidos rechazó las

37 Ver MinCIT (s.f.), afirmando que la piratería biológica y el acceso a la medicina son temas sensibles para Colombia (pp. 19-20).

38 Afirmando que los EE. UU. le puso un veto a la participación de Carlos Correa en las negociaciones de la USCO.

39 Indicando que el capítulo de derechos de propiedad intelectual del TLC ha suscitado muchas controversias en la opinión pública.

40 Afirmando que para Colombia era importante proteger el acceso a los medicamentos para sus ciudadanos. 
propuestas de Colombia sobre el tema, y en consecuencia, las disposiciones de patentes se convirtieron en un obstáculo para cerrar el acuerdo, a lo que el Gobierno colombiano decidió que las "negociaciones técnicas" habían terminado y que las "negociaciones políticas" tomarían la decisión final (Von Braun, 2012) ${ }^{41}$. En consecuencia, tres expertos de la comisión negociadora de Colombia renunciaron a su puesto como muestra de su malestar con la decisión (Von Braun, 2012) ${ }^{42}$.

No obstante, para los negociadores colombianos, las disposiciones de derecho de autor de la propuesta de Estados Unidos no eran tan polémicas como las disposiciones de patentes, a pesar del hecho de que las instituciones educativas colombianas tienen materiales educativos escasos y el acceso a los recursos educativos y culturales es limitado. Como parte de la política de Estados Unidos, el capítulo de los derechos de autor incorporó obligaciones detalladas en materia de derecho de autor, incluyendo un régimen de limitaciones a la responsabilidad de los ISP y protección a las medidas tecnológicas de protección basada en la DMCA. Aunque estas disposiciones pueden ser controversiales y complejas, dichas incorporaciones por parte de Estados Unidos no generaron mayores preocupaciones entre los negociadores colombianos. Fernando Zapata, exdirector de la Oficina de Derechos de Autor de Colombia y negociador, se sentía confiado de que la regulación autoral de los países andinos, con fuertes niveles de protección, le permitía negociar con Estados Unidos a un mismo nivel. Por lo tanto, la incorporación de las normas de derechos de autor impuesta por Estados Unidos no causó desconfianza para Colombia o despertó un sentimiento de desventaja (Pabón. 2006, p. 11). Adicionalmente, ninguna ONG participó en la discusión de derechos de autor (Díaz, 2006, p. 85) ${ }^{43}$.

Las preocupaciones en el tema de regulación autoral por parte de la comisión colombiana se limitaron a ciertos aspectos de las disposiciones de TPM e ISP. Respecto de la primera, preocupaba la exigencia de limitar las excepciones al acto de elusión de una TPM de control de acceso

\footnotetext{
Describiendo la posición del Gobierno.

42 Describiendo la situación que llevó a la renuncia de los negociadores de Colombia.

43 Afirmando que en la negociación de los TLC de la región participaron diversas ONG dedicadas a los temas de patentes. Sin embargo, no había ninguna ONG dedicada a los derechos de autor y el acceso a la información. Este movimiento comenzó a llegar después de la firma de los TLC.
} 
(Dirección Nacional de Derecho de Autor, 2005) ${ }^{44}$. No obstante, dichas preocupaciones se disiparon mediante la incorporación de la posibilidad de incluir un procedimiento administrativo o legislativo para establecer limitaciones a la acción de eludir medidas de control de acceso (MinCIT, $2005)^{45}$. En cuanto a la cuestión de la responsabilidad de los ISP, la comisión negociadora de Colombia pidió que cada país fuera libre de establecer el tipo de responsabilidad para los intermediarios en situaciones en las que no estuvieran excluidos de responsabilidad. Este aspecto fue incorporado en el acuerdo, y la comisión colombiana lo presentó como un resultado positivo (MinCIT, 2005). Al final, todas las propuestas en materia de derechos de autor hechas por Estados Unidos se incorporaron en el texto final del USCO. En consecuencia, las obligaciones del USCO son, por tanto, similares a las incluidas en otros tratados comerciales de Estados Unidos y siguen de cerca la legislación estadounidense.

\section{Las disposiciones de derechos de autor incorporadas en el USCO.}

$\mathrm{Al}$ comparar el texto del USCO con el texto de la DMCA, es evidente que el USCO incorporó en gran medida todas las características principales de los modelos de limitaciones a la responsabilidad de ISP y a la protección de medidas tecnológicas de protección de dicha ley. A continuación se describen las obligaciones adquiridas en materia de derechos de autor.

El USCO, al igual que los acuerdos previos sobre el tema, se basa en el principio de "trato nacional" (USCO, 2006, 16.1.8). El TLC aclara que sus términos son normas mínimas (16.1.7) y se aplican con carácter retroactivo (16.1.11). En cuanto a las disposiciones de derecho de autor, el TLC comienza mandando la ratificación del Convenio sobre la Distribución de Señales Portadoras de programas Transmitidas por Satélite (1974) (16.1.2 (a)), el WCT $(16.1 .2$ (c)) y el WPPT (16.1.2 (d)). Por otra parte, el USCO afirma las obligaciones adquiridas en virtud del Convenio de Berna (16.5.1), aclara la aplicación del derecho de reproducción sobre las reproducciones temporales (16.5.2), incluye las redacciones del derecho de distribución-sin mencionar el

\footnotetext{
44 Buscando en la página de internet: http://www.aplicaciones-mcit.gov.co/mcit_tlc por el término "derechos de autor".

45 Buscando en la página de Internet http://www.aplicaciones-mcit.gov.co/mcit_tlc por el término "derechos de autor".
} 
derecho de determinar el agotamiento-y de comunicación pública incluidas en el WCT (16.5.3; 16.5.4), aumenta la regla general de duración de los derechos de autor establecida en Berna a 70 años después de la muerte del autor (16.5.5) y aclara que la propiedad inicial recaerá en el autor (16.5.6). Por otra parte, el USCO estableció una obligación común a los derechos de autor y los derechos conexos a fin de "garantizar que no se establezca ninguna jerarquía entre el derecho de autor, por una parte, y los derechos de los artistas intérpretes o ejecutantes y productores de fonogramas, por otra parte" (16.7.1). También exige la aplicación del artículo 18 del Convenio de Berna (16.7.2) y ratifica la transferibilidad de los derechos económicos del autor y los derechos conexos (16.7.3). La mayoría de estas obligaciones ya estaban en vigor bajo la ley de derecho de autor de Colombia, como se discutirá en el capítulo 5.

En cuanto a la limitación de la responsabilidad de los ISP, el artículo 16.11.29 del USCO exige a los signatarios establecer un sistema de limitación de la responsabilidad de los ISP basados en los cuatro puertos seguros que se encuentran en la DMCA: (1) comunicaciones transitorias; (2) el almacenamiento en caché; (3) de alojamiento; y (4) de herramientas de búsqueda de información (16.11.29 (b) (i)). Para obtener protección, un ISP debe estar dentro de la definición de proveedor de Internet, incluida en el texto del USCO (16.11.29 (b) (xii)), al igual que cumplir con las obligaciones generales de adoptar una política de terminación de cuentas a infractores reincidentes, y no interferir con medidas tecnológicas estándar (16.11.29 (b) (vi)). Además, el USCO obliga a las partes a no establecer una obligación de monitorio sobre la ISP (16.11.29 (b) (vii)) al igual que la ley de Estados Unidos. El USCO exige a las partes crear un sistema para identificar al presunto infractor. En este caso, aunque el acuerdo establece la finalidad del proceso, dejó en libertad a las partes para decidir si se debe utilizar un procedimiento administrativo o judicial (16.11.29 (b) (xi)). Por último, el USCO obliga a las partes a establecer un procedimiento de bajada de contenidos (16.11.29 (b) (i) (C) (D)), y aunque no describe los términos precisos del procedimiento, sí incluye algunas de las características únicas del modelo estadounidense como lo son el contenido de una notificación y contranotificación (16.11.29 (b) (i) $(\mathrm{C})(\mathrm{D}))^{46}$, una acción contra la falsa representación (16.11.29 (b) (ix)), y

46 ISP side letter. 
una protección para los ISP que bajan contenidos de buena fe (16.11.29 (b) (x)). Por lo tanto, las obligaciones USCO en cuanto a asuntos de ISP es casi una reproducción del sistema de DMCA.

Los requisitos del USCO respecto a medidas tecnológicas de protección son similares a la de la responsabilidad de los ISP, en el sentido de que las obligaciones de la USCO sobre medidas tecnológicas de protección también incorporan las características de la DMCA. El artículo 16.7.4 manda a los socios comerciales a sancionar con sanciones penales y recursos civiles los tres actos prohibidos por la DMCA, que son (1) eludir medidas tecnológicas de control de acceso; (2) el tráfico de dispositivos y servicios para eludir una medida de control de acceso; y (3) disposiciones contra el tráfico de dispositivos y servicios para eludir una medida de control de copia (USCO, 2006, 16.7.4 (a)). Adicionalmente, el USCO incorpora otras características específicas del modelo estadounidense, entre ellas, siete excepciones confinadas (16.7.4 (e)) con instrucciones sobre la aplicación a los diferentes actos prohibidos (16.7.4 (g)), hacer de la protección anti-elusión una disposición independiente (16.7.4 (d)), una norma de no mandato (16.7.4 (c)) y una definición de TPM (16.7.4 (b)). El USCO también obliga a las partes a crear un proceso para la creación de excepciones adicionales al acto de elusión (16.7.4 (f)), como la DMCA. No obstante, una vez más, el USCO permite a las partes a elegir entre establecer un procedimiento administrativo o legislativo.

La situación descrita anteriormente demuestra que el modelo estadounidense fue trasladado en gran extensión al texto del USCO, estableciendo obligaciones que superan los estándares internacionales actuales de derechos de autor. De esta manera, el USCO se convirtió en el acuerdo internacional que establece las normas que Colombia debe seguir a nivel nacional para implementar las disposiciones de aplicación de los derechos de autor en la era digital.

Así, el USCO es un ejemplo de cómo los Estados Unidos opera en el ámbito del derecho internacional de derechos de autor y de los efectos de los vínculos comerciales con la protección de los derechos de autor, donde países en desarrollo muchas veces, impulsados principalmente por el deseo de tener un acuerdo económico con Estados Unidos, terminan aceptando los DPI establecidos por EE. UU. a sabiendas de que esas normas no son apropiados para ellos, como Colombia lo hizo con respecto a las disposiciones de patentes (Díaz, 2006, p. 12). 


\section{Conclusión}

Estados Unidos utiliza su posición predominante para exportar su propio nivel de protección de derechos de autor a los países en desarrollo, principalmente a través de acuerdos bilaterales. Durante la negociación de acuerdos de libre comercio las disposiciones DPI, que incluyen obligaciones detalladas en materia de derecho de autor en la era digital, se presenta a los países en desarrollo como una plantilla que en esencia no se puede modificar. Los países en desarrollo aceptan los términos de propiedad intelectual de los acuerdos de libre comercio porque la aceptación es un requisito previo para obtener el acuerdo comercial con Estados Unidos, que la mayoría de las veces, es visto como una gran oportunidad. Estados Unidos, que busca garantizar un nivel elevado de protección a los titulares de derechos de autor en la era digital, exporta su propia legislación establecida en la DMCA. Este modelo no solo aumenta los niveles de protección existentes, sino que también acerca más la legislación del socio comercial al modelo estadounidense. Además, asegura que Estados Unidos no tendrá que implementar nuevas normas de protección. Por lo tanto, los acuerdos de libre comercio de Estados Unidos se convierten en la nueva obligación internacional en contener las normas mínimas de protección de derechos de autor en la era digital para varios países. Uno de estos países es Colombia. 


\section{Capítulo 5}

\section{ESTUDIO DE LOS INTENTOS DE IMPLEMENTACIÓN DE COLOMBIA DEL TRATADO DE LIBRE GOMERGIO DE ESTADOS UNIDOS-COLOMBIA Y SUS POTENGIALES EFEGTOS EN LA EDUGAGIÓN}

Hn la actualidad, Colombia está en el proceso de

Cimplementación del USCO, que como se ha mencionado antes, es el acuerdo internacional que establece las nuevas normas mínimas para la protección de derechos de autor en la era digital. Aunque como se indicó en los capítulos previos estas obligaciones internacionales disminuyen cada vez más la autonomía de los países miembros para determinar sus políticas en la materia de DPI, durante los intentos de implementación del USCO, Colombia sobrestimó las limitaciones impuestas a su autonomía por el acuerdo comercial decidiendo seguir el acuerdo de cerca, prácticamente "copiando y pegando" el texto del acuerdo. Por otro lado, el deseo de Colombia de tener el acuerdo económico en vigencia influyó durante el proceso de implementación. De las anteriores circunstancias se deriva que el Congreso de Colombia durante los intentos de implementación del USCO siguió muy de cerca el modelo estadounidense, sin estar obligado a hacerlo. No obstante, este tipo de implementación no beneficia a Colombia y puede afectar su capacidad de utilizar la tecnología para resolver los problemas más destacados de la educación, aun cuando no se esté infringiendo el derecho de autor. 
Como se explicará al interior de este capítulo, decidir aplicar el estilo americano en Colombia junto con su actual ley de derechos de autor, tal como lo intentó el Congreso colombiano, aumenta el potencial del modelo de Estados Unidos de socavar la transformación del proceso de aprendizaje. De igual manera, la adopción de este modelo de implementación también influirá en la evolución futura de la ley de derechos de autor de Colombia. Aunque Estados Unidos puede sentir estas consecuencias ${ }^{1}$, como se explicó en el capítulo 3, el impacto es mucho mayor en Colombia debido a la importancia de la política de TIC en la educación para el país. ${ }^{2}$ No obstante, los prospectos de implementación del USCO han fracasado en gran parte gracias al importante papel de la sociedad civil. Así, Colombia aún tiene tiempo para tomar un enfoque de implementación diferente.

La sección primera de este capítulo describe el estado actual de la ley de derechos de autor colombiana y el cumplimiento de los acuerdos internacionales. Esta sección es importante para describir más adelante cómo la ley de derechos de autor existente puede aumentar los potenciales efectos negativos de establecer un modelo siguiendo las normas estadounidenses de limitaciones a la responsabilidad de los ISP y protección a TPM. La sección segunda describe la historia del intento de implementación del USCO. Por último, la sección tercera explica cómo una implementación realizada en el estilo de copiar y pegar las obligaciones del USCO, junto con la actual ley colombiana, puede aumentar los potenciales efectos negativos del modelo estadounidense en el desarrollo de un proceso de aprendizaje transformado.

\section{La ley actual de derechos de autor de Colombia}

Colombia es signataria de los principales tratados internacionales de derechos de autor, como el Convenio de Berna ${ }^{3}$, el Acuerdo sobre los ADPIC $^{4}$ y el Tratado de la OMPI sobre Derechos de Autor ${ }^{5}$. Debido a esto, la autonomía de Colombia para forjar su propia política de derechos de autor está limitada por las obligaciones internacionales adquiridas en esos acuerdos, y su ley de derechos de autor, en términos generales, refleja el

\footnotetext{
Ver capítulo 3.

Ver capítulo 1.

Ver World Intellectual Property Organization [WIPO] (s.f. a).

Ver WIPO (s.f. b)

Ver WIPO (s.f. c)
} 
cumplimiento de las normas mínimas de protección. Por otra parte, a nivel regional, Colombia es miembro de la Comunidad Andina ${ }^{6}$ y, por tanto, está sujeta a la Decisión Andina 351 del 17 de diciembre de 1993. La decisión establece disposiciones sustanciales de protección del derecho de autor. De esta manera, los países miembros no pueden regular materias ya reguladas por la Decisión o establecer disposiciones que puedan hacer que sea difícil obtener los derechos establecidos en la decisión (Palacio, 2013, p. 209) ${ }^{7}$. En este sentido, la Decisión 351 también limita la autonomía de Colombia para definir su propia política de derechos de autor.

En Colombia, la protección del derecho de autor tiene sus fundamentos constitucionales en el artículo 61 de la Constitución Política de 1991 y el marco de derechos de autor se forma por la legislación nacional y regional: la Ley 23 de $1982^{8}$ y la Decisión 351, respectivamente. La relación entre estas dos leyes es jerárquica; la Decisión Andina 351 prevalece sobre la Ley 23 de 1982. Por tanto, en caso de conflicto entre ambas legislaciones, la primera deberá ser aplicada ${ }^{9}$. En términos generales, la ley de derechos de autor colombiana sigue la tradición europea de los derechos de autor. En este sentido, la legislación protege los derechos morales del autor como un derecho humano ${ }^{10}$ y los derechos económicos de autor como un derecho constitucional $^{11}$. La protección de derechos de autor prevalece sobre la protección de los derechos conexos ${ }^{12}$.

La legislación de derechos de autor de Colombia puede ser descrita como protectora de los autores, ya que la legislación otorga derechos económicos ilimitados a los autores mediante la protección de cualquier forma conocida o

6 Ver Acuerdo de Integración Subregional Andino - Acuerdo de Cartagena, 26 de mayo de 1969.

7 Estableciendo las obligaciones de los países miembros frente a las disposiciones andinas.

8 Se ha modificado por la Ley 44 de 1993 y ha sido complementada por la Ley 1403 de 2010.

9 Ver Sentencia C-228 de 1995; Sentencia 4630 de 2000.

10 Ver Sentencia C-276 de 1996, explicando las razones para proteger los derechos de autor como un derecho humano.

11 Ver Sentencia C-155 de 1998. Afirmando que si bien los derechos económicos del autor no se consideran los derechos humanos, merecen protección como lo manda la Constitución.

12 Ver Ley 23 de 1982, art 2 y Ley 44 de 1993, art 67, afirmando la primacía del derecho de autor sobre los derechos conexos. 
por conocer de explotación de la obra ${ }^{13}$. Esto significa que la ley de derechos de autor colombiana ha concedido todos los derechos sustanciales mínimos establecidos en Berna, el ADPIC, o el WCT - reproducción ${ }^{14}$, adaptación ${ }^{15}$, distribución (Decisión 351, art. 13 (c)) y comunicación pública ${ }^{16-}$, y va más allá de esos mínimos mediante la protección de todos los usos conocidos o por conocer (Proceso No 23-IP-98 de 1998). Estos derechos son transferibles (Decisión 351, art. 29). Por otro lado, las limitaciones y excepciones son limitadas. Dichas limitaciones y excepciones se encuentran enumeradas en una lista exhaustiva, sujetas a interpretación restringida (Proceso $\mathrm{N}^{\circ}$ 24IP-98, p. 9) y generalmente se aplican a los derechos económicos y no a los derechos morales ${ }^{17}$. En cuanto a los derechos morales, la ley protege el derecho de paternidad (Ley 23 de 1982, art. 30 (a); Decisión 351, art. 11 (b)); derecho de integridad (Ley 23 de 1982, art. 30 (b); Decisión 351); derecho de modificación (Ley 23 de 1982, art. 30 (d)); derecho de retracto (art. 30 (e)); y el derecho a conservar la obra inédita (art. 30 (c); Decisión 351, art. 11 (a)). Estos derechos son inalienables e imprescriptibles (Ley 23 de 1982, art. 30; Decisión 351, art 11; sentencia C-975 de 2002), superando los requisitos mínimos de Berna, el cual establece que los derechos morales serán protegidos por la misma duración que los derechos económicos (Convenio de Berna de 1971, art. 6 bis). Además, la Ley 23 de 1982 se guía por el principio in dubio pro Autor, que establece que en caso de duda sobre la aplicación de la ley de derechos de autor, la interpretación favorable para el autor debe aplicarse (art. 257).

El alcance de la protección de derechos de autor en la legislación colombiana es amplio ya que protege cualquier obra original capaz de ser divulgada o reproducida por cualquier medio conocido o futuro (Decisión 251, art. 4). El requisito de originalidad se refiere a "la individualidad", lo que significa que el autor ha hecho el trabajo por sí mismo en lugar de

13 Ver Proceso No ${ }^{\circ}$ 23-IP-98 de 1998, p. 9. Explicando las características de los derechos económicos como ilimitada.

14 Ver Ley 23 de 1982, art. 12 (a); Decisión 351, art. 13 (a).

15 Ver Ley 23 de 1982, art. 12 (b); Decisión 351, art. 13 (e).

16 Ver Ley 23 de 1982, art. 12 (c); Decisión 351, art. 13 (a), 13 (b) y 13 (c).

17 Las excepciones y limitaciones solo se aplican a los derechos morales en dos casos: Ley 23 de 1982, art. 43 referido a las obras arquitectónicas y en el art. 91 referido a los empleados públicos. Ver Sentencia C 871 de 2010. 
$\operatorname{copiarlo}^{18}$. La "capacidad de ser divulgada" significa que el trabajo ha salido de la esfera interna del autor y se ha exteriorizado. Como resultado de ello, la ley de derechos de autor colombiana protege las obras fijadas y obras orales ${ }^{19}$. Por lo tanto, la ley de derechos de autor colombiana protege casi toda obra original a menos que sea una obra tradicional de folclor; una obra de autores desconocidos o que la obra se encuentra en el dominio público (Ley 23 de 1982, art. 187, no. 3). Las ideas no están sujetas a la protección autoral, solo la expresión de esas ideas (art. 6) que se alinea con un principio general del derecho de autor creado en virtud del WCT (Tratado de la OMPI, 20 de diciembre de 1996, art. 2). Finalmente, la duración de la protección bajo la ley colombiana es extensa. La regla general es que una obra está protegida durante 80 años después de la muerte del autor (Ley 23 de 1982, art. 21) ${ }^{20}$ y 50 años después de la realización, divulgación o publicación de la obra (Decisión 351, art. 18) cuando una corporación es el titular de los derechos de autor.

La ejecución de la ley es estricta; las infracciones al derecho de autor están fuertemente sancionadas en la legislación colombiana. Los recursos civiles, como el embargo preventivo de las obras o el beneficio de la venta o alquiler de tales obras, están disponibles (Decisión 351, art. 244). En el caso de las obras cinematográficas, musicales y teatrales, el titular de los derechos de autor puede solicitar una orden para detener la actuación no autorizada de la obra (art. 245). Por último, el titular de los derechos de autor puede traer cualquier tema relacionado con los derechos de autor al sistema de justicia civil (art. 242). La aplicación de la responsabilidad civil se describirá al momento de explicar la situación de los intermediarios de Internet.

El derecho penal ${ }^{21}$ también establece fuertes sanciones contra la infracción a los derechos de autor tanto de los derechos morales como económicos. La infracción de los derechos morales es fuertemente condenada y castigada con

18 Ver Interpretación Prejudicial 10-IP-99 de 1999, explicando el concepto de originalidad.

19 Ver Decisión 351, art. 4, establece una lista no exhaustiva de obras protegidas, dentro de la cual están obras orales como conferencias, sermones, discursos y obras de lenguaje corporal como coreografías.

20 Otros términos de protección se aplican en función de diferentes circunstancias, por ejemplo, el plazo de protección es diferente si el trabajo se transfiere a una empresa o a una persona distinta a los herederos; o si las obras es anónima, entre otros.

21 Ver Ley 599 de 2000 (Código Penal [C Pen]). 
treinta y dos a noventa meses de prisión y una multa de 26,6 a 300 salarios mínimos legales vigentes (SMLV) (Ley 599 de 2000, art. 270). Esta posición se pone de manifiesto en el caso de la Corte Suprema, donde una profesora universitaria recibió veinticuatro meses de prisión y una multa de cinco veces el salario mínimo por infringir los derechos morales de uno de sus alumnos después de incluir en su artículo algunos extractos de trabajo del estudiante sin citación adecuada (Proceso de Casación 31403 de 2010, pp. 78-79). Aunque este caso fue una violación típica del derecho de paternidad del autor, el Código Penal no incluye una disposición en contra de la violación de dicho derecho (Ley 599 de 2000, art. 270). No obstante, la Corte Suprema en su decisión amplió el alcance del delito contra los derechos morales al hacer una interpretación Pro Homine para sancionar al supuesto infractor. En otras palabras, la Corte Suprema utilizó un principio aplicado en la interpretación de los derechos humanos para cubrir una acción no incluida en el ámbito del tipo penal (Proceso de Casación 31403 de 2010, pp. 78-79).

La infracción de los derechos económicos se castiga con cuatro a ocho años de prisión y una multa de 26,66 a 10,000 veces el salario mínimo ${ }^{22}$. El delito no requiere ninguna intención de lucro o que la infracción sea a escala comercial. Por lo tanto, se tipifica una amplia gama de conductas. La rigidez con que dicha prohibición se ha aplicado ha variado de caso en caso; a veces, la Corte Suprema ha sido más flexible para decidir si aplicar las sanciones penales. Por ejemplo, en un caso relacionado con la puesta en venta de dos libros "piratas", la Corte no condenó al infractor argumentando que el derecho penal debe aplicarse cuando el bien protegido ha sido fuertemente vulnerado (Proceso de Casación 31362 de 2009). Sin embargo, en un caso relacionado con la puesta en venta de diecinueve fonogramas piratas y cuatro DVD, el infractor fue condenado a cuarenta y ocho meses de prisión y una multa de 26,66 veces el salario mínimo (Proceso de Casación 30532 de 2009). Por otra parte, la Corte Suprema en algunos casos ha requerido la existencia de una intención de lucro, que no ha sido requerida en otros $\operatorname{casos}^{23}$. El derecho penal también sanciona la elusión de una medida tecnológica, lo cual discutiremos en detalle más adelante.

$22 \quad$ Ver Ley 599 de 2000, art. 270, modificado por la Ley 1036 de 2006.

23 Ver Proceso de Casación 29188 de 2008 requiriendo intención de lucro; ver también Rengifo (2010), donde se habla de las diferencias en el tratamiento de la "intención de lucro" por la Corte Suprema de Colombia (p. 315). 
Por último, la ley de derechos de autor de Colombia permite la creación de sociedades de gestión colectivas de derechos de autor. En este sentido, los titulares de derecho de autor pueden decidir si cobrar las tarifas por el uso de las obras de forma individual o mediante la creación de sociedades de gestión colectivas (Ley 23 de 1982, art 73; Ley 44 de 1993, art. 10). En caso de que los autores decidan crear una sociedad colectiva, dicha sociedad debe ser una persona jurídica distinta de sus miembros conferido por la Dirección Nacional de Derechos (Ley 44 de 1993, art. 11). Igualmente dicha entidad es la encargada de vigilar su funcionamiento (art. 37). Las sociedades colectivas tienen derecho a llevar tanto acciones civiles como penales en la representación de sus miembros (Tobón y Varela, 2010).

Aunque la ley de derechos de autor incluye algunas disposiciones relativas a la protección de software y bases de datos, dicha ley no ha sido actualizada para enfrentar el mundo digital (Decisión 351, art. 23, 27 y 28). A pesar de esta realidad, en el año 2000, el Congreso colombiano aprobó el Tratado de la OMPI sobre Derechos de Autor. Esta aprobación nos demuestra que la ley de derecho de autor de Colombia se aplica en el entorno digital ${ }^{24}$, posición que está igualmente sustentada por la forma en que la ley de derechos de autor está escrita. Como se mencionó anteriormente, las disposiciones relativas a los derechos económicos del autor son cláusulas generales que permiten la adaptación de la protección del derecho de autor a las nuevas tecnologías (Zapata, 1998, p. 140)25. Los distintos artículos de la Decisión 351 y la Ley 23 de 1982 establecen los derechos económicos del autor en términos generales. Por ejemplo, el artículo 13 de la Decisión 351 concede el derecho de reproducción "por cualquier forma o procedimiento" o la comunicación pública de la obra "por cualquier medio" (art. 13) ${ }^{26}$. Además, el Tribunal de la Comunidad Andina ha reconocido la aplicación de los derechos económicos a cualquier uso conocido o por conocer (Proceso $\mathrm{n}^{\circ}$ 24-IP-98). Por lo tanto, incluso si la ley de derechos de autor fue escrita

24 Colombia ratificó el WCT y el WPPT en noviembre 29 de 2000. Ver Melé (2007), indicando que a medida que Colombia ha ratificado los tratados de Internet de la OMPI se entiende que la ley de derechos de autor se aplica tanto al medio ambiente análogo y al digital (p. 27).

25 Indicando que la protección de las obras a lo largo de la evolución tecnológica parece estar garantizada por la ley que protege como una cláusula general.

26 Ver Rodríguez (2004), indicando que los diferentes derechos económicos están escritos en una forma que permiten su aplicación en el mundo digital (p. 258). 
para un mundo analógico, sus derechos económicos se aplican a Internet (Monroy, 2010, p. 202) 27. La protección de los derechos morales también está disponible para las obras que se encuentran en Internet, debido al hecho de que la protección de los derechos de autor se da independientemente de los medios que se utilizan para difundir la obra ${ }^{28}$.

Por otra parte, la Dirección Nacional de Derechos de Autor (DNDA) ha emitido conceptos que afirman la aplicación de la ley de derechos de autor a Internet ${ }^{29}$. Los conceptos de la DNDA son respuestas a preguntas formuladas a la oficina de derechos de autor por las personas acerca de la aplicación de la ley de derechos de autor. Aunque estos conceptos no son vinculantes (Ley 1437 de 2011, art. 28) ${ }^{30}$, representan una importante fuente secundaria para comprender el significado y el alcance de la ley de derechos de autor. De esta manera, la DNDA ha dado algunas orientaciones acerca de cómo estos derechos se aplican a las obras en Internet. Por ejemplo, en relación con el acto de subir contenido a Internet, la DNDA ha declarado que una publicación en Internet representa un acto de reproducción, más un acto de comunicación pública (Dirección Nacional de Derecho de Autor, 6 de diciembre de 2010) ${ }^{31}$. La descarga también representa un acto de reproducción (DNDA, 24 de febrero de 2010, p. 2) y el derecho de poner a disposición es un acto de comunicación pública (DNDA, 2009, p. 4). Todos los actos mencionados anteriormente requieren la autorización del titular de los derechos de autor. Por lo tanto, la ley de derechos de autor de Colombia cumple con los requisitos mínimos del WCT.

\footnotetext{
27 Indicando que las legislaciones de derecho de autor de los países de América Latina no fueron escritas para un mundo digital.

28 Ver Ley 23 de 1982, otorga protección al autor de una obra original capaz de ser reproducida o definida por "cualquier medio conocido o por conocer" (art. 2). Además la Decisión 351 otorga protección a una obra que pueda "reproducirse o divulgarse por cualquier forma o medio conocido o por conocer" (art. 4).

29 Ver Dirección Nacional de Derechos de Autor (6 de diciembre de 2005, p. 4); ver también Dirección Nacional de Derechos de Autor (15 de abril de 2005, pp. 2-3).

30 Indicando que las respuestas de las instituciones públicas a las preguntas formuladas por los individuos, como el ejercicio del derecho a formular preguntas, no son vinculantes.

31 La DNDA respondiendo a una consulta sobre la potencial publicación en línea de la tesis de los estudiantes por una institución educativa afirma que la publicación en Internet significa el almacenamiento en la memoria de un servidor o de la intranet de la obra además de una comunicación pública que requiere la autorización del titular del derecho de autor.
} 
En cuanto a las limitaciones y excepciones, el artículo 10 del WCT permite extender la aplicación de las excepciones y limitaciones existentes al entorno digital, por lo tanto, en teoría, las limitaciones y excepciones existentes en virtud de la legislación colombiana podrían aplicarse al entorno digital cuando la aplicación analógica sea posible (Tratado de la OMPI, 20 de diciembre de 1996, art. 10 y declaración concertada). Sin embargo, bajo la ley de Colombia ninguna excepción y limitación ha sido diseñada específicamente para el mundo digital (Monroy, diciembre de 2009, p. 109)32.

Por lo tanto, la descripción anterior de la ley de derechos de autor de Colombia apoya la afirmación de que el sistema colombiano de autor es proteccionista. Colombia ha cumplido con sus obligaciones en el plano internacional; proporcionando derechos sustanciales y un mecanismo de observancia de la ley. Por otra parte, el derecho de autor se aplica al entorno digital y algunas limitaciones y excepciones se proporcionan con el fin de asegurar los objetivos de interés público.

\section{La responsabilidad del ISP sobre infracciones de derechos de autor bajo la ley colombiana actual.}

Aunque está fuera del alcance de este libro hacer un análisis profundo del sistema de responsabilidad civil por infracción de derechos de autor, es importante exponer sus principales características con el fin de explicar la situación de las actividades de los ISP en la legislación colombiana. Bajo la ley colombiana no existe una ley específica que regule la responsabilidad de los ISP. Sus actividades están, por tanto, sujetas a los principios generales de la responsabilidad (Ramírez, 2009, p. 292) ${ }^{33}$. No obstante, para el momento de esta investigación ningún tribunal había aplicado esos principios a las actividades de un ISP en los casos de derecho de autor, y la aplicación de dichos principios a la conducta de los ISP no ha sido ampliamente discutida o determinada. Sin embargo, la obligación de establecer un sistema de limitación a la responsabilidad de estos intermediarios puede llevar a determinar de manera automática que estos sí son responsables bajo los

32 Indicando que los países latinoamericanos no han promulgado las limitaciones y excepciones para el mundo digital.

33 Afirmando que debido a la falta de una regulación de un sistema específico, los ISP están sujetos a los principios generales de la responsabilidad. 
principios. En adelante discutiremos las posibles adaptaciones de dichas teorías a la conducta de los ISP.

En primer lugar, un tipo de responsabilidad que preocupa a la mayoría de los proveedores de Internet en todo el mundo es la responsabilidad objetiva, ya que los ISP sostienen que no son más que intermediarios y que sus actividades son el producto de un proceso automático que carece de voluntad (Bayer, 2007, p. 6) $)^{34}$. Según la legislación colombiana, la infracción de derechos de autor no está sujeta a responsabilidad objetiva. La regla general de responsabilidad civil ${ }^{35}$, que se aplica en la infracción a los derechos de autor, requiere un elemento de intencionalidad del acusado con el fin de ser responsable (Proceso de casación 4345 de 1995). De esta manera, el demandante tiene la carga de probar que hubo conducta y que la conducta se hizo con un elemento de intencionalidad (Plata, 2010, pp. 106-107) ${ }^{36}$. Por lo tanto, los ISP inicialmente no podrían ser declarados responsables de infracción directa de derechos de autor por las reproducciones automáticas que ocurren en sus sistemas.

Con el fin de incurrir en responsabilidad civil por violación directa de derechos de autor debe haber conducta (acción u omisión), y un elemento de intencionalidad (negligencia o fraude). Tal conducta debe violar los derechos de autor de una obra protegida y no debe estar cubierta por una limitación o excepción(pp. 101, 103, 106-107, 111, 113, 135)37. La aplicación de estos elementos a las actividades llevadas a cabo por los ISP plantea interrogantes sobre su responsabilidad: ¿un ISP que sabe de la existencia de materiales infractores de los derechos de autor que se transmiten, y por lo tanto, se reproducen por su sistema, pero no actúa de acuerdo con su conocimiento, es responsable en virtud de una teoría de la violación directa de derechos de autor?

La respuesta a esta pregunta podría ser positiva. En el marco del derecho civil, la conducta sancionable puede ser por acción u omisión. En

34 "Strict or absolute liability clauses pose a particular danger to ISPs since the mental element would not be required to be held liable" (p. 6).

35 La regla general de responsabilidad se encuentra en el art. 2341 del Código Civil. (C. C.)

36 Afirmando que en la legislación colombiana, la responsabilidad por la infracción de los derechos de autor requiere un elemento mental.

37 Indicando y explicando los requisitos para ser responsable de la infracción directa del derecho de autor. 
el escenario anterior, la conducta sancionable sería la omisión del ISP para actuar después de que tuviera conocimiento de la infracción. El elemento de intencionalidad requerido surge después de que el ISP sabe que hay una obra infractora dentro de su red y no actúa para detener la infracción. Por último, la violación del derecho de autor se produce debido a las diferentes reproducciones de la obra que se producen dentro de la red del proveedor de Internet durante el proceso automático. Es importante destacar que, en la legislación colombiana, y a diferencia de otros países, no existe una excepción que abarque una reproducción temporal hecha como resultado de un proceso automático. Una reproducción temporal automática realizada por el proveedor de Internet, por lo tanto, podría ser un uso infractor. No obstante, los tribunales no han abordado esta cuestión y la adopción de este tipo de posición podría impedir el desarrollo de Internet.

Bajo los principios de responsabilidad civil de Colombia, el principio que se asemeja más a una responsabilidad objetiva es la creación de una presunción de responsabilidad que se aplica en el caso de actividades peligrosas (Proceso de Casación 5012 de 1999) ${ }^{38}$. La presunción de responsabilidad por actividades peligrosas está establecida en el artículo 2356 del Código Civil, el cual manda la responsabilidad de las personas que han creado un riesgo adicional a los demás y, por tanto, debe asumir los costos de los daños creados por esta actividad peligrosa (Barros, 2006, pp. 456-457) ${ }^{39}$. Como tal, las personas que realizan actividades peligrosas se presumen responsables, lo que significa que si la persona fue negligente o no, no se discute (Proceso de casación 5012 de 1999) ${ }^{40}$. De esta manera, las defensas de la parte demandada se reducen a demostrar caso fortuito, fuerza mayor, culpa exclusiva de la víctima, o negligencia de un tercero (Proceso de casación 4345 de 1995) ${ }^{41}$.

38 Afirmando que bajo la responsabilidad de las actividades peligrosas hay una presunción de responsabilidad. Lo que significa que no es necesario probar el elemento de intencionalidad del infractor. Sin embargo, no significa que se modificó la regla general de responsabilidad que requiere un elemento mental.

39 Explicando las razones para crear la responsabilidad a una persona que participa en una actividad peligrosa.

40 Afirmando que la responsabilidad por actividades peligrosas crea una presunción de responsabilidad.

41 Indicando las defensas disponibles para la responsabilidad por actividades peligrosas. 
La pregunta importante en virtud de esta teoría es ¿qué constituye una actividad peligrosa? La Corte Suprema ha establecido que una actividad peligrosa es un concepto objetivo, que tiene en cuenta la naturaleza de las cosas y las circunstancias bajo las cuales se realiza la actividad peligrosa (Proceso de casación 5012 de 1999). Esto significa que no todas las actividades se consideran peligrosas, pero al mismo tiempo, que no es un concepto cerrado y nuevas actividades pueden ser incluidas (Mantilla, 2007, p. 135) ${ }^{42}$.

$\mathrm{Al}$ traer este tipo de responsabilidad a la situación de los ISP, algunos comentaristas han afirmado que el ISP puede estar involucrado en actividades peligrosas debido a la capacidad de Internet para difundir ampliamente y comunicar las infracciones ${ }^{43}$. Si esta teoría es adoptada por los tribunales colombianos, significará que los ISP podrían ser considerados responsables, independientemente de si sabía de la existencia del material infractor en su red, a menos que el proveedor de Internet pueda establecer que su presencia fue fortuita o causa de fuerza mayor, culpa exclusiva de la víctima, o negligencia de un tercero. No obstante, el escenario también nos permite preguntarnos si podría argumentarse que el comportamiento de la tercera parte, que cometió la infracción, podría ser considerado como la negligencia de un tercero, y de esta forma dejar al ISP exento de responsabilidad. Si se acepta este argumento, un ISP no sería responsable. Una vez más, la discusión sobre la aplicación de esta teoría no ha pasado de la discusión doctrinal, y los tribunales no han aplicado este principio a los ISP.

Debido a que la responsabilidad de los ISP se refiere, en la mayoría de los casos, a sus actividades como las de un intermediario y no un proveedor de contenido, es importante explicar el principio de la responsabilidad indirecta en la legislación colombiana. El art. 2347 establece la presunción de que una persona es responsable de la actividad de su dependiente. La doctrina ha establecido algunas pautas para determinar si existe responsabilidad indirecta en virtud del artículo 2347, que incluye (a) la responsabilidad directa del dependiente; (b) obligaciones legales o contractuales de la persona encargada de cuidar a los dependientes; y (c) el acto perjudicial del dependiente debe

42 Afirmando que el concepto de actividades peligrosas no es una lista exclusiva de las actividades, es un concepto cambiante.

43 Ramírez (2009) indica que algunas personas consideran Internet como una actividad peligrosa para las infracciones de derechos de autor (p. 292); ver también Peña (2013, p. 216). 
tener lugar durante la relación de subordinación (Velásquez, 2013, p. 543) . $^{44}$ Si se cumplen todos los elementos, entonces hay una presunción de que la persona a cargo es responsable (p. 552) ${ }^{45}$. Para evitar la responsabilidad, esta persona puede demostrar que ella ejerció diligencia y cuidado ${ }^{46}$.

La aplicación de este principio para establecer la responsabilidad de un proveedor de Internet por la infracción de derechos de autor de un usuario solo se aplicaría si el ISP tiene el control de la actividad infractora ${ }^{47}$. El nivel de control requerido es que el daño causado por el infractor directo sea el producto de la autorización de un ISP, como evidencia del control y dirección del proveedor de Internet y la subordinación del usuario (Proceso de casación 4637 de 1996). Este principio de responsabilidad se asemeja a la responsabilidad vicaria de Estados Unidos. No obstante, una de las mayores diferencias entre ambos principios es que la responsabilidad vicaria genera responsabilidad objetiva ${ }^{48}$, mientras que el principio de Colombia genera una presunción de responsabilidad que es refutable demostrando cuidado. Además, en virtud del principio de Colombia, el elemento mental desempeña un papel importante en la infracción debido a que el infractor directo, como regla general, debe actuar con un elemento de intencionalidad para encontrar al tercero responsable (Fernández, 2003, p. 237) ${ }^{49}$.

Por último, la Decisión 351 contiene una disposición que merece atención en materia de responsabilidad ISP. El art. 54 establece que ni una persona, ni una entidad pueden "prestar su apoyo" para utilizar una obra con derechos

44 Estableciendo los elementos de la responsabilidad subsidiaria.

45 Estableciendo que hay una creación de una presunción.

46 Ver Proceso de casación 6264 de 2000, señalando que en virtud del art. 2347 el cumplimiento del deber de cuidado debe ser ejercido en el momento de la ocurrencia del evento; ver Fernández (2003), indicando que el presunto responsable puede defenderse demostrando cuidado (pp. 233-235); ver también Velásquez (2013), el establecimiento de las defensas disponibles para el presunto responsable (p. 551).

47 Ver Rengifo (2014): "[...] the liability figure for actions of a third party applied to the ISP could be inferred as long as it is proven that he had or could have control on the infringing actions of third parties" (p. 183); ver también Rengifo (2013), señalando que en virtud del art. 2347 si el ISP tiene el control y el conocimiento sobre el contenido infractor disponible en la nube, por tanto, puede ser encontrado responsable si no actúa en virtud del conocimiento (p. 235).

48 Ver capítulo 3.

49 Afirmando que la responsabilidad por el acto de un dependiente, el infractor directo debe actuar con culpa. 
de autor si el usuario no está autorizado para hacer tal uso. Si la persona o entidad lo hace, entonces, será solidariamente responsable (Decisión 351, art. $54)^{50}$. El Tribunal Andino, interpretando el artículo en un caso relacionado con la infracción de software por una autoridad judicial, declaró que cuando una autoridad judicial o administrativa sabe de la infracción, pero lo tolera, la tolerancia proporciona ayuda para el uso infractor del usuario (Proceso $\mathrm{n}^{\circ}$ 24-IP-98). Por otra parte, el tribunal declaró que cada proceder o conducta dirigida a respaldar, apoyar, proteger o permitir la utilización no autorizada de obras protegidas, incluso en el caso de omisión y acción, caen bajo el supuesto de hecho en virtud del artículo 54 de la Decisión 351 del Acuerdo de Cartagena (Proceso n 24-IP-98).

El artículo 54 puede permitir realizar el argumento de que cuando un ISP sabe sobre el material infractor, pero no actúa, podría ser solidariamente responsables de la infracción de derechos de autor. Sin embargo, no hay casos que hayan aplicado esta teoría, y el Tribunal Andino tendría que interpretar si este régimen de responsabilidad se aplica a un ISP en los casos de infracción de derechos de autor (Rengifo, 2014, p. 184) ${ }^{51}$.

Por lo tanto, la discusión acerca de si un ISP podría ser responsable de la infracción de los derechos de autor de un tercero no ha sido abordado por los tribunales colombianos. Además, los principios generales de responsabilidad difieren de las teorías de responsabilidad contributiva y vicaria en Estados Unidos. El tema hasta ahora está empezando a ser desarrollado por la doctrina jurídica. Por lo tanto, no hay certeza acerca de cómo aplicar estos conceptos de responsabilidad por infracción de derechos de autor de un tercero a un ISP.

50 Ninguna autoridad, ni persona natural o jurídica, podrán autorizar la utilización de una obra, interpretación, producción fonográfica o emisión de radiodifusión o prestar su apoyo para su utilización, si el usuario no cuenta con la autorización expresa previa del titular del derecho o de su representante. En caso de incumplimiento será solidariamente responsable (art. 4).

51 Hablando de la aplicación de la Decisión al ISP: "But here we are in the area of speculation because in the Andean region there has not been a judicial precedent to clarify this situation" (p. 184). 


\section{La implementación del USCO}

Colombia tiene la obligación de implementar el sistema de limitación de responsabilidad de los ISP y las protecciones a TPM establecidos en el $\mathrm{USCO}^{52}$. Por lo tanto, es probable que la siguiente enmienda a la ley de derechos de autor colombiano sea la implementación del USCO. A pesar del detalle de las disposiciones del USCO, su parecido con el modelo estadounidense y de limitar la autonomía de Colombia para decidir sobre ciertos aspectos de la aplicación de la ley de derechos de autor en Internet, el USCO, como un acuerdo internacional, debe pasar por un proceso de implementación a nivel nacional, donde sus disposiciones podrían adaptarse a las necesidades nacionales de Colombia. Sin embargo, la historia de los distintos intentos por implementar dichas disposiciones revela una situación completamente diferente.

El Congreso de Colombia ha tratado de implementar las disposiciones de la USCO casi en un estilo de copiar y pegar, principalmente motivado por el deseo de tener un TLC en vigor. De esta forma, vemos como el Congreso se ha visto a sí mismo más limitados en su capacidad para determinar la política en materia de derechos de autor por el USCO de lo que realmente está.

\section{Historia de la implementación del USCO: Ley Lleras (Proyecto de Ley 241) y Ley Lleras 2.0 (Ley 1520).}

Los intentos de implementación del modelo de limitaciones a la responsabilidad de los ISP y la protección a TPM se desarrollaron en dos proyectos de ley diferentes: el proyecto de Ley 241 de 2011 que trató de implementar el sistema de limitación de responsabilidad de los ISP. Esta ley fue conocida públicamente como la "Ley Lleras" debido a su presentador, el exministro de Justicia, Germán Vargas Lleras ${ }^{53}$. Y la Ley 1520 de 2012 que implementó las obligaciones en materia de TPM. Esta ley fue conocida públicamente como "Ley Lleras 2.0" (Urrego, 27 de enero de 2013) ${ }^{54}$, ya que se consideró como una continuación de la Ley Lleras aunque regulaba cuestiones diferentes. A diferencia del proyecto 241, la Ley 1520

\footnotetext{
52 Ver capítulo 4.

53 Ver Ley Lleras (s.f.).

54 Afirmando que la ley fue denominada Ley Lleras 2.0
} 
fue promulgada. Sin embargo, como se explicará más adelante, la Corte Constitucional la declaró inexequible.

Ambos intentos de implementación tuvieron características comunes en su proceso legislativo. En primer lugar, ninguno de los dos tuvo el propósito de actualizar o reequilibrar la ley de derechos de autor. En su lugar, estas medidas simplemente intentaron añadir las obligaciones del USCO a una ley sin cambios $^{55}$. Como se explicará en la siguiente sección, este enfoque genera disposiciones más restrictivas. En segundo lugar, ambos intentos de implementación siguieron de cerca el texto del acuerdo sin grandes cambios (Proyecto de Ley 306 de 2013; Peñarredonda, 20 de mayo de 2013). Este enfoque sugiere que el Congreso colombiano se sentía más limitado por el texto del USCO de lo que estaba en la realidad. Esto también es evidente en el hecho de que, después que la Ley de 1520 fue declarada inexequible, el Gobierno presentó casi el mismo texto del proyecto de ley al Congreso ${ }^{56}$. No obstante, dicho proyecto fue archivado debido a la terminación de la legislatura.

En tercer lugar, los dos intentos de implementación se caracterizaron por tener una discusión legislativa limitada sobre el asunto y dirigida por un impulso para regular el tema de manera rápida (Galindo, Martínez y Yañez, 2013, pp. 5, 17) ${ }^{57}$. Por ejemplo, la Ley 1520 fue promulgada en 18 días para tenerla como regalo en la visita del presidente Obama a Cartagena para la reunión de "Cumbres de las Américas" ${ }^{58}$. El Congreso no invitó a

55 Ver texto de proyecto de Ley 241 de 2011 y Ley 1520 de 2012, estableciendo la implementación de las obligaciones de derechos de autor adquiridos en el USCO. Sin embargo, estas leyes no buscaban equilibrar la actual ley de derechos de autor.

56 Ver proyecto de Ley 306 de 2013; ver Peñarredonda (20 de mayo de 2013), indicando que a pesar de la presión de la sociedad civil para dar debate público con el tema, el Gobierno sigue presentando el mismo texto de la ley anterior.

57 Indicando que la velocidad con que las obligaciones del TLC se promulgaron excluyeron la oportunidad de dar discusión a los temas.

58 Ver Romero (s.f., p. 2), el congresista Camilo Romero criticó el proceso de vía rápida dada a la Ley Lleras 2.0. El congresista especialmente critica que no se dio el debate público; ver Los Problemas de la 'Ley LLeras 2.0' (11 de abril de 2012), afirmando que la Ley 1520 fue criticada debido a la prisa de su promulgación, a fin de tenerlo como un regalo para la visita del presidente Obama; ver también Vargas (2013), afirmando que la Ley 1520 se promulgó rápidamente con el fin de tenerlo listo para las "Cumbres de las Américas" (p. 5-25). 
las partes interesadas (Santos, 23 de abril de 2012) ${ }^{59}$ para explorar cómo estas disposiciones podrían afectar intereses colombianos o cómo podrían favorecerlos. Por otro lado, aunque el proyecto de Ley 241 recibió alguna discusión pública de la sociedad civil, el Gobierno no ofreció la oportunidad de tener un debate público oficial sobre el tema.

Una justificación a este rápido intento de implementación fue la necesidad y el deseo de tener el acuerdo comercial en vigor, incluso si la pieza legislativa promulgada no era impecable. Por ejemplo, en un artículo de opinión, Carolina Botero -líder de la sociedad civil de los derechos de los usuarios en Internet- comentó que uno de los senadores de la coalición le dijo en un contexto informal que no importaba qué problemas podría crear la regulación de implementación, ya que la Ley 1520 será declarada inconstitucional, sin embargo, cuando llegue ese momento el USCO estará ya en vigor (Botero, 31 de enero de 2013) ${ }^{60}$. Este comentario revela que el Congreso de Colombia se encontraba motivado en obtener los privilegios económicos del USCO independientemente del efecto que dichas obligaciones pudieran tener en Colombia. Esta es una de las consecuencias de vincular el comercio y los DPI.

En cuarto lugar, ambos proyectos de ley se justificaron en la necesidad de cumplir con el USCO y no como herramienta necesaria para la protección de los titulares del derecho de autor en el entorno digital ${ }^{61}$. Por lo tanto, la razón principal para implementar esos mecanismos de derechos de autor no era proteger a los titulares de derechos de autor en la era digital o para proteger a los ISP de la responsabilidad, sino para obtener los privilegios económicos del tratado. En quinto lugar, por primera vez en la historia del derecho de autor colombiano la sociedad civil desempeñó un papel importante durante el procedimiento. Durante la etapa de implementación, la sociedad civil se

59 Afirmando que una de las mayores molestias contra la Ley 1520 fue la falta de debate público, incluyendo las partes interesadas.

60 Adicionalmente, el ministro de Justicia Germán Vargas Lleras, luego de la promulgación de la ley 1520, afirmó que después de este paso (en referencia a la promulgación de la ley) Colombia cumplió con las obligaciones internacionales para acelerar la entrada en vigor de la USCO. Ver también Colombia da último paso para el TLC con Estados Unidos en medio de polémica (11 de abril de 2012).

61 Ver Exposición de Motivos de Ley 241 de 2011; ver también art. 1. 
opuso al intento de implementación haciendo que dichos proyectos fallaran ${ }^{62}$. Por ejemplo, la Ley 1520, que implementaba la protección a las medidas tecnológicas de protección, fue declarada inexequible gracias a una demanda presentada por un miembro de la oposición ("La Corte Constitucional tumba toda la Ley Lleras", 24 de enero de 2013). La Corte Constitucional sostuvo que la ley recibió el procedimiento equivocado en el Congreso debido a que fue discutido en la Comisión que no correspondía, no obstante, la Corte no examinó las reclamaciones de fondo (sentencia C-011 de 2013).

Por lo tanto, la implementación de las obligaciones del USCO se ha guiado por el deseo económico de tener el acuerdo y no por la solución de las necesidades domésticas. Por otra parte, el Congreso de Colombia erróneamente cree que el USCO requiere seguir de cerca el modelo estadounidense de regulación. No obstante, a pesar de dicha creencia, en algunos aspectos, el Congreso colombiano implementó disposiciones aún más restrictivas.

\section{El contenido de los intentos de implementación del USCO.}

El proyecto de Ley 241 de 2011 trató de regular las obligaciones sobre limitaciones a la responsabilidad de intermediarios de Internet por infracción a los derechos de autor por un tercero ${ }^{63}$. Dicho tema ya había sido tratado de regular en el 2001, antes de firmar el USCO y antes de que se presentara el proyecto 241 de 2011 al Congreso, en el proyecto de Ley 035 de 2001

62 Ver Vargas (2013), afirmando que la Ley Lleras se presentó debido a la fuerte oposición en su contra (p. 8); ver también Galindo et al. (2013), indicando que los usuarios de Internet se oponen a la ley Lleras porque aparece como una restricción a su derecho a acceder a la información y libertad de expresión (p. 16).

63 Alguna legislación relativa a los ISP fue promulgada en Colombia en otros campos. Por ejemplo, la Ley 679 de 2001, modificada por la Ley 1336 de 2009, regula la conducta de los proveedores de Internet en relación con los casos de pornografía infantil. En el artículo 7, la ley prohíbe al ISP, administrador o usuarios, albergar pornografía infantil o recibir enlaces que dirigen a sitios web con dicho contenido. En el artículo 8 se obliga a los ISP, administradores y usuarios a denunciar cualquier abuso a los niños incluyendo la pornografía y utilizar toda la tecnología disponible para luchar contra la distribución de pornografía infantil. Dicho artículo también obliga a permitir mecanismos tecnológicos para conceder a los usuarios protegerse o a sus hijos de acceder a este tipo de contenido. El castigo por la infracción de esta ley puede ser una multa o la cancelación de la página web. 
que pretendía regular la sociedad de la información (Ríos, 2012, p. 245) ${ }^{64}$, incluyendo algunas disposiciones relativas a la responsabilidad de los ISP basado en la Directiva Europea 31 de 2000 (p. 245). No obstante, el proyecto fue abandonado cuando el congresista que presentó el proyecto perdió su puesto en el Congreso (p. 245). El abandono rápido de este proyecto sugiere que limitar la responsabilidad de los ISP no era una necesidad crítica en Colombia.

En 2011 Colombia firmó el USCO y el tema de la responsabilidad de los ISP se reanudó. El proyecto 241 de 2011 siguió estrechamente el modelo estadounidense impreso en el texto del acuerdo. De esta manera, el proyecto 241 intentó poner en práctica cuatro "puertos seguros", como manda USCO, donde para encuadrar dentro de los puertos seguros los ISP deben cumplir algunos requisitos generales y algunos requisitos específicos. Aunque el USCO mandó a regular a los socios comerciales las situaciones en que los ISP no eran responsables de la infracción de derechos de autor de terceros después del cumplimiento de algunos requisitos, el texto desafortunado del proyecto pareciera que creaba responsabilidad al ISP a menos que cumpliera con ciertos requisitos, lo cual tenía sentido debido a la falta de claridad sobre la aplicación de los principios generales de responsabilidad a estos intermediarios.

Desde su mismo título -"Proyecto de Ley 241 de 2011, por el cual se regula la responsabilidad por las infracciones de derechos de autor y derechos conexos en Internet"- el proyecto de ley estaba enviando el mensaje de que establecía responsabilidad a los ISP en lugar de limitarla. Igualmente, el capítulo 1 del proyecto de ley, denominado "criterios de responsabilidad" incluía el artículo 4 que enumera los puertos seguros. La redacción del artículo 4 era pobre y abierta a la confusión. Declaró:

Sin perjuicio de las normas generales sobre responsabilidad civil aplicables, en el caso de aquellas infracciones al derecho de autor y derechos conexos cometidas por terceros, que ocurran a través de sistemas o redes controladas u operadas por personas naturales o jurídicas que presten algunos de los servicios señalados en los artículos siguientes, los prestadores de tales servicios no serán obligados a indemnizar el daño, en la medida que cumplan con las

\footnotetext{
64 Ver también Vargas (2013), describiendo el proyecto de Ley 35 de 2001 (p. 23).

65 Ver Proyecto de Ley 241, capítulo 1.
} 
condiciones previstas en los artículos siguientes para limitar tal responsabilidad, conforme a la naturaleza del servicio prestado (Proyecto de Ley 241 de 2011, art. 4).

La redacción del artículo envió el mensaje de que los ISP serían responsables de una infracción de derechos de autor a menos que cumplieran con ciertos requisitos. En el mismo sentido, el artículo se equivocó al no aclarar que no extendía responsabilidad a los ISP si no cumplían con dichos requisitos, lo que apoyaba la interpretación de que la ley era creadora de responsabilidad a los intermediarios. La confusión generada por el texto del proyecto de ley se puede encontrar en diferentes observaciones hechas a la ley en dicho. Por ejemplo, el grupo de la sociedad civil RedPaTodos que llevó la discusión sobre el tema, basado en el texto, le dio este sentir a la regulación ${ }^{66}$.

Sin embargo, el proyecto en su parte motiva, al hacer referencia a la DMCA y la Directiva Europea 2000/31, permitió inferir que el verdadero objetivo de la ley no era crear un sistema de responsabilidad de los ISP, como su texto hacía creer, sino limitar dicha responsabilidad ${ }^{67}$.

En cuanto al cumplimiento de las demás disposiciones del sistema ISP, el proyecto 241 incorporaba una definición de ISP, según el mandato de USCO, pero con un alcance más amplio. El artículo 1 estableció que un ISP es una persona que, o bien transmite, almacena datos caché, almacena datos a petición del usuario o vincula a otros sitios a través de herramientas de búsqueda de información (Proyecto de Ley 241 de 2011, art. 1) El proyecto de ley incorporaba además otros requisitos de la USCO, tales como la no obligación de monitorear (art. 3), la protección a los ISP por la eliminación de contenido de buena fe (art. 9) y la acción contra los abusos del sistema (art. 10, parágrafo), sin modificaciones más destacadas del texto de la USCO. La evidencia más importante de que el Congreso de Colombia se sintió obligado a seguir el modelo de los Estados Unidos fue la adopción de un procedimiento de bajada de contenidos privado, como el establecido por la DMCA, a pesar

66 Ver Botero, Gómez, Salamanca, Aguirre y Vargas (12 de mayo de 2011); ver también algunos otros comentarios formales e informales acerca de la ley que le dan el mismo significado: Cortés (2013); Buitrago (2011).

67 La parte motiva compara el proyecto 241 a la Directiva Europea 2000/31 y a la DMCA. Esta comparación permite inferir que el proyecto 241 no crea responsabilidad a los ISP. 
de que el USCO no especifica la naturaleza del procedimiento de bajada de contenidos.

El proyecto 241 adoptó un procedimiento privado basado en el modelo americano, aunque con algunas diferencias en el marco de tiempo, por lo que el resultado final fue más restrictivo que el modelo americano original. En el intento de implementación de Colombia, el ISP debía bajar el contenido después de la recepción de una notificación o de haber tenido conocimiento de hechos o circunstancias por los que la infracción era evidente (Proyecto de Ley 241 de 2011, art. 9). Cuando la notificación de derechos de autor se refería a material almacenado por el ISP bajo la dirección del usuario, el ISP contaba con 72 horas después de la recepción de una notificación ${ }^{68}$ para informar al usuario (art. 11). En caso de recibir una contranotificación (art. 12), el ISP debía restaurar el contenido a menos que el solicitante obtuviera una orden judicial en un plazo razonable (art. 9, parágrafo). La ley estadounidense establece un período de 14 días $^{69}$.

Por último, el proyecto de ley adoptaba un procedimiento judicial para obtener información que identificaría el presunto infractor del ISP. Este procedimiento permitía al demandante que solicitara medidas cautelares o hubiera demandado para obtener una orden definitiva de retiro o inhabilitación del acceso al material infractor y/o la terminación de cuentas, pedir al juez que ordenara al ISP a revelar la identidad del presunto infractor (Proyecto de Ley 241 de 2011, art. 15). El proyecto de ley no aclaró a quién la información debía ser revelada.

El Congreso de Colombia también decidió seguir de cerca la redacción del USCO en lo que respecta a la aplicación de la protección a las medidas tecnológicas de protección. No obstante, la situación resultante era un poco diferente a la del sistema de responsabilidad de los ISP, ya que, en este caso, el Congreso no estaba considerando un asunto no regulado. A diferencia de las limitaciones de responsabilidad de los ISP, Colombia había promulgado legislación relativa a la protección de medidas tecnológicas de protección antes de la ratificación del USCO. Colombia, como parte de su implementación de los tratados de Internet de la OMPI, estableció sanciones penales a la elusión de medidas tecnológicas, pero no recursos civiles. En cualquier caso,

\footnotetext{
68 La notificación debe cumplir con todos los requisitos del art. 10.

69 Ver capítulo 3.
} 
la regulación colombiana existente sobre medidas tecnológicas de protección es muy abstracta y permite opiniones opuestas acerca de su significado.

En la legislación existente, que aún sigue en vigor, el Código Penal prohíbe tanto la elusión de medidas tecnológicas de control de copia (art. 272 (1)) como el tráfico en dispositivos para eludir una medida de control de copia (art. 273(3)). Las violaciones a estas disposiciones se castigaban con multas, no obstante, la sanción se modificó posteriormente como lo veremos más adelante. Hay aspectos importantes de la legislación colombiana en lo que respecta a la prohibición del acto de elusión. En primer lugar, la legislación colombiana no proporciona una definición de TPM (Pabón, 2007, p. 11) En segundo lugar, la ley no exige que las medidas tecnológicas de protección sean "efectivas" como lo mandan los dos Tratados de Internet de la OMPI. La incorporación del término "eficaz" desempeña un papel importante en la determinación del alcance de la protección, significando que no todas las TPM merecen protección legal. La legislación colombiana, sin embargo, no incorporó tales límites a la protección. En tercer lugar, la ley no establece quién tiene derecho a imponer las medidas tecnológicas de protección $(\mathrm{C}$. Pen, art. 272(1)). Los Tratados de Internet de la OMPI establecen que los países miembros deben proteger las TPM impuestas por los autores, lo que significa que un TPM impuesta por un tercero no debería tener derecho a la protección legal ${ }^{72}$. Sin embargo, la ley colombiana no aclara quién tiene derecho a establecer medidas tecnológicas de protección legalmente protegidos, y los jueces deben recurrir a una interpretación sistemática del Código Penal con el fin de negar la protección legal de medidas tecnológicas de protección impuestas por terceros.

En cuarto lugar, la redacción del tipo penal es vaga, lo que ha dado lugar a diferentes interpretaciones acerca de si la ley hace de la elusión de un TPM una disposición independiente. La ley sanciona a aquella persona que

70 Afirmando que la ley de derechos de autor de Colombia no proporciona una definición de TPM.

71 Ver artículo 272 (1) del Código Penal; ver Pabón (2007), afirmando que la legislación colombiana no requiere que una medida de protección tecnológica sea "efectiva" (p. 131).

72 Ver Tratado de la OMPI (20 de diciembre de 1996, art. 11); WPPT (1997, art. 18); ver capítulo 2. 
"supere o eluda las medidas tecnológicas adoptadas para restringir los usos no autorizados".

Una lectura lógica es que la disposición crea una protección independiente, lo que significa que la elusión es sancionada independientemente de si existe infracción de derechos de autor (Pabón, 2008, p. 132) ${ }^{73}$. Bajo esta lectura, el significado de las palabras "usos no autorizados" es que la ley debe ser entendida en el contexto de los derechos de autor y que un TPM debe proteger los derechos económicos y los derechos morales (p. 131) ${ }^{74}$. Para esta interpretación, no hay excepción al acto de elusión debido a la falta

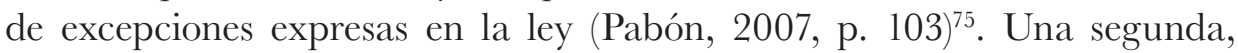
e igualmente plausible interpretación es que la elusión solamente está prohibida si amenaza los derechos de autor. En otras palabras, la ley penal no prohíbe el acto de elusión como una disposición independiente, y por tanto, la protección a TPM proporciona una protección complementaria a la ley de derechos de autor. El razonamiento detrás de esta teoría es diverso. Por ejemplo, cuando la ley dice "actos no autorizados", se sugiere que se permite la elusión para usos permitidos (Barrero, 2012, p. 101) ${ }^{76}$. Un argumento diferente es que se debe considerar que la disposición se encuentra en el capítulo de delito contra los derechos de autor, lo que sugiere que debe haber una infracción de derechos de autor con el fin de sancionar la elusión ${ }^{77}$. Sin embargo, al momento de esta investigación no hay jurisprudencia en que las cortes hayan aplicado esta disposición, y por lo tanto dado sentido.

En quinto lugar, la ley no protege a las medidas de control de acceso $(\mathrm{C}$ Pen, art. 272(1)). Por último, la ley no obliga a escala comercial o la intención de lucro para sancionar. La disposición contra el tráfico de dispositivos de

73 Afirmando que no hay necesidad de hacer una infracción de derechos de autor con el fin de ser responsable de la elusión de una medida tecnológica de protección.

74 Indicando que la expresión "usos no autorizados" de la ley colombiana hace referencia a los derechos económicos y morales del autor.

75 Afirmando que la ley de derechos de autor colombiano no prevé excepciones al acto de elusión.

76 Afirmando que el art. 272 sanciona la elusión de un TPM, cuando dicha elusión se realiza con el propósito de hacer actos no autorizados.

77 Ver Rengifo (2008), afirmando que parece que la elusión de un TPM solo será un crimen cuando amenaza el derecho de autor (p. 105); ver Matíz (2002), indicando que la elusión de medidas tecnológicas de protección solo es castigado cuando amenaza los derechos de autor (p. 12). Esta conclusión se basa en la incorporación del delito en el capítulo de delitos contra los derechos de autor en el Código Penal. 
la ley prohíbe cualquier tipo de dispositivo para eludir, incluso si su objetivo es ser usado en actos de elusión para actos permitidos (art. $272(3))^{78}$. La ley no establece ningún otro requisito para caer en esta conducta tipificada, aunque no dice nada acerca de los servicios. Por último, la disposición contra el tráfico de dispositivos no está sujeta a excepciones (Pabón, 2007, p. 105)79.

No obstante, las disposiciones de TPM del Código Penal se modificaron producto del USCO incluso antes de que el USCO fuera ratificado. Después de la fase de negociación del USCO, el Congreso de Colombia - con el propósito hacer lobby en favor del acuerdo-(Rengifo, 2008, p. 12) ${ }^{80}$ modificó las disposiciones de TPM aumentando la pena, tanto del acto de elusión de una TPM de control de copia como del tráfico en dispositivos para eludir. Aunque la nueva enmienda dejó el texto sustantivo de la disposición anterior sin cambios, aumentó las penas a cuatro a ocho años y una multa de entre 26,66 a 1000 veces el salario mínimo (Ley 1032 de 2006, art. 3). Como la parte sustantiva de la ley se mantuvo sin cambios, la disposición no requiere escala comercial o intención de lucro o beneficio privado y no se establece ninguna limitación y excepción de manera expresa, a pesar de su fuerte castigo. Esta es la ley actualmente en vigor.

Después de que Colombia ratificó el USCO hubo otra modificación a las disposiciones de TPM con el fin de implementar las obligaciones del acuerdo en el asunto. La Ley 1520 de 2012 implementó las medidas contra la elusión del USCO. Como se mencionó anteriormente, la implementación no intentó volver a equilibrar la ley de propiedad intelectual existente. Por lo tanto, en el caso de medidas tecnológicas de protección, la Ley 1520 prácticamente añadió el texto de la USCO a la ley existente.

78 "Fabrique, importe, venda, arriende o de cualquier forma distribuya al público un dispositivo o sistema que permita [...] cualquier forma de eludir, evadir, inutilizar o suprimir un dispositivo o sistema que permita a los titulares del derecho controlar la utilización de sus obras o producciones, o impedir o restringir cualquier uso no autorizado de éstos" (art. 272 (3)).

79 Indicando que la disposición contra el tráfico de dispositivos no está sujeta a excepciones.

80 Afirmando que la Ley 1032 de 2006, que aumentó el castigo contra la elusión de medidas tecnológicas de protección fue promovido como una estrategia de presión para apoyar el USCO. 
La Ley 1520 estableció la responsabilidad civil por la elusión de una medida de protección tecnológica en el artículo 14. Como se ha mencionado, la regulación anterior sobre el tema solo establecía sanciones penales. Como producto de la metodología de implementación, la ley prohibió el tráfico en los dispositivos y servicios tanto de una TPM de control de copia como de una TPM de control de acceso (art. 14(b) $)^{81}$. Además, prohibió la elusión de una medida de control de acceso, como lo requiere la USCO, y la elusión de una medida de control de copia, como la ley anterior establecía (art. 14 (a)). La ley aclaraba que la responsabilidad civil por una elusión de una medida de protección tecnológica era una disposición independiente ${ }^{82}$. En el artículo 15, la ley establecía las excepciones a la elusión de una medida de control de acceso siguiendo de cerca el texto de la USCO, y por lo tanto, mandando las siete excepciones permitidas (art. 15). En relación con el procedimiento legislativo o administrativo para crear excepciones adicionales a la elusión de una medida de control de acceso para los usos no infractores, la Ley de 1520 optó por un procedimiento legislativo con base a la recomendación del Gobierno. Lo anterior significa que, el Gobierno era el encargado de determinar la necesidad de presentar un proyecto de ley al Congreso para deliberar la promulgación de nuevas excepciones (art. 15 (g), parágrafo). Por último, la ley establecía una norma de no mandato (art. 14, parágrafo), como el USCO establecía.

En cuanto a la responsabilidad penal, el artículo 17 siguió de cerca la redacción del artículo 14 sobre responsabilidad civil. En este caso, la prohibición no establecía de manera expresa su calidad de disposición independiente. El Congreso de la República ejerció la capacidad otorgada por la USCO de establecer disposiciones ya sea civil o penal como medida independiente (USCO, 2006, 16.7.4 (d) $)^{83}$. La prohibición penal también sancionó cuatro actos de elusión (Ley 1520 de 2012, art. 17(1)-(2)), aunque

81 En relación con la definición de la medida de protección tecnológica establecida en el artículo 2.

82 El USCO dio la posibilidad de hacer de la protección contra la elusión de medidas tecnológicas de protección, ya sea una disposición independiente civil o penal. La Ley 1520 parece haber escogido la primera posibilidad. El artículo 14 de la Ley 1512 de 2012 establece expresamente el carácter independiente de los recursos civiles contra la elusión de un TPM. Mientras que el artículo 17 de esta ley, con respecto a las sanciones penales, no indica expresamente el carácter independiente de la protección.

83 Afirmando que la disposición independiente puede ser civil o penal. 
en algunos aspectos redujo el alcance de la legislación penal anterior. En primer lugar, la ley sancionaba solo los actos que no fueron autorizados por el titular de los derechos de autor o de la ley. Por lo tanto, pone algunas limitaciones a las disposiciones contra la elusión (art. 17). En segundo lugar, la ley requería que exista un propósito de obtener una ventaja comercial o ganancia financiera privada con el fin de ser un acto castigado. En tercer lugar, creó una excepción a la responsabilidad penal para bibliotecas sin fines de lucro, archivos, instituciones educativas y entidades públicas de radiodifusión no comerciales (art. 17, parágrafo) como requiere la USCO (2006, 16.7.4).

Por lo tanto, la regulación general de medidas tecnológicas de protección promulgada bajo la Ley 1520 creó un régimen más restrictivo que el mandato USCO. Sin embargo, y como se mencionó anteriormente, la Corte Constitucional anuló esta ley declarándola inexequible. En consecuencia, la legislación anterior está todavía en vigor.

\section{Las consecuencias de un estilo de implementación copy-paste del USCO para la promoción de la educación del siglo XXI}

Como se mencionó anteriormente, el Congreso de Colombia consideró el USCO como un texto legal en el sentido que no se intentó hacer una implementación de una ley más adecuada y adaptada a las necesidades de Colombia haciendo uso de las flexibilidades disponibles en el tratado. No obstante, dicho tipo de implementación escogido por el Congreso puede impedir la capacidad de utilizar la tecnología para resolver los problemas más destacados de la educación a través de la implementación de un sistema educativo transformado ${ }^{84}$, aun cuando el derecho de autor no está siendo infringido.

Respecto de las limitaciones a la responsabilidad de intermediarios, el intento de adaptación del modelo estadounidense de responsabilidad de los ISP en Colombia puede dar lugar a consecuencias no deseadas para Colombia. La razón es el resultado de la propia ley ${ }^{85}$. La adopción del modelo de Estados Unidos, sin tratar de arreglar los problemas del modelo, simplemente transfiere a Colombia los problemas intrínsecos del modelo.

\footnotetext{
84 Ver capítulo 1.

85 Ver capítulo 3.
} 
Adicionalmente, la DMCA fue el resultado de una realidad de Estados Unidos que no está presente en Colombia. Bajo la ley estadounidense, los ISP estaban ansiosos por obtener las limitaciones de la responsabilidad, ya que estaba claro que podrían ser responsables por infracciones de terceros a los derechos de autor ${ }^{86}$. Sin embargo, la situación en Colombia es diferente; aún queda la duda acerca de si el establecimiento de un régimen ISP bajo la ley colombiana favorecerá al ISP o impondrá una carga adicional para ellos.

En Colombia, la discusión sobre la aplicabilidad de la responsabilidad subsidiaria de los ISP hasta ahora está comenzando. No obstante, como se vio anteriormente, no hay certeza de si los principios de responsabilidad civil cubrirán las actividades del ISP por infracción de derechos de autor por parte de terceros y cómo esos principios serán adaptados a su realidad ${ }^{87}$. Resolver estos problemas requerirá un poco de pensamiento creativo por parte de los jueces para aplicar los principios de responsabilidad a los proveedores de Internet, sobre todo debido a la falta de responsabilidad objetiva en virtud de los principios de responsabilidad civil colombiana. Por otra parte, los principios de responsabilidad secundaria difieren de las teorías de Estados Unidos hasta cierto punto $^{88}$. Sin embargo, luego del establecimiento de limitaciones a la responsabilidad, hay más posibilidades de que la responsabilidad subsidiaria se impondrá a los ISP.

Por otra parte, la adopción de este mecanismo en Colombia permitirá a las industrias de Estados Unidos ejercer una política de recelo de la protección de derechos de autor en el país suramericano. Esta situación es preocupante porque aunque las consecuencias no deseadas del modelo estadounidense son producto de la propia ley, tales consecuencias se ven agravadas por un exceso de celo de la industria de los derechos de autor de Estados Unidos ${ }^{89}$. De esta manera, el establecimiento de este modelo permite que dicha industria realice este tipo de política en Colombia, y por lo tanto, la transferencia de las consecuencias negativas para este país. Esta política de recelo de las industrias estadounidenses se ha desarrollado en otros países. En España,

\footnotetext{
86 Ver capítulo 3.

87 Por ejemplo, algunos comentaristas sostienen que los principios generales de la responsabilidad no son apropiados para la situación de los proveedores de Internet. Ver Vargas (2013, pp. 23-26).

88 Ver discusión en secciones previas.

89 Ver capítulo 3.
} 
por ejemplo, varias universidades recibieron notificaciones del Motion Picture Association of America y Record Industry Association of America respecto a la infracción de P2P. En las notificaciones, las industrias del derecho de autor requerían a las universidades suprimir el acceso a Internet de los estudiantes y tomar otras medidas adecuadas de acuerdo con la política de la escuela (Monroy, 2009, pp. 164-165).

Como resultado de los avisos de la MPPA y la RIAA, la Universidad de Valencia decidió prohibir cualquier uso de un programa de intercambio de archivos (pp. 164-165), a pesar de que el software no es infractor en sí mismo y tiene beneficios académicos significativos. Aunque en España no se aplica el sistema de responsabilidad ISP de la DMCA, sino que sigue la Directiva sobre comercio electrónico, este ejemplo pone de manifiesto la capacidad de la industria de los derechos de autor de Estados Unidos para ejercer su política en todo el mundo en el que tiene las herramientas para apoyarse. De esta manera, la situación en la que se crea un mecanismo para favorecer políticas de recelo de industrias de derechos de autor en su mayoría extranjeras es preocupante debido al fuerte propósito social que la transformación del proceso de aprendizaje tiene en Colombia.

Además, como se mencionó anteriormente, intentar pasar el mismo modelo de Estados Unidos a Colombia transferirá los mismos defectos de este modelo, que serán reforzados debido a la ley de derechos de autor colombiano. Uno de los problemas del sistema de limitaciones a la responsabilidad de los ISP estadounidense es la posibilidad de abusar del mecanismo de bajada de contenidos, que es casi una herramienta automática permitiendo eliminar información y materiales valiosos ${ }^{90}$. Esta situación erosiona usos de los materiales educativos permitido, y en el caso de un proceso de aprendizaje transformado, impide el uso de iniciativas de aprendizaje permanente y actividades de colaboración ${ }^{91}$. El proyecto 241 optó por seguir el mecanismo de bajada de contenidos privado del modelo estadounidense (Proyecto de Ley 241 de 2011, art. 9-12). No obstante, debido a algunas peculiaridades del sistema de derecho de autor colombiano, que fue dejado intacto, el proyecto 241 puede tener la habilidad de potencializar la respuesta automática a un sistema privado de bajada de contenidos, y por lo tanto, erosionar aún más

$90 \quad$ Ver capítulo 3.

91 Ver capítulo 3. 
los usos educativos de material con derechos de autor, como explicaremos a continuación.

El sistema de Estados Unidos de ISP ha sido abusado ${ }^{92}$, como se mencionó en el capítulo 3, y a pesar de esta realidad, la ley de derechos de autor de Estados Unidos contiene herramientas para reducir o minimizar los potenciales abusos del sistema ISP, las cuales, las cortes están empezando a utilizar. Bajo la ley de Estados Unidos, la aplicación de la doctrina del fair use a los usos de material con derechos de autor en Internet (Ginsburg, 2012, p. 193) ${ }^{93}$ puede desempeñar un papel de equilibrio importante dentro del proceso de bajada de contenidos. Por ejemplo, la doctrina del fair use puede ayudar a mitigar la naturaleza potencialmente abusiva de las notificaciones. En este sentido, una corte de Estados Unidos ha declarado que el titular de derechos de autor debe tener en cuenta el fair use antes de enviar una notificación ${ }^{94}$. Esta decisión sugiere que los tribunales están intentando usar la doctrina tradicional del fair use para evitar o controlar aquellos casos en el que el titular de los derechos de autor envía indiscriminadamente notificaciones sin analizar el contexto en el que se está usando la obra por el usuario (Lenz vs. Universal Music Corp, 2008, p. 1156 ${ }^{95}$. Igualmente, la acción contra falsas representaciones, diseñada para equilibrar el proceso, también aplica en los casos donde el titular del derecho de autor no tuvo en cuenta la aplicación del fair use antes de enviar la notificación (pp. 1154-1155) ${ }^{96}$.

Adicionalmente, la doctrina del fair use desempeña un papel importante durante la contranotificación. La existencia del fair use y su aplicación a

$\overline{92}$ Ver capítulo 3.

93 Afirmando que el uso justo aplica al entorno digital.

94 Ver Lenz vs. Universal Music Corp (2008): "Accordingly, in order for a copyright owner to proceed under the DMCA with 'a good faith belief that use of the material in the manner complained of is not authorized by the copyright owner, its agent, or the law', the owner must evaluate whether the material makes fair use of the copyright" (p. 1154). Esta posición fue mantenida por el Ninth circuit al analizar el caso, ver Lenz vs. Universal Music Corp. (2015).

95 Hablando del requisito de analizar los usos permitidos antes de enviar la notificación a la Corte dijo: "The purpose of Section 512(f) is to prevent the abuse of takedown notices. If copyright owners are immune from liability by virtue of ownership alone, then to a large extent Section 512(f) is superfluous" (p. 1156).

96 "An allegation that a copyright owner acted in bad faith by issuing a takedown notice without proper consideration of the fair use doctrine thus is sufficient to state a misrepresentation claim pursuant to Section 512(f) of the DMCA" (pp. 1154-1155). 
los usos de material con derecho de autor en Internet ofrece soporte para muchas reclamaciones contenidas en la contranotificación, como en los casos de los profesores Seltzer y Lessig ${ }^{97}$. En otras palabras, sin la aplicación del fair use al entorno digital, la contranotificación se reduciría a una herramienta para informar al proveedor de Internet sobre la existencia de una licencia o autorización.

Aunque Colombia está tratando de proporcionar un sistema de bajada de contenidos privado siguiendo de cerca el sistema de Estados Unidos, su ley de derechos de autor no proporciona herramientas de equilibrio claras para aminorar las consecuencias no deseadas, como lo hace la ley de copyright de Estados Unidos ${ }^{98}$. Como se mencionó anteriormente, aunque los derechos de los titulares son protegidos en el mundo digital, Colombia no ha promulgado nuevas excepciones para aplicar a este ambiente. Igualmente, a pesar de que el WCT permite la extensión de las limitaciones y excepciones existentes al entorno digital, no está claro cómo la lista actual de excepciones y limitaciones puede aplicarse en dicho entorno ${ }^{99}$. En primer lugar, existen dudas acerca del cumplimiento del test de los tres pasos, al aplicar las limitaciones y excepciones existentes al mundo digital, el cual es un requisito de la Decisión 351 en el art. 21 para todas las limitaciones establecidas por la legislación nacional ${ }^{100}$. En segundo lugar, algunas limitaciones no pueden ser aplicables al mundo digital ya que sus requisitos son relevantes solo para las tecnologías analógicas (Monroy, 2009, p. 143) ${ }^{101}$. En tercer lugar, algunas limitaciones y excepciones no cubren todos los derechos que están involucrados en la

97 Ver capítulo 3.

98 Debido a la incertidumbre acerca de la aplicación de las limitaciones y excepciones en el entorno digital que se describe en la sección anterior.

99 Ver Rengifo (2008), afirmando que las limitaciones y excepciones no se han aplicado al mundo digital. Sin embargo, es claro que el derecho de reproducción se aplica (pp. 109-114); ver también Monroy (2010), afirmando que hay una falta de normas claras sobre los usos permitidos en el mundo digital (p. 203).

100 Ver Dirección Nacional de Derechos de Autor (18 de enero de 2010), afirmando que las limitaciones y excepciones en Colombia tienen que cumplir con la prueba de tres pasos (p. 2); ver también Monroy (2010), indicando que uno de los problemas de la aplicación de las limitaciones y excepciones al entorno digital es que fueron desarrollados para el mundo análogo y pueden ser contrarias al test de los tres pasos si se aplican al mundo digital (p. 203).

101 Indicando el caso de la limitación a favor de la reproducción con medios reprográficos que no es aplicable en el mundo digital. 


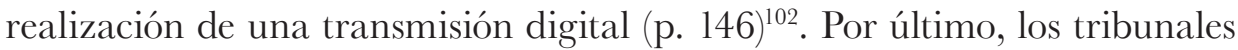
no han establecido parámetros para la aplicación de estas limitaciones y excepciones al ambiente digital. Como resultado de esta incertidumbre, la susceptibilidad del sistema privado de bajada de contenidos puede ser aumentada, ya que aunque Colombia decidiera seguir la jurisprudencia de los tribunales de Estados Unidos y requerir a los titulares de derechos de autor analizar los usos permitidos antes de enviar la notificación y también permitiera a los usuarios presentar la acción de falsa representación cuando los usos permitidos no han sido considerados por el titular de los derechos de autor, la actual ley de derechos de autor no brinda las herramientas para llevar a la práctica este tipo de equilibrio debido a la incertidumbre sobre la aplicación de las excepciones y limitaciones en el entorno digital.

Ilustremos la situación con un ejemplo. Una profesora de historia de Colombia se da cuenta de la importancia de las herramientas de colaboración para la educación y decide crear un blog para su clase. En una de sus tareas, ella decide involucrar a los estudiantes en la discusión sobre los temas "movimientos guerrilleros de la década de 1990", donde ella hace un collage de imágenes en miniatura de los eventos más importantes de la época. Las imágenes se tomaron de diferentes fuentes, incluyendo sitios web y libros de historia. La idea de utilizar las imágenes es ilustrar a sus alumnos las dificultades de esos años. No obstante, si el titular de los derechos de autor del libro de historia envía una notificación de derechos de autor para bajar el collage después de encontrar algunas de sus fotos en el blog, entonces es muy posible que el collage vaya a ser bajado y no será devuelto nunca más. Bajo este escenario, el titular de los derechos de autor puede argumentar que él tenía una creencia de buena fe la profesora estaba infringiendo sus derechos debido a la incertidumbre sobre la aplicación de las limitaciones y excepciones a Internet ${ }^{103}$. La maestra podría tener motivos razonables para temer enviar una contranotificación precisamente debido a la falta de certeza sobre la aplicación de las excepciones y limitaciones en el entorno digital, al igual, que dudaría utilizar la acción de falsa representación por

\footnotetext{
102 Indicando que la mayoría de las limitaciones y excepciones en América Latina no se refieren tanto al derecho de reproducción y comunicación pública que son los derechos involucrados en una transmisión digital.

103 Siguiendo la exigencia de buena fe establecido en el artículo 10. Ver proyecto de Ley 241 de 2011, art. 10.
} 
las mismas razones, aunque en el mundo analógico, el actuar de la profesora posiblemente hubiera estado cubierto por la excepción de cita o la excepción de ilustración, dado los demas presupuestos ${ }^{104}$. Por último, el ISP simplemente necesita cumplir de forma automática con la notificación y ahorrarse a sí mismo, el trabajo de seguir con el proceso de contranotificación. Si este ejemplo se presentara en los Estados Unidos, el profesor tendría el apoyo de la doctrina de fair use para defender sus usos educativos, ya sea en una contranotificación o presentar una acción de falsa representación.

Además de estos problemas creados por elordenamientoautoralcolombiano, el Congreso colombiano también disminuyó la estructura de equilibrio del sistema de bajada de contenidos bajo la DMCA durante su intento de implementación. De esta manera, el Congreso colombiano aprobó un sistema de responsabilidad de los ISP más susceptibles a los abusos que el sistema de la DMCA. El texto de implementación del tratado no procuró mantener el equilibrio parcial entre la notificación y contranotificación establecido bajo la DMCA, aunque la mayoría de las características de la DMCA fueron seguidas. El proyecto 241 estableció la obligación del proveedor de Internet de bajar el contenido después de la recepción de la notificación de derechos de autor y, en el caso de las actividades de almacenamiento de material del usuario, la obligación de notificar al suscriptor (Proyecto de Ley 241 de 2011, art. 11). Aunque el usuario podía presentar una contranotificación, el proyecto de ley establecía que el ISP debía restablecer la información a menos que el demandante hubiera obtenido una orden judicial en un "plazo razonable" (art. 9). Esta situación difiere del modelo de DMCA donde el titular del derecho de autor tiene un tiempo establecido de catorce días para obtener una orden judicial antes de que se reanude el contenido ${ }^{105}$. La falta de una fecha clara para reemplazar la información bajo el proyecto 241 una vez enviada la contranotificación puede socavar la utilidad de una contranotificación; ya que no existe un tiempo establecido para obtener el restablecimiento de la información o para presentar una acción por falsa representación. Por lo tanto, el equilibrio del procedimiento se ve afectado negativamente.

El establecimiento de un mecanismo de bajada de contenidos privado con alto potencial para ser abusada como se describe anteriormente, puede tener

104 Ver Ley 23 de 1982, art 31-32; Decisión 351, art. 22(a).

105 Ver capítulo 3. 
fuertes efectos sociales en Colombia. Este mecanismo tiene la capacidad de afectar el progreso de las actividades educativas desarrolladas en el marco de la Web 2.0, tales como entornos colaborativos y plataformas de contenido generado por usuarios, dirigidas a promover el aprendizaje continuo y la colaboración ${ }^{106}$. Estas iniciativas representan para Colombia la oportunidad no solo de entrenar a los nuevos generadores de contenido, sino también de resolver los problemas más destacados en la educación, incluyendo la posibilidad de brindar oportunidades para educar a las poblaciones marginadas a través de un mayor acceso a los recursos educativos, el acceso a expertos externos, mayor tiempo de escolaridad, y como herramienta para educar fuera de la escuela ${ }^{107}$.

Aparte del procedimiento de bajada de contenidos, el sistema de responsabilidad de ISP establecido en la DMCA deposita en las instituciones educativas el poder/deber de cancelar la cuenta de los estudiantes en función de su historia de supuesta infracción a los derechos de autor. De esta manera, el sistema de limitación de responsabilidad de ISP permite a las industrias de derechos de autor presionar a las instituciones educativas a adoptar políticas de derechos de autor estrictas que dan lugar a la terminación de cuentas de los estudiantes después de la recepción de una sola notificación. Esta situación genera un problema para desarrollar un proceso de aprendizaje transformado porque hace que Internet sea un bien prescindible cuando en realidad es el núcleo central de la educación ${ }^{108}$.

El proyecto 241 adoptó dos características de la DMCA que pueden transferir este problema a Colombia. En primer lugar, la definición de ISP del proyecto de ley es más amplia que la definición de la DMCA (Proyecto de Ley 241 de 2011, art. 1). Bajo el proyecto de Ley 241 las instituciones educativas como las universidades y las bibliotecas se consideran proveedores de Internet. En segundo lugar, como el USCO mandó, el proyecto 241 requiere al ISP establecer una política para la terminación de las cuentas de los infractores reincidentes, que en el caso de las instituciones educativas, son estudiantes. Siguiendo la DMCA, el proyecto 241 dejó a los proveedores de Internet la oportunidad de dar sentido a dicha política. Sin embargo, el

\footnotetext{
106 Ver capítulo 3.

107 Ver capítulo 1.

108 Ver capítulo 3.
} 
proyecto 241 fue más allá de la DMCA, evitando establecer cuándo y cómo la política se debe aplicar. El artículo simplemente requiere al ISP establecer condiciones generales y públicas acerca de cuándo el ISP podrá rescindir el contrato del proveedor de contenido cuando son infractores reincidentes (art. 5 (d); 6 (e); 7 (e)). La DMCA establece que la política debe ser "implementada razonablemente" y bajo "circunstancias apropiadas" (17 U.S.C § 512 (i) (A)).

Esta situación deja a las instituciones educativas altamente vulnerables a la presión de las industrias extranjeras y nacionales de derechos de autor. $\mathrm{Al}$ igual que en Estados Unidos, en Colombia la industria del derecho de autor será capaz de dirigirse a las instituciones educativas y presionarlas a adoptar una política estricta de autor ${ }^{109}$. Este tipo de política podría finalizar en la terminación de la cuenta de los estudiantes cuando no hay infracción de derechos de autor como ha ocurrido en Estados Unidos ${ }^{110}$. Por otra parte, en Colombia, bajo el intento de implementación del USCO, esa política podría tener aplicación en cualquier caso de infracción porque la ley no aclara que la política debe ser razonablemente aplicada y solo bajo circunstancias apropiadas (Proyecto de ley 241 de 2011, art. 5 (d), 6 (e), 7 (e)), aumentando de esta forma los problemas de esta disposición.

Dar este poder/deber a las instituciones educativas y a las bibliotecas en Colombia puede tener fuertes efectos sociales en el país. El Gobierno de Colombia está trayendo conectividad a través de las instituciones educativas y bibliotecas a las personas que no pueden obtenerlo ${ }^{111}$. Si se requiere a las instituciones educativas terminar las cuentas bajo una estricta política, sin la necesidad de una decisión judicial, las personas se quedarán fuera de cualquier fuente de conectividad ${ }^{112}$. Por otra parte, terminar el acceso a los estudiantes y usuarios de bibliotecas reduce la capacidad de utilizar la tecnología para ampliar el acceso a la educación y llevar la educación de calidad a más personas ${ }^{113}$. Es importante recordar que en Colombia Internet representa la única herramienta que muchos lugares tienen para acceder a los materiales educativos y a los expertos.

\footnotetext{
109 Ver capítulo 3.

110 Ver capítulo 3.

111 Ver capítulo 1.

112 Ver capítulo 1.

113 Ver capítulo 1.
} 
Por lo tanto, la situación de la adopción del mecanismo privado junto con una ley de derechos de autor que no sea re-balanceada podría socavar la incorporación de la tecnología en la educación, lo cual es especialmente preocupante porque Colombia no está obligada a proporcionar un modelo de este tipo ${ }^{114}$. Si Colombia no elige seguir el modelo de Estados Unidos eso no quiere decir que no protegerá al titular del derecho de autor o que no cumplirá con las obligaciones adquiridas en el TLC. Por otro lado, Colombia podría proteger los usos educativos, si el país adopta un modelo diferente.

La situación de las TPM es similar a la de la responsabilidad de los ISP. Al igual que con el modelo de responsabilidad de los ISP, la elección de seguir de cerca la DMCA - como Colombia lo hizo con la Ley 1520- puede transferir las consecuencias no intencionadas de las disposiciones en materia de educación con las TIC, e incluso potencializarlas, especialmente cuando dicho modelo es adicionado a la regulación actual en materia de TPM colombiana. Esta situación es preocupante porque, como en el caso de la responsabilidad de los ISP, Colombia no está obligada a proporcionar tal modelo de protección ${ }^{115}$.

Uno de los problemas de las disposiciones sobre TPM del modelo de la DMCA es la imposibilidad de hacer usos permitidos de los contenidos protegidos. El problema en este escenario es que a pesar de que las medidas de control de copia no están protegidos por la ley de Estados Unidos, la prohibición de los dispositivos y servicios elusivos hacen que sea difícil eludir un $\mathrm{TPM}^{116}$, incluso para realizar usos permitido haciendo más difícil -y a veces imposible- para los estudiantes y profesores incursionar en el uso de citas o uso de extractos para la ilustración en la enseñanza ${ }^{117}$.

Bajo el intento de implementación de Colombia de las obligaciones del USCO, este problema podría ser replicado y aumentado debido a la adición del modelo de DMCA a la legislación colombiana vigente. Como se mencionó anteriormente, en virtud de las medidas civiles contra la elusión, a diferencia de Estados Unidos, el intento de implementación trató de prohibir la elusión de las medidas de control de copia, independientemente de la existencia de

\footnotetext{
114 Ver capítulo 6, describiendo otros modelos.

115 Ver ejemplo de otro modelo de implementación en capítulo 6.

116 Ver capítulo 3.

117 Ver capítulo 3.
} 
la infracción de derechos de autor (Ley 1512 de 2012, art. 14). Bajo este escenario, y suponiendo por un momento que bajo las leyes actuales de derechos de autor colombiano existe claridad acerca de la aplicación de las limitaciones y excepciones en el entorno digital ${ }^{118}$, sería imposible realizar los usos permitidos por los profesores, investigadores y estudiantes. La razón de esta situación se debe a que la ley prohíbe la elusión de control de copia prohibiendo cualquier intento de hacer un uso permitido ${ }^{119}$. En otras palabras, la imposibilidad de participar en la realización de usos permitidos cuando el contenido está protegido por una medida de control de copia no proviene de la prohibición de dispositivos y servicios elusivos como en Estados Unidos, sino de la prohibición de eludir la propia medida de control de copia.

En términos prácticos, la regulación colombiana significa que, incluso si el usuario fuera tecnológicamente bien informado, no estaría autorizada a eludir el control de copia para hacer usos permitidos, como en la legislación estadounidense ${ }^{120}$. En este sentido, la ley socava la participación en el aprendizaje colaborativo para estudiantes colombianos, maestros e investigadores más que en Estados Unidos.

Por ejemplo, un profesor de arte compra una compilación digital de obras de arte desde el siglo XV. La compilación reúne todas las obras de los maestros como Leonardo da Vinci, Miguel Ángel y Rafael. El profesor queriendo hacer una comparación entre los pintores, pone las obras de los diferentes pintores lado a lado y sube la comparación a la plataforma "Colombia Aprende". El propósito de la comparación es comenzar la discusión con sus alumnos y compañeros maestros y también permitir a cualquier otro profesor utilizar dicho trabajo después en sus propias lecciones. Para poner en acción esta idea, el profesor quería hacer uso de las imágenes disponibles en su nuevo libro, aprovechando que todas están reunidas en

118 Como se ha mencionado uno de los problemas de la ley de derechos de autor de Colombia es que actualmente no hay certeza sobre la aplicación de las excepciones y limitaciones en el entorno digital.

119 Ver Monroy (2012), indicando que la regulación contra la elusión establecida en la Ley 1520 no dejó margen para la aplicación de las limitaciones y excepciones en materia de educación existente; ver también Ríos (18 de abril de 2012), indicando que la disposición contra la elusión de la Ley 1520 no establece limitaciones en favor de la educación.

120 Ver capítulo 3. 
el mismo lugar haciendo la comparación más fácil. No obstante, debido a que la compilación está protegida por una medida de control de copia, el profesor no puede copiar las obras para hacer su presentación, incluso si adquirió acceso legal a la obra y las pinturas, dicho uso podría estar cubierto por la excepción de ilustración (Ley 23 de 1982, art. 32) o cita (Decisión 351, art. 22 (a)), y el profesor es un experto en elusión de TPM. Si este profesor se encontrara en Estados Unidos, hubiera podido eludir la TPM para hacer su presentación sin infringir la ley.

La situación descrita anteriormente puede tener fuertes efectos sociales en Colombia ya que puede obstaculizar la posibilidad de mejorar la calidad de la educación mediante el uso de las TIC, pues las comunidades de aprendizaje - como Colombia Aprende- promueven el intercambio de recursos y experiencias y permiten ayudar a los profesores y estudiantes de zonas marginadas a acceder a materiales pertinentes y de calidad que no están disponibles para ellos de otra manera ${ }^{121}$.

Otro ejemplo de cómo el intento de implementación colombiano puede potencializar la afectación al desarrollo de iniciativas educativas con el uso de las TIC, incluso cuando los derechos de autor no están siendo infringidos, es en el caso de las bibliotecas. Por ejemplo, si una biblioteca ha comprado un libro electrónico protegido con control de acceso y control de copia, la biblioteca no sería capaz de hacer una copia de archivo de la obra (Ley 23 de 1982, art. 38), que es un uso permitido, a pesar de que la licencia da a la biblioteca la clave para descifrar la medida de control de acceso. La razón se debe a que bajo la implementación colombiana la elusión de un control de copia es ilegal. Si la misma biblioteca se encuentra en Estados Unidos, por lo menos, se podría realizar la copia de archivo si tuviera un empleado con conocimientos tecnológicos.

Adicionalmente, otro problema del modelo de Estados Unidos es que disuade la discusión académica en el campo de la investigación de cifrado debido al limitado alcance de la excepción para investigación de cifrado. Esta situación puede socavar el desarrollo y beneficio de las comunidades de aprendizaje en la materia. En Colombia dicha situación se podría duplicar y potencializar. La Ley 1520 de 2012 (art. 15, b) estableció una excepción

121 Ver capítulo 1. 
para la investigación de cifrado $^{122}$, igualmente limitada a la de la DMCA, no obstante fue acompañada de unas altas sanciones penales para quien eluda una TPM, mayores que la establecida en Estados Unidos. Dichas características exacerban estos problemas ya que los investigadores de cifrado tendrían razones fundadas para temer la persecución por la diseminación de su investigación.

Por otro lado, el modelo de Estados Unidos prohíbe la elusión de las medidas de control de acceso cuando esa elusión está diseñada para lograr la interoperabilidad del programa a datos. La razón es que la excepción de ingeniería inversa solo aplica a los casos de la interoperabilidad de programa a programa (Ley 1520 de 2012, art. 14, 17). En virtud del intento de implementación en Colombia, la imposibilidad de utilizar la elusión para lograr la interoperabilidad del programa a los datos pueden ser transferidos a este país. La ley colombiana también prohibió la elusión de una medida de control de acceso, y el alcance de la excepción de interoperabilidad es limitada debido a los mandatos del USCO, y por lo tanto, solo se aplica a la interoperabilidad de programa a programa (USCO, 2006, 16.7.4, (e) (i)). Aunque en esta situación las consecuencias no deseadas solamente se transfiere y no son reforzadas por la ley de derechos de autor de Colombia, es importante mencionar que la prohibición de interoperabilidad de datosprograma puede generar fuertes consecuencias sociales en Colombia ya que afectan el uso educativo de siempre en el aprendizaje disuadiendo la oportunidad de mejorar la educación, incluso cuando no hay infracción de derechos de autor. Un sistema siempre en el aprendizaje podría ser utilizado para aumentar las horas de escolaridad de los niños de recursos socioeconómicos bajos que suelen tener menor tiempo de escolaridad ${ }^{123}$. Por otra parte, la situación es más preocupante porque este tipo de sincronización de las obras bajo la protección de derechos de autor no es necesariamente una infracción, ya que podría estar cubierto por la excepción de uso privado (Ley 23 de 1982, art. 37, 44).

El modelo estadounidense también permite el bloqueo de las obras de dominio público, que a su vez limita el acceso a los materiales educativos. Aunque bajo dicho modelo, las TPM impuestas a las obras de dominio

\footnotetext{
122 Ver capítulo 3.

123 Ver capítulo 1.
} 
público no están sujetos a la protección, la prohibición casi ilimitada del tráfico de dispositivos de elusión no permite en la práctica la elusión de una medida de protección (Ley 1520 de 2012, art. 14, 17). Este problema puede ser transferido a Colombia y también puede empeorar debido a la aplicación más restrictiva del modelo que se realizó y a la ley de derechos de autor colombiano, puesto que, las medidas tecnológicas de protección que protegen el acceso a las obras de dominio público pueden entrar en el ámbito de la protección de las disposiciones de elusión cuando se impongan TPM mixtas a tales obras.

La Ley 1520 prohibió tanto la elusión de medidas tecnológicas de protección de acceso como el tráfico de dispositivos y servicios dirigidos a eludir una TPM de acceso, como lo requiere la USCO (2006, 16.7.4 a; Ley 1520 de 2012, art. 14, 17). Esta situación puede hacer que sea imposible acceder a las obras de dominio público en Colombia. Sin embargo, como en Estados Unidos, las medidas tecnológicas de protección de acceso impuestas a una obra de dominio público no reciben protección legal en Colombia. No obstante, el problema surge cuando se impone una TPM mixta a una obra de dominio público, es decir, una TPM donde la protección de acceso y copia-protección son indivisibles ${ }^{124}$.

El intento de implementación brindó protección a cualquier TPM que protege los derechos de autor ${ }^{125}$. Debido a la dualidad de la ley de derechos de autor en Colombia, esta definición abarca tanto la protección de los derechos morales como los patrimoniales. Por ejemplo, la legislación colombiana vigente sobre protección de TPM se aplica tanto a los derechos económicos

124 Durante la aplicación de las disposiciones de TPM del TLG de Estados UnidosAustralia, el Comité Permanente de Asuntos Jurídicos y Constitucionales de la Cámara de Representantes a cargo de analizar el tema declaró: "In practice, many current TPMs contain both access and copy control elements. The Decision of copyright holders to combine or 'bundle' such elements into the one TPM can result in difficulty when determining the exact nature and purpose of a TPM containing both elements." (House of Representatives, 2006, pp. 8-9); "In practice, however, copyright owners may not need to choose between different types of legal protection available. Copyright owners may instead be able to employ technological protection systems that incorporate both and access control and a rights control." (Reese, 2003, pp. 619-621).

125 Ver Ley 1520 de 2012, art. 2. 
como morales ${ }^{126}$. Esta situación no está presente en Estados Unidos donde la protección de los derechos morales es limitada y no tiene aplicación en el entorno digital ${ }^{127}$. Por lo tanto, bajo la legislación colombiana las medidas tecnológicas de protección impuestas para proteger los derechos de paternidad e integridad en una obra de dominio público merecen protección legal $^{128}$. En un escenario donde una TPM mixta sea impuesta para proteger los derechos morales de autor a una obra de dominio público, dicha TPM no podrá eludirse debido a la indivisibilidad entre los dos tipos de protección, encerrando obras de dominio público legalmente. A modo de ejemplo, podríamos encontrar un escenario donde las obras de famosos escritores colombianos como José Asunción Silva (1865-1896), autor de obras literarias importantes como El libro de versos, la cual ya está en el dominio público ${ }^{129}$; o Jorge Isaacs (1837-1895), quien escribió La María, también en el dominio público, podrían encontrarse protegidas por TPM. Suponiendo que José Asunción Silva o Jorge Isaac tengan herederos que viven, estos herederos podrían decidir imponer una medida de TPM mixta con el fin de proteger los derechos de paternidad e integridad ${ }^{130}$. De esta forma, cuando el acceso y la protección de copia no son divisibles, el acceso a El libro de versos o a la obra La María no puede lograrse legalmente (Ley 23 de 1982, art. 21, 30, parágrafo 2).

La afectación al acceso, incluso a las obras de dominio público, socava uno de los principales propósitos de la inversión del Gobierno de Colombia en tecnología. Los recursos educativos son escasos en este país, y por medio de acceso a Internet y repartición de los dispositivos el Gobierno está tratando de mitigar este vacío. La inhibición de acceso a obras en el dominio

126 Ver Pabón (2007), indicando que la protección de TPM colombiana se aplica tanto a los derechos económicos como morales del autor (p. 104).

127 Ver Ballon (2013), afirmando que en Estados Unidos los derechos morales no son aplicables al entorno digital (vol. 1, p. 4.04 [4]).

128 La Ley 23 de 1982, art. 30 parágrafo 2- 3, establece que después de la muerte del autor sus herederos tienen derecho a hacer valer los derechos de integridad y paternidad; a falta de estos, el Instituto Colombiano de Cultura es el encargado de hacer respetar esos derechos. Esto significa que incluso si el trabajo ha entrado en el dominio público. Por lo tanto, los herederos del autor son los que tienen derecho a hacer cumplir los derechos morales.

129 Ver Ley 23 de 1982, art. 21, indicando el plazo de protección de derechos de autor.

130 De acuerdo con la Ley 23 de 1982, art. 30, parágrafo 2 los herederos del autor tienen el derecho a defender la paternidad y la integridad de la obra. 
público podría ser devastadora, especialmente en zonas remotas donde no hay disponibles medios alternativos para acceder a obras protegidas ${ }^{131}$. Esto significa en la práctica que la única versión disponible de la obra de dominio público para esta población será una versión digital de la obra presentada por el hardware y conectividad brindada por el Gobierno. Sin embargo, como se explicó, la oportunidad de tener acceso a este tipo de obras puede ser obstaculizada por una protección a TPM que afecta el acceso a las obras de dominio público.

Además, el modelo estadounidense de TPM ha afectado la posibilidad de proporcionar una educación más inclusiva, especialmente para las personas con discapacidad visual. Los estudiantes con discapacidad visual se ven afectados por medidas tecnológicas de protección debido a la imposibilidad de eludir una medida de control de acceso para permitir el uso del software de lectura en voz alta o la ampliación de texto ${ }^{132}$. La Ley 1520 habría transferido potencialmente esta consecuencia no deseada afectando a los alumnos con esta discapacidad. Como el mandato de la USCO (2006, 16.7.4, a), el intento de la legislación proporciona una amplia prohibición de elusión a las medidas tecnológicas de protección de acceso siguiendo el modelo estadounidense (Ley 1520 de 2012, art. 14, 17). Esta protección de TPM no permite la elusión para conceder el uso de software de lectura en voz alta como una de las excepciones establecidas ni proporciona una excepción general para realizar usos permitidos (art. 16). De esta manera, los estudiantes colombianos con discapacidad visual no se podrán beneficiar de las tecnologías en la educación. Esto es especialmente preocupante ya que su situación no podría ser fácilmente resuelta por la aplicación de las excepciones creadas a partir del procedimiento legislativo.

La razón de este problema es que, en virtud de la implementación de las medidas tecnológicas de protección en Colombia, los titulares de derechos de autor podrían obstaculizar fácilmente la posibilidad de ejercer en la práctica las siete excepciones a la TPM de acceso, al igual que las excepciones creadas por el proceso legislativo. El hecho de que las disposiciones USCO fueron añadidas a la legislación vigente también afectó la aplicación práctica de las excepciones de la USCO. Así como la USCO no dice nada acerca de la

\footnotetext{
131 Ver capítulo 1.

132 Ver capítulo 3.
} 
protección de una medida de control de copia, la legislación colombiana en materia de protección de control de copia se mantuvo sin cambios. De esta manera, eludir una medida de control de copia fue proscrita y establecida como una disposición independiente, al menos en el ámbito civil, pero no fue sujeta a excepciones siguiendo la anterior regulación. Por lo tanto, las excepciones promulgadas a través del procedimiento legislativo y las siete excepciones aprobadas se aplican solo a la elusión de una medida de control de acceso y en algunos casos a las disposiciones contra el tráfico (USCO, 2006, 16.7.4 a; Ley 1520 de 2012, art. 15 parágrafos 2 y 3). Bajo este escenario regulatorio, los titulares de derechos de autor en Colombia podrían adoptar medidas tecnológicas de protección que contienen tanto protección de acceso como de copia para anular la aplicación de las excepciones. Como se mencionó antes, este tipo de TPM hace indivisible ambos tipos de protección. Debido a que las excepciones solo se aplican a las TPM que controlan el acceso, técnicamente hablando, una TPM mixta no podría eludirse en el ámbito de las excepciones.

Retomando el tema de las personas con discapacidad visual, la inhibición de elusión para permitir el funcionamiento del software de lectura en voz alta socavará los esfuerzos del Gobierno colombiano de aplicar la tecnología para un sistema educativo más inclusivo. El Ministerio de Tecnologías de la Información y la Comunicación ha trabajado en proporcionar a las personas con discapacidad tecnologías para facilitar su acceso al conocimiento ${ }^{133}$. Como resultado de los esfuerzos del Gobierno, la ley de derechos de autor de Colombia estableció una excepción a favor de los alumnos con discapacidades visuales en el 2013 (Ley 1680 de 2013, art. 12). El Ministerio promovió esta excepción con el fin de permitir a los colombianos con discapacidad visual hacer uso gratuito de la licencia recién adquirida para un software de lectura en voz alta, como parte del Plan Nacional de TIC, con el objetivo de dar acceso a la información y formación a personas con discapacidad visual (TIC y Discapacidad, noviembre de 2014). Sin embargo, la capacidad de utilizar el programa y la excepción en favor de las personas con discapacidad visual podrán ser socavados por medidas tecnológicas de protección. En consecuencia, se perderán los esfuerzos y dinero del Gobierno de Colombia en el desarrollo de dicha política.

$\overline{133 \text { Ver capítulo } 1 .}$ 
Por último, pero no menos importante, los futuros cambios en la legislación de derechos de autor colombiano y futuros intentos de equilibrar el sistema podrían verse comprometidos por la protección de medidas tecnológicas de protección. Colombia tiene una larga tradición de proteger los intereses de los autores ${ }^{134}$. Desde 1993, la mayoría de las enmiendas a la ley de derechos de autor han aumentado la protección de los autores, sobre todo en el derecho penal (Matíz, 2002) ${ }^{135}$. El interés público, sin embargo, está lentamente comenzando a hacer algunas ganancias y a desempeñar algún tipo de papel en el desarrollo de la ley de derechos de autor que se puede ver reflejado en el deseo del Gobierno de promover la revisión de la ley de derechos de autor en favor de usos educativos digitales establecidos en el plan de las TIC (Ministerio de Comunicaciones, 2008, pp. 66, 110): el proyecto de Ley 001 de 2012, que intentó promulgar una excepción adicional en favor de las personas con discapacidad visual, las bibliotecas, la educación, las reproducciones temporales y parodias ${ }^{136}$; y la Ley 1680 de 2013, que establece una excepción en favor de las personas con discapacidades visuales para reproducir, distribuir, comunicar, traducir, adaptar, organizar o transformar en braille y cualquier otro medio o formato accesible para las personas con discapacidades visuales (Ley 1680 de 2013, art. 12). No obstante, ninguna de estas excepciones, de ser promulgadas, tendría aplicación práctica si se estableciera dicho tipo de regulación de TPM, ya que la legislación de TPM no estableció una excepción general al acto de elusión o para el uso

134 Ver en secciones previas la descripción de la ley actual de derechos de autor colombiana.

135 La Ley 44 de 1993 ya había aumentado el castigo penal contra la infracción de derechos de autor. En el 2000 el nuevo Código Penal en los artículos 270 y 271, aumentó la protección de derechos de autor incrementando el alcance del tipo penal y las sanciones a las infracciones de los derechos económicos. Posteriormente, la Ley 890 de 2004 aumentó el castigo a todos los crímenes incorporado en el Código Penal. Por tanto, se incrementó el castigo contra la infracción de derechos de autor. Por último, la Ley 1032 de 2006 que modifica los artículos 271 y 272 del Código Penal aumentó el castigo del crimen contra los derechos económicos del autor y las medidas tecnológicas de protección. Para obtener más información acerca de las disposiciones del derecho penal contra la infracción de derechos de autor.

136 El proyecto de Ley 001 de 2012 fue presentado en un momento muy polémico después de la promulgación de la Ley 1520 de 2012. El proyecto de ley buscaba traer un poco de equilibrio en el sistema de derechos de autor como la oposición a la Ley 1520 estaba reclamando. Sin embargo, esta ley se retiró debido a las controversias contra el artículo sobre la parodia. 
de dispositivos elusivos en favor de los usos permitidos (Ley 1520 de 2012, art. 15). Por lo tanto, los usos permitidos promulgados en un futuro para beneficiar la educación digital serán anulados por la protección de medidas tecnológicas de protección.

\section{Conclusión}

La ley de derechos de autor colombiana se caracteriza por ser proteccionista de los derechos de autor. Colombia, como parte en los principales acuerdos de derechos de autor, ha cumplido con las normas mínimas de protección y ha ido más allá de los estándares mínimos. Sin embargo, no ha ejercido todo el ámbito para desempeñar las flexibilidades permitidas por las mismas normas internacionales. En cuanto a la implementación de las nuevas obligaciones de derecho de autor, establecidas en el TLC entre Estados Unidos-Colombia, el Congreso de Colombia ha parecido más limitado o restringido por las obligaciones de la USCO de lo que realmente está.

En la actualidad, Colombia está en el proceso de implementación de las nuevas obligaciones internacionales en la materia, incluida en el FTA Estados Unidos-Colombia. El impulso para tener el acuerdo comercial vigente ha desempeñado un papel central en el proceso de implementación del tratado. De esta manera, el Congreso colombiano ha optado por una implementación acelerada de las obligaciones de la USCO casi copiando y pegando dichas obligaciones en una ley de derechos de autor colombiano sin cambios, y a veces proporcionando regulaciones aún más restrictivas. Este tipo de aplicación no beneficia a Colombia y puede afectar su capacidad de utilizar la tecnología para resolver los problemas más destacados de la educación, aun cuando el derecho de autor no está siendo infringido. Esto se debe a que la propia ley, basada en el modelo norteamericano, viene con algunos defectos que le permiten ser objeto de abuso y que el Congreso colombiano no trató de solucionar.

Adicionalmente, estas consecuencias no deseadas de la ley pueden aumentarse en algunos casos cuando se añade un modelo siguiendo las disposiciones de Estados Unidos a la legislación vigente de derecho de autor de Colombia, como se intentó. En el caso del régimen de ISP, la falta de equilibrio de las disposiciones aplicables a la era digital en el marco del derecho de autor colombiano impide la capacidad de utilizar el marco legal 
para el control de los abusos de un sistema privado de bajada de contenidos. En el caso de las disposiciones de TPM, proscribir cuatro actos de elusión hace aún más difícil el ejercicio de las limitaciones y excepciones en el mundo digital. Al mismo tiempo, la adopción de este modelo de implementación influirá en la evolución futura de la ley de derechos de autor colombiana. Por último, afectar la adopción de las TIC en Colombia y su uso en educación, cuando no hay infracción de derechos de autor, puede infligir un costo social grande porque esta tecnología puede traer varios beneficios para la educación colombiana.

El papel activo de la sociedad civil en temas relacionados con los derechos de autor ha detenido los impulsos desenfrenados de legislar del Congreso y el Gobierno. Por lo tanto, Colombia todavía tiene una oportunidad para promover una mejor implementación de sus obligaciones. 



\section{Capítulo 6}

\section{CHILE Y AUSTRALIA COMO EJEMPLOS DE IMPLEMENTAGIÓN: HAGIA UNA PROPUESTA DE IMPLEMENTAGIÓN PARA COLOMBIA}

Colombia, como signatario del Tratado de Libre
Ciomercio con Estados Unidos, tiene la obligación de implementar algunas disposiciones relativas a las limitaciones de responsabilidad de los ISP y protección de TPM. Aunque el texto de la USCO es detallado y sigue de cerca el modelo estadounidense de regulación, la implementación que sigue de manera estricta el texto del tratado y el modelo estadounidense - que es el enfoque de Colombia- no es necesaria. Otros socios comerciales de los Estados Unidos durante la implementación de disposiciones similares han tomado en cuenta sus necesidades domésticas y leyes nacionales para tratar de evitar replicar consecuencias no deseadas del modelo estadounidense en sus países. Chile y Australia son los principales ejemplos de este tipo de implementación. Su experiencia establece que la implementación de las limitaciones de responsabilidad de ISP y la protección a TPM requiere un análisis profundo y concienzudo. Además, su modelo de implementación podría mitigar algunos obstáculos del modelo estadounidense en el tema del uso de las TIC en la educación.

La sección primera de este capítulo describe la implementación de las disposiciones de limitación de responsabilidad de los ISP que se incorporan en el TLC de Estados Unidos-Chile y argumenta que dicha implementación 
podría mitigar los efectos negativos sobre el proceso de aprendizaje transformado de Chile. La sección segunda describe la experiencia de Australia en la implementación de su TLC en el tema de TPM y argumenta que esta implementación también podría aminorar el efecto negativo sobre las TIC en la educación. Por último, la sección tercera establece las lecciones que Colombia puede extraer de dichas experiencias.

\section{Ghile}

Chile es un buen caso de estudio para Colombia debido a las similitudes entre ambos países. Chile, al igual que Colombia, es un país de América Latina; su sistema jurídico sigue la tradición del derecho civil ${ }^{1}$ y su ley de derechos de autor sigue la tradición continental de la protección de los derechos económicos y derechos morales del autor ${ }^{2}$ sujetos a una lista exhaustiva de las limitaciones y excepciones. Chile ha sido socio comercial de Estados Unidos desde 2003, y también se considera un país en desarrollo como lo es Colombia (United Nations Development Programme, 2013).

\section{E1 Tratado de Libre Comercio entre Estados Unidos-Ghile (USGHILE).}

\section{La negociación.}

Estados Unidos y Chile firmaron un acuerdo de libre comercio en junio de 2003 (USCHILE) luego de dos años y catorce rondas de negociación. Las partes habían tratado de negociar este TLC diez años antes, pero fue solo en el año 2000 bajo los gobiernos de Ricardo Lagos y Bill Clinton cuando se reanudaron las negociaciones y fueron finalmente exitosas (Roffe, 2004; Ministerio de Relaciones Exteriores, 2014).

1 Además, el Código Civil de Chile escrito por Andrés Bello en 1855, fue adoptado por Colombia con algunas modificaciones. Aunque el Código Civil colombiano ha tenido algunas modificaciones a través del tiempo muchos principios generales permanecen y son similares entre ambos países (Bernardino, 1982).

2 La ley de derechos de autor de Chile es la Ley 17.336 y ha sido modificada varias veces. El capítulo IV de la ley se dedica a la protección de los derechos morales y el capítulo $\mathrm{V}$ está dedicado a la protección de los derechos económicos del autor.

3 El USCHILE FTA fue el primer acuerdo comercial firmado por los EE. UU. con un país de América Latina. 
Ambos países percibían ventajas económicas y políticas en la firma del tratado. Para Estados Unidos el TLG representaba la primera firma de un importante tratado bilateral después del North American Free Trade Agreement (NAFTA). Para Chile, el TLG fue un logro de comercio e inversión con un gran socio comercial y se esperaba que aumentara las exportaciones chilenas y consolidara el Sistema Generalizado de Preferencias (SGP) que Estados Unidos había otorgado a Chile ${ }^{4}$. Además, era políticamente ventajoso para el país suramericano firmar acuerdos de libre comercio tanto con Estados Unidos y la Unión Europea en el mismo año (Roffe, 2004, p.4).

Aunque el TLC fue un logro importante, Chile no era tan optimista acerca de la inclusión de los DPI en el texto del tratado. No obstante, Estados Unidos siguiendo su política en la materia buscó un TLC que incluyera disposiciones ADPIC-Plus a pesar de que Chile no consideraba apropiado incorporar en el tratado disposiciones que excedieran los ADPIC, principalmente debido a que ya se había hecho parte de la implementación de las disposiciones del ADPIC y había firmado importantes convenios internacionales sobre el tema (Roffe, 2004, p. 9). Por lo tanto, durante la negociación de USCHILE las partes discutieron detenidamente los DPI. De hecho, el desacuerdo de las partes sobre el tema tuvo un papel importante en el retraso de la firma del acuerdo 5 . Al final, Chile aceptó el capítulo DPI de USCHILE con el fin de obtener el acuerdo económico con los Estados Unidos (Díaz, 2006, p. 12).

\section{Las obligaciones de derechos de autor incluidas en USCHILE.}

Siguiendo la política de Estados Unidos en el derecho internacional de derechos de autor, el capítulo 17 del USCHILE $^{6}$ incorporó obligaciones detalladas en la materia. No obstante, a pesar de su detalle, en general son menos extensas que las obligaciones de derechos de autor incluidas en el USCO. Una de las razones es que USCHILE fue uno de los primeros acuerdos bilaterales en exportar las disposiciones de derecho de autor de Estados Unidos y, como resultado, la plantilla estadounidense utilizada

$4 \quad$ Ver Roffe (2004), indicando las ventajas económicas percibidas por ambos países con la firma del acuerdo (p. 4).

5 Ver De la Barra (2010), afirmando que las principales dificultades para el cierre de las negociaciones eran la propiedad intelectual, los flujos de capital y las cuestiones ambientales (p. 11).

6 Ver Free Trade Agreement, U.S. - Chile [USCHILE] (junio 6 de 2003), 42 ILM 1026. 
durante la negociación no se encontraba tan refinada. Con el paso del tiempo y algunas críticas de la industria estadounidense, Estados Unidos mejoró sus requisitos en materia de DPI (Díaz, 2006, p. 29).

De la misma manera que el USCO, el capítulo de DPI de USCHILE se basa en el principio de "trato nacional" (USCHILE, 2003, art. 17.1.6) y contiene normas mínimas de protección (art. 17.1.1). En cuanto a la obligación de los derechos de autor, el USCHILE exige la ratificación del Convenio sobre la Distribución de Señales Portadoras de programas Transmitidas por Satélite (1974) ${ }^{7}$. No obstante, el USCHILE guarda silencio acerca de la obligación de adherirse al WCT y el WPPT, como lo manda el USCO. Al igual que el USCO, el USCHILE aclara la aplicación del derecho de reproducción para cubrir las reproducciones temporales (art. 17.5.1), incluye la redacción tanto del derecho de distribución como del derecho de comunicación pública incluidos en el WCT (art. 17.5.2; 17.5.3), y aumenta la regla general de protección de los derechos de autor establecida en Berna a 70 años después la muerte de un autor (art. 17.5.4). Por otra parte, USCHILE establece algunas obligaciones comunes que requieren que no se establezca jerarquía en los casos donde se necesita la autorización tanto del autor como del artista intérprete o ejecutante o productor (art. 17.7.1). Sin embargo, USCHILE no es tan explícita como la USCO en relación con dicho mandato. Finalmente, el USCHILE también ordena la aplicación del artículo 18 del Convenio de Berna (art. 17.7.2) y ratifica la transferibilidad de los derechos económicos del autor y los derechos conexos (art. 17.5.3).

En la obligación de otorgar protección jurídica a las TPM, USCHILE es más benevolente que el USCO. Aunque ambos tratados se basan en la DMCA, USCHILE parece permitir la promulgación de nuevas excepciones al acto de elusión y a las disposiciones contra el tráfico de dispositivos elusivos $^{8}$, mientras que la DMCA y el USCO confinan dichas excepciones a siete casos. Por otra parte, USCHILE solo requiere que la elusión de una medida de control de acceso sea sancionada, cuando dicha elusión se hizo con conocimiento y la elusión da lugar a responsabilidad civil. La responsabilidad

Ver USCHILE, 2003, art. 17.1.3, c.

8 Esta flexibilidad se debe al uso de la expresión "en particular" al enumerar las siete excepciones (USCHILE, 2003, 17.7.5 (d)); ver U.S.-Chile Free Trade Agreement analysis of Implementation (s.f.). 
penal debe ser impuesta solamente en circunstancias apropiadas. Por último, USCHILE no requiere que las disposiciones relativas a la elusión sean disposiciones independientes. Estas características de USCHILE lo diferencian del USCO (USCHILE, 2003, art. 17.7.5, a).

El USCHILE, como el USCO, incluye disposiciones sobre limitaciones a la responsabilidad de ISP basado en las características principales de la OCILLA. El USCHILE establece que los ISP que en la transmisión, almacenamiento en caché, almacenamiento de material de los usuarios y el uso de herramientas de búsqueda de información (17.11.23 (b)) cumplan con algunos requisitos generales y específicos (17.11.23 (d); 17.11 .23 (c)), se beneficiarán de la limitación de su responsabilidad por la infracción de derechos de autor por un tercero. En cuanto al almacenamiento en caché, almacenamiento de material por el usuario y el uso de herramientas de búsqueda de información, el USCHILE requiere que sus partes creen un mecanismo de notificación y retirada de contenidos que incluya las obligaciones de proporcionar una acción por falsa representación contra quien abuse del procedimiento de bajada de contenidos (17.11.23 (f)), y una limitación de la responsabilidad al ISP que desactive o elimine el acceso a un contenido de buena fe $(17.11 .23(\mathrm{~g}))$. Además, se manda a establecer un proceso para identificar al supuesto infractor (17.11.23 (h)), se libera al ISP de la obligación de supervisión (17.11.23 (d)), y finalmente el texto del USCHILE establece una definición de ISP (17.11.23 (i)). Al igual que la USCO, USCHILE no incorpora una excepción para las instituciones educativas.

El texto de USCHILE y el USCO presentan muy pocas diferencias en materia de limitaciones a la responsabilidad de los ISP. En primer lugar, USCHILE afirma que los puertos seguros no excluyen el uso de diferentes defensas a la responsabilidad de derechos de autor por un ISP durante un procedimiento de derecho de autor (USCHILE, 2003, 17.11.23 (b)). Esta disposición se asemeja a las disposiciones de la DMCA que apoyan el carácter no obligatorio de las disposiciones OCILLA, aclarando que la DMCA no extiende responsabilidad a los ISP por falta de cumplimiento de sus disposiciones (17 U.S.C § 512, l). En cualquier caso, esta disposición fue omitida en el texto de la USCO.

En segundo lugar, el USCHILE establece que los tribunales, al considerar las limitaciones de responsabilidad a favor de los ISP, pueden considerar otras 
medidas a las allí establecidas, si es necesario, cuando esas medidas "sean lo menos gravosas para el proveedor de servicio, para los usuarios y para los suscriptores entre formas comparables de reparación efectiva". Además, USCHILE ofrece que cualquier otra reparación tendrá en cuenta "la carga relativa para el proveedor de servicio, para los usuarios y para los suscriptores y el daño al titular del derecho de autor" (USCHILE, 2003, 17.11.23 (e)). Esta especificación de USCHILE es importante dentro del procedimiento de bajada de contenidos de Chile, como se explicará más adelante. Este aspecto de USCHILE difiere de la DMCA y la USCO, los cuales permiten que el tribunal considere cualquier otra medida, pero teniendo en cuenta que estas medidas sean menos onerosas solo para el proveedor de servicios (17 U.S.C § 512 (j) (1) (A) (iii); USCO, 2006, 16.11.29, viii). Por otro lado, el USCO también requiere que los tribunales tomen en consideración el daño al titular del derecho de autor al decretar otra medida, pero excluye de la consideración la carga impuesta a los usuarios ${ }^{9}$.

La última diferencia entre los textos de los acuerdos se encuentra en el procedimiento de bajada de contenidos. El USCHILE se refiere expresamente a la capacidad de los socios comerciales de establecer un proceso transparente de acuerdo con la legislación nacional ${ }^{10}$. Por otro lado, el USCO omite la referencia a la legislación nacional. Esta referencia expresa al derecho interno dentro USCHILE ha apoyado la aplicación nacional del procedimiento de bajada de contenidos, el cual es diferente del modelo de Estados Unidos y ha sido muy criticado por dicho país ${ }^{11}$.

Aparte de las tres diferencias mencionadas anteriormente, las demás disposiciones relativas a la limitación de la responsabilidad del ISP en los textos de ambos acuerdos son las mismas. Por lo tanto, la implementación chilena del régimen de responsabilidad de los ISP es un buen caso de estudio para demostrar que las obligaciones del acuerdo son lo suficientemente flexibles como para permitir una implementación que no necesariamente siga de manera fidedigna el modelo estadounidense.

\footnotetext{
$9 \quad$ Ver USCO (2006), 16.11.29 (viii).

10 Ver USCHILE (2003), 17.11.23 (e): "appropriate procedures through an open and transparent process which is set forth in domestic law".

11 Ver USCO (2006), 16.11.29 (viii).
} 


\section{La implementación chilena del modelo de limitación a la res- ponsabilidad de ISP.}

\section{Generalidades.}

Chile fue el primer país de la región en implementar las obligaciones relativas a las limitaciones en materia de responsabilidad de ISP incluidas en un acuerdo de libre comercio con los Estados Unidos. Sin embargo, no ha cumplido sus obligaciones en materia de protección de medidas tecnológicas de protección. Hay tres diferencias principales entre el proceso de implementación de Chile y los intentos de implementación de Colombia. En primer lugar, el proceso de Chile fue largo y cuidadosamente discutido. En segundo lugar, Chile tuvo en cuenta las críticas contra el régimen estadounidense de responsabilidad de los ISP, así como sus propias necesidades internas. Por último, Chile utilizó dicho proceso de implementación para reequilibrar todo el sistema de derechos de autor.

La implementación de USCHILE, que incluyó el régimen de ISP, fue un proceso largo. Tres años pasaron entre el momento en que el Ejecutivo presentó inicialmente el proyecto de Ley No 5012-03 al Congreso en mayo de 2007 y su entrada en vigor en mayo de 2010 (Walker, 2012). Durante el proceso, muchos interesados participaron en la discusión ${ }^{12}$, haciendo de la implementación de las disposiciones de ISP un tema altamente discutido en el Congreso chileno ${ }^{13}$. Igualmente, Chile intentó tomar en cuenta las críticas internacionales al modelo estadounidense de responsabilidad de ISP, especialmente del procedimiento de bajada de contenidos. Por ejemplo, uno de los argumentos en el Congreso chileno para apoyar la creación de un procedimiento de bajada de contenidos judicial era que de esta forma

12 El proceso de implementación incluye la participación de una gran variedad de organizaciones interesadas en el tema (Walker, 2012, p.250).

13 El proyecto de ley no fue abierto al debate con las partes interesadas hasta que se presentó al Congreso. Durante la redacción del proyecto de ley del Ejecutivo no hizo la consulta política o técnica con las partes interesadas. Otra característica importante del período de redacción es que los diferentes ministerios contribuyeron a la redacción del proyecto de ley. De esta manera, se unificó la posición del ejecutivo (Álvarez, diciembre de 2011); ver: Walker (2012), afirmando que los argumentos sobre este tema eran numerosos y diversos y habían muchas organizaciones participando en la discusión (p. 254). 
de implementación limitaría los posibles abusos al mecanismo de bajada de contenidos privado generados en Estados Unidos $^{14}$.

Además, el procedimiento de implementación de Chile también tuvo en cuenta las necesidades nacionales y el sistema legal nacional. Por ejemplo, una de las mayores preocupaciones durante la implementación era cómo hacer que el régimen de bajada de contenidos cumpliera con los derechos constitucionales chilenos, ya que se consideraba que un sistema prejudicial basado en notificaciones privadas a la ISP, que es esencialmente el procedimiento de bajada de contenidos de DMCA, era inconstitucional porque permitiría censura, afectar derechos constitucionales y restringir los derechos de la persona acusada sin resolución judicial ${ }^{15}$.

Otro aspecto importante de la aplicación USCHILE es que el Congreso de Chile aprovechó la oportunidad para actualizar la legislación nacional de derechos de autor ("Chile Breaks New Ground in Regulating IP Liability", junio de 2010) ${ }^{16}$, donde se les dio un lugar importante dentro del proceso a la actualización de las excepciones y limitaciones ${ }^{17}$. Por lo tanto, a diferencia de los intentos de Colombia para implementar las obligaciones del USCO, el proceso de implementación de Chile fue reflexivo y extenso.

14 Ver Rodrigo Tabja (Presidente de la Asociación de Proveedores de Internet) en Biblioteca del Congreso Nacional de Chile (2010, p. 253); ver también Walker (2012, p. 253).

15 Ver Amenabar (2010), indicando la prohibición de tener un sistema que permite la censura (p. 22). Ver también Tabja, una notificación privada que afecta los derechos constitucionales está en contra de la Constitución; Claudio Magliona, Director de la Asociación de Derecho e Informática de Chile; Pedro Less, Gerente de Asuntos Gubernamentales y Políticas para Latinoamérica de Google, afirmando los derechos de la persona imputada (Biblioteca del Congreso Nacional de Chile, 2010).

16 Ver Hornbeck (2003), indicando que si bien Chile ha ratificado tratados de la OMPI y los ADPIC, esos tratados no se han aplicado en el momento de la negociación del acuerdo de libre comercio (p. 13).

17 Las enmiendas anteriores a la ley de derechos de autor se centró casi exclusivamente en el aumento de los derechos de los titulares de derechos de autor. Sin embargo, la reforma de 2010 que trató de poner en práctica las obligaciones adquiridas en el USCHILE también se utilizó para equilibrar el sistema de derechos de autor existente mediante la inclusión de algunas limitaciones y excepciones. Ver: Álvarez, citado en Biblioteca del Congreso Nacional de Chile (2010, p. 4). 


\section{La implementación del modelo de limitación sobre responsabilidad ISP del USCHILE: el toque chileno.}

Como resultado del proceso parlamentario, la Ley 20.435, que modificó la Ley de Propiedad Intelectual 17.336 de 1970, fue promulgada. Esta ley incorpora el régimen de limitaciones a la responsabilidad de los ISP en el artículo 85 L. Este régimen se basa inicialmente en la DMCA, por lo que crea un sistema vertical de limitaciones al ISP en materia de responsabilidad por infracciones a los derechos de autor basado en cuatro puertos seguros y sujeto al cumplimiento de dos obligaciones generales (salvo en los casos de uso de herramientas de búsqueda de información donde el ISP no tienen que cumplir con las dos obligaciones generales $)^{18}$. Aunque la ley tiene algunas similitudes con la DMCA, también tiene diferencias importantes especialmente en el procedimiento de bajada de contenidos, entre otros. Esta situación nos demuestra que no es necesario hacer una implementación del TLC en parámetros de copiar y pegar el sistema de Estados Unidos.

\section{La definición ISP.}

La definición de ISP incluida en la Ley 17.336 distingue al modelo chileno del modelo estadounidense. Aunque el USCHILE incluía una definición de ISP basada en el modelo de Estados Unidos ${ }^{19}$, dicha definición era en realidad más amplia que la definición de ISP incluida en la DMCA, ya que no hacía referencia a un proveedor de Internet como una entidad. De este modo, la definición de ISP incluida en el USCHILE era aplicable no solo a las personas jurídicas, como en la $\mathrm{DMCA}^{20}$, sino también a los individuos. Durante el debate parlamentario se puso de relieve esta situación, y el Congreso decidió añadir a la definición de ISP del USCHILE la palabra

18 Ver Ley 17.336 de 1970, art. 85º, excluyendo el ISP de herramientas de búsqueda de información de las obligaciones generales; ver también Lara y Vera (s.f.), afirmando que la ley excluye de estas obligaciones el ISP cuando actúa como herramienta de búsqueda de información.

19 Ver USCHILE, 17.11.23 (i), incorpora el modelo de definición de ISP de EE. UU. En este modelo, la definición de ISP tiene dos partes: la primera es una definición estrecha dirigida a aplicar a las actividades de transmisión. El segundo es una definición más amplia dirigida a aplicar a otras actividades.

20 La definición de ISP incluida en 17 U.S.C $§ 512(\mathrm{k})(1)(\mathrm{A})$ de la DMCA establece: "the term 'service provider' means an entity $(. .$.$) ".$ 
"empresa" 21 . El propósito de esta incorporación era restringir la definición de ISP y evitar crear excesivas exigencias tecnológicas y de tiempo para los individuos ${ }^{22}$.

La incorporación del término "empresa" en la ley chilena limita la aplicación de la definición de ISP más que en la legislación de los Estados Unidos, esto se debe a que la definición de ISP del DMCA aplica a una entidad. De acuerdo con la definición en el Black's Law Dictionary, la entidad es "[a]n organization (such as a business or a governmental unit) that has a legal identity apart from its members or owners" (Garner \& Campbell, 2009, p. 612). En el caso de la ley chilena que aplica a "empresas", una empresa ${ }^{23}$ es "[a] corporation - or, less commonly, an association, partnership, or union - that carries on a commercial or industrial enterprise" (Garner \& Campbell, 2009, p. 318). De esta forma, cada empresa es una entidad, pero no cada entidad es una empresa. La empresa debe tener como objetivo una asociación comercial con el fin de ser considerada como tal. Cuando la ley chilena define un ISP como empresa excluye de su ámbito de aplicación las instituciones gubernamentales y organizaciones sin fines de lucro, como las instituciones educativas, bibliotecas y archivos. Esta situación difiere de la DMCA, donde las instituciones educativas caen dentro la definición de ISP,

21 El proyecto de ley inicial incorporaba una transcripción literal de la definición de ISP del USCHILE, el cual, no decía nada sobre el requisito de "entidad", aunque la DMCA define un ISP como una entidad. Sin embargo, durante la discusión parlamentaria se argumentó que con el fin de limitar el alcance de la aplicación de la ley era importante incluir la exigencia de un ISP de ser una "entidad". El propósito de incluir el término "entidad" fue acortar la definición y evitar su aplicación a los individuos. Ver CerdaSilva (2014), Director of the NGO Digital Rights [ONG Derechos digitales]; Lara y Bonilla (s.f.), afirmando la necesidad de añadir el término entidad a la definición (pp. 128-130).

22 Ver Cerda-Silva (2014), estableciendo que la ley no buscaba poner requisitos onerosos a los individuos. Sin embargo, aunque el art. 5 de la ley de derechos de autor define el ISP como una empresa, hay una falta de coherencia en la legislación chilena en este sentido. El artículo $85 \mathrm{~L}$ al establecer la limitación de la responsabilidad por infracción de derechos de autor por parte de terceros, afirma que tal limitación se aplica a la red o sistemas controlados u operados por personas o entidades.

23 La definición tomada del Black's law dictionary, fue basada en la traducción del término empresa al inglés siguiendo la traducción del English/Spanish legal dictionary. Empresa es: enterprise, undertaking, intention, company, firm, concern. (Kaplan, 2013, p. 447) 
e inclusive la DMCA en la sección 512 (e) crea una excepción especial para las instituciones educativas como ISP.

Por lo tanto, en virtud de la legislación chilena, las instituciones educativas sin fines de lucro o las bibliotecas y archivos no se consideran un ISP bajo la Ley 17.336, incluso si ofrecen conexión a Internet o servicios en línea para sus estudiantes, personal, investigadores o visitantes.

\section{El requisito de terminación de cuentas a los infractores reincidentes judicialmente calificados.}

El USCHILE requiere al ISP establecer una política que mande la cancelación de las cuentas de infractores reincidentes en circunstancias apropiadas $^{24}$. Este requisito también se toma de la DMCA, que requiere a los ISP a adoptar y aplicar una política razonable para la terminación de la cuenta de los infractores reincidentes en determinadas circunstancias (17 U.S.G § 512 (i) (1) (A)), bajo este modelo la decisión de suspender la cuenta de alguien, por lo tanto, recae en el ISP. Chile adoptó este procedimiento de acuerdo con su ordenamiento jurídico ${ }^{25}$ y requirió dos circunstancias específicas con el fin de terminar la cuenta de otra persona: (1) que el infractor reincidente sea calificado como tal judicialmente y no por un ISP (Ley 17.336 de 1970, art. 85 O, a); y (2) que el tribunal, y no el ISP, sea quien decida si se ordena la cancelación de la cuenta ${ }^{26}$. Además, la medida solo se aplica cuando el usuario actúa como un proveedor de contenidos, es decir, cuando el usuario pone el contenido protegido disponible en Internet sin autorización y no por la sola descarga ${ }^{27}$.

Estos requisitos diferencian la ley chilena del modelo de Estados Unidos, en el sentido de que, en Chile, ningún ISP está facultado para, bajo su

24 Ver USCHILE, 17.11 .23 (d) (i).

25 Esta ley está de acuerdo con la Ley de neutralidad en la red 20, 453, del 18 de agosto de 2010, que prohíbe al ISP restringir el servicio del usuario. Además, este tipo de mecanismo judicial busca llegar a un acuerdo con el marco constitucional chileno de protección de los derechos humanos. Ver Cerda-Silva (2014), afirmando que la ley trata de ponerse de acuerdo con el marco constitucional de Chile, donde se requiere la protección a los derechos humanos de los actores públicos y privados (p. 143).

26 Ver Ley 17336 de 1970, art. 85 R (b); ver también Cerda-Silva (2014), afirmando que el tribunal es el encargado de decidir si terminar la cuenta del suscriptor (p. 144).

27 Ver Cerda-Silva (2014), indicando que la medida solo se aplica a aquellos usuarios que proporcionan el contenido en lugar de aquellos que lo descargan (p. 143). 
propia decisión, terminar la cuenta de un usuario después de recibir una notificación. Además, el hecho determinante acerca de si un infractor es un infractor reincidente no está dado por el número de notificaciones enviadas contra este.

\section{El procedimiento de bajada de contenidos.}

El USCHILE también requiere que los proveedores de Internet establezcan un proceso de bajada de contenidos en el caso de almacenamiento en caché, almacenamiento de material proporcionado por el usuario y por el uso de herramientas de búsqueda de información ${ }^{28}$. Este requisito se basa en el procedimiento de bajada de contenidos de la DMCA que establece un procedimiento privado y expedito en favor de los titulares de derechos de autor para hacer valer sus derechos en Internet y proteger a los ISP de responsabilidad (17 U.S.G $\$ 512$ (c) (3); capítulo 2). Aunque hay similitudes entre el texto del tratado y la ley estadounidense, el USCHILE deja abierto a Chile la posibilidad de implementar un proceso de acuerdo con su legislación nacional ${ }^{29}$.

En este sentido, la ley chilena estableció un procedimiento de bajada de contenidos a los ISP en los casos de almacenamiento en caché, de alojamiento de contenidos y uso de vinculación (Ley 17.336 de 1970, art. 85 Q). No obstante, es en este procedimiento donde la ley chilena difiere más de la ley estadounidense. El procedimiento de bajada de contenidos de Chile es un procedimiento prejudicial ${ }^{30}$ o judicial en el que el titular del derecho de autor o su representante pueden pedir a un juez que ordene al proveedor de servicios desactivar o eliminar el contenido o cancelar la cuenta del infractor reincidente (Ley 17.336, art. 85 Q, 85 R). La petición de bajada de contenidos debe incluir, entre otros requisitos: (1) la designación del tribunal ante el cual la solicitud se presenta; (2) nombre, domicilio y profesión del

28 Ver USCHILE, art. 17.11.23 (f).

29 Ver USCHILE, 17.11.23 (f): "each Party shall establish appropriate procedures through an open and transparent process which is set forth in domestic law, for effective notifications of claimed infringement, and effective counter-notifications".

30 Esto significa que la desactivación o eliminación del contenido se puede pedir antes de iniciar un proceso judicial. Sin embargo, en este caso algunos otros requisitos deben cumplirse para obtener la orden judicial: 1) suficientes razones urgentes, 2) el pago de una caución si la medida se concede sin la participación del proveedor de contenido, el titular de los derechos de autor tiene que pagar caución (Ley 17.336 de 1970, art. 85 Q). 
titular de los derechos de autor o su representante y, en tal caso, el tipo de representación; (3) el nombre, domicilio y profesión del demandado; (4) los derechos supuestamente infringidos con indicación precisa de la propiedad y la modalidad de infracción; (5) la indicación del material infractor; y (6) la localización del material infractor dentro de la red o el sistema del proveedor de servicios (Ley 17.336, art. 85 Q $^{31}$.

Al considerar la petición, los jueces deben tener en cuenta las cargas relativas impuestas a los ISP, suscriptores y usuarios, así como el daño al titular del derecho de autor ${ }^{32}$, la viabilidad técnica y la eficacia de las medidas y la existencia de medidas menos gravosas para la protección del derecho supuestamente infringido (Ley 17.336 de 1970, art. 85 R). La idea de este procedimiento es que el juez analice los méritos de la reclamación con el fin de evitar abusos del sistema ${ }^{33}$. Después de que el ISP ha sido notificado de la orden judicial debe cumplirla con prontitud. El proceso también le da la oportunidad al usuario de oponerse a la orden ante el juez ${ }^{34}$.

Solo una orden judicial para eliminar o desactivar contenido dará al ISP el "conocimiento efectivo" de la existencia de una supuesta infracción en sus redes o sistema (Ley 17.336 de 1970, art. 85 Ñ; Lara \& Vera, s.f., p. 21).

31 La solicitud presentada por el titular de los derechos de autor debe incluir la información obligatoria de la Ley 17.336 de 1970, art. 85 Q.

32 Esta cláusula se toma del USCHILE al 11/17/23 (e), como se mencionó en la sección anterior esta disposición es una de las diferencias entre los textos de ambos acuerdos. Esta disposición es importante por traer equilibrio a la ley chilena ya que cualquier recurso que el tribunal considere no debe crear una carga para ninguno de los participantes del proceso. No como la DMCA o como los mandatos USCO que considera solo las cargas que se imponen al proveedor de servicios sin tener en cuenta los costos para los usuarios.

33 Ver El impacto de los acuerdos comerciales sobre la innovación. (s.f), describiendo el sistema de bajada de contenidos chileno y declarando que permite al juez hacer un breve análisis de los méritos de la reclamación. Sin embargo, esta parte del proceso es difícil de entender de la transcripción literal de la ley. El artículo 85 Q afirma que tras el cumplimiento del anterior párrafo -enunciando los elementos que deben incluirse en la solicitud de los derechos de autor- el tribunal sin demora ordenará el retiro o bloqueo de los contenidos infractores. Esto puede llevar a pensar que solo el cumplimiento de los requisitos formales genera automáticamente el deber del juez de ordenar la eliminación o el bloqueo del material.

34 El proveedor de contenido debe presentar una solicitud que cumpla con todos los requisitos establecidos para la solicitud del titular del derecho de autor en el artículo 85 Q, además de toda la información que apoye su petición. Esto implica su consentimiento a la jurisdicción del tribunal (Ley 17.336 de 1970, art 85 Q). 
Esta característica es muy importante en el sentido de que un ISP pierde la protección de la ley solo si no cumple cuando tiene conocimiento efectivo. En otras palabras, incluso si el ISP es consciente del material infractor, este no necesita bajar o desactivar el acceso al contenido con el fin de estar protegido de responsabilidad. Así pues, el requisito de "conocimiento efectivo" también difiere del procedimiento de bajada de contenido de la DMCA, durante el cual, el ISP adquiere conocimiento efectivo después de la recepción de una notificación que cumpla sustancialmente con los requisitos de la ley enviada por el reclamante ${ }^{35}$. Igualmente, en virtud de la DMCA, el ISP podría ser considerado responsable si tiene conocimiento de los hechos o circunstancias por los que la actividad infractora es evidente ${ }^{36}$. En Chile, la ley consideró que el ISP solo tiene conocimiento en los términos del procedimiento de bajada de contenidos después de la recepción de la orden judicial. De esta forma, Chile decidió no incluir el sistema de "red flag" (Ley 17.336, art. 85 N), aunque fue mandada por el USCHILE ${ }^{37}$.

A diferencia de la DMCA y de los requisitos de USCHILE, el procedimiento de bajada de contenidos de Chile también se puede utilizar cuando el presunto contenido infractor se está transmitiendo por el sistema o red controlado u operado por el ISP ${ }^{38}$. Sin embargo, en este caso, la orden del tribunal se limitará a tomar medidas razonables para bloquear el acceso al material supuestamente infractor sin bloquear el acceso a otro tipo de contenido legítimo (Ley 17.336, art. 85 R). Otra diferencia notable entre la DMCA y la legislación chilena es que esta última no contempla una

35 Ver 17 U.S.C $\$ 512$ (c) (1) (A) (i); 17 U.S.G $\$ 512$ (c) (A) (i); 17 U.S.G $\$ 512$ (c) (2) (B) (i).

36 Ver 17 U.S.C $\$ 512$ (c) (A) (ii); ver también Casey (2000), este doble nivel de conocimiento fue buscado por la industria de los contenidos bajo la idea de que solo el estándar de "conocimiento efectivo" proporcionaría poca protección para ellos (p. 110). En este sentido empujaron para incluir el estándar de "red flag" en el que el ISP que debiera haber sabido o podría haber tenido conocimiento de la infracción debe ser responsable.

37 USCHILE establece el estándar de doble conocimiento en el artículo 17.11.23 (c) (ii) con respecto de las funciones (b) (iii) y (iv).

38 La DMCA aplica el procedimiento de bajada de contenidos únicamente a las actividades de almacenamiento en caché, almacenamiento y vinculación. 17 USC § 512 (a) que regula el puerto seguro para las transmisiones no requiere al ISP cumplir con el procedimiento de bajada de contenidos como lo hace para los puertos seguros restantes. Mientras que la ley chilena en la Ley $\mathrm{N}^{\circ} 17.336$ art. $85 \mathrm{R}$ regula la aplicación de dicho proceso a las actividades de transmisión de un ISP. 
excepción a la responsabilidad de los ISP que de buena fe deshabiliten o eliminen contenido, aunque el USCHILE lo requiere ${ }^{39}$. Sin embargo, la falta de dicha protección se puede explicar por la prohibición de la ley chilena en permitir que los ISP decidan si bajar el contenido por su cuenta.

El propósito de implementar un procedimiento judicial de bajada de contenidos era proteger los derechos de los autores a través de Internet, pero también tener un procedimiento compatible con el marco constitucional de Chile (Lara \& Vera, s.f., p. 22), que, como se mencionó antes, parecía amenazado por un mecanismo de bajada de contenidos privado. Aunque los redactores de la ley mediante dicho procedimiento intentaron equilibrar los derechos de las partes, este proceso fue criticado en el ámbito interno. Durante el debate parlamentario, este proceso fue criticado por ser lento y costoso para los titulares de derechos de autor y por no ajustarse a la realidad digital. También se argumentó que crearía una carga muy grande a los tribunales con las solicitudes de notificación de derechos de autor ${ }^{40}$ y no crearía verdaderos incentivos para que los ISP colaboraran con los titulares de los derechos de autor ${ }^{41}$. De manera alterna a esta opción, un procedimiento administrativo fue propuesto ${ }^{42}$. No obstante, el Congreso decidió que la mejor manera de proteger los derechos constitucionales era través de un proceso judicial.

$39 \quad$ La DMCA protege al ISP que de buena fe elimina o deshabilita el acceso al contenido. Ver 17 U.S.G $§ 512$ (g) (1). Esta protección fue también incluida en el USCHILE, citado en Díaz (2006,17.11.23 (g)).

40 Ver Fernando Silva, Asesor Legal Asociación Gremial de Productores Fonográficos de Chile; Karina Ruiz, Gerente General de la Asociación Gremial para la Protección de los Derechos Intelectuales sobre Fonogramas y Videos Musicales (APDIF A.G); Miguel Pérez, Asociación Chilena de Empresas de Tecnologías de Información A.G y Francisco Chahuán, Diputado, Discusión en Sala (Biblioteca del Congreso Nacional de Chile, 2010).

41 Para más argumentos contra el procedimiento de bajada de contenidos judicial ver Walker (2012), las discusiones en el Congreso chileno encarnaban todas las preocupaciones internacionales sobre el régimen de responsabilidad de los ISP (p. 252).

42 Uno de los defensores del procedimiento administrativo fue Antonio Marinovic, abogado de la Asociación de Distribuidores de Videogramas A.G y Cámara de Distribuidores Cinematográficos (CADIC) (Biblioteca del Congreso Nacional de Chile, 2010, pp. 153-154). 


\section{La herramienta de aprendizaje.}

La herramienta de aprendizaje es una creación específica de la legislación chilena y parte del procedimiento de bajada de contenidos. El artículo $85 \mathrm{U}$ establece un mecanismo educativo cuyo objetivo es educar a la sociedad sobre el uso de las obras protegidas en Internet ${ }^{43}$. El procedimiento requiere que un ISP que recibe una notificación privada que cumple con algunos requisitos (Ley 17.336 art. 85 U) notifique al usuario dentro de los cinco días siguientes a la recepción de la notificación. Sin embargo, bajo este procedimiento, la decisión de bajar el contenido se deja al presunto infractor, y no al ISP como en la DMCA. Adicionalmente, el ISP no puede bajar el material presuntamente infractor y, si lo hace, no estaría protegido de responsabilidad por dicha conducta. Este procedimiento se aplica sin perjuicio del procedimiento de bajada de contenidos (art. $85 \mathrm{U}$ ). No obstante, la herramienta de aprendizaje es parte del procedimiento de bajada de contenidos, y el incumplimiento de sus términos por un ISP podría hacer que éste pierda la protección de responsabilidad de la Ley 17.336 de 1970.

La herramienta de aprendizaje ha sido el mecanismo más utilizado del procedimiento de notificación y retirada de contenidos. Desde su promulgación a 2012, 4000 chilenos recibieron una notificación enviada por la Asociación de Productores Fonográficos de Chile (IFPI) sobre el contenido descargado ilegalmente mediante sistemas P2P. La IFPI señala que se trata de una medida educativa, pero que en el futuro la gente puede ser demandada ("Cuatro mil chilenos han sido notificados", 30 de julio de 2013).

\section{El procedimiento de identificación de presuntos infractores.}

El USCHILE requiere la creación de un procedimiento administrativo o judicial que permita a los titulares de derechos de autor obtener información para identificar al supuesto infractor de un ISP de manera expedita ${ }^{44}$. Este requisito se basa en el procedimiento de subpoena de la DMCA (17 U.S.G § 512 (h)). Chile adoptó un procedimiento judicial para la identificación de los presuntos infractores, que puede ser utilizado durante el procedimiento de bajada de contenidos donde el titular del derecho de autor puede pedir al juez

43 Ver Cerda-Silva (2014), mecanismo de la 85 U como un mecanismo educativo (p. 136).

44 Ver USCHILE (2003), 17.11.23 (h). 
que ordene al ISP proporcionar información que permita la identificación del presunto infractor. El tratamiento de los datos debe estar sujeto al cumplimiento de la ley de privacidad de Chile ${ }^{45}$. No obstante, el juez tiene poder discrecional para emitir tal orden. Por último, la ley no establece a quién el ISP le debe proporcionar los datos (Cerda-Silva, 2014, p. 137-139).

\section{Las reacciones internacionales a la implementación del US- GHILE en Ghile.}

La implementación del USCHILE en Chile ha generado opiniones contrarias a nivel internacional. Estados Unidos no ha quedado conforme con la implementación de Chile del TLC. Desde el 2011 y hasta el último informe en el 2014, Estados Unidos ha incluido al país suramericano en el Informe Especial 301 en la categoría de lista de vigilancia prioritaria debido a su implementación de las obligaciones del TLC. En el informe "[The United States] urge[s] Chile to amend its Internet service provider (ISP) liability regime to permit effective action against piracy over the Internet" (Kirk, 2011; Froman, 2014, p. 44). Aunque Estados Unidos no ha utilizado el procedimiento de solución de controversias establecido en la TLC para este problema, la anotación en el Informe 301 contra el régimen de responsabilidad de los ISP de Chile significa que Estados Unidos no tiene la intención de retirar a Chile del informe hasta que se modifique su régimen de responsabilidad de los ISP. Esta situación pone de manifiesto la capacidad de Estados Unidos y el interés por exportar el modelo de este país sin cambios, ya que si bien la aplicación de Chile cumple con el texto de USCHILE y crea un sistema equilibrado, el país norteamericano no está satisfecho con dicha implementación.

Por otro lado, el proceso chileno se ha exaltado y reconocido como un procedimiento adecuado para la protección de los derechos de los usuarios. La Organización de los Estados Americanos ha reconocido que un procedimiento de bajada de contenidos judicial, como el implementado en Chile, es deseable debido a su capacidad de equilibrar los derechos, respetar los derechos de los usuarios, y proteger los derechos fundamentales como la libertad de expresión y el debido proceso (Botero, 2013, pp. 227-228).

$\overline{45 \quad \text { Ver Ley } 17.336}$ de 1970, art. 85 S; Ley 19.628 de 1999. 


\section{Los efectos sobre educación con nuevas tecnologías.}

Tal vez debido a la novedad de la ley chilena, aún no ha habido casos en que el ISP ha utilizado las disposiciones de protección de la ley o que los titulares de derechos de autor hayan hecho uso del procedimiento de bajada de contenidos. El único mecanismo utilizado hasta la fecha ha sido la herramienta de aprendizaje. Por lo tanto, la evidencia empírica de los efectos de tales mecanismos en materia de educación con las TIC no está aún disponible. Por otra parte, la educación no desempeñó un papel central en el debate parlamentario sobre la responsabilidad de los ISP, tal vez porque en el momento de discusión parlamentaria de la implementación la incorporación de las TIC no era un objetivo central en la política educativa.

La integración de las TIC en la educación en Chile comenzó a finales de 2002 con la creación de "El Programa de Tecnologías para la Educación (TIC EDU)" de Fondef. Entre 2004-2007, los años de discusión en torno a la aplicación de las limitaciones de responsabilidad de ISP, las TIC se empezaron a incorporar en la educación, en particular la provisión de infraestructura, conectividad y hardware. A finales de 2007, el proyecto de las TIC en la educación empezaba a comprender que era necesario promover la creación de contenidos digitales y las nuevas metodologías. Aunque el debate de implementación del USCHILE no se centró en las TIC en la educación, es evidente que algunas de las consecuencias no deseadas de la ley de Estados Unidos que obstaculizan la transformación del proceso de aprendizaje por el uso de la tecnología se minimizan en Chile debido a las características únicas de la ley chilena (Fondo de Fomento al Desarrollo Científico y Tecnológico - Fondef, 2008).

Como se explicó anteriormente, la ley chilena tiene algunas diferencias importantes con la ley de Estados Unidos. Estas diferencias son más pronunciadas en el procedimiento de bajada de contenidos y generalmente se caracterizan por la intervención del poder judicial durante todo el proceso $^{46}$. Esta notable diferencia puede reducir la presión sobre el ISP, que

46 El papel del juez durante el procedimiento es evitar los abusos de los mecanismos por los titulares de derechos de autor. En otras palabras, el juez debe asegurarse de que el reclamo tiene fundamentos y que el balance de la ley de derechos de autor se conserva entre otros. La intervención del juez es una medida para proteger los derechos fundamentales, las limitaciones y excepciones y evitar el abuso del mecanismo (CerdaSilva, 2014, p. 145). 
bajo el régimen de DMCA, motiva al ISP a bajar el contenido con el fin de recibir protección. Aliviar al ISP de dicha presión removiendo el poder de este de bajar contenidos ayudará a eliminar los casos en que los mecanismos de bajada de contenido se han utilizado para controlar, inclusive, usos no infractores ${ }^{47}$. También eliminará los casos en que el ISP reacciona de forma exagerada a favor del cumplimiento de una notificación. Bajo la ley chilena, ya que el juez es el único facultado para ordenar la bajada de los contenidos, la primera consideración es si el usuario ha ejercido un uso permitido del contenido (Ley 17.336 de 1970, art. 85 Q) ${ }^{48}$. De esta manera, el uso de la tecnología para promover iniciativas de aprendizaje permanente y comunidades de aprendizaje será salvaguardado, al igual que cualquier otra iniciativa educativa que incluya usos permitidos de un contenido con derechos de autor.

Otra diferencia entre ambas leyes es la definición de ISP. Esta distinción tiene un papel importante en la relación entre las limitaciones a la responsabilidad de los ISP y las instituciones educativas ayudando a aliviar algunas de las consecuencias negativas creadas bajo la DMCA. Como las instituciones educativas sin fines de lucro no están comprendidas en la definición de ISP, estas instituciones no están obligadas a cancelar las cuentas, salvaguardando la presencia en el mundo digital de los estudiantes y su capacidad de participar en un proceso de aprendizaje que se basa en la información y capacidades de comunicación de Internet. Incluso si las instituciones educativas se consideraran ISP bajo la ley chilena, la intervención judicial previa a terminar el acceso a los suscriptores ayuda a aliviar reacciones exageradas de las instituciones educativas ${ }^{49}$.

Sin embargo, el hecho de que las instituciones y bibliotecas educativas sin fines de lucro no se consideren proveedores de Internet también tiene un lado negativo dentro de un proceso de aprendizaje transformado. Aunque el cumplimiento de los requisitos de la responsabilidad de los ISP pueden ser costosos, protegen los ISP de responsabilidad secundaria por infracción de derechos de autor que ocurre dentro de la red del ISP. Dada la cantidad

\footnotetext{
$\overline{47 \quad \text { Ver capítulo } 3 .}$

48 Ver Cerda-Silva (2014), indicando que la decisión del tribunal no está destinado a ser automática (p. 145).

49 Ver Ley 17.336 de 1970, art. 85 O, 85 R.
} 
de materiales con derechos de autor y los actores involucrados en el uso de materiales con derechos de autor dentro de las instituciones educativas, sería deseable proteger a estas instituciones de la responsabilidad. Es imposible para cualquier institución educativa controlar la legalidad de cada material transmitido, almacenado o vinculado en su red por sus estudiantes, profesores y personal. Además, la imposibilidad de controlar todos los usos se convierte en un problema más grande en un proceso de aprendizaje transformado por el uso de las TIC, donde las herramientas de colaboración como wikis y blogs desempeñan un papel central. Por lo tanto, sería deseable proteger dichas instituciones de la infracción a derechos de autor por terceros, realizados con el fin de promover la incorporación de las TIC en el proceso de aprendizaje.

\section{Australia}

A diferencia de Colombia, Australia es un país desarrollado ${ }^{50}$ y su sistema legal sigue la tradición del derecho común. Sin embargo, al igual que Colombia, Australia tuvo que implementar las disposiciones contra la elusión basadas en la DMCA debido a un Tratado de Libre Comercio negociado con Estados Unidos en el 2004.

El Tratado de Libre Comercio Estados Unidos-Australia (AUSFTA).

\section{La negociación.}

En el año 2000 el gobierno australiano entró en negociaciones de un acuerdo comercial con Estados Unidos. En el 2002, bajo la presidencia de George W. Bush, Estados Unidos anunció su intención de negociar con Australia (Philippa, 2005, p. 1). Los Estados Unidos y Australia firmaron un acuerdo de libre comercio (AUSFTA) ${ }^{51}$ en el 2004, que entró en vigor en el 2005. Este acuerdo fue el primer convenio bilateral que Estados Unidos firmó con un país desarrollado ${ }^{52}$. En Australia, la decisión de entrar en un acuerdo de libre comercio con Estados Unidos fue un tema

\footnotetext{
Ver UNDP, 2014

Ver AUSFTA, 2004, 43 ILM 1248.

52 EE. UU. ya había firmado un acuerdo comercial con Canadá, pero no de forma bilateral (Fisch, 2006).
} 
discutido acaloradamente (Fisch, 2006, p. 152). El acuerdo fue impulsado principalmente por consideraciones políticas ${ }^{53}$, pero al final, los beneficios de tener acceso a la principal economía del mundo y tener la posibilidad de atraer inversión estadounidense a Australia pesó fuertemente en la decisión. De hecho, el primer ministro de Australia describió el AUSFTA como una "once-in-a-generation opportunity" (Capling, 2005, p.58). Para el momento del acuerdo, Estados Unidos y Japón eran los dos socios comerciales más importantes de Australia. Las exportaciones al mercado norteamericano estaban creciendo más que a cualquier otro socio comercial debido a la crisis asiática. Estados Unidos fue el mayor mercado único para los fabricantes australianos de productos transformados ${ }^{54}$. Igualmente, se convirtió en la mayor fuente de inversión en Australia y una red importante de exportación de servicios para este último (The Australian APEG Study Centre, Monash University, 2001, pp. 10,12-13).

A pesar de esta relación, la incorporación de un capítulo de DPI dentro del AUSFTA no era poco controversial ${ }^{55}$. Por ejemplo, durante la negociación de las disposiciones de derechos de autor, los grupos de los bibliotecarios, instituciones educativas y grupos relacionados con la tecnología hablaron en contra de la aceptación de las disposiciones de derecho de autor de AUSFTA. La Alianza Digital Australiana (ADA) advirtió sobre las consecuencias que podrían tener estas disposiciones en la reducción del acceso a los materiales y el aumento del costo de proporcionar acceso público al conocimiento. La Biblioteca de Australia y la Asociación de Información encontraron el acuerdo malo para los estudiantes, bibliotecas e investigadores (Khor, 2008; Capling, 2005, pp. 64-65).

53 John Howard, primer ministro de Australia en el momento de la negociación de la AUSFTA, vio en el acuerdo el vehículo para fortalecer los vínculos políticos y estratégicos de su país con los EE. UU. (Capling, 2005).

54 El Departamento de Asuntos Exteriores y Comercio encontró que el AUFTA ofrecería beneficios sustanciales para Australia porque "the U.S. is the largest trading partner, largest provider of foreign investment and the main destination for Australian investment overseas" (Senate Select Committee on the Free Trade Agreement between Australia \& the United States of America Committee Secretariat, 2004).

55 Para más información sobre las diferentes críticas al capítulo IP ver: Senate Select Committee on the Free Trade Agreement between Australia and the United States of America Committee Secretariat (2004, pp. 52-56). 
El hecho de que Australia era un importador neto de derechos de propiedad intelectual en lugar de un exportador de estos productos generaba dudas sobre los beneficios de aumentar la protección de derechos de autor, especialmente en relación con los costos económicos. Por ejemplo, en Australia, durante 1996-1997, el porcentaje del PIB para la importación de contenido con derechos de autor fue 0,38 mientras que las exportaciones fueron de 0,16 $\%$ (Richardson, 2004). Mientras que, por otro lado, Estados Unidos, como exportador de productos de propiedad intelectual, tenía motivos fuertes para incluir fuertes derechos de propiedad intelectual en el TLG ${ }^{56}$. A pesar de estas controversias y las promesas del gobierno australiano ${ }^{57}$, la plantilla de Estados Unidos de las disposiciones de derechos de autor fue aceptada con el fin de asegurar el TLC ${ }^{58}$.

\section{Las disposiciones de derechos de autor del AUSFTA.}

En el AUSFTA (2004), los Estados Unidos siguiendo su política internacional de derechos de autor incluyó disposiciones en la materia en el capítulo 17, el cual, es el capítulo más largo ${ }^{59}$ y sustancial del acuerdo. Debido a que la plantilla de EE. UU. sobre el capítulo de DPI se hizo más fuerte y detallado con el tiempo, el AUSFTA incluye disposiciones más fuertes que USCHILE pero disposiciones más favorables que el USCO.

El AUSFTA, como el USCHILE y el USCO, se basa en el principio de "trato nacional" (AUSFTA, 2004, 17.1.6) y contiene normas mínimas

56 "The US motive for strong protection of IP rights is clear. The US has a disproportionately high share of IP rights and products that contain IP rights in its exports" (Senate Select Committee on the Free Trade Agreement between Australia \& the United States of America Committee Secretariat, 2004, p. 49).

57 Por ejemplo, el Ministerio de Comercio en el momento de la negociación de la AUSFTA, Mark Vaile, prometió que no habría la extensión del derecho de autor debido al costo que crearía a bibliotecas e instituciones educativas. Sin embargo, al final la propuesta de EE. UU. para extender la protección de los derechos de autor a 70 años fue aceptada (Capling, 2005, p. 64).

58 "The Committee acknowledges the comment in JSCOT's report that the term of copyright protection was defended vehemently by the Australian negotiators, but that the final outcome was necessary to secure the overall package" (Senate Select Committee on the Free Trade Agreement between Australia \& the United States of America Committee Secretariat, 2004, p. 75).

59 Ver Senate Select Committee on the Free Trade Agreement between Australia and the United States of America Committee Secretaria (2004), estableciendo que el capítulo 17 sobre DPI es "the largest chapter in the AUSFTA in content and substance" (p. 45). 
de protección (17.1.1). El AUSFTA afirma que las partes han ratificado o se han adherido al Convenio sobre la Distribución de Señales Portadoras de Programas Transmitidas por Satélite $(1974)^{60}$ y el Convenio de Berna $(1971)^{61}$. Adicionalmente, como el USCO, el AUSFTA requiere a las partes ratificar o adherirse al WCT y el WPPT (17.1.4).

$\mathrm{Al}$ igual que el USCHILE y el USCO, el AUSFTA aclara la aplicación del derecho de reproducción a las reproducciones temporales ${ }^{62}$, e incluye la redacción del derecho de distribución del WCT -sin mencionar el derecho de determinar el agotamiento-, pero es silencioso acerca del derecho de comunicación pública incluido en el WCT (17.4.2). El AUSFTA aumenta la regla general de la duración de los derechos de autor establecida en Berna a 70 años después de la muerte del autor (17.4.4). Asimismo, se estableció una obligación común a los derechos de autor y los derechos conexos de "ensure that no hierarchy is established between rights of authors, on the one hand, and rights of performers and producer of phonograms on the other hand" (17.4.3). También exige la aplicación del artículo 18 de la Convención de Berna (17.4.5) y ratifica la transferibilidad de los derechos económicos del autor y los derechos conexos (17.4.6).

El AUSFTA requiere establecer un sistema de limitaciones sobre responsabilidad a ISP basado en el modelo de la DMCA (17.11.29). En aras de la brevedad, dichas disposiciones no se describirán en detalle. En cuanto a la protección de medidas tecnológicas de protección el AUSFTA, como el USCHILE y el USCO, incorpora disposiciones contra la elusión de medidas tecnológicas de protección (17.4.7). El tratado requiere que las partes firmantes establezcan recursos civiles y sanciones penales ${ }^{63}$ para evitar la elusión de medidas tecnológicas de protección, abarcando tres actos diferentes: (1) la prohibición de eludir una medida de control de acceso (17.4.7 (a) (i)); (2) la prohibición de tráfico en servicios y dispositivos para eludir una medida de control de acceso (17.4.7 (a) (ii)) (en conexión con AUSFTA 17.4.7, (b)); y (3) la prohibición al tráfico en los servicios y dispositivos para eludir

\footnotetext{
60 Ver AUSFTA, 2004, 17.1.2 (b).

${ }_{61}$ Ver AUSFTA, 2004, 17.1.2 (h).

62 Ver AUSFTA, 2004, 17.1.2 (h).

63 El texto del AUSTFTA establece una excepción a las sanciones penales en favor de las bibliotecas, archivos, instituciones educativas y organismos de radiodifusión no comercial pública (17.4.7).
} 
una medida tecnológica de control de copia. Al igual que la DMCA, esta prohibición está sujeta a siete excepciones confinadas enumeradas en el texto del acuerdo (17.4.7 (e) (i-vii)), el cual, también establece la forma en que tales excepciones deben aplicarse (17.4.7 (f)).

Por otra parte, el AUSFTA requiere la creación de un procedimiento administrativo o legislativo para crear excepciones adicionales al acto de elusión de una medida de control de acceso "when an actual or likely adverse impact on those non-infringing uses is credibly demonstrated" (17.4.7 (e) (viii)). Además, el texto del acuerdo también requiere que las partes incorporen otras características de legislación de Estados Unidos, tales como la definición de TPM, abarcando tanto las medidas de acceso y control de copia (17.4.7 (b)), y una "regla de no mandato" (17.4.7 (c)). Por último, al igual que el USCO, el AUSFTA requiere que la protección de una TPM sea una disposición independiente (17.4.7 (d)).

Aunque los tres tratados incluyen obligaciones de proteger TPM basada en la DMCA, hay algunas diferencias entre ellos que demuestran un tratamiento más favorable en USCHILE que en el AUSFTA, y, al mismo tiempo, una obligación más estricta y detallada en la USCO que en el AUSFTA. Tres obligaciones específicas ilustran estas diferencias. En primer lugar, la prohibición del acto de elusión difiere entre los acuerdos. El AUSFTA, como el USCHILE, prohíbe el acto de elusión cuando la persona sabe o tiene motivos razonables para saber que él o ella está eludiendo una TPM de acceso. El USCO no incorpora el requisito de conocimiento ${ }^{64}$. Esta diferencia permite limitar el alcance de la protección de medidas tecnológicas de protección en el sentido de que el AUSFTA no busca aplicar a la elusión accidental, mientras que la USCO puede ser aplicada. Por ejemplo, el USCO puede permitir castigar a una persona que, sin saberlo, eluda una medida de control geográfica impuesto en un DVD al ser reproducido en un reproductor de DVD multi-región (EFF Analysis of the TPM Provisions

64 States that each party should provide effective legal remedies against any person who: "knowingly, or having reasonable grounds to know, circumvents without authority any effective technological measure that controls access to a protected work (...)". Este artículo se opone al establecido en el USCO 16.7.4 (a) (i) "that each party should provide effective legal remedies against any person who circumvents without authority any effective technological measure that controls access to a protected work (...)" (17.4.7 (a) (i)). El USCHILE sigue la disposición del AUSFTA. 
In The U.S. February 2011. Proposal for the TPP Intellectual Property Chapter, s.f.). El AUSFTA también incorpora el requisito de conocimiento en el caso del tráfico de dispositivos elusivos mientras que el USCO no lo hace. Esta aclaración es aún más definida en el USCHILE, donde la definición de medida tecnológica efectiva excluye expresamente de la protección esas medidas tecnológicas de protección que pueden ser eludidas por accidente ${ }^{65}$, mientras que el AUSFTA guarda silencio al respecto.

En segundo lugar, en cuanto a la carga de la prueba en el procedimiento administrativo o legislativo, el AUSFTA requiere que un peticionario "credibly demonstrate the adverse impact on the non-infringing uses", mientras que la USCO requiere una demostración sustancial ${ }^{66}$ estableciendo un umbral similar a la DMCA en el procedimiento de elaboración de normas ${ }^{67}$, que al ser más alto que el mandato de AUSFTA puede influir en la capacidad de crear excepciones adicionales de Colombia para el acto de elusión de una medida de control de acceso. Por otro lado, el USCHILE solo requiere que un peticionario "demonstrate or recognize" el efecto adverso ${ }^{68}$. En tercer lugar, el AUSFTA otorga un alcance más amplio para la excepción del gobierno que el USCO al permitir su aplicación a "similar governmental purposes"

A pesar de las tres diferencias entre los acuerdos, el AUSFTA incorporó obligación, muy similar al de USCO, con respecto a la aplicación de las

65 Ver AUSFTA, 2004, 17.7.5 (f): "Effective Technological Protection Measure: Effective technological measure means any technology, device, or component that, in the normal course of its operation, controls access to a work, performance, phonogram, or any other protected material, or that protects any copyright or any rights related to copyright, and cannot, in the usual case, be circumvented accidentally".

66 Confróntese el artículo del AUSFTA, 2004, 17.4 .7 (e) (viii) con el artículo del USCO, 2006, 16.7.4 (f).

67 El Registro Federal constituye que a partir de la historia legislativa de la DMCA se puede establecer que la clase exenta de obras debe basarse en "substantial adverse effect on noninfringing use of that particular class of works" (Exemption to prohibition. noviembre de 1999).

68 Ver USCHILE, 2003, 17.7.5 (d) (i).

69 Confróntese AUSFTA, 2004 17.4.7 (e) (vi), en conexión con el artículo del AUSFTA 17.4.7 (f). Esta disposición establece una excepción a cualquier actividad autorizada llevada a cabo por los empleados del gobierno, agentes o contratistas para diferentes propósitos gubernamentales como la policía, inteligencia, seguridad esencial, pero esto no es una lista exhaustiva. Esta excepción se aplica a las tres prohibiciones. Por otro lado, el artículo del USCO, 2006, 16.7.4 (h), no deja abierta la posibilidad de aplicar esta excepción a actividades similares como lo hace el AUSFTA. 
disposiciones contra la elusión. Por lo tanto, la implementación de Australia a las disposiciones contra la elusión de AUSFTA proporciona un buen caso de estudio para demostrar que son posibles otros tipos de implementación.

\section{La implementación de las disposiciones sobre medidas tecno- lógicas de protección.}

\section{Generalidades.}

Una visión general de la implementación australiana de medidas tecnológicas de protección del AUSFTA evidencia algunas similitudes con la implementación de Chile, y en consecuencia, algunas diferencias con respecto a los intentos de implementación en Colombia. En primer lugar, el proceso de implementación de Australia fue objeto de acalorados debates. En segundo lugar, se tuvo en cuenta las críticas a las disposiciones sobre TPM en los Estados Unidos, así como sus propias necesidades internas. Por último, se utilizó el proceso de implementación como una oportunidad para reequilibrar todo el sistema de derechos de autor que se estaba alterando por las disposiciones del AUSFTA ${ }^{70}$.

La implementación de las disposiciones contra la elusión de AUSFTA tuvo lugar en 2006 con el fin de cumplir con el plazo del acuerdo ${ }^{71}$. Para Australia, la aplicación de la AUSFTA significó la modificación de su propio régimen antielusión para adoptar unas normas ${ }^{72}$ más cercanas al régimen estadounidense. Dicho proceso de implementación fue muy discutido ${ }^{73}$. Uno de los ejes de la discusión fue la capacidad de las disposiciones de TPM del AUSFTA para inclinar la balanza del sistema de derecho de autor de

70 "The Government was obliged by the AUSFTA to strengthen copyright laws at a time when consumer copying was becoming widespread. This meant it felt obliged to respond to demands to 'balance' the strengthened copyright with increased exceptions for copyright users" (Zwart, 2009).

71 En virtud del acuerdo se suponía que las obligaciones de TPM entrarían en vigor el 1 de enero de 2007 (Fischer, 2006, pp. 12-17).

72 The Copyright Act of 1968 amended by the Copyright Amendment (Digital Agenda) Act 2000 incorpora la legislación nacional en materia de protección de las medidas tecnológicas para dar cumplimiento a los tratados WCT.

73 Ver Weatherall y Burrel, (2007), indicando que el AUSFTA levantó críticas incluso de una parte de la población que normalmente no participa en la discusión de estos temas (pp. 22-24). 
Australia en favor de los autores mediante la concesión de la posibilidad de restringir el acceso de los usos no infractores ${ }^{74}$.

Igualmente, la preocupación por alterar el equilibrio de la ley de derechos de autor de Australia se declaró por los comités encargados de la implementación. Dos comités distintos se encargaban de ofrecer recomendaciones tanto para la ratificación e implementación del tratado: el Comité Permanente Conjunto sobre Tratados (JSCOT) y el Comité Selecto del Senado (Weatherall \& Burrel, 2007, p.14). Estos comités también vieron en las disposiciones del AUSFTA la capacidad de desequilibrar el marco del derecho de autor y recomendaron poner atención en no restringir la capacidad de los consumidores para ejercer las limitaciones y excepciones. Por ejemplo, el JSCOT recomienda que:

[T] he Attorney General's Department and the Department of Communications, Information Technology and the Arts ensure that exceptions will be available to provide for the legitimate use and application of all legally purchased or acquired audio, video and software items on components, equipment and hardware, regardless of the place of acquisition (The Parliament of the Commonwealth of Australia, 2004, p. 21.).

Al mismo tiempo, el comité del Senado declaró:

However, the Committee remains concerned that the AUSFTA goes too far. TPM circumvention may be done for legitimate, non-infringing purposes, not simply piracy. A ban on TPM circumvention, while possibly assisting to curb some piracy, may also prevent many legitimate purposes. This severely interferes with the rights of consumers to do as they wish with property that they have legally purchased. It is important to ensure that certain classes of copyrighted work be exempt from the normal TPM circumvention prohibitions where the circumvention is for a non-infringing use (Senate Select Committee on the Free Trade Agreement between Australia \& the United States of America Committee Secretariat, 2004, p. 90).

Además, el Fiscal General, Philip Ruddock, incitó al Comité Permanente de Asuntos Jurídicos y Constitucionales de la Cámara de Representantes a revisar el tema de las medidas tecnológicas de protección, y en concreto,

$\overline{74}$ Ver House of Representatives (2006), afirmando que muchas cartas expresaron su preocupación por la capacidad de las normas de TPM del AUSFTA de desequilibrar el sistema de derechos de autor (p. 14). 
determinar si otras limitaciones y excepciones podrían ser creadas en la legislación de implementación (House of Representatives, 2006).

El proceso de implementación de Australia puso especial atención en la implementación del acuerdo de conformidad con las necesidades nacionales de Australia y su legislación ${ }^{75}$. Dicha preocupación se mencionó en varias ocasiones durante el debate de implementación. Por ejemplo, durante el examen del procedimiento de reglamentación administrativa, el Comité Permanente de la Cámara de Representantes dijo que Australia no debía seguir la interpretación de la Oficina de Derechos de Autor de Estados Unidos. Una de las razones para apoyar esta recomendación fue:

$[\mathrm{T}]$ he legislative framework and history surrounding copyright regulation in the U.S. is not the legislative framework and history surrounding copyright regulation in Australia. Australia's legislative copyright regime and regulatory history can be clearly differentiated from that of the US. Thus, while the USCO interpretation may be perfectly correct in the US regulatory context, it has no automatic congruence or weight with the Australian regulatory context (House of Representatives, 2006, p. 66).

\section{La implementación de las disposiciones de TPM: el toque australiano.}

Australia tuvo que modificar su propio modelo de medidas tecnológicas de protección para acercarla al modelo de Estados Unidos debido a la obligación adquirida en el AUSFTA. Sin embargo, el modelo australiano todavía contiene algunas características especiales que lo diferencian del modelo estadounidense. Siguiendo la estructura general del modelo de Estados Unidos, la Ley de Derecho de Autor de 1968 modificada por la Ley de 2006 establece sanciones civiles y penales contra la elusión de medidas tecnológicas de protección. Los recursos civiles se establecen contra el acto de elusión de una medida de control de acceso cuando la persona sabe o debería razonablemente saber que está eludiendo una medida de control de acceso (Copyright Act 1968, 116 AN). Adicionalmente, la ley crea sanciones penales

75 The Standing Committee of the House of Representatives estableció en la revisión a las excepciones de TPM: "The Committee also agrees with further comment from this submission that 'the AUSFTA' is not a statute, but a treaty which should be interpreted, and implemented, in accordance with Australian public policy" (House of Representatives, 2006, p. 21). 
cuando el acto de elusión de una medida de control de acceso se realiza con la intención de obtener una ventaja comercial o ganancia (Copyright Act 1968, 132 APG) $)^{76}$. Por otra parte, la ley prohíbe el tráfico en los dispositivos y servicios para la elusión de ambas medidas de acceso y control de copia. En el caso de los recursos civiles, la ley requiere que la persona tenga conocimiento o debería saber razonablemente que el dispositivo o servicio es un dispositivo ${ }^{77}$ o servicio de elusión ${ }^{78}$. En el caso de los recursos penales, la ley requiere que la persona que incurra en la conducta con la intención de obtener una ventaja comercial o ganancia (Copyright Act 1968) ${ }^{79}$.

El acto de eludir una medida de control de acceso está sujeto a siete excepciones enumeradas en el AUSFTA (Copyright Act 1968, 116N, 3, 8), algunas de las cuales se aplican a las disposiciones contra el tráfico ${ }^{80}$. Por último, la Ley de 2006 solo crea dos nuevas excepciones que no figuran en el AUSFTA, que se dirigen a limitar el ámbito de aplicación de la prohibición contra la elusión.

En primer lugar, en relación con el acto de elusión de una medida de control de acceso, la ley de derechos de autor no se aplica cuando la persona haya actuado con la autorización del titular de los derechos de autor o como licenciatario exclusivo para llevar a cabo dicha elusión (Copyright Act 1968, $116 \mathrm{~N}, 2)$. Este permiso puede ser expreso o implícito. No obstante, no puede considerarse una autorización implícita cuando el acto desarrollado por el usuario está cubierto por una limitación o excepción (Explanatory Memoranda, 2006, sch. 12, ítem 9, 12.46). Esta clarificación impide el uso de

76 Sanciona con 60 unidades de multa, pero no prisión. Esta prohibición no se aplica a las medidas de protección de control de copia (Explanatory Memoranda, 2006, Sch 12 Item 9 Subsec. A 12.43) (Austl.). Disponible en http://www.austlii.edu.au/au/legi

77 Establece los recursos civiles contra el tráfico de dispositivos de elusión (Copyright Act 1968, $116 \mathrm{AO})$.

78 Establece los recursos civiles contra el tráfico de servicios de elusión (Copyright Act 1968, 116 AP ).

79 Establece recursos penales contra el tráfico en los dispositivos elusivos requiriendo que la persona tenga la intención de obtener una ventaja comercial o ganancia. La conducta se sanciona con 550 unidades de multa o prisión por 5 años o ambos. El artículo 132 APE establece remedios penales contra el tráfico de los servicios elusivos requiriendo que la persona tenga la intención de obtener una ventaja comercial o ganancia y sanciona la conducta con 550 unidades de multa o encarcelamiento de 5 años, o ambos (Copyright Act 1968, 132 APD).

80 Ver Copyright Act 1968, 116 AO, for devices and 116 AP for services. 
esta limitación como una regla general para proteger los usos permitidos. En segundo lugar, en relación con el tráfico de dispositivos y servicios de elusión, la ley establece la "no-advertising exception". Esta excepción se aplica cuando el dispositivo se promueve como un dispositivo de elusión pero la persona no participó en la promoción, publicidad o marketing, ni tampoco dirigió o solicitó a otra persona hacerlo (Copyright Act 1968, 116 AO, 2; Copyright Act 1968, 116 AP, 2). Por último, la ley prevé un mecanismo administrativo para crear excepciones adicionales a la elusión de una medida de control de acceso, según lo establecido por AUSFTA.

\section{La definición de TPM.}

Un enfoque que la legislación australiana utiliza para reducir los efectos de las disposiciones contra la elusión de AUSFTA fue limitar el alcance de la definición de TPM. Durante el proceso de implementación se puso de relieve la necesidad de estrechar la definición incluida en el AUSFTA ${ }^{81}$. En este sentido, el Comité Permanente de la Cámara de Representantes recomendó incorporar una definición de TPM que asegurara que las medidas de control de acceso se conectaran a la protección de los derechos de autor, a fin de no ampliar el alcance de la protección de derechos de autor (House of Representatives, 2006, Recommendation 2, p. 26).

Como resultado, la Ley de Derecho de Autor de 1968, modificada por la Ley de 2006, incorpora una definición de medidas tecnológicas de protección que abarca tanto las medidas tecnológicas de acceso y las medidas de control de copia $^{82}$, cumpliendo con los requisitos del AUSFTA, pero con un alcance

\footnotetext{
81 Ver The submission to the Standing committee of the house of representative of the DEST and the Australian Digital Alliance / Australian Libraries Copyright Committee 9ADA/ALCG (House of Representatives, 2006, pp. 25-26).

82 "(a) an access control technological protection measure; (b) or a device, product, technology or component (including a computer program) that: (i) is used in Australia or a qualifying country by, with the permission of, or on behalf of, the owner or exclusive licensee of the copyright in a work or other subject-matter; and (ii) in the normal course of its operation, prevents, inhibits or restricts the doing of an act comprised in the copyright; " but does not include such a device, product, technology or component to the extent that it: (iii) if the work or other subject-matter is a cinematograph film or computer program (including a computer game)--controls geographic market segmentation by preventing the playback in Australia of a non-infringing copy of the work or other subject-matter acquired outside Australia of a non-infringing copy of the work or other subject-matter acquired outside Australia; or (iv) if the work is a
} 
más limitado. La sección 10 (1) de la Ley de Propiedad Intelectual de 1968 estableció una definición de medida tecnológica de protección de acceso que consta de dos partes. La primera parte define las medidas de control de acceso en los siguientes términos:

[A]n access control technological protection measure means a device, product, technology or component (including a computer program) that: is used in Australia or a qualifying country: in connection with the exercise of the copyright; and in the normal course of its operation, controls access to the work or other subject-matter.

Esta definición estrecha el alcance de la disposición contra la elusión de una medida tecnológica de acceso de varias maneras. En primer lugar, se concede la protección únicamente a las medidas aplicadas en Australia o en un país miembro de la Unión de Berna o miembro del ADPIC (Explanatory Memoranda, 2006, sch. 12, ítem 1, subsec. 10 (1), 12.3). En segundo lugar, resguarda solo las medidas tecnológicas de protección aplicadas por el titular del derecho de autor o titular de la licencia exclusiva o cuando tales medidas tecnológicas de protección se han aplicado con su permiso o en su nombre. Esto significa que cualquier otra TPM aplicadas por un tercero no recibe protección legal (sch. 12, ítem 1, subsec. 10 (1), 12.4) (explicando subparagraph a-i). Por otra parte, este requisito también significa que el material en el que se ha impuesto la TPM debe estar todavía bajo la protección de los derechos de autor y no en el dominio público (sch. 12, ítem 1, subsec. 10 (1), 12.5). En tercer lugar, protegerá solo las medidas que se utilizan en el ejercicio de un derecho exclusivo (sch. 12, ítem 1, subsec. 10 (1), 12.6) (explicando subpagraph a-ii). En otras palabras, debe haber un vínculo entre la TPM y el ejercicio de un derecho exclusivo. La mera existencia de un derecho de autor sobre la materia protegida no crea ese vínculo (sch. 12, ítem 1, subsec. 10 (1), 12.7). Esta limitación es una distinción importante con el sistema estadounidense que requiere un derecho de autor sobre el contenido protegido con el fin de proteger la TPM que controla el acceso a este tipo de trabajo ${ }^{83}$. El propósito

computer program that is embodied in a machine or device-restricts the use of goods (other than the work) or services in relation to the machine or device" (Copyright Act 1968, sect. 10).

83 "No person shall circumvent a technological measure that effectively controls access to a work protected under this title" (17 U.S.C §1201 (a) (1) (A)). Esta disposición no requiere que la TPM impuesta a los contenidos se vincule al ejercicio de un derecho de autor. Por lo tanto, ha permitido bloquear el acceso legítimo a un producto con el 
de estrechar la definición del AUSFTA era evitar la creación de un derecho adicional para el titular de los derechos de autor como el derecho de acceso.

La segunda parte de la definición de las medidas tecnológicas de control de acceso excluye algunas medidas tecnológicas de protección que de otra manera caerían dentro del alcance de la definición:

[B]ut does not include such a device, product, technology or component to the extent that it: (c) if the work or other subject-matter is a cinematograph film or computer program (including a computer game)--controls geographic market segmentation by preventing the playback in Australia of a non-infringing copy of the work or other subject-matter acquired outside Australia of a non-infringing copy of the work or other subject-matter acquired outside Australia; or (d) if the work is a computer program that is embodied in a machine or device-restricts the use of goods (other than the work) or services in relation to the machine or device (Explanatory Memoranda, 2006, sch. 12, ítem 1, subsec. 10 (1), 12.1).

El propósito de la segunda parte de la definición de medida tecnológica de protección de acceso es excluir del ámbito de protección la codificación de región. Estas tecnologías permiten a las personas y entidades comercializar diferentes productos en distintas ubicaciones geográficas o el mismo producto en distintos momentos (sch. 12, ítem 1, subsec. 10 (1), 12.10). Sin embargo, se utilizan estas medidas para proteger un modelo de negocio en lugar de un derecho de autor. De esta manera, la excepción a la definición tiene la intención de permitir reproducir en Australia una obra codificada para otra región, pero que ha sido legalmente adquirida en el extranjero (sch. 12, ítem 1, subsec. 10 (1) 12.11). Además, la última parte de la definición tiene por objeto evitar los casos en que las medidas tecnológicas inhiben el uso de un suministro de terceros de piezas de repuesto, o servicios de reparación o de mantenimiento por parte de terceros (sch. 12, ítem 1, subsec. 10 (1), 12.13), como ha ocurrido en Estados Unidos. No obstante, la excepción a la definición no se aplica cuando el programa informático es el objeto principal de la explotación de la máquina o dispositivo y dicha medida prohíbe el uso del programa informático (sch. 12, ítem 1, subsec. 10 (1), 12.15).

fin de hacer las cosas no relacionadas con los derechos de autor. Por ejemplo, acceso para el desbloqueo de teléfonos móviles. 
Al adoptar esta definición de medida tecnológica de control de acceso, el parlamento australiano trató de respetar la decisión de la Corte Suprema en el caso de Stevens us Sony ${ }^{84}$. Este caso sostuvo que una codificación regional no estaba comprendida en el ámbito de la definición de TPM porque era una protección del mercado, mas no una protección de los derechos de autor. Además, el parlamento australiano, al estrechar la definición de TPM, trató de evitar situaciones de abuso de mercado como los que habían ocurrido en Estados Unidos en casos como Storage Technology Corporation, Lexmark International y el Chamberlain (Explanatory Memoranda, 2006, sch 12, ítem 1, subsec. 10 (1), 12. 14).

Sin embargo, la definición de TPM fue criticada por excluir el término "efectiva" incluido en el texto del AUSFTA ${ }^{85}$ y en el WCT ${ }^{86}$. Al incluir el término "efectiva", el ámbito de protección a una TPM podría excluir la protección de medidas tecnológicas de protección débiles e ineficaces, como las tecnologías de cifrado básicas ${ }^{87}$, que se pueden eludir fácilmente. También se dijo que la palabra "elusión" podría haber sido definida con el fin de evitar el castigo de elusión donde no exista infracción al derecho de autor. De esta manera, la amplitud de la protección se podría haber restringido (Greenleaf, Maurushat, Vaile, Bond y Paramaguru, 2007, p.5).

\section{El alcance de los términos "fabricación" e "importación".}

Las disposiciones contra el tráfico del AUSFTA prohíbe el acto de la fabricación, importación, distribución, y oferta de productos y componentes que son principalmente dispositivos elusivos o son promovidos para ese propósito $^{88}$. La Ley de 2006 incorporó estas disposiciones, pero limita el alcance de los términos "fabricación" e "importación". Estos términos se refieren solo a la fabricación de dispositivos de elusión para otra persona o a la importación para otra persona. De esta manera, a diferencia de la DMCA, la ley australiana permite a una persona fabricar o importar un

\footnotetext{
84 Ver Stevens v Kabushiki Kaisha Sony Computer Entertainment [2005] HCA 58.

85 Ver AUSTFA, 2004, 17.1.4.7 (b), se refiere a la definición de una medida tecnológica efectiva.

86 Ver Tratado de la OMPI sobre derecho de autor (WCT), 1996, art. 11, estableciendo la protección a una medida tecnológica "efectiva".

87 Ver críticas en Greenleaf, Maurushat, Vaile, Bond \& Paramaguru (2007. pp. 3-4).

88 Ver AUSFTA, 2004, 17.4.7 (a) (ii).
} 
dispositivo de elusión para su uso privado (Explanatory Memoranda, 2006, sch. 12, ítem 9, subsec. A 12.64). Esta alternativa tuvo la intención de mitigar los efectos sobre la prohibición de promulgar excepciones y limitaciones a la disposición contra el tráfico ${ }^{89}$, la cual, impiden que cualquiera pueda proporcionar las herramientas para hacer usos justos de los contenidos protegidos. Esta circunstancia es diferente a la ley de Estados Unidos, donde la importación y la fabricación de dispositivos elusivos también se encuentran prohibidos para uso privado. En este sentido, en Estados Unidos, si una persona tiene el conocimiento para fabricar su propio dispositivo de elusión, estará infringiendo la disposición contra el tráfico de dispositivos.

Sin embargo, este tipo de solución no fue adoptada en el caso de servicios elusivos. En el caso de la prestación de servicios elusivos no hay excepción para la prestación de un servicio con el fin de hacer usos permitidos. La disposición contra el tráfico prohíbe prestar un servicio a otra persona $u$ ofrecer un servicio al público (Copyright Act 1968, 116AP). Esto significa que el servicio de alguna manera debe implicar público. Esta circunstancia no permite a un tercero ayudar a alguien a eludir la TPM (Explanatory Memoranda, 2006, sch. 12, ítem 9, subsec. A 12.87).

\section{El procedimiento administrativo.}

La disposición del AUSFTA le da un alcance más amplio de acción para las partes comerciales, en el sentido que permite escoger entre establecer un procedimiento administrativo o legislativo para crear nuevas excepciones al acto de elusión de una medida de control de acceso. La Ley de Derechos de Autor de 1968 adoptó un procedimiento administrativo facultando al Attorney General para promulgar reglamentos permitiendo un acto de elusión de una medida de protección de acceso bajo la recomendación del ministro (Copyright Act 1968). Este proceso permite que el Attorney General adopte nuevas excepciones, o que modifique o revoque excepciones existentes (Copyright Act 1968,art. (6)-(8)). Este proceso difiere del rule making procedure de EE. UU., ya que crea revisiones ad hoc, así como revisiones periódicas ${ }^{90}$.

89 Confróntese House of Representatives, 2006, recommendation 11, 88. Esta recomendación fue aceptada por el Gobierno. Ver Parliament of Australia, s.f., p. 9.

90 El Comité Permanente de la Cámara de Representantes recomendó tener revisiones ad hoc, junto con revisiones periódicas. Esta recomendación, que fue apoyada por el Gobierno, tiene el propósito de adaptar la regulación al rápido desarrollo de la 
Por otra parte, también difiere en que las excepciones creadas en virtud de este proceso no son temporales ${ }^{91}$. El propósito era proporcionar un procedimiento más ágil que el de Estados Unidos y no tener que esperar tres años con el fin de obtener una excepción, ya que este período de tiempo puede ser muy largo teniendo en cuenta el rápido desarrollo de la tecnología. Además, la razón de la creación de excepciones "permanentes"92 es evitar la imposición de cargas pesadas en usuarios que requerirían probar cada tres años la necesidad de la excepción, como sucede en los Estados Unidos (House of Representatives, 2006, p. 140).

Durante la implementación del AUSFTA, se promulgaron las primeras regulaciones de excepciones adicionales en el proceso de revisión. Estas excepciones fueron recomendadas por primera vez por el Comité Permanente de la Cámara de Representantes y posteriormente aceptadas, y en algunos casos rechazadas por el Gobierno ${ }^{93}$. No obstante, la posición del Gobierno no fue tan flexible como la de la Comisión Permanente ${ }^{94}$, pero, al mismo tiempo, no fue tan estricta como la de la Oficina de Derecho de Autor de

tecnología (Copyright Act 1968, 249, 5). Ver House of Representatives, 2006, pp. 144-146; ver también Parliament of Australia, s.f.

91 Las excepciones previstas no caducan periódicamente. Sin embargo, pueden ser modificadas o revocadas por el Attorney General, previa recomendación del ministro cuando la excepción existente ha sido cuestionada durante el proceso de revisión (Copyright Act 1968, 249, 6-8). Se asumió por algunos documentos presentados a la Comisión Permanente de la Cámara de Representantes que las excepciones producto del proceso de revisión tenían que ser como en el procedimiento de elaboración de normas de Estados Unidos. Sin embargo, el Comité aclaró que nada en el texto del acuerdo apoya esa interpretación o implica dicha interpretación (House of Representatives, 2006, p. 140).

92 Las excepciones son permanentes en el sentido de que no caducan. Sin embargo, esto no significa que no se puedan modificar o revocar durante el proceso.

93 Ver las excepciones aceptadas y rechazadas por el gobierno en Parliament of Australia, s.f., p. 9.

94 En relación con el proceso de revisión la Comisión Permanente de la Cámara de Representantes recomendó establecer una interpretación más flexible en el proceso de revisión que el de la Oficina de Derecho de Autor de EE. UU. De esta manera, el Comité manifestó su propia interpretación de la "clase particular de obras, interpretaciones o ejecuciones o fonogramas" y de "impacto negativo real o potencial creíble demostrado" (House of Representatives, 2006, pp. 61-82). Sin embargo, el Gobierno no aceptó la interpretación del Comité. El Gobierno consideró que no se ajustaba a las obligaciones adquiridas por Australia. De esta manera, el Gobierno estableció sus propios criterios para la concesión de excepciones adicionales (Parliament of Australia, s.f., p. 8). 
Estados Unidos. Por ejemplo, el reglamento $20 \mathrm{Z}$ de la Lista 10A incorpora algunas excepciones en favor de determinados usuarios, como instituciones educativas, bibliotecas y archivos (Copyright Regulations 1969, reg. 20Z, sch. 10, A), a diferencia de Estados Unidos donde no se permite la creación de excepciones en favor de usuarios específicos, sino solo para determinadas clases de obras (Exemption to prohibition, noviembre de 1999). En cualquier caso, una revisión cuidadosa de la norma australiana nos muestra que en la práctica no ha sido tan ágil como buscaba ser, ya que la primera revisión de la regulación administrativa para la creación de nuevas excepciones comenzó en el 2012 después de seis años de la primera revisión y no ha sido concluida aún.

\section{Acción contra una amenaza infundada de procedimiento de TPM.}

Un elemento único de la implementación de TPM de Australia es que proporciona una acción contra las amenazas infundadas de iniciar un procedimiento de TPM. La Ley de Derechos de Autor de Australia de 1968, modificada por la Ley de 2006, estableció en la sección 202A una acción en favor de una persona que ha sido amenazada con un procedimiento de TPM sin fundamento. Dicha acción puede ser interpuesta contra una amenaza, ya sea en relación con el acto de elusión o la prohibición de dispositivos (Copyright Act 1968, 202A, 1). Como resultado, un tribunal podría ordenar que se declare que la amenaza es injustificable, una orden judicial para detener la amenaza o una orden concediendo una indemnización por las pérdidas que la persona sufrió como consecuencia de dicha amenaza (202A, 4). Estados Unidos no establece una causa de acción específica contra una persona que amenace a otra con un procedimiento legal sin fundamento en relación con la protección de medidas tecnológicas de protección.

\section{Los efectos sobre la educación con las nuevas tecnologías.}

Durante el proceso de aplicación de las disposiciones de TPM del AUSFTA, su potencial para impactar negativamente usos educativos de los materiales de las instituciones educativas y los estudiantes tuvo un lugar importante en la discusión. Por ejemplo, una de las preguntas a la Comisión Permanente de la Cámara de Representantes abarcó la preocupación de si 
era necesario promulgar nuevas excepciones al acto de elusión en favor de las instituciones educativas ${ }^{95}$. No obstante, la forma en que la educación y las TIC se relacionan ha cambiado con el tiempo, y por lo tanto, los efectos de las disposiciones TPM en una educación del siglo XXI no podía ser analizada al momento de la implementación.

La principal diferencia entre la implementación de Australia del AUSTA y el modelo de Estados Unidos es que Australia trató de equilibrar sus disposiciones de TPM. Aunque tales cambios pueden beneficiar a la educación, algunas restricciones para realizar usos educativos causadas por el modelo de Estados Unidos no podían ser evitados. Las diferencias entre el modelo australiano y el modelo norteamericano son más pronunciadas en el procedimiento administrativo. Como se describió anteriormente, el procedimiento administrativo de Australia trató de crear un proceso más flexible destinado a responder rápidamente a los cambios tecnológicos mediante la creación de excepciones permanentes, sujetas a revisiones, con el propósito de aliviar el alcance limitado de las siete excepciones. Por otra parte, la ley australiana no acogió el alto umbral adoptado por la Oficina de Derecho de Autor de EE. UU. al conceder nuevas excepciones a las medidas de control de acceso, puesto que la ley australiana permite al Attorney General conceder una excepción a favor de determinados tipos de usuarios, como instituciones educativas (Copyright Regulations, 1969, reg. 20Z, sch. 10, A, 2), lo que permite el uso de materiales protegidos por medidas tecnológicas de protección con fines educativos. Sin embargo, en la práctica el procedimiento de Australia no ha sido tan ágil como se pensó al momento de su diseño, ya que el proceso de revisión ha tomado más tiempo de lo previsto.

Además, la legislación australiana intentó solucionar la falta de aplicación de las excepciones y limitaciones a la prohibición de dispositivos de elusión y, a su vez, la imposibilidad de ejercer las excepciones producto del proceso administrativo para participar en los usos permitidos de una obra con derechos de autor. Esta solución consistía en reducir el alcance de los términos "fabricación" e "importación" para permitir que los usuarios tengan herramientas para eludir medidas tecnológicas de protección que no están protegidos por la ley y dar efecto a las excepciones. En cuanto a la aplicación a la educación, estas modificaciones al modelo de Estados Unidos

$\overline{95}$ Ver "Terms of Reference" en House of Representatives, 2006. 
pueden ayudar a mitigar las consecuencias no deseadas, ya que al autorizar el uso de algunos dispositivos de elusión se podrá acceder a obras de dominio público protegidos por TPM o ejercer usos permitidos, que son importantes para la educación. Esta solución, mientras que es un paso en la dirección correcta, no es perfecta. A pesar de que ofrece la oportunidad a más personas que aquellas tecnológicamente entendidas para ejercer los usos permitidos y acceder a obras de dominio público, todavía ofrece esta oportunidad solo a una parte selecta de la sociedad, como aquellos que tienen el conocimiento para fabricar un dispositivo y a las personas con los medios económicos para importar uno.

La legislación de Australia también modificó la definición de TPM de control de acceso, haciendo hincapié en la importancia de evitar la expansión de la ley de derechos de autor. Esta modificación deja fuera del alcance de la protección de una TPM que protege una obra de dominio público ${ }^{96}$. Además, la definición también deja fuera de la protección las medidas tecnológicas de protección que no están vinculadas con el ejercicio de los derechos de autor. Una vez más, esta disposición es compatible con el aprovechamiento de las obras de dominio público para favorecer entornos educativos..

A pesar de esta definición más generosa, la ley australiana no pudo eliminar los problemas causados por las limitadas excepciones a la medida de control de acceso. El AUSFTA incluye las siete excepciones confinadas del modelo estadounidense y regula su aplicación. Por lo tanto, aunque el Comité Permanente de la Cámara de Representantes y el Gobierno de Australia tuvieron cuidado de no hacer las excepciones más restrictivas (House of Representatives, 2006, p. 9; The Parliament of Australia, s.f., p. 7), las excepciones de Australia son tan estrechas como las de la DMCA, debido a la limitación del AUSFTA sobre la capacidad de legislar de los socios comerciales en la materia.

Por último, en relación con la barrera a la difusión de información, la ley australiana es más generosa. En Estados Unidos las industrias de

96 El Comité Permanente de la Cámara de Representantes se negó a recomendar una excepción para eludir una medida de control de acceso que protege material que no se encuentre bajo el ámbito de protección de los derechos de autor, argumentando que no era necesario debido a que la definición de TPM requiere que se imponga a un contenido protegido por derechos de autor para ser amparada (House of Representatives, 2006, pp. 130-131). 
derechos de autor tienen investigadores amenazados por publicar sus resultados en el campo de la investigación de cifrado. La ley australiana, sin embargo, estableció un remedio para una persona que ha sido amenazada con iniciar un proceso de TPM sin fundamento. Esa persona puede obtener una orden judicial para detener este tipo de amenazas o recibir una indemnización por daños y perjuicios causados. Esta causa de acción se aplica ya sea a una amenaza relacionada con el acto de elusión o de las disposiciones contra el tráfico (Copyright Act 1968, 202A, 1). En este sentido, la ley australiana podría mitigar el temor de los investigadores de participar en las discusiones académicas, especialmente en el campo de la investigación de cifrado.

Por lo tanto, la aplicación nacional de Australia de modelo de medidas tecnológicas de protección de la DMCA intentó solucionar sus problemas, pero no ha sido del todo exitoso. La educación ha cambiado desde la promulgación de la legislación y las instituciones educativas se han visto afectadas por dicha regulación de TPM. En los documentos presentados al Attorney General como parte del desarrollo del primer proceso administrativo para crear excepciones adicionales al acto de elusión ${ }^{97}$, es evidente que la regulación de TPM ha creado barreras al uso de la tecnología en la educación y para hacer usos educativos no infractores. Por ejemplo, el Grupo Asesor de Derechos de Autor $(\mathrm{CAG})$, un grupo que representa a las escuelas en Australia en materia de derechos de autor (Standing Council on School Education and Early Childhood, 2012, p. 4), pidió al departamento del Attorney General considerar nuevas excepciones a la elusión de una medida de control de acceso para permitir que las instituciones educativas hagan uso del contenido protegido por derecho de autor en las circunstancias permitidas por la ley de derechos de autor y que favorece la educación (p. 8). El CAG considera que estas excepciones son necesarias para promover el Currículo Nacional de 2011 (Australian Curriculum, Assessment and Reporting Authority [ACARA], s.f.), que promueve el uso de la tecnología en la educación de una manera diferente a la que fue promovida en el 2006. Esta política, al igual que otras políticas de TIC en la educación en todo el mundo, busca permitir a Australia educar en las habilidades de alfabetización cibernéticas que los

\footnotetext{
97 Diferentes organizaciones presentaron propuestas para crear nuevas excepciones. Ver Review of Technological Protection (s.f.).
} 
estudiantes del siglo XXI necesitan. No obstante, las restricciones a eludir la protección de medidas tecnológicas de protección no permiten cambiar el panorama educativo (Standing Council on School Education and Early Childhood, 2012, p. 6).

Las universidades australianas también expresaron su preocupación acerca de cómo afectan las TPM usos de material educativo y cómo los estudiantes actuales que son "nativos digitales" no pueden hacer usos no infractores de contenidos digitales en sus asignaciones (Universities Australia, 2012, p. 6). De igual manera, el Comité de Derechos de Autor de Bibliotecas australianas (ALCG) pidió al Attorney General incorporar una regulación que permita la elusión para usos permitidos, entre otras cosas.

Las solicitudes presentadas por estas instituciones demuestran que la relación entre la tecnología y la educación ha cambiado, y que, incluso si la ley australiana de autor permite a los estudiantes, profesores e investigadores incorporar la tecnología en el proceso educativo, las disposiciones sobre TPM bloquean este propósito. La revisión de 2012 aún no ha concluido, y el departamento del Attorney Gerneral no ha promulgado la nueva normativa (Australian Digital Alliance \& Australian Libraries Copyright Committee, 2012). De esta forma, no se ha evidenciado si el procedimiento administrativo de Australia será capaz de resolver esta preocupación planteada en materia de educación.

\section{Lecciones para Colombia}

Las experiencias de implementación de Chile y Australia proporcionan enseñanzas importantes para Colombia. Ambos procesos nos demuestran que las partes comerciales de los Estados Unidos deben analizar cuidadosamente la implementación del capítulo DPI con participación de los diferentes grupos de interés. Esto se debe a que tanto el sistema de ISP como las disposiciones TPM tienen efecto en diferentes sectores de la sociedad, y por lo tanto, todos estos intereses deben equilibrarse.

Adicionalmente, dicho proceso de implementación y su debate debe tener en cuenta tanto las necesidades nacionales como las críticas con respecto al sistema estadounidense. El USCO se inspira y sigue de cerca el modelo estadounidense de responsabilidad de los ISP y protección TPM. Este modelo ha sido motivo de controversia en Estados Unidos y sujeto a 
muchas críticas nacionales e internacionales debido a su potencial creación de consecuencias no deseadas. Por otra parte, algunas de estas posibles consecuencias no deseadas podrían socavar la consecución de los intereses nacionales, como en el caso de la transformación de la educación con el uso de la tecnología como se discute en esta investigación.

Ni Chile ni Australia tenían como propósito inmediato la promoción de la política de derechos de autor en la implementación de una política de TIC en la educación. El objetivo principal de Chile era proteger a su régimen constitucional, mientras que Australia estaba preocupada por mantener el equilibrio de su régimen de derechos de autor. Una razón de la falta de atención a las TIC fue, tal vez, que para el momento del proceso de implementación, la incorporación de las TIC en la educación no se encontraba tan avanzada ni era tan necesaria como lo es hoy en día ${ }^{98}$. Colombia, por tanto, debe acercarse a su implementación con el objetivo de mantener su interés nacional de promover el uso de las TIC en la educación, sobre todo porque las políticas de TIC en la educación pueden ser altamente afectadas por una implementación descuidada de las obligaciones de derechos de autor del USCO. Es importante mencionar que tener la promoción de la educación de Colombia como un interés nacional durante el procedimiento de implementación del USCO no significa que se dejen de lado otros intereses importantes como la protección de los derechos constitucionales o equilibrar el sistema de derechos de autor, y mucho menos significa que una implementación que protege la educación deje desprotegidos a los titulares de los derechos de autor.

Con el fin de proteger el desarrollo de la educación mediante el uso de las TIC, la identificación de dicho objetivo debe hacerse antes de la implementación del acuerdo internacional. Acercarse a la implementación de esta manera permitirá a Colombia evaluar las disposiciones del USCO

98 El nuevo plan de estudios para Australia sobre la integración de las TIC en la educación comenzó a ser desarrollado desde el año 2009 cuando el Gobierno de Australia comenzó a financiar ordenadores portátiles para todos los estudiantes. Al mismo tiempo, el Gobierno comenzó a desarrollar una estrategia digital para profesores y escuelas líderes como parte de la Revolución Educación Digital dirigida a construir las capacidades necesarias para utilizar las TIC en la educación mirando la alfabetización en TIC de los estudiantes australianos (Australian Curriculum, s.f.). Ver: Anderson (2010, p. 103). 
desde dicho punto de vista y determinar si se afectan los intereses nacionales. Chile y Australia siguieron este procedimiento.

Además, es importante recordar que el acuerdo comercial de Estados Unidos es un tratado internacional que debe ser implementado de acuerdo con la situación específica de cada país. El USCO no es un texto legal que necesita ser copiado y pegado en Colombia, como se hizo durante los intentos de implementación. Si bien es cierto que la autonomía de Colombia para regular sobre el tema se ha visto socavada por el tratado, todavía hay cierto margen de acción en el que el país puede mover para proteger y promover sus intereses.

Por último, la implementación de las disposiciones del USCO no puede hacerse bajo la actual ley de derechos de autor de Colombia. Tanto Chile como Australia aprovecharon el proceso de implementación del acuerdo comercial de Estados Unidos para reequilibrar y repensar todo su régimen de derechos de autor. Una razón importante que llevó a ambos países a adoptar este enfoque era que herramientas como el modelo de limitaciones a la responsabilidad de los ISP y protección TPM tienen la capacidad de alterar el sistema de derechos de autor a favor de los titulares de derechos de autor. Por lo tanto, Colombia debe tener cuidado de mantener y crear un sistema de derechos de autor equilibrado. Como el capítulo 5 discute en detalle, la ley de derechos de autor colombiano simplemente no está preparada para permitir implementar las TIC en la educación. Además, una implementación descuidada de las obligaciones de la USCO puede complicar el escenario. Por lo tanto, Colombia debe aprovechar la implementación inminente del USCO y ejercer su capacidad de ampliar y crear más excepciones y limitaciones para aplicar al entorno digital bajo el marco del WCT.

Además, con el fin de promover las TIC en la educación, el Gobierno y las entidades privadas, especialmente las instituciones educativas, deben promover aún más la creación de recursos educativos abiertos y el uso de herramientas tales como las licencias Creative Commons para incentivar el intercambio, la colaboración y la promoción de la creación. Por otra parte, todo este proceso de incentivación de la creación de materiales locales debe ir acompañado de financiación de la investigación para alentar y permitir la creación de materiales de calidad. 


\section{Conclusión}

Aunque el texto de los acuerdos de libre comercio firmados con Estados Unidos se caracteriza por incluir obligaciones detalladas en materia de derechos de autor siguiendo de cerca la legislación del país norteamericano, los socios comerciales de Estados Unidos no están obligados a copiar su modelo de protección. Chile y Australia son ejemplos de implementación de dichos acuerdos que tuvieron en cuenta no solo sus sistemas legales y necesidades nacionales, sino también la experiencia de Estados Unidos con su modelo de protección. El resultado es que dichos países desarrollaron un modelo que aunque se basa en el modelo norteamericano, también tienen elementos únicos que responden a sus propias necesidades. De esta manera, ambos ejemplos demuestran a Colombia que el texto del acuerdo comercial aunque detallado aún guarda cierto ámbito de la flexibilidad para adaptarse a las necesidades del país durante un proceso adecuado de implementación.

No obstante, aunque las experiencias de Chile y Australia ofrecen lecciones para Colombia, como que el texto del tratado es lo suficientemente flexible para adaptarse a las necesidades nacionales, que el proceso debe ser discutido con cuidado, y que la aplicación del tratado requiere buscar un equilibrio en la ley autoral, Colombia también tiene que crear algunas disposiciones específicas que aborden sus sistemas jurídicos y necesidades sociales que son diferentes, en lugar de copiar un modelo extranjero. 



\section{GONGLUSIÓN}

- 4 ste libro explora la relación entre la protección

Udel derecho de autor y la transformación de la educación a través de las TIC. Como era de esperar, este libro concluye que una implementación dirigida a copiar y pegar las obligaciones del TLC de Estados Unidos-Colombia, siguiendo de cerca el modelo estadounidense en materia de ISP y medidas tecnológicas de protección, no permite a Colombia, como país en desarrollo, potencializar la educación mediante el uso de la tecnología y resolver problemas sobresalientes de su sistema educativo, incluso cuando no hay peligro de infringir los derechos de autor. Además, este libro establece que una implementación de copiar y pegar no es la única manera de cumplir con las obligaciones impuestas por el TLC.

El uso de la tecnología en la educación representa una transformación del proceso de aprendizaje que debe ser desarrollada en el marco de nuevas metodologías y contenidos como la colaboración, comunidades de aprendizaje, aprendizaje permanente, un modelo de siempre en el aprendizaje y contenidos multimedia. Esta transformación del proceso de aprendizaje o la potenciación de la educación mediante la tecnología es necesaria para la formación de los nuevos generadores de conocimiento, imprescindibles para la economía actual y para proporcionar las habilidades que los aprendices del siglo XXI requieren. Por otra parte, esta potenciación de la educación representa la oportunidad para países en desarrollo, como Colombia, de resolver los problemas más destacados de sus sistemas educativos. Dichos beneficios han sido reconocidos por el Gobierno colombiano, el cual, 
ha invertido importantes cantidades de dinero en la provisión de hardware, conectividad, formación del profesorado e investigación sobre el tema. No obstante, el éxito de estas políticas está estrechamente vinculado a una protección de los derechos de autor equilibrado aplicable al entorno digital. Esto se debe a que la ley de derechos de autor controla el uso de gran parte del contenido utilizado como material educativo.

Colombia como miembro de las principales convenciones internacionales de derechos de autor, incluyendo Berna, el ADPIC y el WCT ha adquirido obligaciones de cumplir con algunas normas mínimas de protección de derechos de autor que se han vuelto más altas con el tiempo. En consecuencia, estas obligaciones internacionales limitan la capacidad de Colombia para calibrar su marco nacional de derechos de autor de acuerdo con sus necesidades nacionales. Las últimas obligaciones internacionales en la materia están incluidas en el Tratado de Libre Comercio entre Estados Unidos y Colombia, que requiere que este último país implemente una regulación sobre las limitaciones a la responsabilidad del ISP y de protección a medidas tecnológicas de protección basados en el modelo de implementación del WGT de EE. UU. Esto se debe a que Estados Unidos utiliza su posición predominante de mercado para exportar su propio nivel de protección de derechos de autor a los países en desarrollo, principalmente a través de acuerdos bilaterales. Las obligaciones incluidas en el TLG no solo aumentan las normas existentes de protección -obligaciones ADPICPlus-, sino también ponen la legislación del socio comercial, en este caso Colombia, más cerca al modelo de EE. UU. a través de un capítulo muy detallado de DPI. Por lo tanto, Estados Unidos intercambia fuerte protección a los derechos de autor por beneficios de mercado, atrayendo a los países en desarrollo.

Aunque el modelo de EE. UU. que está siendo exportado a Colombia y otros países tiene algunos beneficios, también es cierto que ha sido criticado tanto a nivel nacional como internacional debido a su potencial de alterar el equilibrio en el sistema de derecho de autor a favor de los titulares de derechos de autor. La DMCA que implementó un modelo de ISP y protección a TPM se ha caracterizado por su enfoque maximalista de las obligaciones del WCT. La experiencia de Estados Unidos durante los dieciséis años de existencia de la DMCA ha establecido que sus mecanismos de responsabilidad de ISP y 
TPM de protección pueden ser objeto de abuso. Estos potenciales abusos de protección TPM y responsabilidad de los ISP afectan la transformación del proceso de aprendizaje ya que potencialmente hacen de Internet, el elemento central de la educación en un proceso de aprendizaje transformado, un bien prescindible, igualmente pueden disuadir la adopción de metodologías como el aprendizaje permanente y la colaboración, aun cuando no exista infracción al derecho de autor. Por último, estas medidas pueden impedir que los estudiantes y profesores de todo el mundo aprovechen la tecnología para llevar un mayor acceso a los materiales educativos y proporcionar una educación más inclusiva.

En la actualidad, Colombia está en el proceso de implementación de las nuevas obligaciones internacionales en el tema incluido en el TLC. No obstante, el fuerte deseo de Colombia para que el acuerdo comercial entrara en vigor ha desempeñado un papel central en el proceso de implementación del tratado. De esta manera, el Congreso colombiano ha intentado una implementación acelerada de las obligaciones de la USCO casi copiando y pegando estas obligaciones en una ley de derechos de autor colombiano sin cambios, teniendo como resultado, a veces, disposiciones incluso más restrictivas que las norteamericanas, aunque eso no era necesario. Esta situación pone de manifiesto que el Congreso de la República se vio más limitado en su autonomía para legislar por las disposiciones del TLC que lo que realmente se encuentra.

Por otra parte, el intento de implementación no ha sido acompañado por una reestructuración de la legislación de derechos de autor. Por lo tanto, el intento de implementación no tuvo en cuenta ni las necesidades colombianas ni las críticas a las disposiciones de Estados Unidos. Como resultado, el Congreso, combinando el marco legislativo autoral actual que no fue diseñado para aplicar al entorno digital con el modelo de limitaciones de responsabilidad ISP y TPM de la legislación norteamericana, pone obstáculos a la capacidad de Colombia para utilizar la tecnología para potenciar la educación. Afortunadamente, Colombia aún está a tiempo de lograr una implementación adecuada.

Es importante recordar que a pesar de lo detallado del texto del TLC, los socios comerciales de Estados Unidos no están obligados a seguir al pie de la letra la ley estadounidense o a realizar una implementación de 
copiar y pegar el texto del acuerdo. Esta situación se puede evidenciar en los casos de Chile y Australia, donde ambos países implementaron el acuerdo teniendo en cuenta su ordenamiento jurídico interno y necesidades. Estas implementaciones comparten algunas bases comunes con el modelo de EE. UU., pero también difieren de ella en muchos aspectos. De igual manera, ambos ejemplos representan para Colombia el hecho de que existe flexibilidad en el texto del acuerdo comercial para adaptarse a las necesidades del país.

Sin embargo, aunque Colombia puede extraer lecciones importantes del proceso de implementación desarrollado en Chile y Australia -incluyendo que el texto del tratado es lo suficientemente flexible para adaptarse a las necesidades nacionales, que el proceso debe ser altamente discutido y que la aplicación del tratado requiere todo un reequilibrio de la ley de derechos de autor-, Colombia también tiene que crear algunas cifras concretas que aborden sus necesidades legales y sociales.

De esta forma, este libro representa el inicio de la discusión de la implementación de medidas en materia de responsabilidad de los ISP y protección TPM en Colombia, así como la capacidad de adaptación del marco de derechos de autor para permitir que la tecnología potencialice la educación. Por otra parte, la necesidad de promover un debate abierto sobre el tema no es solo para Colombia. Muchos países en desarrollo están tratando de transformar su sistema educativo mediante el uso de la tecnología y al mismo tiempo son partes comerciales de Estados Unidos. Las dificultades que estas disposiciones de derechos de autor pueden crear sobre el objetivo de promover la transformación del proceso de aprendizaje no se han abordado. Por lo tanto, los responsables de políticas públicas de dichos países, instituciones educativas y la academia deben prestar atención a la interacción entre el derecho de autor, la educación para el siglo XXI y la tecnología. 


\section{GLOSARIO}

Tecnologías de la Información y la Comunicación

1 (TIC): Hace referencia a una amplia gama de tecnologías que permite la creación, comunicación, difusión y almacenamiento de información (Blurton, 1999, p. 1). Ejemplos de TIC incluyen desde la televisión hasta radio. No obstante, al interior de este libro, el término TIC se utilizará para hacer referencia a Internet y los diferentes dispositivos que permiten el acceso a la web, incluyendo computadoras portátiles, PG, tabletas y recursos electrónicos. Igualmente, al interior de este libro también se referirá a dichas herramientas como las nuevas tecnologías.

Estableciendo la definición de TIC. 



\section{REFERENCIAS}

Acuerdo de Integración Subregional Andino. Acuerdo de Cartagena. (26 de mayo de 1969). Comunidad Andina. Recuperado de http://www.comunidadandina.org/Documentos. aspx? Gr uDoc $=14$

Acuerdo de Promoción Comercial entre la República de Colombia y Estados Unidos de América. (s.f.). Ministerio de Comercio, Industria y Turismo [MinCIT]. Recuperado de http://ww w.tlc.gov.co/publicaciones.php?id=14853

Acuerdo sobre los Aspectos de los Derechos de Propiedad Intelectual relacionados con el Comercio [TRIPs]. (1994). Agreement Establishing the World Trade Organization, 1869 UNTS 3. Marrakesh.

Adede, A. O. (2003). Origins and History of the TRIPS Negotiations. En C. Bellmann, G. Dutfield \& R. MeléndezOrtíz (Eds.), Trading in Knowledge: Development Perspectives on TRIPS, Trade, and Sustainability (pp. 23-35). New York : Earthscan Publications.

Adobe Digital Ediciations/FAQ, Content Portability. (s.f.). Adobe ebook Platform. Recuperado de http://www.adobe.com/ solutions/ebook/digital-editions/faq.html

Álvarez, D. (diciembre de 2011). The Quest for a Normative Balance: The Recent Reforms to Chile's Copyright Law. Policy Brief, 12. Recuperado de http://www.ictsd.org/sites/defau lt/ files/research/2012/03/the-quest-for-a-normative-balancethe-recent-reforms-to-chilee2 8099s-copyright-law.pdf

Amenabar, S. (2010). La Propiedad Intelectual en Chile y el Tratado de Libre Comercio con los EE.UU, (Documento No. 2). Recuperado de http://www.amchamchile.cl/sites/default/ file s/SET $\% 20$ documento $\% 202 \% 20$ actualizado.pdf

Amicus Curiae Brief of electronic Frontier Foundation et al in Support of Motion to Dismiss at U.S. v Elcom Ltd., 203 F. 
Supp. 2d 111lat 19 (N.D. Cal. 2002). Recuperado de https://w ww.eff.org/es/ node/55467

Anderson, J. (2010). ICT Transforming Education: a Regional Guide. Bangkok: UNESCO. Recuperado de http://unesdoc.unesco.org/images/0018/001892/189216e.pdf_

Aprovechamiento de las TIC para mejorar la calidad educativa. (s.f.). [Archivo de video]. Recuperado de http://www.mintic.gov.co/portal/vivedigital/612/w3propertyvalue-674.html

Armatas, S. A. (2008). Distance Learning and Copyright: a Guide to Legal Issues (1a ed). Chicago: American Bar Association.

Armstrong, C., De Beer, J., Kawooya, D., Prabhala, A. \& Schonwetter, T. (Eds.). (2010). Access to knowledge in Africa: The role of copyright. Sudáfrica: UCT Press.

Australia. Copyright Act 1968. Un acto relativo a derechos de autor y la protección de ciertas actuaciones y otros propósitos.

Australia. Copyright Act 1968. Copyright Amendment (Digital Agenda) Act 2000 -C2004C0123 5. Australia Government Comlaw, agosto de 2002.

Australian Curriculum. (s.f). Information and Communication Technology (ICT) Capability. Recuperado de http://www.australiancurriculum.edu.au/generalcapabilities/ information-and-communication-technology-capability/introduction/ introduction

Australian Curriculum, Assessment and Reporting Authority [ACARA]. (s.f). Curriculum. Recuperado de http://www.acara.edu.au/curriculum/curriculum. html

Australian Digital Alliance \& Australian Libraries Copyright Committee. (2012). Submission regarding exceptions for technological protection measures in the Copyright Act 1968. Camberra: Autor. Recuperado de http://libcopyright.org.au/sites/libcopyright. org.au/files/ documents/ADAALCG\%20TPMs\%20submission\%20final.pdf

Australia. Explanatory Memoranda. (2006). Copyright Amendment Bill 2006. The Parliament of the Commonwealth of Australia. Recuperado de http://www.austlii.edu. au/au/legis/cth/bi ll_em/cab2006223/memo_0.html

Australian Libraries Copyright Committee [ALCG]. (2012). Submission Regarding Exceptions for Technological Protection Measures in The Copyright Act 1968. Camberra: Autor. Recuperado de http://libcopyright.org.au/sites/libcopyright.org.au/files/ documents/ADA-ALCC\%20TPMs\%20submission\%20final.pdf

Bahrain Free Trade Agreement. (s.f.). Office of the United States Trade Representative. Recuperado de https://ustr.gov/trade-agreements/free-trade-agreements/bahrain-fta 
Ballon, I. C. (2009). Dmca Liability Limitations for Social Networks, Blogs, Websites, and Other Service Providers and the UGC Principles. ALI-ABA Course of Study Entertainment, Arts, and Sports Law, 1155-1257.

Ballon, I..C. (2013). E-Commerce and Internet Law (vols. 1-4). Estados Unidos: West Legal Works.

Banco de la República de Colombia. (s.f.). Salario Mínimo Legal en Colombia. Recuperado de http://obiee.banrep.gov.co/analyTIC/saw.dll?Go\&Path=/ shared/Consulta+Series+Estadisticas+desde+Excel/1.+Salarios/1.1+Salario + minimo+legal+en+Colombia/1.1.1+Serie+historica\&Options=rdf\&NQUser $=$ salarios\&NQPassword $=$ salarios\&lang $=$ es

Banco Mundial. (s.f). ICT and Education-Key Issues. Recuperado de http://web. worldbank.org/WBSITE/EXTERNAL/TOPICS/EXTEDUGATION/0, contentMDK:20533883 \%20menuPK:617610 pagePK:148956 piPK:216618 ｔheSitePK:282386 isGURL:Y\%20,00.html

Barreras que impiden la masificación de Internet. (s.f.). Ministerio de Tecnologías de la Información y las Comunicaciones [MinTIG].

Recuperado de http://www.mintic.gov.co/porta 1/vivedigital/612/w3-article-1519. html

Barrero, P. (2012). Derecho de autor en ambientes virtuales. Bogotá: Universidad Cooperativa de Colombia.

Barros, E. (2006). Tratado de responsabilidad extracontractual. Chile: Editorial Jurídica de Chile.

Bayer, J. (2007). Liability of Internet Service Providers for Third Party Content (Working Paper Series: V.1). Nueva Zelanda: Victoria University of Wellington.

Benchell, N. A. (2002). The Digital Millenium Copyright Act: a Review of the and the Court's Interpretation. Fournal of Computer E Information Law, 21, 1-18.

Bernardino, L. (1982). La difusión del código civil de Bello en los países de Derecho castellano y Portugués. Estudios Histórico-furídicos, (7), 71-106. Recuperado de http://www.captur a.uchile.cl/bitstream/handle/2250/16887/difusion_del_ codigo_civil.pdf?sequence=1

Biblioteca del Congreso Nacional de Chile. (2010). Historia de la Ley $\mathcal{N}^{0} 20.435$. Modifica la Ley $\mathcal{N}^{\circ} 17.336$ sobre propiedad intelectual. Chile: Autor.

Biblioteca Nacional de Colombia. (2013). Plan Digital de la Biblioteca Nacional de Colombia avances y retos. Recuperado de http://www.bibliotecanacional.gov.co/ recursos_user/doc umentos_bnc/Plan-Digital-avances-y-retos-15-de-mayo.pdf 
Blom, A. (2009). Search Engines and $\S$ 512(D) of the D.M.C.A. Case Western Reserve Journal of Law, Technology \& Internet, 1(1), 36-60.

Blurton, G. (1999). New Directions of ICT-Use in Education (Reporte mundial de la UNESGO de Comunicación e Información de 1999). Recuperado de http:// www.unesco.org/educati on/lwf/dl/edict.pdf

Blythe, S. E. (2006). The U.S. Digital Millennium Copyright Act and the E.U Copyright directive: Comparative Impact on Fair Use Rights. Tulane Fournal of Technology E Intellectual Property, 8, 111-128.

Botero, G. (2013). Informe anual de la Comisión Interamericana de Derechos Humanos 2013, (Vol. 2. Informe de la relatoría especial para la libertad de expresión). Recuperado de http://www.oas.org/es/cidh/expresion/docs/informes/2014_04_22_ IA_2013_ESP_FINAL_WEB.pdf

Botero, C. (31 de enero de 2013). Ley Lleras 2 es inconstitucional. El Espectador. Recuperado de http://www.elespectador.com/opinion/ley-lleras-2-inconstitucional-columna-402262

Botero, C., Gómez, O. D., Salamanca, D. A., Aguirre, C. D. \& Vargas, I. (12 de mayo de 2011). Comentarios Jurídicos Proyecto Ley Lleras. Redpatodos. Recuperado de http://redpatodo s.co/blog/comentarios-juridicos-proyecto-ley-lleras

Bozeman Science. (10 de marzo de 2014). Integumentary System [Archivo de video]. Recuperado de https://www.youtube.com/watch?v=z5VnOS9Ke3g\&list=PL0mifQXDgbZy8UR93 6WkJcALVm2qiVq3\&index=3

Bradley, J. A. (1987). Intellectual Property Rights, Investment and Trade in Services in the Uruguay Round: Laying the Foundations. Standard Fournal of International Law, 23, 57-87.

Bridy, A. (2010). Graduated Response and the Turn to Private Ordering in Online Copyright Enforcement. Oregon Law Review, 89(1), 81-132.

Brodkin, J. (15 de octubre de 2015). How a Single DMCA Notice Took Down 1.45 Million Education Blogs. Arstechnica. Recuperado de http://arstechnica.com/ information-technology/ 2012/10/how-a-single-dmca-notice-took-down-1-45million-education-blogs/

Buitrago, D. (11 de julio de 2011). Proyecto de Ley 241 de 2011 de Derechos de Autor en Colombia es todo un complique. Lenguaje y Comunicación. Recuperado de http://lenguajey comunicacionudea.blogspot.com/2011/07/proyecto-de-ley241-de-2011-dederechos.html

Burger, P. (1988). The Berne Convention: Its History and Its Key Role in the Future. Journal of Law \& Technology, 3(1), 1-69. 
Burk, D. L. (2002). Anti-Circumvention Misuse (Research Paper No. 02-10, 2002). Minnesota Public Law. doi: 10.2139/ssrn.320961. Recuperado de http://ssrn. com/abstract $=320961$

GAFTA-DR (Dominican Republic-Central America FTA). (s.f.). Office of the United States Trade Representative. Recuperado de https://ustr.gov/trade-agreements/ free-trade-agreem ents/cafta-dr-dominican-republic-central-america-fta

Canada. Copyright Modernization Act, S.G. c. 20. (2012).

Capling, A. (2005). All the way with the USA: Australia, the US and Free Trade. Sydney: University of New South Wales Press Ltd.

Carroll, M. (2014). Pinterest and Copyright's Safe Harbors for Internet Providers. University of Miami Law Review, 68, 421-444.

Casa de Representantes. (1998). Digital Millennium Copyright Act of 1998 (Reporte 105551. Parte. 2). Washington: U.S. Government Information.

Casey, T. D. (2000). ISP Liability Survival Guide: Strategies for Managing Copyright, Spam, Cache, and Privacy Regulations. New York: Wiley \& Sons.

Cerda-Silva, A. J. (2014). Limitación de responsabilidad de los prestadores de servicios de Internet por infracción a los derechos de autor en línea. Revista de Derecho de la Pontificia Universidad Católica de Valparaíso, (42), 121-148. Recuperado de http://www.scielo.cl/pdf/ rdpucv/n42/a04.pdf.

Chander, A. (2006). Exporting DMCA Lockouts. Cleveland State Law Review, 54, 205-217.

Christie, A., Waller, S. \& Weatherall, K. (2007). Exporting the DMCA Through Free Trade Agreements. En C. Heath \& A. Kamperman (eds.), Intellectual Property \& Free Trade Agreements (pp. 211-244). Great Britain: Hart Publishing.

Chile Breaks New Ground in Regulating IP Liability (junio de 2010). Wipo Magazine. Recuperado de http://www.wipo.int/wipo_magazine/en/2010/03/ article_0009.html

Chile Free Trade Agreement [USCHILE]. (2003). Office of the United States Trade Representative. Recuperado de https://ustr.gov/trade-agreements/free-tradeagreements/chile-fta/fina l-text

Chile. Ley 17.336 de 1970. Propiedad intelectual. Diario Oficial No. 19.11.2003. Ministro de Educación Pública, agosto de 1970.

Chile. Ley 19.628 de 1999. Protección de los datos de carácter personal. Diario Oficial No. 23.07.2011. Ministro de Educación Pública, agosto de 1999.

Cobia, J. (2009). The Digital Millennium Copyright Act Takedown Notice Procedure: Misuses, Abuses, and Shortcomings of the Process. University of 
Minnesota. Consortium on Law and Values in Health, Environment $\mathcal{E}^{2}$ the Life Sciences, 10(1), 387-411.

Código Civil. [G.C]. Congreso de la República de Colombia.

Código Penal [C.Pen]. Congreso de la República de Colombia.

Cohen. T. B. (2003). Note, Anti-Circumvention: Has Technology's Child Turned Against its Mother? Vanderbilt Fournal of Transnational Law, 36, 961-996.

Colombia alcanzará meta de conexiones a banda ancha en 2014. (07 de febrero de 2013). Portafolio. Recuperado de http://www.portafolio.co/negocios/colombiaalcanzara-meta-conexi ones-banda-ancha-2014

"Colombia Aprende" presenta nuevos contenidos de Educación Superior. (20 de octubre de 2005). MinEducación. Recuperado de http://www.mineducacion.gov. co/1621/article-897 57.html

Colombia avanza a paso firme en innovación educativa y uso pedagógico de las TIC. (18 de junio de 2013). Centro virtual de noticias de la educación. Recuperado de http://www.mine ducacion.gov.co/cvn/1665/w3-article-324021.html

Colombia da último paso para el TLC con Estados Unidos en medio de polémica. (11 de abril de 2012). El País. Recuperado de http://www.elpais.com.co/elpais/ colombia/noticias/aproba cion-implementacion-del-tlc-ley-lleras-mincomercio

Congote, N. \& Malaver, C. (19 de agosto de 2014). 'En Diez años, Ser Maestro Será lo Más Taquillero’: Gina Parody. El Tiempo. Recuperado de http://www. eltiempo.com/estilo-de-vida/educacion/entrevista-con-gina-parody-ministrade-educacion/14408836

Constitución Política. (1991). Congreso de la República de Colombia.

Convención de Berna de 1948. Convenio para la Protección de las Obras Literarias y Artísticas. Organización Mundial de la Propiedad Intelectual [OMPI], sept. 9, 1886. Revisado en Bruselas el 26 de junio de 1948. 25 U.S.T. 1341, 331 UNTS 217.

Convenio de Berna de 1971. Convenio para la Protección de las Obras Literarias y Artísticas. Organización Mundial de la propiedad intelectual [OMPI]. París.

Cooley, A. H. (2011). A Contractual Detterrence Strategy for User-Generated Copyright Infringement and Subsequent Service Provider Litigation. SMU Law Review, 64, 691-733.

Corbis Corporation vs. Amazon.com, 351 F. Supp. 1090 (W.D. Wash. 2004).

Correa, J. (30 de julio de 2004). Gobierno Prevé Nueva Crisis en el TLC. El Tiempo. Recuperado de http://www.eltiempo.com/archivo/documento/MAM-1513037 
Correa, C. M. (2004). Bilateralism in Intellectual Property: Defeating the WTO System for Access to Medicines. Case Western Reserve Journal of International Law, 36(1), 79-94.

Correa, C. M. (2007). Trade Related Aspects of Intellectual Property Rights: a Commentary on the TRIPS Agreement. Oxford: Oxford University Press.

Correa, C. M. \& Yusuf, A. (Eds.). (2008). Intellectual Property and International Trade: the TRIPs Agreement. London: Kluwer Law International.

Cortés, C. (2013). El debate pendiente en Colombia sobre la protección de derechos de autor en Internet. El Caso de la 'Ley Lleras'. Karisma. Recuperado de http:// karisma.org.co/wp-co ntent/uploads/2013/04/PaperlElCasoLeyLleras.pdf

Cox, K. L. (2012). The United States' Demands for Intellectual Property Enforcement in The Trans-Pacific Partnership Agreement and Impacts for Developing Countries (Working Paper). Recuperado de http://ssrn.com/abstract=2188029. doi:10.2139/ssrn.2188029

Craig, R. (2000). The Development of Internet Education and the Role of Copyright law. Fournal of the Copyright Society of the U.S.A., 47, 75-76.

Crews, K. D. (2000). Distance Education and Copyright Law: The Limits and Meaning of Copyright Policy. Fournal of College and University Law, 27(1), 15-51.

Cuatro mil chilenos han sido notificados por descarga ilegal de música. (30 de julio de 2013). Diario La Tercera. Recuperado de http://diario.latercera. com/2013/07/30/01/contenido/te ndencias/16-142830-9-cuatro-mil-chilenoshan-sido-notificados-por-descarga-ilegal-de-musica.shtml

Davies, G. (2002). Copyright and the public interest (2a ed.). London: Thomson.

Decreto 4807 de 2011. Por el cual se establecen las condiciones de aplicación de la gratuidad educativa para los estudiantes de educación preescolar, primaria, secundaria y media de las instituciones educativas estatales y se dictan otras disposiciones para su implementación. Presidencia de la República. Diario Oficial No. 48289.

Deere, C. (2009). The Implementation Game: the TRIPS Agreement and the Global PoliTIC of Intellectual Property Reform in Developing Countries. Oxford: Oxford University Press.

De la Barra. (2010). La propiedad intelectual en el Tratado de Libre Comercio con los Estados Unidos. Fundamentos. Avances y Temas Pendientes en Chile. La Propiedad Intelectual en Chile y el Tratado de Libre Comercio con los EE.UU, (Documento No. 2). Recuperado de http://www.amchamchile.cl/sites/default/files/SET\%20 documento $\% 202 \% 20$ actuali zado.pdf

Denicola, R. C. (2004). Fair's Fair: An argument for Mandatory Disclosure of Technological Protection Measures. Michigan Telecommunications and Technology Law Review, 11 (1), 1-97. 
Departamento Administrativo Nacional de Estadística [DANE]. (21 de marzo de 2014). Pobreza Monetaria y Multidimensional 2013. Boletín de prensa. Recuperado de http://www.dane .gov.co/files/investigaciones/condiciones_vida/pobreza/ bol_pobreza_13.pdf

Díaz, A. (2006). TLC y Propiedad Intelectual: Desafíos de Política Pública en 9 Países de América Latina y El Caribe. Brasil: Comisión Económica Para América Latina y el Caribe. Recuperado de http://www.cepal.org/publicaciones/xml/4/26974/ lcbrsr163alvarodiaz.pdf_

Dinwoodie, G. B. (2000). The Integration of Domestic and International Intellectual Property Lawmaking. Columbia-VLA Journal of Law E The Arts, 23(3-4), 307-315.

Dinwoodie, G. (2007). The WIPO Copyright Treaty: a Transition to the Future of International Copyright Lawmaking? Case Western Reserve Law Review, 57(4), 751-766.

Dirección Nacional de Derecho de Autor. (2005). Informe XIII Ronda de Negociaciones Tratado de Libre Comercio Andinos - Estados Unidos. Unidad Administrativa Especial Ministerio Del Interior y de Justicia. Recuperado de http://www.aplicacionesmcit.gov.co/mcit_tl c/

Dirección Nacional de Derecho de Autor. (15 de abril de 2005). Página web-Organismo de radiodifusión, Radicación No: 1-2005-7544. Recuperado de http://200.31.21.201/ desarrol lo/CONCEPTOSWEB/arch_conceptos/2-2005-4093.pdf

Dirección Nacional de Derecho de Autor. (6 de diciembre de 2005). Concepto: Página Web, Radicación No: 1-2005-3521. Recuperado de http://200.31.21.201/desarrollo/ CONCEPT OSWEB/arch_conceptos/2-2005-3521.pdf

Dirección Nacional de Derechos de Autor. (2009). Concepto: Reproducción y Puesta a Disposición, Radicación No: 1-2009-4887. Recuperado de http://200.31.21.201/ desarrollo/CON CEPTOSWEB/arch_conceptos/1-2009-4887.pdf

Dirección Nacional de Derechos de Autor. (18 de enero de 2010). Concepto: Limitaciones y Excepciones en la Legislación. Bibliotecas Públicas, Radicación No: 1-2010-7484. Recuperado de http://200.31.21.201/desarrollo/CONGEPTOSWEB/arch_ conceptos/2-2010-7484 .pdf

Dirección Nacional de Derechos de Autor. (24 de febrero de 2010). Concepto: Reproducción de Obras Musicales en una Obra Audiovisual, Radicación No: 2-2010-10712. Recuperado de http://200.31.21.201/desarrollo/CONCEPTOSWEB/arch_ conceptos/2-2010-10712.pdf

Dirección Nacional de Derecho de Autor. (6 de septiembre de 2010). Concepto: Publicación Digitalde Tesis de Grado, Radicación No: 1-2010-40237. Recuperado de http://200.31.2 1.201/desarrollo/CONCEPTOSWEB/arch_conceptos/2-2010-37571.pdf 
Discovery Education \& CDW-G. (2009). All About Computers: Conquering Technophobia Web 2.0 Explained. Recuperado de https://ktitraci.wikispaces.com/file/view/Web2.0.pdf

Drahos, P. (2001). Bits and Bips Bilateralism in Intellectual Property. The fournal of World Intellectual Property, 4, 791-808.

Drahos, P. (2003). Information Feudalism: Who Owns the Knowledge Economy? London: New Press.

Dutfield, G. \& Suthersanen, U. (2008). Global Intellectual Property Law. London: Edward Elgar Publishing.

Economía y negocios. (25 de julio de 2014). Colombia, en el puesto 12 en el mundo en desigualdad: Pnud. El Tiempo. Recuperado de http://www.eltiempo.com/ economia/finanzas-perso nales/desigualdad-en-colombia-el-pais-ocupa-elpuesto-12/14298377

Eduteka. (septiembre de 2007). Hitos que han revolucionado las TIC en los últimos 60 Años. Colombia Aprende. Recuperado de http://www.colombiaaprende.edu.co/ html/directivos/1 598/article-183078.html

EFF Analysis of the TPM provisions in the U.S. February 2011. Proposal for the TPP intellectual property chapter. (s.f.). Electronic Frontier Foundation [EFF]. Recuperado de https://ww w.eff.org/files/filenode/eff_tpp_tpm_analysis_0.pdf

Efroni, Z. (2001). Access Right. Oxford: Oxford University Press.

El impacto de los acuerdos comerciales sobre la innovación, la libertad de expresión y la privacidad: Los Proveedores de Servicios de Internet: Seguridades y Responsabilidades. (s.f.). Electronic Frontier Foundation [EFF]. Recuperado de https://www.eff.org/files/filenod e/tpp_isps.pdf

Elkin-Koren, N. (2007). Making Room for Consumers under the DMCA. Berkeley Technology Law Fournal, 22(3), 1119-1156.

El programa nacional de nuevas tecnologías en cifras. (2006). [Documento para descargar]. Colombia aprende. Recuperado de http://www.colombiaaprende.edu. co/html/home/1592/art icle-102549.html

Estados Unidos. Digital Millennium Copyright Act (1998). Pub.L. No 105-304 112 Stat. 2860, enmendando, 17 U.S.C. 101, et seq.

Estados Unidos. Technology, Education, and Copyright Harmonization Act of 2002, Pub. L. No. 107-273, 116 Stat. 1758 (2002), modificando el 17 U.S.C. 101, et seq.

Estados Unidos. The Copyright Infringement Liability of Online and Internet Service Providers: Hearing on S. 1146 Before the Committee on the Judiciary United States Senate. (1997). 105 ${ }^{\text {th }}$ Cong. 2,4. 
Exemption to Prohibition on Circumvention of Copyright Protection System for Access Control. (noviembre de 1999). Technologies. Federal Register, Vol. 64, no. 226, 66139. (to be codified at 37 G.F.R. pt. 201). Recuperado de http://www. copyright.gov/fedreg/1999/64fr 66139.pdf

Exemption to Prohibition on Circumvention of Copyright Protection System for Access Control. (noviembre de 2006). Technologies. Federal Register, Vol. 71, no. 227, 68472. (to be codified at 37 C.F.R. pt. 201). Recuperado de http://www. copyright.gov/fedreg/2006/71fr68472.pdf

Exemption to Prohibition on Circumvention of Copyright Protection System for Access Control Technologies. (Octubre de 2012). Federal Register, Vol. 77, no. 208, 65260-65279. (to be codified at 37 G.F.R. pt. 201). Recuperado de http:// copyright.gov/fedreg/2012/77fr65260.pdf

Exemption to Prohibition on Circumvention of Copyright Protection System for Access Control. (octubre de 2015). Technologies. Federal Register, Vol. 80, no. 208, 65944. (to be codified at 37 C.F.R. pt. 201). Recuperado de http://copyright. gov/fedreg/2015/80fr65944.pdf

Fair Use Principles for User Generated Video Content. (s.f.). Electronic Frontier Foundation. Recuperado de https://www.eff.org/es/pages/fair-use-principlesuser-generated-video-con tent

Fedesarrollo. (2013). El papel de las TIC en el desarrollo de la pequeña empresa: Reflexiones de política a la luz del caso colombiano. Bogotá: Autor. Recuperado de http://www. fedesar rollo.org.co/wp-content/uploads/2013/12/TIG_diciembre_2013.pdf

Ferlazzo, L. (octubre de 2009). The Best Web 2.0 Applications for Education - 2009. Edublogs. Recuperado de http://larryferlazzo.edublogs.org

Fernández, M. (2003). La culpa en el régimen de responsabilidad por el hecho ajeno. Estudios Socio-furídicos. 5(1), 230-249.

Ficsor, M. (2010). Protection of 'DRM' under the WIPO 'Internet Treaties': Interpretation, Implementation and Application. En I. A. Stamatoudi(Ed.), Copyright Enforcement and The Internet (pp. 257-302). London: Kluwer Law International.

Fischer, R. (2006). The Expansion of Intellectual Property Rights by International Agreement: A Case Study Comparing Chile and Australia's Bilateral FTA Negotiations with the U.S. Loyola of Los Angeles International and Comparative Law Review, 28(1), 129-170. Recuperado de http://digitalcommons.lmu.edu/ilr/vol28/iss1/4

Fisher, W., III et al. (2006). The Digital Learning Challenge: Obstacles to Educational Uses of Copyrighted Material in the Digital Age. A Foundational White Paper. Recuperado de http://cyber.law.harvard.edu/media/files/copyrightandeducation.html\#TOC 
Fondo de Fomento al Desarrollo Científico y Tecnológico [Fondef]. (2008). ICTs for education in Chile. Results of the TIC EDU Fondef Program. Santiago de Chile: Fondef CONICYT. Recuperado de http://www.conicyt.cl/fondef/files/downloads/2012/09/folletotic-edu.pdf

Free Trade Agreement U.S. - Australia [AUSFTA]. (Mayo 18 de 2004). 43 ILM 1248.

Free Trade Agreements Australia [AUSFTA]. (s.f.). Office of the United States Trade Representative. Recuperado de http://www.ustr.gov/trade-agreements/free-tradeagreements/au stralian-fta

Free Trade Agreement U.S. - Chile [USCHILE]. (Junio 6 de 2003). 42 ILM 1026.

Free Trade Agreements U.S. - Colombia [USCO]. (2006). Office of the United States Trade Representative. Recuperado de https://ustr.gov/trade-agreements/free-trade-agreements/c olombia-fta/final-text

Froman, M. (2014). 2014 Special 301 Report. Washington, D.C.: Office of the United States Trade Representative. Recuperado de http://www.ustr.gov/sites/default/ files/USTR $\% 202014 \% 20$ Special $\% 20301 \% 20$ Report $\% 20$ to $\% 20$ Congress $\% 20$ FINAL.pdf

Galindo, L., Martínez, A., \& Yañez, R. (2013). Derechos de autor en el entorno digital y el Internet en Colombia. Revista de Derecho, Comunicaciones y Nuevas Tecnologías, 10, 2-36.

Gana, R. L. (1995). Has Creativity Died in the Third World? Some Implications of the Internationalization of Intellectual Property. Denver Fournal of International Law and Policy, 24,109-144.

Gana, R. L. (1996). Prospects for Developing Countries Under the TRIPS Agreement. Vanderbilt Fournal of Transnational Law, 29, 735- 774

García, S., Maldonado, D., Perry, G., Rodríguez, C. \& Saavedra, J. (2014). Tras la excelencia docente: cómo mejorar la calidad de la educación para todos los colombianos. Bogotá: Puntoaparte. Recuperado de http://fundacioncompartir.org/front/ media/Tras_la_excelenci a_docente_Estudio_Final.pdf

García-Valcárcel, A., Basilotta, V. \& López, C. (2014). ICT in Collaborative Learning in the Classroom of Elementary and Secondary Education. Comunicar, 42(21), 65-74. doi: 10.3916/C42-2014-06

Garlick, M. K. (2004). Locking up the Bridge on the Digital Divide. Santa Clara High Technology Law Fournal, 20(4), 941-990.

Garner, B. \& Campbell, H. (Eds.). (2009). Black's Law Dictionary. , (9th ed). United States: Thomson West. 
Garon, J. M. (2013). Tidying up the Internet: Takedown of Unauthorized Content under Copyright, Trademark, and Defamation Law. Capital University Law Review, 41(3), 513-552.

Gasaway, L. N. (2001). Distance Learning and Copyright: An Update. Fournal of the Copyright Society of the U.S.A., 49(1), 195-224.

Gasser, U. (2006). Legal Frameworks and Technological Protection of Digital Content: Moving Forward Towards a Best Practice Model (Research Publication No 2006-04). The Berkman Center for Internet \& Society at Harvard Law School. Recuperado de http://ssrn.com /abstract $=908998$

Geist, M. (20 de octubre de 2003). Why we must stand on guard over copyright. Toronto Star. Recuperado de http://www.michaelgeist.ca/resc/html_bkup/ oct202003.html

Gervais, D. (1998). The TRIPS Agreement: Drafting History and Analysis. London: Sweet \& Maxwell.

Gilden, A. (2013). Copyright essentialism and the performativity of remedies. William E Mary Law Review, 54(4), 1123-1183.

Ginsburg,J. C. (1999). Copyright Legislation for the "Digital Millennium". ColumbiaVLA Fournal of Law and the Arts, 23, 137-180.

Ginsburg, J. C. (2000). International Copyright: From a "Bundle" of National Copyright Laws to a Supranational Code? The Fournal of the Copyright Society of the United States, 47, 265-290.

Ginsburg, J. C. (2012). Copyright Law. New York: Foundation Press.

Glickman, L., \& Fingerhut, J. (2012). User-Generated Content: Recent Developments in Canada and the United States. Internet and E-Commerce Law in Canada, 12(6), 4976.

Goldstein, P. (2001). International Copyright: Principles, Law, and Practice. Oxford: Oxford University Press.

Goldstein, P. \& Hugenholtz, B. (2010). International Copyright: Principles, Law, and Practice. (2a ed.) Oxford: Oxford University Press.

Gossain, J. (28 de febrero de 2014). ¿Por qué es tan mala la educación en Colombia? El Tiempo Recuperado de http://www.eltiempo.com/archivo/documento/CMS13570938

Greenleaf, G., Maurushat, A., Vaile, D., Bond, C. \& Paramaguru, A. (2007). Not a Fair Trade: Australia's TPM Protection and AUSFTA-Inspired Reforms. (Paper No. 2007-19). Recuperado de http://ssrn.com/abstract=977118 
Hadl, R. D. (1970). Toward International Copyright Revision: Report on the Meetings in Paris and Geneva. Bulletin of the copyright society of the U.S.A, 18, 183- 228.

Hansen, H. C. (1996). International Copyright: An Unorthodox Analysis. Vanderbilt Journal of Transnational Law, 29, 579-594.

Hinze, G. (2007). Brave New World, Ten Years Later: Reviewing the Impact of Policy Choices in The Implementation of the WIPO Internet Treaties' Technological Protection Measures Provisions. Case Western Reserve Law Review, 57(4), 779-822.

Hoffman, G. (2005). Copyright in cyberspace 2: Questions and Answers for Librarians. Chicago: Neal-Schuman Publishers.

Hornbeck, J. F. (2003). The U.S.-Chile Free Trade Agreement: Economic and Trade Policy Issues (Order Code RL31144). Recuperado de http://fpc.state.gov/documents/ organization/2318 9.pdf

House of Representatives. (2006). Review of technological protection measures exceptions. Commonwealth: The Parliament of Australia. Recuperado de http://www.aph.gov.au/parliamen-tary_business/committees/house_of_ representatives_committees?url=/laca/protect ion/report/fullreport.pdf

Imfeld, C. (2003). Playing Fair with Fair Use? The Digital Millennium Copyright Act's Impact on Encryption Researchers and Academicians. Communication Law and Policy, 8 (1), 111-144. doi: 10.1207/S15326926CLP0801_03

Indiana University. (s.f.). Copyright tutorial, Information Security \& Policy. Recuperado de http://protect.iu.edu/cybersecurity/safeonline/filesharing/tutorial\#q8

Institute for Communication and Development [IICD]. (2007). ICTs for Education: Impact and lessons learned from IICD-supported activities. La Haya: Autor.

Jamar, S. D. (2010). Crafting Copyright Law to Encourage and Protect Usergenerated Content in the Internet Social Networking Context. Widener Law fournal, 19, 843-868.

Johnson, G. F. (1970). The Origins of the Stockholm Protocol, The Part I. Bulletin of the copyright society of the U.S.A.,18, 91-181.

Kaminski, M. E. (2014). The Capture of International Intellectual Property Law Through The U.S Trade Regime. Southern California Law Review, 87, 977-1053

Kaminstein, A. (1964). Global Copyright: Recent International Copyright Conferences in Africa, Europe and Asia. Bulletin of the copyright society of the U.S.A.,11, 225-233.

Kalaš, et al. (2012). ICT in Primary Education. Analytical survey (Vol. 1. Exploring the origins, settings and initiatives). Moscú: UNESCO. Recuperado de http://iite. unesco.org/pics/public ations/en/files/3214707.pdf 
Kaplan, L. (2003). Copyright and the Internet. Temple Environmental Law \& Technology Journal, 22, 1-14.

Kaplan, S. (2013). English/Spanish and Spanish/English Legal Dictionary, (4 ${ }^{\text {th }}$ ed). New York: Kluwer Law International.

Kehoe, B. T. (2006). The TEACH Act's Eligibility Requirements: Good Policy Or A Bad Compromise? Brooklyn Law Review, 71(2), 1029-1063.

Kindle. (s.f.). Read Everywhere With our Free Reading Apps. Amazon. Recuperado de https://w ww.amazon.comqq/gp/digital/fiona/kcp-landingpage?ie=UTF8\&ref_=klp_mn

Kioscos vive digital. (s.f.). MinTIC. Recuperado de http://www.mintic.gov.co/ portal/vivedigital/ 612/w3-propertyvalue-7059.html

Kirk, R. (2011). 2011 Special 301 Report. Washington, D.G.: Office of the United States Trade Representative. Recuperado de https://ustr.gov/about-us/policyoffices/press-office/repor ts-and-publications/2011/2011-special-301-report

Kozma, R. B. (2011). AFramework for ICT Policiesto TransformEducation. EnUNESCO (Ed.), Transforming Education: The Power of ICT Policies (pp. 19-36). París: UNESCO. Recuperado de http://unesdoc.unesco.org/images/0021/002118/211842e.pdf

Kozma, R. B. \& Wagner, D. A. (2005). Core Indicators for Monitoring and Evaluation Studies for ICT for Education. En M. Trucano (Ed.), Monitoring and Evaluation of ICT in Education Projects, A Handbook for Developing Countries (pp. 21-31). Washington: Banco Internacional de Reconstrucción y Desarrollo. Recuperado de http://www.infodev.org/infodev -files/resource/InfodevDocuments_9.pdf

Krikorian, G. \& Kapczynski, A. (Eds.). (2010). Access to Knoweledge: A Conceptual Genealogy. New York: Zone Books.

Kuanpoth, J. (2007). TRIPS-Plus Rules under Free trade Agreements: An Asian Perspective. En C. Heath \& A. Kamperman (Eds), Intellectual Property \& Free Trade Agreements (pp. 27-48). Gran Bretaña: Hart Publishing.

Kur, A. (2013). European Intellectual Property Law: Texts, Cases and Materials. London: Edward Elgar.

La Corte Constitucional tumba toda la Ley Lleras. Un vicio de trámite en la ley que limita el libre (24 de enero de 2013). CME. Recuperado de http://www.cmi.com. co/la-corte-const itucional-tumba-toda-la-ley-lleras-un-vicio-de-tramite-en-laley-que-limita-el-libre/97619

La educación se revoluciona en el campo. (s.f.). Colombia Aprende: la red del conocimiento. Recuperado de http://www.colombiaaprende.edu.co/html/productos/1685/ article-166201. html 
Land, M. (2014). Adjudicating TRIPS for Development. En G. Ghidini(Ed.), TRIPS and Developing Countries, (pp.142-162). Londres: Edward Elgar.

Lara, J., \& Vera, F. (s.f.). Responsabilidad de los Prestadores de Servicios de Internet, (Policy Paper No 3). Recuperado de https://www.derechosdigitales.org/wp-content/ uploads/pp03. pdf

Latourette, A. W. (2006). Copyright Implications for Online Distance Education. The Fournal of College and University Law, 32, 613-654.

Leaffer, M. A. (1991). Protecting United States Intellectual Property Abroad: Toward a New Multilateralism. Iowa Law Review, 76, 273-308.

Leal, D. E. (2008). Iniciativa colombiana de objetos de aprendizaje: situación actual y potencial para el Futuro. Apertura, 8(8), 76-85. Recuperado de http://www. redalyc.org/pdf/688/68 811215006.pdf

Leary, B. (2012). Safe Harbor Startups: Liability Rulemaking under the DMCA. New York University Law Review, 87, 1135-1171.

Lejeune, M. (2003). Protection under US Copyright Law. En E. Becker (Ed.), Digital Rights Management: Technological, Economic, Legal and Political Aspects (pp. 366-382). Berlín: Springer.

Lemley, M. A. (1997). Dealing with Overlapping Copyrights on the Internet. University of Dayton Law Review, 22, 547-585.

Lenz vs. Universal Music Corp., 572 F. Supp. 2d. 1150 (ND Cal. 2008).

Lenz vs. Universal Music Corp, Nos. 13-16106, 13-16107, U.S. App. LEXIS 16308 (9th Cir. 2015).

Lessig, L. (2009). Update on Warner Music (UPDATED) (AGAIN). Recuperado de http://www.l essig.org/2009/04/update-on-warner-music/

Ley 23 de 1982. Sobre derechos de autor. Congreso de la República de Colombia, enero de 1982. Recuperado de http://www.alcaldiabogota.gov.co/sisjur/ normas/Normal.jsp? $\mathrm{i}=3431$

Ley 44 de 1993. Por la cual se modifica y adiciona la Ley 23 de 1982 y se modifica la Ley 29 de 1944. Diario Oficial No. 40.740. Congreso de la República de Colombia, febrero de 1993. Recuperado de http://www.alcaldiabogota.gov.co/ sisjur/normas/Normal.jsp?i=342 9

Ley 599 de 2000. Por la cual se expide el Código Penal. Diario Oficial No. 44097. Congreso de la República de Colombia, julio de 2000.

Ley 679 de 2001. Por medio de la cual se expide un estatuto para prevenir y contrarrestar la explotación, la pornografía y el turismo sexual con menores, en 
desarrollo del artículo 44 de la Constitución. Diario Oficial No. 44509. Congreso de la República de Colombia, agosto de 2001.

Ley 890 de 2004. Por la cual se modifica y adiciona el Código Penal. Diario Oficial 45602. Congreso de la República de Colombia, julio de 2004. Recuperado de http://www.alcaldiabog ota.gov.co/sisjur/normas/Normal.jsp?i=14137

Ley 1032 de 2006. Por la cual se modifican los artículos 257, 271, 272 y 306 del Código Penal. Diario Oficial No. 46307. Congreso de la República de Colombia, junio de 2006.

Ley 1036 de 2006. Por medio de la cual la Nación declara Patrimonio Histórico y Cultural de la Nación a la institución educativa Santa Librada del municipio de Neiva, departamento del Huila, y se dictan otras disposiciones. Diario Oficial No. 46.340. Congreso de la República de Colombia, julio de 2006.

Ley 1336 de 2009. Por medio de la cual se adiciona y robustece la Ley 679 de 2001, de lucha contra la explotación, la pornografía y el turismo sexual con niños, niñas y adolescentes. Diario Oficial No. 47.417. Congreso de la República de Colombia, julio de 2009.

Ley 1403 de 2010. Por la cual se adiciona la Ley 23 de 1982, sobre Derechos de Autor, se establece una remuneración por comunicación pública a los artistas, intérpretes o ejecutantes de obras y grabaciones audiovisuales o "Ley Fanny Mikey". Diario Oficial No. 47.775. Congreso de la República de Colombia, julio de 2010.

Ley 1437 de 2011. Por la cual se expide el Código de Procedimiento Administrativo y de lo Contencioso Administrativo. Diario Oficial No. 47.956. Congreso de la República de Colombia, julio de 2012.

Ley 1520 de 2012. Por medio de la cual se implementan compromisos adquiridos por virtud del "Acuerdo de Promoción Comercial", suscrito entre la República de Colombia y los Estados Unidos de América y su "Protocolo Modificatorio, en el Marco de la Política de Comercio Exterior e Integración Económica”. Diario Oficial No. 48.400. Congreso de la República de Colombia, abril de 2013.

Ley 1680 de 2013. Por la cual se garantiza a las personas ciegas y con baja visión, el acceso a la información, a las comunicaciones, al conocimiento y a las tecnologías de la información y de las comunicaciones. Diario Oficial No. 48.980. Congreso de la República de Colombia, noviembre de 2013. Recuperado de http://www. secretariasenado.gov.co/senado/b asedoc/ley_1680_2013.html

Ley Lleras. (s.f.). Colombia.com. Recuperado de http://www.colombia.com/tecnologia/ derechos-de-autor-propiedad-intelectual/nacional/ley-lleras.aspx

Light, D. \& Polin, D. (2010). Integrating Web 2.0 tools into the classroom: Changing the culture of learning. New York: EDC Center for Children and Technology. Recuperado 
de http://c ct.edc.org/sites/cct.edc.org/files/publications/Integrating $\% 20$ Web2.0.PDF

Linares, A. (17 de diciembre de 2012). Colombia necesita tener profesores de calidad: Experto. El Tiempo. Recuperado de http://www.eltiempo.com/archivo/ documento/CMS-12456651

Lipton, J. D. (2005). Solving the digital piracy puzzle: Disaggregating fair use from the DMCA's Anti-Device provisions. Harvard fournal of Law \& Technology, 19(1), 111-160.

Liu, J. P. (2003). The DMCA and the Regulation of Scientific Research. Berkeley Technology Law Fournal, 18(2), 501-538.

López, C. (2007). ¿Cómo se negocia un TLC en Colombia? Colombia Internacional, 65, 154-161. Recuperado de http://www.redalyc.org/pdf/812/81206508.pdf

Loren, L. P. (2011). Deterring Abuse of the Copyright Takedown Regime by Taking Misrepresentation Claims Seriously. Wake Forest Law Review, 46, 745-782.

Los problemas de la 'Ley Lleras 2.0' [editorial]. (11 de abril de 2012). El Espectador. Recuperado de http://www.elespectador.com/opinion/editorial/los-problemasde-ley-lleras-20-artic ulo-337685

Lugo, M. T. \& Schurmann, S. (2012). Turning on Mobile Learning in Latin America, Illustrative Initiatives and Policy Implications (Working Paper, Series on Mobile Learning). París: UNESCO. Recuperado de http://unesdoc.unesco.org/ images/0021/002160/216080E.pdf

Madrid, L. (mayo de 2006). Negociaciones de propiedad intelectual en el TLC con EE. UU: proceso, resultados y algunos mitos. Universidad Sergio Arboleda. Recuperado de http://ww w.usergioarboleda.edu.co/tlc/tlc_propiedad_intelectual_2.htm

Mantilla, F. (2007). El principio general de responsabilidad por culpa del Derecho Privado colombiano. Opinión furídica, 6(11), 131-150.

Mark, R. (2003). Verizon Seeks Stay of RIAA Ruling. Internet Neres. Recuperado de http://www .internetnews.com/bus-news/article.php/1577111

Marobie-FL vs. Nat. Assn. of Fire Equipment Distributors, 983 F. Supp. 1167 (N.D. III. 1997).

Masnick, M. (2010). Bogus Copyright Claim Silences Yet Another Larry Lessing YouTube Presentation. TechDirt. Recuperado de https://www.techdirt.com/ articles/20100302/0354 498358.shtml

Masouyé, C. (1978). Guide to the Berne Convention for the Protection of Literacy and Artistic Works. París: WIPO Publication. Recuperado de ftp://ftp.wipo.int/pub/library/ ebooks/wi popublications/Guide-Berne-Convention-wipopub615E.pdf 
Matiz, C. A. (2002). Delitos Contra los Derechos de Autor en el Nuevo Código Penal (Ley 599 de 2001). Propiedad Inmaterial, 5, 3-16.

Mazzone, J. (2011). Copyfraud and Other Abuses of Intellectual Property Law. California: Stanford Law Books.

McCardle, L. C. (2004). Despite Congress's Good Intentions, The DMCA's Anti-Circumvention Provisions Produce a Bad Result - A Means to Create Monopolies. Loy. L. Rev, 50, 997-1032.

McKay, P. (abril de 2013). YouTube Refuses to Honor DMCA Counter-Notices. Promoting Fair Use in Online Video. Recuperado de http://fairusetube.org/ articles/27-youtube-refus es-counter-notices

Medina, E. (18 de noviembre de 2014). Libro digital: un mercado aún incipiente en Colombia, editoriales y bibliotecas empiezan a desarrollar iniciativas para aprovechar formatos electrónicos. El Tiempo. Recuperado de http://www. eltiempo.com/tecnosfera/novedades-tecn ologia/libros-digitales-un-mercadoque-inicia-en-colombia/14844815

Mehra, D., K. \& Trimble, M. (2014). Secondary Liability, ISP Immunity, and Incumbent Entrenchment. The American fournal Of Comparative Law, 62, 685-706.

Melé, B. M. (2007). La explotación directa de obras y prestación protegidas en redes digitales. En C. Buganza \& N. G. Castellet (Coords.), Novedades en la Ley de Propiedad Intelectual (pp.13-60). Madrid: J.M. Bosch.

Miller, J. M. (2010). Fair Use Through the Lenz of Section 512(c) of the DMCA: A Preemptive Defense to a Premature Remedy Note. Iowa L. Rev., 95(5), 1697-1729

Ministerio de Comercio, Industria y Turismo [MinCIT]. (2006a). TLC Principales Logros. Bogotá: Oficina de Comunicaciones. Recuperado de http://www.mincit. gov.co/tlc/publicaci ones.php?id=747

Ministerio de Comercio, Industria y Turismo [MinCIT]. (2006b). El tratado de libre comercio Colombia - Estados Unidos. Resumen. Bogotá: Autor. Recuperado de http://www.mincit .gov.co/tlc/publicaciones.php?id=747

Ministerio de Comercio, Industria y Turismo [MinCIT]. (s.f.). La negociación del TLC de Colombia con Los Estados Unidos. Bogotá: Oficina de Comunicaciones.

Ministerio de Comunicaciones. (2008). Plan Nacional de Tecnologías de la Información y las Comunicaciones. Bogotá: Autor. Recuperado de http://www.eduteka.org/ pdfdir/Colombi aPlanNacionalTIG.pdf

Ministerio de Educación Nacional de Colombia [MinEducación]. (2004a). www.colombiaaprend e.edu.co La nueva red del conocimiento. Altablero, 29. Recuperado de http://www.mined ucacion.gov.co/1621/article-87398.html 
Ministerio de Educación Nacional de Colombia [MinEducación]. (2004b). Una llave maestra las TIC en el aula. Altablero, 29. Recuperado de http://www. mineducacion.gov.co/1621/ article-87408.html

Ministerio de Educación Nacional de Colombia [MinEducación]. (2006). Visión 2019 - Educación. Propuesta para discusión. Bogotá: Autor. Recuperado de http:// www.plandecenal.e du.co/html/1726/articles-121193_archivo.pdf

Ministerio de Educación Nacional de Colombia [MinEducación]. (abril de 2012). Disminuir la deserción es fortalecer el capital humano. Boletín de Educación Superior, 20, 7-10. Recuperado de http://www.mineducacion.gov.co/1621/ articles-92779_archivo_pdf_Boletin 20.pdf

Ministerio de Relaciones Exteriores. (2014). Evaluación de las relaciones comerciales entre chile y los estados unidos a diez años de la entrada en vigencia del tratado de libre comercio. Recuperado de http://www.direcon.gob.cl/wpcontent/uploads/2014/01/ Evaluacio nTLC_EEUU_10_años-14-ene.pdf

Ministerio de Tecnologías de la Información y las Comunicaciones [MinTIC]. (2005). Resultados Positivos en Derechos de Autor (Prensa no. 135). Bogotá: Autor.

Ministerio de Tecnologías de la Información y las Comunicaciones [MinTIC]. (2014). Informe Rendición de Cuentas 2014. Recuperado de http://www.mintic.gov. co/portal/604/articles-4323_recurso_1.pdf

Ministerio de Tecnologías de la Información y las Comunicaciones [MinTIC]. (3 de junio de 2014). Más computadores para las escuelas [Archivo de video]. Recuperado de https://www.youtube.com/watch?v=Wfu6-TZt7Yg

Ministerio de Tecnologías de la Información y las Comunicaciones [MinTIC]. (14 de septiembre de 2014). Las TIC al servicio de la Educación en Vive Digital TV [Archivo de video]. Recuperado de https://www.youtube.com/watch?v=_ Alg4jjt4Mk\&list=PLhTx9maDqE9 LJVkn4r6jv-y47_g-x4amb

Monroy, J. C. (2009). OMPI, Estudio sobre las limitaciones o excepciones al derecho de autor $y$ los derechos conexos en beneficio de las actividades educativas y de investigación en América Latina y el Caribe. Comité permanente de derecho de autor y derechos conexos, Ginebra. Recuperado de http://www.wipo.int/meetings/en/doc_details. jsp?doc_id=13030 3

Monroy, J. C. (2010). Necesidad de nuevas limitaciones o excepciones para facilitar la digitalización y puesta a disposición de las obras protegidas en el marco de la educación virtual. La Propiedad Inmaterial, 14, 195-208.

Monroy, J. C. (2012). Regulación de las Excepciones a las Medidas Tecnológicas en Beneficio de la Educación, en la ley 1520 de 2012. Campus RRA Formación. Recuperado de http://www.rraformacion.com/mod/page/view 
Morocco Free Trade Agreement. (s.f.). Office of the United States Trade Representative. Recuperado de https://ustr.gov/trade-agreements/free-trade-agreements/ morocco-fta

Mulligan, C. (2013). Technological Intermediaries and Freedom of the Press. SMU Law Review, 66, 157-188.

Ndiaye, N. (1986). The Berne Convention and Developing Countries. Columbia Journal of Law $\&$ the Arts, 11, 47-56.

Nimmer, M. B. \& Nimmer, D. (1998). Nimmer on Copyright (vols. 3-4). United States: Matthew Bender.

No Downtime for Free Speech. (s.f.). Electronic Frontier Foundation EFF. Recuperado de https: //www.eff.org/issues/ip-and-free-speech

Nuestro Proyecto Social. (25 de febrero de 2013). El Biblioburro. Biblioburrosinfronteras. Recuperado de http://biblioburrosinfronteras.blogspot.com.co/2013/02/elbiblioburro.html

Nueva Zelanda. Copyright Act 1994. Parliamentary Counsel Office (Public Act 1994 No 143).

OECD. (2013). Colombia Student Performance (PISA 2012). Education GPS. Recuperado de http://gpseducation.oecd.org/CountryProfile?primaryCountry=COL\&treshold $=10 \&$ topic $=$ PI

Okediji, R. (2003-2004). Back to Bilateralims? Pendulum Swings in International Intellectual Property Protection. Ottawa Law E Technology Journal, 1, 125-147.

Okediji, R. (2006). The International Copyright System: Limitations, Exceptions and Public Interest Considerations for Developing Countries (Issue Paper No 15). Ginebra: ICTSD. Recuperado de http://unctad.org/en/Docs/iteipc200610_en.pdf

Olian, I. A. Jr. (1974). International Copyright and the Needs of Developing Countries: The Awakening at Stockholm and Paris. Cornell International Law Journal, 7(2), 81-112.

Otieno, J. (2014). The Illusion of TRIPS Agreement to Promote Creativity and Innovation in Developing Countries: Case Study on Kenya. En G. Ghidini (Ed.), TRIPS and Developing Countries (pp. 239-301). London: Edward Elgar.

Pabón, J. A. (2006). Tratado de Libre Comercio con Estados Unidos de Norteamérica y el derecho de autor. Entrevista a Fernando Zapata. Derecho de Autor, 11, 1-7. Recuperado de http://www.cecolda.org.co/images/publicaciones/numerol1/ed11_1.pdf

Pabón, J. (2007). Medidas tecnológicas de protección en el Tratado de Libre Comercio con los Estados Unidos de Norteamérica. Propiedad Inmaterial, 10-11, 93-116. 
Pabón, J. (2008). Los riesgos de la tecnología. Medidas tecnológicas de protección: el caso de los DVD. Propiedad Inmaterial, 12, 121-152.

Palacio, M. (2013). Conflicto de leyes al interior del régimen común de derechos de autor y de derechos conexos de la comunidad andina de naciones. La Propiedad Inmaterial, (17), 205-222.

Papadopoulou, M. D. (2010). CopyrightLimitations and Exceptions in an E-Education Environment. European. Fournal of Law and Technology, 1(2). Recuperado de http:// ejlt.org/ article/view/38/56

Parliament of Australia. (s.f.). Government response to the House of Representatives Standing Committee on legal and constitutional affairs report "Review of technological protection measures exceptions". Recuperado de http://www.aph.gov.au/Parliamentary_Business/C ommittees/ House_of_representatives_Committees?url=laca/protection/govresp.pdf

Parliament of the Commonwealth of Australia. (2004). The Australia - United States Free Trade Agreement. (Reporte 61). Camberra: Autor. Recuperado de http://www. aph.gov.au/parlia metary_business/committees/house_of_representatives_ committees?url=jsct/usafta/report.htm\#fullreport

Peña, D. (2013). Responsabilidad de los proveedores de servicio de internet en relación con la propiedad intelectual. Bogotá: Universidad Externado de Colombia.

Peñarredonda, J. L. (20 de mayo de 2013). La pelea entre el Gobierno y los activistas por las leyes "Lleras". Enter.Co. Recuperado de http://www.enter.co/culturadigital/colombia-digital/e l-viacrucis-de-las-leyes-lleras/

Peru Trade Promotion Agreement. (s.f.) Office of the United States Trade Representative. Recuperado de https://ustr.gov/trade-agreements/free-tradeagreements/peru-tpa

Philippa. D. (2005). The Australia-US Free Trade Agreement: An Assessment. (Paper No. 345, 2005). Canberra: The Australian National University. Recuperado de https://digitalcollec tions.anu.edu.au/bitstream/1885/43027/2/pep-345.pdf

Plan Nacional de Lectura y Escritura. (s.f.). Red Nacional de Bibliotecas Públicas. Recuperado de http://www.bibliotecanacional.gov.co/rnbp/plan-nacional-delectura-y-escritura

Plata, L. C. (2010). Responsabilidad civil por infracciones al derecho de autor. Barranquilla: Universidad del Norte Editorial.

Playboy Enterprises vs. Frena, 839 F. Supp. 1552 (M.D. Fla. 1993).

Primo, G. A. (1989). The Economics of intellectual Property Rights and the GATT: A view from the South. Vanderbilt Fournal of Transnational Law, 22(2), 243-264. 
Primo, G. A. (2004). Trade-Related Intellectual Property Issues: the Uruguay Round Agreement and its Economic Implications. En K. E. Maskus (Ed.), The WTO, Intellectual Property Rights and the Knowledge Economy (pp. 3-41). London: Edward Elgar Publishing.

Proceso de Casación 4345 (1995, febrero 22). Daños en actividades peligrosas ocasionados por cosas inertes. M.P. Carlos Esteban Jaramillo. Corte Suprema de Justicia de la República de Colombia.

Proceso de Casación 4637 (1996, marzo 15). Recurso de casación. M. P. Carlos Esteban Jaramillo. Corte Suprema de Justicia de la República de Colombia.

Proceso de Casación 5012 (1999, octubre 25). Demanda por casación. M. P. José Fernando Ramírez Gómez. Corte Suprema de Justicia de la República de Colombia. Sala. Civil y Agraria.

Proceso de Casación 6264 (2000, mayo 29). Recurso de casación. M. P. Jorge Santos Ballesteros. Corte Suprema de Justicia de la República de Colombia., Sala. Civil y Agraria.

Proceso de Casación 29188 (2008, abril 30). Demanda por casación. M. P. José Leonidas Bustos Martínez. Corte Suprema de Justicia de la República de Colombia.

Proceso de Casación 31362 (2009, mayo 13). Demanda por violación de derechos de autor. M.P. Julio Enrique Socha Salamanca. Corte Suprema de Justicia de la República de Colombia.

Proceso de Casación 30532 (2009, octubre 21). Demanda de Casación. M.P. Jorge Luis Quintero Milanés. Corte Suprema de Justicia de la República de Colombia.

Proceso de Casación 31403 (2010, mayo 28). Demanda por violación de derechos de autor. M.P. Sigifredo Espinoza Pérez. Corte Suprema de Justicia de la República de Colombia.

Programa nacional de nuevas tecnologías. (s.f.). Colombia aprende: la red del conocimiento. Recuperado de http://www.colombiaaprende.edu.co/html/home/1592/article-102549.html

Proyecto de Ley 241 de 2011. Senado. Por la cual se regula la responsabilidad por las infracciones al derecho de autor y los derechos conexos en Internet. Congreso de la República de Colombia.

Proyecto de Ley 001 de 2012. Cámara. Por medio de la cual se establecen limitaciones y excepciones al Derecho de Autor. Congreso de la República de Colombia, julio de 2012. Recuperado de http://www.imprenta.gov.co/gacetap/gaceta.mostrar_ documento?p_tipo $=05 \&$ p _numero $=001 \&$ p_consec $=33420$ 
Proyecto de Ley 306 de 2013. Cámara. Por la cual se modifica la Ley 23 de 1982 y se adiciona la legislación nacional en materia de derecho de autor y derechos conexos. Ministerio de Comercio, Industria y Turismo y Ministerio del Interior.

Queen, B. \& Lewis, L. Distance Education Courses for Public Elementary and Secondary School Students: 2009-10 (NCES 2012-008). Washington, DC: Government Printing Office. Recuperado de http://nces.ed.gov/pubs2012/2012008.pdf

Quilter, L. \& Heins, M. (2007). Intellectual Property and Free Speech in the Online World: How Educational Institutions and Other Online Service Providers are Coping with Cease and Desist Letters and Takedown Notices. New York: Brennan Center for Justice at NYU School of Law. Recuperado de http://www.fepproject.org/policyreports/ quilterheinsreport .pdf

Ramírez, M. A. (2009). La responsabilidad de los ISP desde el punto de vista de los contenidos. La Propiedad Inmaterial, 13, 283-302.

Raymond, A. H. (2013). Heavyweight Bots in the Clouds: the Wrong Incentives and Poorly Crafted Balances that Lead to the Blocking of Information Online. Northwestern Fournal of Technology And Intellectual Property, 11(6), 473-500.

Recording Indus. Ass'n de Am. vs. Verizon Internet Servs., Inc, 351 F.3d 1229, 1233 (DC. Cir 2003), negado, 543 EE.UU. 924, 125 S. Ct. 309, 160 L. Ed. 2d 222 (2004).

Red Clara. (s.f.). Preguntas frecuentes. Recuperado de http://www.redclara.net/ index.php/somos/ faq-s

Reese, A. (2003). Will Merging Access Control and Rights Controls Undermine the Structure of Anticircumvention Law? (Research Paper no. 021 and Research Paper no. 61). Recuperado de http://papers.ssrn.com/sol3/papers.cfm?abstract_id=502263

Reid, B. E. (20 de marzo de 2013). The Digital Millennium Copyright Act is Even Worse Than You Think. Future Tense. Recuperado de http://www.slate.com/ articles/technology/futur e_tense/2013/03/dmca_copyright_reform_u_s_law_ makes_digital_media_inaccessible.html

Reinbothe, J. \& Von Lewinski, S. (2002). The WIPO Treaties 1996. London: Butterworths Lexis Nexis.

Religious Technology Center vs. Netcom On-Line Services, 907 F. Supp. 1361 (N.D. Cal. 1995).

Rengifo, E. (2008). Un nuevo reto del Derecho en la edad de la información. Propiedad Inmaterial, 12, 105-120.

Rengifo, E. (2010). ¿El plagio es una conducta reprimida por el derecho penal? La Propiedad Inmaterial, 14, 303-315. 
Rengifo, E. (2013). Computación en la nube. Propiedad Inmaterial, 17, 223-245.

Rengifo, E. (2014). Toward the Extension of Obligations to other Intermediaries in the Internet. Propiedad Inmaterial, 18, 167-189.

República del Ecuador. Proceso No 23-IP-98 (25 de septiembre 25 de 1998). Interpretación prejudicial de los artículos 81, 82 literales a), b) y c) de la Decisión 344 de la Comisión del Acuerdo de Cartagena. M.P. Ernesto Rafael Ariza Muñoz. Expediente Interno $\mathrm{N}^{\circ}$ 3841. Tribunal de Justicia de la Comunidad Andina [T.J.G.A], Quito. Recuperado de http://intra net.comunidadandina. org/Documentos/Procesos/23-IP-98.doc

República del Ecuador. Proceso No 24-IP-98 (25 de septiembre de 1998). Interpretación prejudicial de los artículos 26, 54 y 56 de la Decisión 351 de la Comisión del Acuerdo de Cartagena solicitada por el Juzgado Tercero de Primera Instancia en lo Civil, Mercantil y del Tránsito de la Circunscripción Judicial del Área Metropolitana de Caracas. Actora: "PROMOTORA CEDEL C.A.", e interpretación de oficio de los artículos 3, 4, 13 y 23 de la misma Decisión. Tribunal de Justicia de la Comunidad Andina [T.J.G.A], Quito.

República del Ecuador. Interpretación Prejudicial 10-IP-99 (11 de junio de 1999). Interpretación prejudicial de los artículos 28 y 58 de la Decisión 351 de la Comisión del Acuerdo de Cartagena. Proceso Interno No. 5316-LR. Tribunal de Justicia de la Comunidad Andina [T.J.C.A], Quito. Recuperado de http:// intranet.comunidadandina.org/Documentos/Proces os/23-IP-98.doc

Reuveni, E. (2013). Copyright, Neuroscience and Creativity. Alabama Law Review, $64(4), 735-801$.

Review of Technological Protection Measure exceptions made under the Copyright Act 1968. (s.f.). Recuperado de https://www.ag.gov.au/Consultations/Documents/Robert\%20X\%20 Submission.pdf

Richardson, D. (2004). Intellectual Property Rights and the Australia-US Free Trade Agreement. (Research Paper No. 14 2003-04). Recuperado de http://www.aph.gov. au/About_Parliam ent/Parliamentary_Departments/Parliamentary_Library/ pubs/rp/rp0304/04rpl4

Ricketson, S. (junio de 2003). WIPO Study on Limitation and Exceptions of Copyright and Related Rights in the Digital Environment. Standing committee on copyright and related rights, Ginebra. Recuperado de http://www.wipo.int/edocs/mdocs/ copyright/en/sccr_9/sc cr_9_7.pdf

Ricketson, S. \& Ginsburg, J. (2006). International Copyright and Neighbouring Rights: The Berne Convention and Beyond (2a ed.). Oxford: Oxford University Press. 
Ringer, B. (1968). The role of the United States in International Copyright-Past, Present and Future. Georgetown Law Fournal, 56, 1050-1079.

Ríos, W. R. (18 de abril de 2012). Aciertos y desaciertos de la Ley 1520, sobre derecho de autor y conexos en el marco del TLC. Ambitojurídico. Recuperado de http:// www.ambitojuridico .com/BancoConocimiento/N/noti-20418actualizacion_y_ repotenciacion_de_nuestras_normas/noti-120418actualizacion_y_ repotenciacion_de_nuestras_normas.asp?Miga=1

Ríos, W. R. (2012). Eventos y eximentes de responsabilidad de los proveedores de servicios de Internet ante las infracciones a los derechos de propiedad intelectual realizadas por sus suscriptores. En R. Metke \& E. I. León (Eds.), Propiedad Intelectual: Reflexiones (pp. 223-298). Bogotá: Universidad del Rosario.

Roda, A. (20 de marzo de 2013). Hacia una política pública de acceso a la información: el papel de la Biblioteca Nacional. Biblioteca Nacional de Colombia. Recuperado de http://www. bibliotecanacional.gov.co/content/hacia-una-pol\%C3\%ADticap $\%$ C3 $\%$ BAblica-de-acces o-la-informaci $\% \mathrm{C} 3 \% \mathrm{~B} 3 \mathrm{n}$

Rodríguez, S. (2004). La era digital y las excepciones y limitaciones al derecho de autor. Bogotá: Universidad Externado de Colombia.

Roffe, P. (2004). Bilateral agreements and a trips-plus world: The Chile-USA Free Trade Agreement. (Paper No. 4). Recuperado de http://twn.my/title2/FTAs/ Intellectual_Property /IP_and_other_Topics/Chile-USAFTAP.Roffe.pdf

Roffe, P. (2006). Intellectual Property Provisions in Bilateral and Regional Trade Agreements: The Challenges of Implementation. Washington: CIEL; ICTSD; TRALAC. Recuperado de http://www.iprsonline.org/unctadictsd/dialogue/2006-10-06/

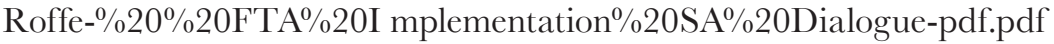

Roffe, P., Spennemann, C., \& Von Braun, J. (2010). Intellectual Property Rights in Free Trade Agreements: Moving Beyond TRIPS Minimum Standards. En C. M. Correa (Ed.), Research on The Protection of Intellectual Property Under WTO Rules (Vol. 1), (pp. 266-318). London: Edward Elgar.

Romero, C. (s.f.). Ley Lleras 2.0, en riesgo los derechos a la igualdad, a la libertad de expresión, y a la intimidad. Recuperado de http://www.asleyes.com/descargas/pdf/ comentario/ ley_lleras.pdf

Romero, A. (2006). Colombia-USA Free Trade Agreement (El TLC Colombia-USA). Tendencias, 7(2), 29-68. Recuperado de http://papers.ssrn.com/abstract=957133

Rossi vs. Motion Picture Ass'n of America Inc, 391 F. 3d 1000 (9th Cir. 2004).

Rossini, C. (2010). Green-Paper: The State and Challenges of OER in Brazil: From Readers to Writers? (Berkman Research Publication No 2010-01). Recuperado de http:// papers.ssrn. com/sol3/papers.cfm?abstract_id=1549922 
Rueda, N. R. E. (2012). TLG Colombia-Estados Unidos y sus implicaciones en el turismo (FTA Colombia-United States and its implication in the tourism). Anuario Turismo y Sociedad, 13, 265-294. Recuperado de http://papers.ssrn.com/ abstract $=2269164$.

S. Rep. 105-109, $107^{\circ}$ Cong. (1998).

Sadd, T. J. (2001). Fair Use as a Defense under the Digital Millennium Copyright Act's Anti-Circumvention Provisions. George Mason Law Review, 10(2), 321-1071.

Samuelson, P. (1997). U.S. Digital Agenda at WIPO. Virginia Fournal of International Law, 37, 369-440.

Samuelson, P. (1999). Intellectual Property and the Digital Economy: Why the AntiCircumvention Regulations Need to be Revised. Berkeley Technology Law Fournal, 14, 519-568.

Santos, G. (23 de abril de 2012). Conclusiones sobre la Ley Lleras. El Tiempo. Recuperado de http://www.eltiempo.com/archivo/documento/CMS-11629603

Scheinblatt, J. S. (1998). The WIPO Copyright Treaty. Berkeley Technology Law Journal, 13(1), 535-550.

Schrader, D. M. (1970). Analysis of the Protocol Regarding Developing Countries. Bulletin of the copyright society of the U.S.A.,18, 160-232.

Schwabach, A. (2006). Internet and The Law: Technology, Society, and Compromises ( ${ }^{\text {nd }}$ ed). Santa Barbara: ABC-CLIO.

Sell, S. K. (2011). TRIPs Was Never Enough: Vertical Forum Shifting, FTAS, ACTA, and TPP. Fournal of Intellectual Property Law, 18, 447- 478.

Seltzer, W. (2010a). Free Speech Unmoored in Copyright's Safe Harbor: Chilling Effects of the DMCA on the First Amendment. Harvard Fournal of Law \& Technology, 24(1), 171-232.

Seltzer, W. (2010b). The Imperfect is the Enemy of the Good: Anticircumvention Versus Open User Innovation. Berkeley Technology Law Fournal, 25(2), 909-972

Senate Select Committee on the Free Trade Agreement between Australia \& the United States of America Committee Secretariat. (2004). Select Committee on the Free Trade Agreement between Australia and the United States of America. Camberra: Senate Printing Unit, Parliament House. Recuperado de http://www.aph.gov. $\mathrm{au} /$ binaries/senate/committee/freetrade_ctte/report/final/report.pdf

Senftleben, M. R. F. (2004). Copyright, limitations, and the Three-Step test: an analysis of the Three-Step Test in International and EC Copyright Law. La Haya: Kluwer Law International 
Seng, D. (diciembre de 2009). WIPO Study on the Copyright Exceptions for the Benefit of Educational Activities for Asia and Australia. Standing committee on copyright and related rights, Ginebra. Recuperado de http://www.wipo.int/meetings/en/doc_ details.jsp?doc_id= 130249

Sentencia C-228 (1995, mayo 25). Acción pública de inconstitucionalidad. M.P. Antonio Barrera. Corte Constitucional de Colombia. Recuperado de http:// www.corteconstitucional.go v.co/relatoria/1995/C-228-95.htm

Sentencia C-276 (1996, junio 20). Acción pública de inconstitucionalidad contra los artículos 20, 81 y 98 de la ley 23 de 1982, sobre derechos de autor. M.P. Julio Cesar Ortiz. Corte Constitucional de Colombia. Recuperado de http://www. corteconstitucional.gov.co/relat oria/1996/c-276-96.htm

Sentencia C-155 (1998, abril 28). Demanda de inconstitucionalidad contra la Ley 397 de 1997 (total, por vicios de forma) y contra los artículos 33 y 34. M.P. Vladimiro Naranjo Mesa. Corte Constitucional de Colombia. Recuperado de http://www.corteconstitucional.gov.c o/relatoria/1998/C-155-98.htm

Sentencia 4630 (2000, enero 27). Acción en la propiedad industrial. M.P. Manuel Urueta Ayola. Consejo de Estado. Recuperado de http://190.24.134.114:8080/ WebRelatoria/ce/index.x html

Sentencia C-975 (2002, noviembre 13). Demanda de inconstitucionalidad contra la totalidad de la Ley 719 de 2001 y, en subsidio, contra los artículos $1^{\circ}, 3^{\circ}$ y su transitorio, $6^{\circ}$ y $8^{\circ}$. M.P. Rodrigo Escobar Gil. Corte Constitucional de Colombia. Recuperado de http://www .corteconstitucional.gov.co/RELATORIA/2002/C-975-02.htm

Sentencia C-871 (2010, noviembre 4). Demanda de inconstitucionalidad contra el artículo 43 (parcial) de la Ley 23 de 1982. M.P. Luís Ernesto Vargas Silva. Corte Constitucional de Colombia. Recuperado de http://www.corteconstitucional. gov.co/relatoria/2010/C-871-10.htm

Sentencia C-011 (2013, enero 23). Demanda de inconstitucionalidad contra la Ley 1520 de 2012. M.P. Jorge Enrique Robledo Castillo. Corte Constitucional de Colombia. Recuperado de http://www.corteconstitucional.gov.co/relatoria/2013/c-011-13.htm

Serwin, A. (Ed.). (2010). Information Security and Privacy a Guide to International Law and Compliance. London: Brand LegalWorks

Shashikant, S. (diciembre de 2005). Copyright, Information Communications Technologies and Access to Information and Technology. Asian Regional Workshop on Free Trade Agreements. Bangkok.

Sharp, J. (2002). Coming Soon to Pay-Per-View: How the Digital Millennium Copyright Act Enables Digital Content Owners to Circumvent Educational Fair Use. American Business Law Fournal, 40(1), 1-81. 
Silva, L. (2007). El proceso de negociación del TLC Colombia-Estados Unidos. Colombia Internacional, 65, 112-133. Recuperado de http://dialnet.unirioja.es/ servlet/articulo?codigo $=2345401$

Singapore FTA. (s.f.). Office of the United States Trade Representative. Recuperado de https://us tr.gov/trade-agreements/free-trade-agreements/singapore-fta

Sirichit, M. (2013). Catching the Conscience: An Analysis of the Knowledge Theory Under $\$ 512(\mathrm{C})$ 's Safe Harbor \& the Role of Willful Blindness in the Finding of Red Flags. Albany Law Fournal of Science E Technology, 23, 85-190.

Sirinelli, P. (diciembre de 1999). Exceptions and Limits to Copyright and Neighboring Rights. Workshop on implementation issues of the WIPO Copyright Treaty (WCT) and the WIPO Performances and Phonograms Treaty (WPPT). Ginebra.

Skynet Kvd. (29 de octubre de 2013). Kiosco vive digital [Archivo de video]. Recuperado de https://www.youtube.com/watch?v=Daq0hWpMtBQ

Smith, E. H. (1996). Worldwide Copyright Protection Under the TRIPS Agreement. Vanderbilt Journal of Transnational Law, 29(3), 559-578.

Standing Council of School Education and Early Childhood. (2002). 'Review of Technological Protection Measure exceptions made under the Copyright Act 1968' (Submission to the Attorney-General's Department). Recuperado de https:// www.yumpu.com/en/document/v iew/8568478/microsoft-word-120817-tpmsubs-finaldoc-attorney-generals-

Stanford University. (s.f.). Stanford Academic Computing Services, File-Sharing and Copyright Law: How it Affects you. Recuperado de https://acomp.stanford.edu/info/ dmca\#conseque nces

Stewart, T. P. (Ed.). (1993). The GATT Uruguay Round: a Negotiating History, 1986-1992. Kluwer Law and Taxation Publishers.

Stevens vs. Kabushiki Kaisha Sony Computer Entertainment [2005] HCA 58.

Suiza. Über das Urheberrecht und Verwandte Schutzrechte [Federal Act on Copyright and Related Rights]. (1992). Federal Council. SR 231.1 (Switz).

Sundara, M.T. (2011). Moral Rights. Oxford: Oxford University Press.

Sy Tan. (4 de marzo de 2008). ICT in Education. My digital life. Recuperado de http://www.myd igitallife.info/ict-in-education/

The Australian APEG Study Centre, Monash University. (2001). An AustraliaUnited States Free Trade Agreement-Issues and Implications. Canberra: Union Offset Printers Recuperado de http://www.sice.oas.org/TPD/USA_AUS/Studies/ MonashU_e.pdf 
The Australian Law Reform Commission [ALRG]. (2013). Copyright and the Digital Economy. (Paper No. 79-DP 79). Recuperado de https://www.alrc.gov.au/sites/ default/files/pdfs/pu blications/dp79_whole_pdf_.pdf

Therien, J. R. (2001). Exorcising the Specter of a "Pay-Per-Use" Society: Toward Preserving Fair Use and the Public Domain in the Digital Age. Berkeley Technology Law Journal, 16(4), 979-1044.

Tian, Y. (2009). Re-Thinking Intellectual Property: The Political Economy of Copyright Protection in The Digital Era. London: Routledge-Cavendish.

TIC y Discapacidad. (2014). El Gobierno cumple lo que promete. El Plan Vive Digital es una realidad. Recuperado de http://www.vivedigital.gov.co/logros-plan/logro.php?lg=23

Tilling, B. \& Fadel, C. (2009). 21 1st Century Skills Learning for life in our times. San Francisco: Jossey-Bass. Recuperado de https://yasamboyuogrenme.wikispaces. com/file/view/21st+ CENTURY+SKILLS.pdf

Tobón, N. \& Varela, E. (2010). Derechos de Autor Para Creativos. Bogotá D.C.: Grupo Editorial Ibañez.

Tocups, N. M. (1982). The Development of Special Provisions in International Copyright Law for the Benefit of Developing Countries. Fournal of Copyright Society of the U.S.A., 29, 402-421.

Tratado de la OMPI sobre Derecho de Autor (WCT). (20 de diciembre de 1996). Organización Mundial de la propiedad intelectual [OMPI], Ginebra.

Trucano, M. (2005). Knowledge Maps: ICTs in Education. Washington, D.C.: InfoDev; Banco Mundial. Recuperado de http://www.infodev.org/articles/impact-ictslearning-achieveme nt

Ulmer, E. (1971). The Revisions of the Copyright Conventions. International Review of Intellectual Property and Competition Law, 2, 345.

UMG Recordings, Inc. vs. Veoh Networks Inc., 665 F. Supp. 2d 1099, 1118 (C.D. Cal. 2009).

UNDP. (2014). Human Development Report 2014, Sustaining Human Progress: Reducing Vulnerabilities and Building Resilience. New York: Autor. Recuperado de http://hdr. undp.or g/sites/default/files/hdr14-report-en-1.pdf

UNDP. (2015). Human Development Report 2015, Work for Human Development. New York: Autor. Recuperado de http://hdr.undp.org/sites/default/files/2015_human_ development_report_1.pdf

UNESCO. (s.f). UNESCO and the Use of the Internet in its Domains of Competence. Recuperado de http://www.unesco.org/new/fileadmin/MULTIMEDIA/HQ/ ED/ICT/pdf/useinternet domains.pdf 
UNESCO. (2002a). Technologies for Education. Potentials, parameters, and prospects. París: UNESCO \& AED. Recuperado de http://unesdoc.unesco.org/images/0011/001191/11912 9e.pdf

UNESGO. (2002b). Open and Distance Learning: Trends, Policy and Strategy Considerations. París: Autor. Recuperado de http://unesdoc.unesco.org/ images/0012/001284/128463e.pdf

UNESCO. (2002c). Information and Communication Technology in Education: A curriculum for schools and programme of teacher development. París: Autor. Recuperado de http:// unes doc.unesco.org/images/0012/001295/129538e.pdf

UNESCO. (2005). Towards knowledge societies. París: Autor. Recuperado de http:// unesdoc.une sco.org/images/0014/001418/141843e.pdf

UNESCO. (2012). Informe de Seguimiento de La EPT en el Mundo. Luxemburgo: Autor. Recuperado de http://unesdoc.unesco.org/images/0021/002180/218083s.pdf

UNESCO. (2013). Policy Guidelines for Mobile Learning. París: Autor. Recuperado de http://un esdoc.unesco.org/images/0021/002196/219641E.pdf

UNESCO. (2014a). Enseñanza y aprendizaje: lograr la calidad para todos. París: Autor. Recuperado de http://unesdoc.unesco.org/images/0022/002261/226159s.pdf

UNESCO. (2014b). CentralAsia Symposium on ICT in Education 2014: Embracing technologies, Empowering teachers. Bangkok: Autor. Recuperado de http://www.unescobkk.org /fileadmin/user_upload/ict/Workshops/casie2014/CASIE_2014_Outcome_ Document_English_version_.pdf

UNESCO. (2014c). Enfoques estratégicos sobre las TIC en educación en América Latina y el Caribe. Chile: Autor.

Unintended Consequences: Fifteen Years under the DMCA. (marzo de 2013). Electronic Frontier Foundation. Recuperado de https://www.eff.org/pages/ unintended-consequences-fift een-years-under-dmca

Unión Europea. Directiva Europea 2001/29/CE del Parlamento Europeo y del Consejo, relativa a la armonización de determinados aspectos de los derechos de autor y derechos afines a los derechos de autor en la sociedad de la información, O.J (L 167/10), (2011).

Unión Europea. Directiva 2000/31/CE del Parlamento Europeo y del Consejo, relativa a determinados aspectos jurídicos de los servicios de la sociedad de la información, en particular el comercio electrónico en el mercado interior, OJ (L 178).

Unión Europea. Electronic Commerce. (2002). The Electronic Commerce (EG Directive) Regulations 2002.No. 2012-2013. Reino Unido. 
United Nations Development Programme [UNDP]. (2013) Developed and Developing Regions (United Nations Statistic Division). Recuperado de http://unstats.un.org/ unsd/methods/m 49/m49regin.htm\#developed

United States vs. Elcom Ltd., No. CR 01-20138 RMW (N.D. Cal. May 8, 2002). Order Denying Defendant's Motion to Dismiss the Indictment on Constitutional Grounds.

Universal City Studios, Inc. vs. Corley, 273 F.3d 429, 459 (2d Cir. 2001).

Universal Copyright Convention [UCG]. (1952). 6 UST 2732, 216 UNTS 132. WIPO.

Universal Copyright Convention, with Appendix Declaration relating to Article XVII and Resolution concerning Article XI. Geneva, 6 September 1952. (s.f.). UNESCO. Recuperado de http://www.unesco.org/eri/la/convention. asp?order $=$ alpha\&language $=\mathrm{E} \& \mathrm{KO}=15381$

Universities Australia. (2012). Submission to the Review of Technological Protection Measure exceptions made under the Copyright Act 1968. Camberra: Autor. Recuperado de https:// www.ag.gov.au/Consultations/Documents/Universities\%20Australia\%20Submission.pdf

Urban, J. M \& Quilter, L. (2005). Efficient Process or "Chilling Effects"? Takedown Notices Under Section 512 of the Digital Millennium Copyright Act. Santa Clara Computer \& High Tech. Law Journal, 22, 621-694.

Urrego, R. (27 de enero de 2013). Ley Lleras 2.0: vuelve a ganar Robledo. Semana. Recuperado de http://www.semana.com/nacion/articulo/ley-lleras-20-vuelveganar-robledo/330983-3

U.S. - Chile Free Trade Agreement analysis of Implementation of exceptions and limitations and technological protection measure provisions. (s.f). Electronic Frontier Foundation- [EFF]. Recuperado de https://www.eff.org/files/filenode/ FTAA/20040830_uschile_fta.p df

U.S.Code [U.S.G].Congreso de los Estados Unidos de América.

U.S. Copyright Office. (1999). Report on Copyright and Digital Distance Education: A Report of the Register of Copyrights. Washington, D.C.: Government Printing Office. Recuperado de http://www.copyright.gov/reports/de_rprt.pdf

U.S. Department of Education. (enero de 2004). e-learning. Recuperado de http:// www2.ed.gov/ about/offices/list/os/technology/reports/e-learning.html

U.S. Department of Education. (2012). Toward a New Golden Age in American EducationHow the Internet, the Law and Today's Students are Revolutionizing Expectations. Washington: Autor. Recuperado de http://files.eric.ed.gov/fulltext/ED484046.pdf 
U.S. Department of Education. (2010). Transforming American Education: Learning Powered by Technology. Washington: Autor. Recuperado de http://www.ed.gov/ sites/default/files/ netp2010.pdf

U.S. - Korea Free Trade Agreement. (s.f.). Office of the United States Trade Representative. Recuperado de https://ustr.gov/trade-agreements/free-trade-agreements/ korus-fta

U.S. - Panama Trade Agreement Now in Force. (s.f.). Office of the United States Trade Representative. Recuperado de https://ustr.gov/uspanamatpa

Van Eechoud, M. Hugenholtz, P. B., Van Gompel, S., Guibault, L., \& Helberger, N. (2009). Harmonizing European Copyright Law: The Challenges of Better Lawmaking. Great Britain: Wolters Kluwer Law \& Business.

Vargas, J. (2013). Responsabilidad de los prestadores de servicio de almacenamiento de datos por infracciones a derechos de autor. Revista de Derecho, Comunicaciones y Nuevas Tecnologías, 10,1-37 Recuperado de https://derechoytics.uniandes.edu.co/ components/co m_revista/archivos/derechoytics/ytics134.pdf

Velásquez, O. (2013). Responsabilidad Civil Extracontractual (2a ed.). Bogotá: Temis.

Vivas-Eugui, D. (2003). Regional and Bilateral Agreements and TRIPS-Plus World: the Free Trade Area of the Americas (FTAA) (Trips Issues Papers 1). Ginebra: Quaker United Nations Office (QUNO). Recuperado de http://www.quno.org/sites/default/ files/resources/F TAs-TRIPS-plus-English.pdf

Von Braun, J. (2012). La negociación en propiedad intelectual en los Tratados de Libre Comercio de los EE.UU. con Colombia y Perú. Puentes, 13(2). Recuperado de http://ictsd.org/i/ news/puentes/132572/\#sthash.GXvyHtic.dpuf

Von Lewinski, S. (2008). International Copyright Law and Policy. Oxford: Oxford University Press.

Wahid, R. (2011). The Fairness of 'Stealing' Knowledge for Education. Fournal of International Commercial Law and Technology, 6(2), 86-95.

Walker, E. (2012). Implementing the IP Chapter of the FTA between Chile and the USA: Criticisms and Realities from a Developing Country Perspective. SCRIPTed 9(2), 233-257. Recuperado de http://script-ed.org/wp-content/ uploads/2012/08/walker.pdf

Watal, J. (2001). Intellectual Property Rights in The WTO and Developing Countries. London: Kluwer Law International.

WCT Notification No. 32, WIPO Copyright Treaty. (2001). WIPO. Recuperado de http://www.w ipo.int/treaties/en/notifications/wct/treaty_wct_32.html 
Weatherall, K. \& Burrel, R. (2007). Exporting Controversy? Reactions to the Copyright Provisions of the U.S-Australia Free Trade Agrement: Lessons for the US Trade Policy. (Research Paper No. 07-13). Recuperado de http://ssrn.com/abstract=1010833

Wells, J. \& Lewis, L. (2006). Internet Access in U.S. Public Schools and Classrooms: 19942005 (NCES 2007-020). Washington, D.G.: National Center for Education Statistics. Recuperado de http://nces.ed.gov/pubs2007/2007020.pdf

West, M. \& Chew, H. (2014). Reading in the Mobile Era, A Study of Mobile Reading in Developing Countries. París: UNESCO. Recuperado de http://unesdoc.unesco. org/images/0022 /002274/227436e.pdf

Why educators use blogs. (s.f.). Teacher challenges. Recuperado de http:// teacherchallenge.edub logs.org/step-1-set-up-your-class-blog/

WIPO-Administered Treaties. (s.f.). Contracting Parties Berne Convention (Total Contracting Parties: 169). WIPO. Recuperado de http://www.wipo.int/treaties/ en/ShowResults.jsp?la ng=en\&treaty_id=15

WIPO. (2003). Guide to The Copyright and Related Rights Treaties Administered by WIPO and Glossary of Copyright and Related Rights Terms. Ginebra: Autor. Recuperado de http:// www.wipo.int/edocs/pubdocs/en/copyright/891/wipo_ pub_891.pdf

WIPO Performances and Phonograms Treaty [WPPT]. (1997). 36 I.L.M. 76, Ginebra.

Wong, T. (2011). Intellectual Property Through the Lens of Human Development. En T. Wong \& G. Dutfield (Eds.), Intellectual Property and Human Development: Current Trends and Future Scenarios (pp. 1-59). New York: Cambridge University Press.

World Bank (s.f.). World Links for Development Programme (WorLD). Recuperado de http://ww w.unites.org/world.htm

World Intellectual Property Organization [WIPO]. (s.f.a). Treaties and Contracting Parties. Recuperado de http://www.wipo.int/treaties/en/remarks.jsp?cnty_id=932C

World Intellectual Property Organization [WIPO]. (s.f.b). Other IP Treaties. Recuperado de http: //www.wipo.int/wipolex/en/other_treaties/parties. jsp?treaty_id=201\&group_id=22

World Intellectual Property Organization [WIPO]. (s.f.c). WIPO-Administered Treaties. Recuperado de http://www.wipo.int/treaties/en/ShowResults. jsp?lang=en\&treaty_id $=16$

Xalabarder, R. (2003). Copyright and Digital Distance Education: The Use of PreExisting Works in Distance Education Through the Internet. Columbia fournal of Law E the Arts, 26, 101-178. 
Xalabarder, R. (diciembre de 2009). OMPI, Estudio sobre las limitaciones y excepciones del derecho de autor para las actividades educativas en América del Norte, Europa, los Países Caucaso, Asia Central e Israel. Comité permanente de derecho de autor y derechos conexos, Ginebra. Recuperado de http://www. wipo.int/edocs/mdocs/copyright/es/sccr_19/sccr_19_8.pdf

Yen, A. C. (2000). Internet Service Provider Liability for Subscriber Copyright Infringement, Enterprise Liability, and the First Amendment. The Georgetown Law fournal, 88, 1833-1889.

Yi-Chong, X. (2008). Last Chance? Multilateralism, TRIPS and Developing Countries. En J. Malbon \& C. Lawson (Eds.), Interpreting and Implementing the TRIPS Agreement is it Fair? (pp. 46-70). Massachusetts: Edward Elgar Publishing.

Yi-Jun, T. (2005). Problems of Anti-Circumvention Rules in the DMCA \& More Heterogeneous Solutions. Fordham Intellectual Property, Media and Entertainment Law Fournal, 15(3), 749-788.

YouTube (s.f.). YouTube Edu. Recuperado de https://www.youtube.com/t/education

YouTube Help. (s.f.). Videos Removed or Blocked Due to Youtube's Contractual Obligations. Support Google. Recuperado de https://support.google.com/youtube/ answer/3045545?hl= en

YouTube. (enero de 2010). Terms of Service. Recuperado de https://www.youtube. $\mathrm{com} /$ static?gl $=\mathrm{US} \& \mathrm{hl}=$ en-GB\&template $=$ terms

Yu, P. K. (2004). Currents and Crosscurrents in the International Intellectual Property Regime (Michigan State University College of Law Research Paper No.02-12). Recuperado de http://ssrn.com/abstract=578572

Yu, P. K. (2006). Anti-circumvention and Anti-Circumvention. Denver University Law Review, 84(1), 13-78.

Yu, P. K. (2010). The Objectives and Principles of the TRIPS Agreement. En C. Correa (Ed.), Research Handbook on the Protection of Intellectual Property under WTO rules, (PP. 146-191). London: Edward Elgar.

Yu, P. K. (2011). Are developing Countries Playing a Better TRIPS Game? UCLA Journal of International Law and Foreign Affairs, 16, 311-342.

Zapata, F. (1998). Las nuevas tecnologías. Desafíos para el derecho de Autor. Dikaion, 7, 137-145.

Zwart, M. (2009). The Copyright Amendment Act 2006: the New Copyright Exceptions. (ResearchPaperNo.2007-32). Recuperadodehttp://ssrn.com/abstract=1350064. 


\section{Serie Investigación}

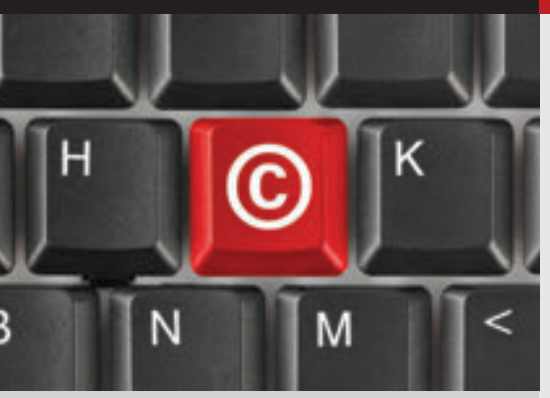

DERECHOS DE AUTOR, TEGNOLOGÍA Y EDUCACIÓN PARA EL SIGLO XXI:

EL TRATADO DE LIBRE COMERCIO Entre Colombia y Estados Unidos

Este libro abarca por primera vez en la literatura existente la intersección de tres temas controversiales en el mundo de los derechos de autor: educación, tecnología y tratados de libre comercio (TLC), enfocándose en el caso de Colombia. De esta manera, este libro advierte como una implementación inadecuada de las obligaciones en materia de derechos de autor incorporadas en el tratado de libre comercio con los Estados Unidos, como se intento en Colombia, puede afectar los efectos positivos de políticas que buscan incorporar la tecnología en la educación con el propósito de arreglar diversas falencias del sistema educativo y promover la inclusión social. Por lo tanto, este libro se convierte en una herramienta importante para los estudiosos del tema al igual que para los encargados de políticas públicas de países que, al igual que Colombia, están en proceso de implementar las obligaciones adquiridas en TLC con los Estados Unidos.

\section{UINIVERSIDAD SERGIO ARBOLEDA}

Calle 18 No. 14A-18. Tels: (575) 4203838 - 420 2651. Santa Marta Carrera 15 No. 74-40. Tels: (571) 3257500 ext. 2131 - 322 0538. Bogotá, D.C. www.usergioarboleda.edu.co 